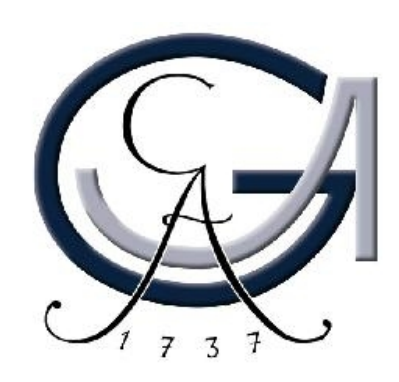

\title{
Zur Funktion von Leupaxin beim Karzinom der Prostata
}

\author{
Dissertation \\ zur Erlangung des Doktorgrades \\ der Mathematisch-Naturwissenschaftlichen Fakultäten \\ der Georg-August-Universität zu Göttingen
}

\author{
vorgelegt von \\ Silke Kaulfuß, geb. Voigt \\ aus \\ Löbau
}

Göttingen, 2006 
D 7

Referent: $\quad$ Prof. Dr. W. Engel

Korreferent: $\quad$ Prof. Dr. R. Hardeland

Tag der mündlichen Prüfung: $\quad$ 31.10. 2006 


\section{Inhaltsverzeichnis}

\section{Abkürzungsverzeichnis}

VIII

Fachwortverzeichnis

$1 \quad$ Einleitung

1.1 Das Prostatakarzinom im Überblick …........................................................ 1

1.2 Beginn und Entwicklung von Prostatakrebs, Klassifizierungssysteme ................ 2

1.3 Leupaxin als Mitglied der Paxillin-Proteinfamilie............................................... 4

$1.4 \quad$ Ziele der Arbeit.............................................................9

2 Material und Methoden $\quad 11$

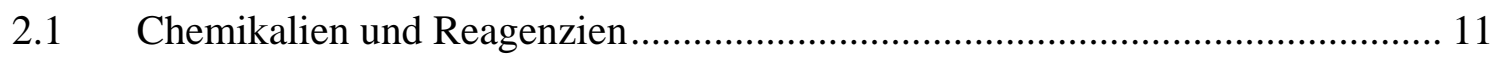

2.2 Biochemikalien und Enzyme ….................................................................... 13

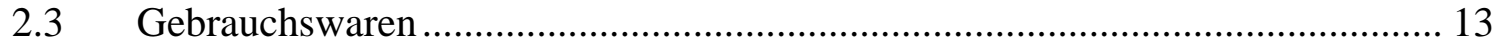

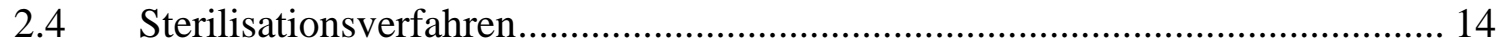

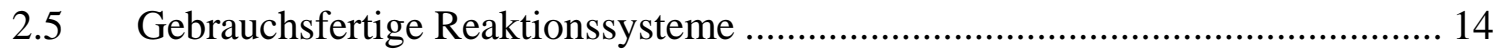

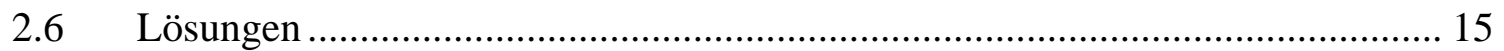

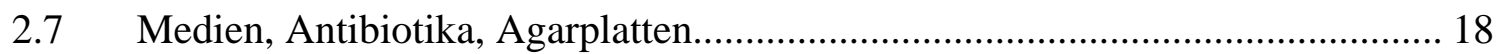

2.7.1 Medien für Bakterien .............................................................................. 18

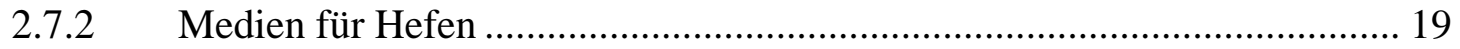

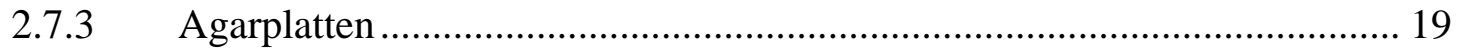

2.7.4 Medien für eukaryontische Zellkulturen .................................................... 20

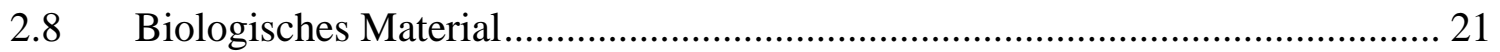

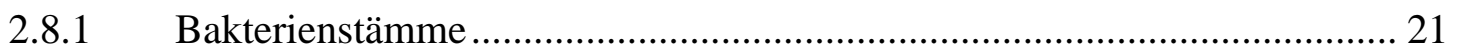

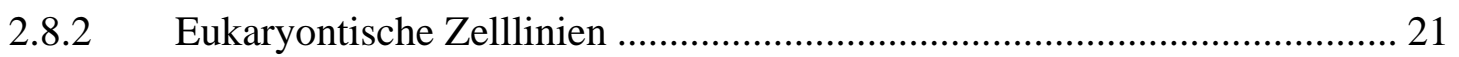

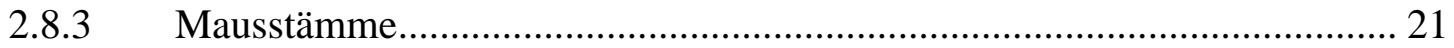

2.8.4 Synthetische Oligonukleotide ................................................................ 22 
2.8.4.1 Synthetische DNA-Oligonukleotide ..................................................... 22

2.8.4.2 Synthetische RNA-Oligonukleotide................................................... 25

2.8.4.3 Synthetische DNA-Oligonukleotide für quantitative real time PCR-

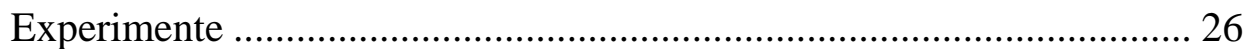

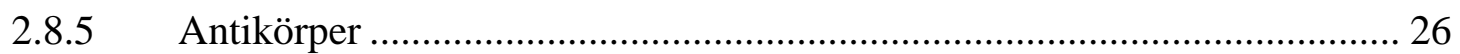

2.8.6 Plasmide und Vektoren ...................................................................... 28

2.8.7 Verwendete Konstrukte und Plasmide ......................................................... 29

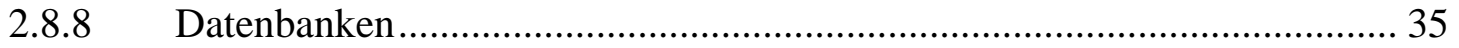

2.9 Isolierung und Aufreinigung von Nukleinsäuren.............................................. 36

2.9.1 Minipräparation von Plasmid-DNA _....................................................... 36

2.9.2 Herstellung von Bakterien-Glycerin-Stocks ............................................. 36

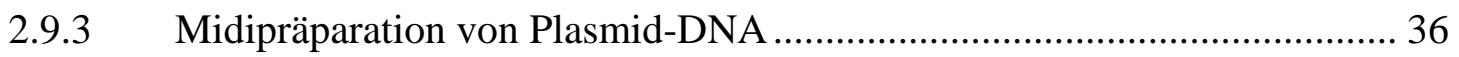

2.9.4 Ethanolfällung von DNA aus wässrigen Lösungen .................................... 37

2.9.5 Phenol/Chloroform- Aufreinigung von Nukleinsäuren............................... 37

2.9.6 Isolierung von Plasmid-DNA aus Hefe.................................................... 37

2.9.7 Isolierung von Gesamt-RNA aus Zellkulturen.......................................... 38

2.9.8 Konzentrationsbestimmung von Nukleinsäuren ...................................... 38

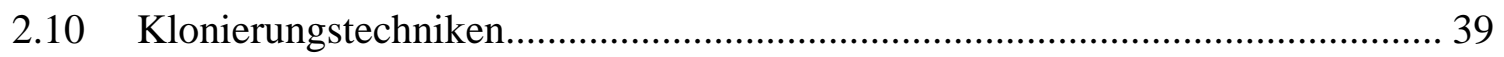

2.10.1 Spaltung von DNA mit Restriktionsendonukleasen.................................. 39

2.10.2 Isolierung von DNA-Fragmenten aus Agarosegelen .................................. 39

2.10.3 Dephosphorylierung von Plasmid-DNA …................................................... 39

2.10.4 Ligation von DNA-Fragmenten .............................................................. 40

2.10.5 Subklonierung von PCR- und RT-PCR-Produkten...................................... 40

2.10.6 Transformation kompetenter Zellen mit Plasmid-DNA............................. 41

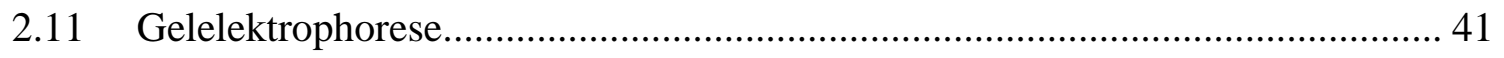

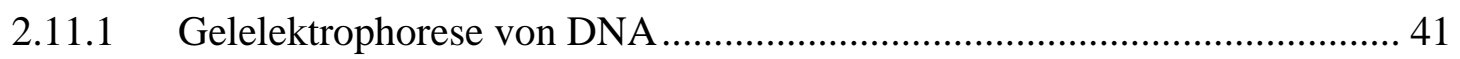

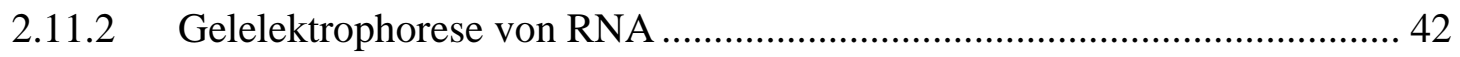

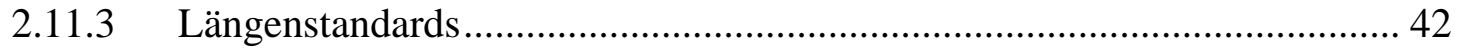

2.12 Transfertechniken von Nukleinsäuren ............................................................. 43

2.12.1 Southern Blot-Analysen ............................................................................ 43

2.13 Radioaktive Markierung von DNA und Hybridisierung membran-

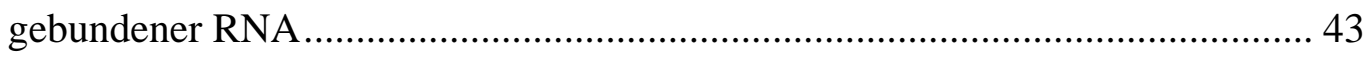

2.13.1 Random Prime-Markierung..................................................................... 43 
2.13.2 Hybridisierung membrangebundener DNA mit radioaktiv markierten

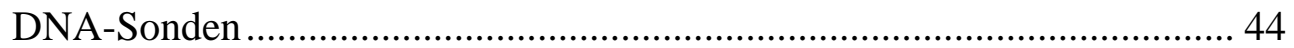

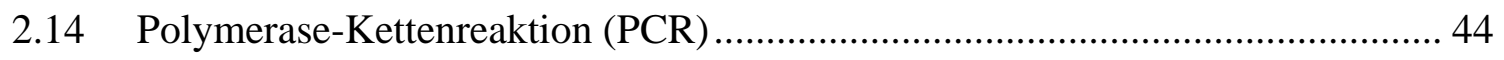

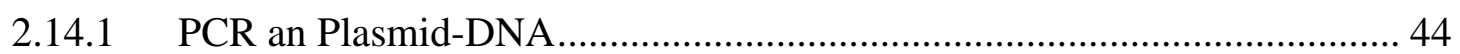

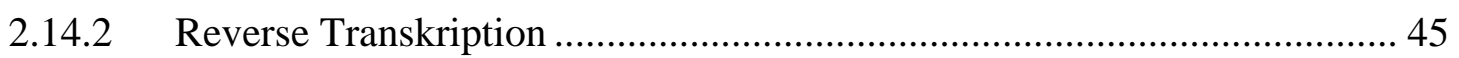

2.14.3 Quantitative real time PCR-Analysen ..................................................... 46

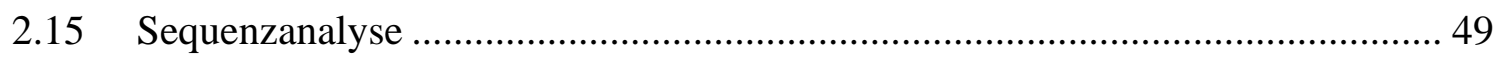

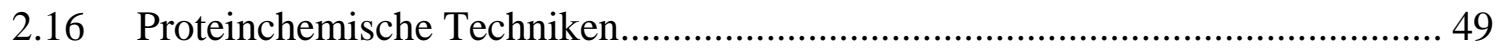

2.16.1 Isolierung von Gesamtprotein aus Zellkulturen ........................................ 49

2.16.2 Isolierung von Gesamt-Protein aus Organen der Maus ............................. 50

2.16.3 Konzentrationsbestimmung von Proteinen ............................................... 50

2.16.4 SDS-Polyacrylamidgelelektrophorese (SDS-PAGE).............................. 50

2.16.5 Western Blot-Analysen von Proteinen auf PVDF-Membranen ................... 51

2.16.6 Färbung von Polyacrylamidgelen............................................................ 52

2.16.7 Inkubation von membrangebundenen Proteinen mit Antikörpern .............. 52

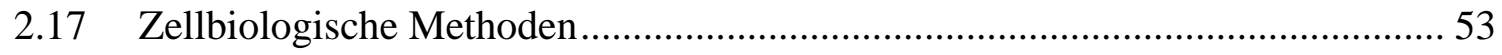

2.17.1 Zellkultur eukaryontischer Zellen ........................................................ 53

2.17.2 Kryokonservierung und Revitalisierung von eukaryontischen Zellen........ 54

2.17.3 Transfektion eukaryontischer Zellen...................................................... 54

2.17.4 Stabile Transfektion von eukaryontischen Zellen ...................................... 55

2.17.5 Anfertigung von Zytospin-Präparaten...................................................... 55

2.17.6 Bestimmung der PSA-Konzentration im Kulturmedium von LNCaP-

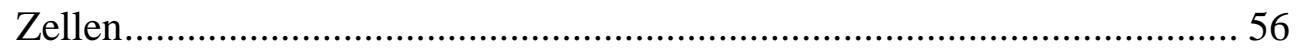

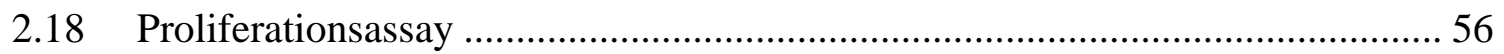

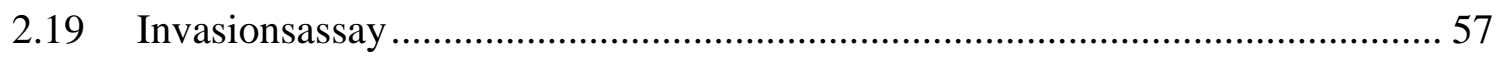

2.20 Herunterregulierung der Genexpression mittels RNA-Interferenz ..................... 57

2.20.1 Überblick über den Mechanismus von RNAi ............................................. 58

2.20.2 Transfektion eukaryontischer Zellen mit siRNAs..................................... 59

2.21 Assay zur Bestimmung der Adhäsion von Zellen .............................................. 60

2.22 Bestimmung der Migrationsfähigkeit von Zellen ............................................. 60

2.23 Soft-Agar-Assay zur Analyse des Verankerungs-unabhängigen Zellwachstums61

2.24 Methoden zur subzellulären Lokalisierung eines Proteins................................. 61

2.24.1 Immunzytochemische Färbung eukaryontischer Zellen ............................ 61

2.24.2 Subzelluläre Lokalisation von Fusionsproteinen ...................................... 62 


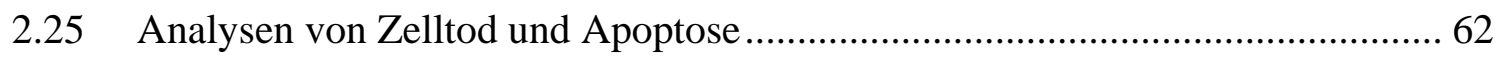

2.25.1 Immunzytochemische Färbung von eukaryontischen Zellen (Caspase-3).. 62

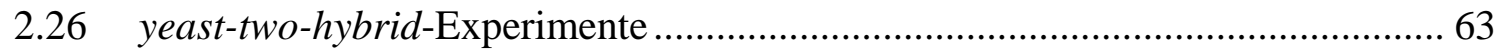

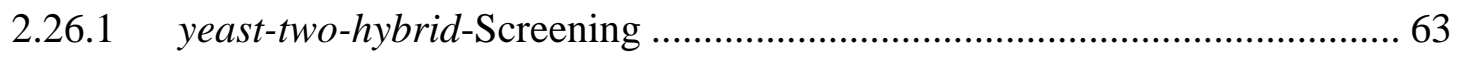

2.26.2 Transformation kompetenter Hefezellen mit Plasmid-DNA ...................... 65

2.26.3 Interaktionsnachweis von Leupaxin und AR, GR und PGR über Selektion65

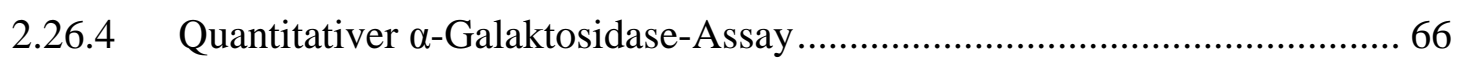

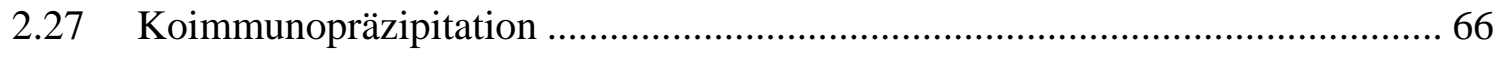

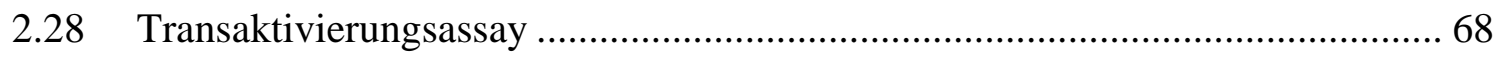

2.28.1 Quantitativer Nachweis von Reporterenzymen....................................... 69

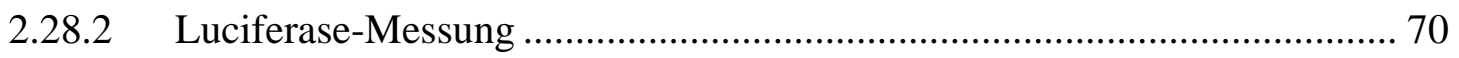

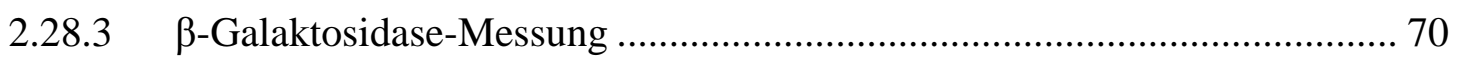

2.28.4 Auswertung der Reportergen-Messungen ................................................ 71

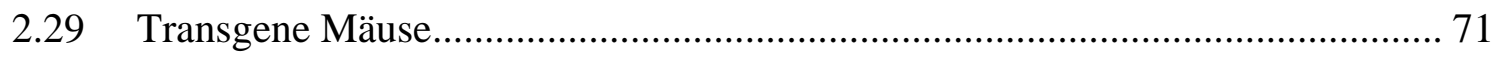

2.29.1 Vorbereitung und Injektion des transgenen Leupaxin-Konstrukts ............. 71

2.29.2 Isolierung genomischer DNA aus Organen ............................................ 71

2.29.3 Kopienzahlbestimmung bei transgenen Mäusen (T/- vs. T/T)................... 72

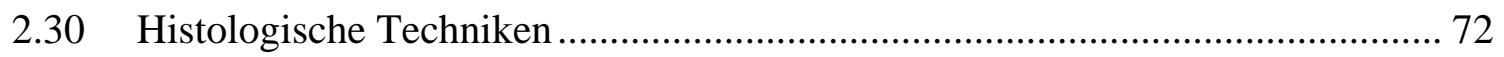

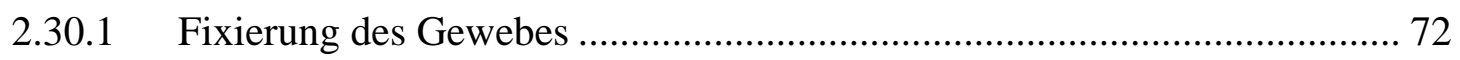

2.30.2 Vorbehandlung der Objektträger............................................................... 73

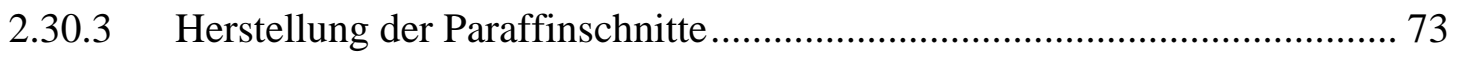

2.30.4 Immunlokalisierung von Proteinen in Paraffingewebeschnitten ................ 74

2.30.5 Der immunoreactive score zur Quantifizierung der Leupaxin-Expression in humanen Prostatakarzinomen ................................................................. 74

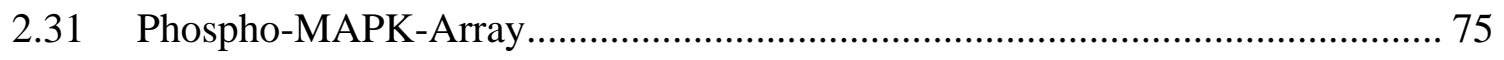

2.31.1 Herstellung der zu untersuchenden Proteinlysate ..................................... 76

2.31.2 Durchführung und Auswertung des Arrays ................................................. 77

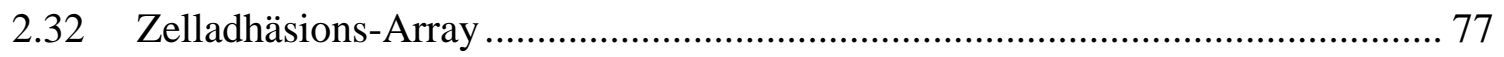

2.32.1 Durchführung des Zelladhäsions-Arrays ................................................... 77

2.32.2 Auswertung der Array-Daten .................................................................. 78 
3.1 Isolierung von Leupaxin als differentiell exprimiertes Gen im kapselinvasiven

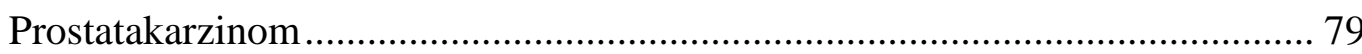

3.2 Expression von Leupaxin in etablierten Prostatakarzinomzelllinien ................... 82

3.3 Subzelluläre Expression von Leupaxin in den PCa-Zelllinien............................. 83

3.4 Leupaxin enthält ein Kernexportsignal .............................................................. 84

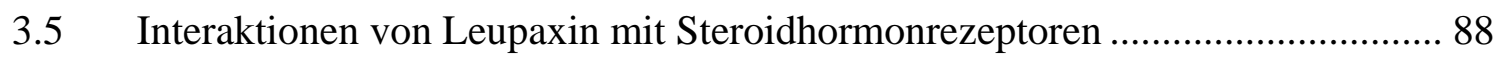

3.5.1 Interaktion von Leupaxin mit dem Androgenrezeptor ................................ 88

3.5.1.1 Durchführung eines gerichteten yeast-two-hybrid-Experiments.............. 88

3.5.1.2 Bestätigung und Quantifizierung der Interaktion von Leupaxin und

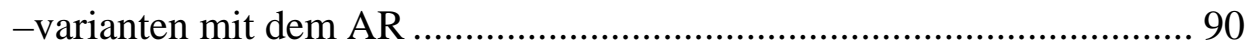

3.5.1.3 Bestätigung der Interaktion von Leupaxin mit dem AR mittels

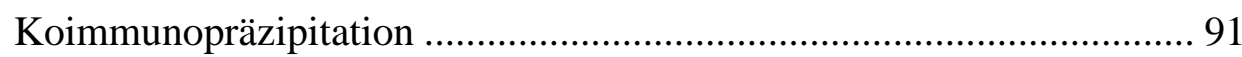

3.5.1.4 Leupaxin erhöht die transkriptionelle Aktivität des AR ........................ 93

3.5.1.5 Nachweis der Interaktion von Leupaxin mit dem AR mit Hilfe des

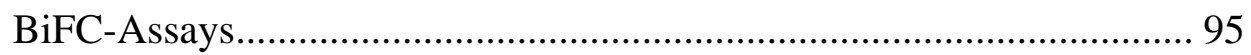

3.5.2 Interaktion von Leupaxin mit weiteren Steroidhormonrezeptoren .............. 98

3.5.2.1 Interaktionsnachweis von Leupaxin mit dem Progesteron- und Glukokortikoidrezeptor mit Hilfe eines gerichteten yeast-two-hybridExperiments 99

3.5.2.2 Bestätigung der Interaktion von Leupaxin mit GR und PGR mittels Koimmunopräzipitation

3.5.2.3 Leupaxin erhöht die transkriptionelle Aktivität sowohl vom GR als auch vom PGR 101

3.5.2.4 Analyse der Interaktionen zwischen Leupaxin und GR bzw. PGR mit Hilfe des BiFC-Assays. 103

3.6 Analysen zur Funktion von Leupaxin 104

3.6.1 Herunterregulierung der Leupaxin-Expression in den PCa-Zelllinien mittels RNA-Interferenz. 104

3.6.2 Induktion von Apoptose in androgen-abhängigen LNCaP-Zellen nach Herunterregulierung der Leupaxin-Expression. 105

3.6.3 Reduktion der PSA-Bildung in LNCaP-Zellen mit verminderter Leupaxin-Expression. 
3.6.4 Leupaxin hat keinen Einfluss auf die Proliferation von PCa-Zellen......... 109

3.6.5 Reduktion der Invasivität und Migrationsfähigkeit von androgenunabhängigen PC-3- und DU 145-Zellen nach Herunterregulierung der Leupaxin-Expression.

3.6.6 Analysen zum Einfluss von Leupaxin auf die Expression Adhäsions-

relevanter Gene mittels eines Zelladhäsions-Arrays

3.6.6.1 Durchführung des Zelladhäsions-Arrays ........................................... 112

3.6.6.2 Überprüfung der Daten aus dem Zelladhäsions-Array ........................ 115

3.6.7 Analysen zur Phosphorylierung und Aktivität von Proteinen des MAPK (mitogen activated protein kinase)-Signalweges nach

Herunterregulierung der Leupaxin-Expression.

3.6.7.1 Durchführung des Phospho-MAPK-Arrays

3.6.7.2 Überprüfung der Ergebnisse des Phospho-MAPK-Arrays an PCa-

Zellen mittels Western Blot-Analysen .

3.6.8 Überexpression von Leupaxin in den PCa-Zelllinien

3.6.8.1 Generierung von induzierbaren stabilen Transfektanten

3.6.8.2 Charakterisierung der LNCaP-Klone mit induzierbarer Leupaxincmyc-Expression

3.6.8.2.1 Subzelluläre Lokalisation des Fusionsproteins Leupaxin-cmyc nach Stimulation mit Doxycyclin.

3.6.8.2.2 Erhöhte Aktivität des AR nach Induktion der Leupaxin-cmycExpression 128

3.6.8.2.3 Einfluss der Überexpression von Leupaxin auf die Proliferation von LNCaP-Zellen

3.6.8.2.4 Untersuchung der adhäsiven und invasiven Eigenschaften der Leupaxin-überexprimierenden LNCaP-Klone

3.7 Mausmodell zur Prostata-spezifischen Überexpression von Leupaxin.............. 132

3.7.1 Das Konstrukt zur Generierung einer transgenen Leupaxin-Maus ............ 132

3.7.2 Generierung und Etablierung transgener Leupaxin-Mäuse ...................... 133

3.7.3 Integration des Leupaxin-Transgens ins Mausgenom............................... 133

3.7.4 Verpaarung und Etablierung von homozygot transgenen LeupaxinMauslinien

3.7.5 Überprüfung der Expression des Leupaxin-Transgens in vivo ................. 138

3.7.6 Immunhistochemische Analyse der transgenen Leupaxin-Mäuse ............ 139 
3.7.7 Histologische Analysen der Prostatae in verschiedenen Altersstadien der transgenen Leupaxin-Mäuse der Linien \#19 und \#20

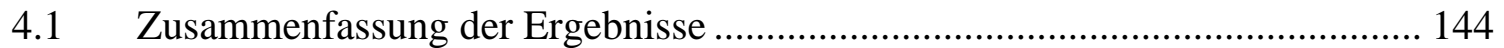

4.2 Zur Initiation und Progression von malignen Läsionen .................................... 146

4.2.1 Zur Initiation und Progression des Prostatakarzinoms.............................. 150

4.3 Zur Expression der Paxillin-Proteinfamilie und deren potentielle Rolle in der Entwicklung und bei verschiedenen Erkrankungen

4.4 Ist Leupaxin in die Initiation oder Progression von humanen

Prostatatumoren involviert?

4.5 Wie kann Leupaxin die Progression von Prostatakarzinomen beeinflussen? ... 162

4.5.1 Hypothese 1: Einfluss von Leupaxin auf die Androgenrezeptor-

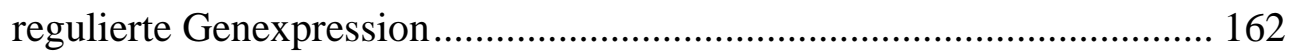

4.5.2 Hypothese 2: Direkter Einfluss von Leupaxin auf die Genregulation ....... 166

4.5.3 Hypothese 3: Leupaxin besitzt direkten Einfluss auf die Invasion und Migration über Interaktionen mit Proteinen an den focal adhesion sites.. 168

4.6 Perspektiven

$5 \quad$ Zusammenfassung 


\section{Abkürzungsverzeichnis}

\begin{tabular}{|c|c|}
\hline Abb. & Abbildung \\
\hline Amp & Ampicillin \\
\hline As & Aminosäure \\
\hline ATP & Adenosintriphosphat \\
\hline bp & Basenpaar \\
\hline bzw. & beziehungsweise \\
\hline${ }^{\circ} \mathrm{C}$ & Grad Celsius \\
\hline ca. & circa (ungefähr) \\
\hline cDNA & komplementäre DNA \\
\hline $\mathrm{Ci}$ & Curie \\
\hline $\mathrm{cm}$ & Zentimeter \\
\hline DAPI & 4’,6'-Diamidino-2-Phenylindol \\
\hline dATP & Desoxyadenosintriphosphat \\
\hline dCTP & Desoxycytosintriphosphat \\
\hline dGTP & Desoxyguanosintriphosphat \\
\hline DEPC & Diethylpyrocarbonat \\
\hline DMSO & Dimethylsulfoxid \\
\hline DNA & Desoxyribonukleinsäure \\
\hline dNTPs & Desoxynukleotidtriphosphate \\
\hline ds & doppelsträngig \\
\hline DTT & 1,4-Dithiothreitol \\
\hline dTTP & Desoxythymidintriphosphat \\
\hline ECM & Extrazelluläre Matrix \\
\hline EDTA & Ethylendiamintetraessigsäure \\
\hline et al. & et alteri (und andere) \\
\hline FISH & Fluoreszenz in situ Hybridisierung \\
\hline FITC & Fluoreszeinisothiocyanat \\
\hline g & Gramm, Erdbeschleunigungskonstante \\
\hline GFP & green fluorescent protein \\
\hline GST & Glutathion-S-Transferase \\
\hline
\end{tabular}


h

His

IPTG

ISEL

Kan

$\mathrm{kb}$

$\mathrm{kD}$

Luc

$\mu$

$\mu \mathrm{g}$

$\mu \mathrm{l}$

$\mu \mathrm{m}$

$\mu \mathrm{M}$

$\mathrm{m}$

M

$\mathrm{mA}$

MCS

mg

$\min$

$\mathrm{ml}$

$\mathrm{mM}$

MOPS

mRNA

n

$\mathrm{nm}$

OD

$\mathrm{p}$

PCa (-Zellinie)

PAGE

PBS

PCR

pg

$\mathrm{pH}$

RNA
Stunde

Histidin

Isopropyl- $\beta$-thiogalactopyranosid

in situ end labeling

Kanamycin

Kilobasenpaare

Kilodalton

Luciferase

micro $=10^{-6}$

Microgramm

Microliter

Micrometer

Micromolar

milli $=10^{-3}$

Molar

Milliampere

multiple cloning site (Polylinker)

Milligramm

Minute

Milliliter

Millimolar

Morpholinopropansulfonsäure

messenger RNA = Boten-RNA

nano $=10^{-9}$

Nanometer

Optische Dichte

pico $=10^{-12}$

prostate carcinoma $=$ Prostatakarzinom

Polyacrylamidgelelektrophorese

Phosphat-gepufferte Kochsalzlösung

Polymerase-Kettenreaktion

Picogramm

Negativer dekadischer Logarithmus der Protonenkonzentration

Ribonukleinsäure 


$\begin{array}{ll}\text { RNase } & \text { Ribonuklease } \\ \text { RT } & \text { Raumtemperatur; reverse Transkription } \\ \text { SDS } & \text { Natriumdodecylsulfat } \\ \text { sec } & \text { Sekunde } \\ \text { siRNA } & \text { small interfering RNA } \\ \text { sog. } & \text { sogenannt } \\ \text { ss } & \text { einzelsträngig } \\ \text { Tab. } & \text { Tabelle } \\ \text { Taq } & \text { Thermus aquaticus } \\ \text { U } & \text { Unit = definierte Enzymeinheit } \\ \text { UV } & \text { ultraviolettes Licht } \\ \text { u.a. } & \text { unter anderem } \\ \text { V } & \text { Volt } \\ \text { Vol } & \text { Volumen } \\ \text { X-GAL } & \text { 5-Brom-4-Chlor-3-Indolyl- } \beta \text {-D-Galactopyranosid } \\ \text { z.T. } & \text { zum Teil } \\ \text { z.B. } & \text { zum Beispiel }\end{array}$




\section{Fachwortverzeichnis}

Englische Fachbegriffe der Molekularbiologie werden, soweit sinnvoll, auch als solche verwendet und nicht ins Deutsche übersetzt, da deutsche Ersatzwörter oftmals unwissenschaftlich klingen und nur eine Umschreibung dessen sind, was im Englischen mit einem Wort ausgedrückt werden kann. Die Bedeutung dieser Fachbegriffe wird hier nochmals aufgeführt, sofern dies nicht im Text geschieht.

Alignment

Annealing

antisense

Assay

cluster

downstream

Elongation
Wörtlich übersetzt: anordnen, abgleichen

Zwei oder mehrere Sequenzen werden so angeordnet, dass sie bestmöglich übereinstimmen. Auf diese Weise können gleiche oder komplementäre Sequenzen oder Sequenzbereiche ermittelt werden.

Wörtlich übersetzt: ausglühen, härten

Primer-Anlagerung während der PCR

Komplementär zum kodierenden Nukleinsäurestrang

Wörtlich übersetzt: untersuchen, Untersuchung

Test, Versuchsreihe

Wörtlich übersetzt: Anhäufung

Hier: Bei Kontakt mit der ECM sammeln sich viele Integrine an der Kontaktstelle und bilden Integrin-,,Anhäufungen“.

Wörtlich übersetzt: stromabwärts

In einer Kaskade: unterhalb, als nachgeschalteter Faktor

Bei einem Gen: weiter 3’ gelegen

Wörtlich übersetzt: Verlängerung

Hier: DNA-Strang-Verlängerung während der PCR 
focal adhesion site(s)

full length

housekeeping

in frame

inside-out

knockdown

outside-in

Primer

Proofreading
Wörtlich übersetzt: fokale Adhäsionsstelle(n)

Dies sind Bereiche der Zellmembran, die über Integrincluster mit der ECM interagieren.

Wörtlich übersetzt: Volle Länge

Hier: das gesamte Protein oder kompletten kodierenden

Bereich einer cDNA betreffend

Wörtlich übersetzt: Haushalt

Ein housekeeping-Gen ist ein konstitutiv exprimiertes Gen, das in allen Zellen essentiell ist.

Wörtlich übersetzt: im Rahmen

Bei der Herstellung eines Fusionsproteins muss darauf geachtet werden, dass bei der Klonierung der nachgeschalteten cDNA der Leserahmen der vorgeschalteten cDNA eingehalten wird.

Wörtlich übersetzt: innen-außen

Hier: die Übertragung von Signalen vom Zellkern zur Membran der Zelle

Wörtlich übersetzt: herabsetzen, niederschlagen

Hier: Herunterregulierung der Expression eines Gens

Wörtlich übersetzt: außen-innen

Hier: die Übertragung von Signalen von der Membran einer Zelle in den Zellkern

Oligonukleotid von 20-35 Basenpaaren, welches von Polymerasen als Starthilfe zum Ansynthetisieren weiterer Nukleotide genutzt wird.

Wörtlich übersetzt: Korrekturlesen

Polymerasen mit einer Proofreading-Aktivität sind in der Lage, falsch eingebaute Nukleotide über ihre $3^{\prime}-5^{\prime}$ Exonuklease-Aktivität zu entfernen. 
real time

sandwich

screening

second messenger

sense

silencing

template

upstream

yeast-two-hybrid-screening
Wörtlich übersetzt: Echtzeit

Während der PCR kann die Zunahme der Amplifikate auf einem Monitor in Echtzeit verfolgt werden

Wörtlich übersetzt: belegtes Brot

Hier: Art des Aufbaus beim Western und Northern BlotTransfer. Die Membran wird zwischen Whatman-Papier + Gel und Whatman-Papier gelegt.

Wörtlich übersetzt: (durch)sieben, untersuchen

Hier: Durchsuchen einer Bibliothek nach bestimmten

Proteinen und Genen

Botenstoff, der in Reaktion auf extrazelluläre Signale in der Zelle gebildet wird und die Signalkaskade verstärkt fortsetzt

Entspricht dem kodierenden Nukleinsäurestrang

Wörtlich übersetzt: zum Schweigen bringen

Bei der Transkription: Umstände, die die Transkription eines

Gens unterdrücken

Wörtlich übersetzt: Schablone, Vorlage, Matrize

Hier: RNA oder DNA, die während einer PCR amplifiziert werden soll

Wörtlich übersetzt: stromaufwärts

In einer Kaskade: oberhalb, als vorgeschalteter Faktor

Bei einem Gen: weiter 5’-gelegen

Hefesystem, um Proteine nachzuweisen, die an ein bestimmtes Protein, das untersucht werden soll, binden 



\section{Einleitung}

\subsection{Das Prostatakarzinom im Überblick}

Das Prostatakarzinom hat sich in der männlichen Bevölkerung der westlichen Welt zu einem Hauptgesundheitsproblem entwickelt. Es ist die am häufigsten diagnostizierte Malignität vor Darm- und Lungenkrebs in Deutschland (22,3\%) mit 48650 Prostatakrebsneuerkrankungen im Jahr 2002. 10,4\% der Krebssterbefälle in Deutschland (im Jahr 2002: 11422 Fälle) werden durch Prostatakrebs verursacht, wodurch das Prostatakarzinom zur dritthäufigsten Ursache von Krebstod beim Mann in Deutschland wird [„Krebs in Deutschland“, 2006]. Im Vergleich mit den übrigen Ländern der Europäischen Union liegen die in Deutschland ermittelten Erkrankungsraten für Prostatakrebs im oberen Bereich. Die höchsten Raten finden sich in Schweden und Finnland, die niedrigsten in Griechenland, Polen und Lettland. In den USA wurden über 200000 neue Fälle von Prostatakrebs im Jahr 2001 festgestellt. 25-30\% der Tumoren verhalten sich aggressiv, was in fast 40000 Todesfällen jährlich resultiert. Daher ist das Prostatakarzinom in den USA die zweithäufigste Ursache von Krebstod beim Mann [Greenlee et al., 2000; Jemal et al., 2005].

Für die Entwicklung von Prostatakrebs werden zahlreiche Faktoren wie etwa Alter, Rasse, Ernährung und Umweltfaktoren, Steroidhormone, Familiengeschichte etc. als Risikofaktoren in Betracht gezogen. Der häufigste Risikofaktor ist das Alter, da ca. 75\% der klinisch detektierbaren Prostatakarzinome bei Männern im Alter zwischen 50 und 70 Jahren diagnostiziert werden. Mit zunehmendem Alter verändert sich die Produktion der Steroidhormone, was zu vorteilhaften Bedingungen in der Mikroumgebung für die Entwicklung und Progression von Prostatakrebs führt [Prehn, 1999; Burnstein, 2005].

Prostatakrebs entwickelt sich zunächst als eine androgen-abhängige Läsion der Prostatadrüsen, die erfolgreich durch operatives Entfernen des Tumors oder lokale Bestrahlung behandelt werden kann. Die Mehrzahl der Patienten mit einem frühen, metastasierenden Prostatakarzinom werden mit einer androgen-unterdrückenden Therapie behandelt, die operativ durch Kastration oder chemisch durch Unterdrückung der Androgenproduktion mit Hilfe von LHRH (Luteinisierungshormon-Releasing-Hormon)Agonisten erzielt werden kann. Diese Therapie wird oft mit Androgenrezeptor (AR)Antagonisten kombiniert, um eine maximale Androgenblockade zu erhalten. Die androgenunterdrückende Therapie resultiert in einer merklichen Reduktion der androgen-abhängigen 
Krebszellen. Anfangs reagieren 70-80\% der Patienten auf diese Therapie. Jedoch tritt bei den meisten Patienten in einem Zeitraum von 18 bis 24 Monaten ein Rezidiv auf, welches durch erhöhte PSA (prostate specific antigen)-Konzentrationen im Serum als Charakteristikum des erneuten Tumorwachstums gekennzeichnet ist [Trachtenberg et al., 2002]. Die erhöhten PSAWerte stellen daher einen Indikator des Fortschritts des Tumors zu einem hormonunabhängigen Prostatakarzinom dar, welches durch eine stärkere Invasivität und metastasierende Eigenschaft der Tumorzellen charakterisiert ist [Edwards et al., 2005a]. Obwohl die lokal begrenzte Krankheit effektiv mit radikaler Prostatektomie oder anderen Methoden therapiert werden kann, gibt es keine effektive Therapie für das hormonunabhängige Stadium der Krankheit. Die derzeitigen therapeutischen Methoden gegen die fortgeschrittenen Stadien des humanen Prostatakarzinoms sind eher lindernd als heilend, und die durchschnittliche Überlebensdauer von Patienten mit einem hormon-unabhängigem Prostatakarzinom beträgt etwa 12 Monate [Trachtenberg et al., 2002]. Daher besteht ein dringender Bedarf, die Grundlagen für die Progression der Krankheit zu verstehen und daraus gegebenenfalls Therapieoptionen zu entwickeln. Die Analyse der molekularen Mechanismen, die mit der Entwicklung und Progression der Krankheit assoziiert sind, sind wegen der Heterogenität des Tumors und dem multifokalen Muster der Krankheit jedoch schwierig. Weiterhin erhöht auch das Fehlen von geeigneten in vitro-Modellen mit etablierten Zelllinien die Schwierigkeit, schlüssige Resultate zu erzielen.

\subsection{Beginn und Entwicklung von Prostatakrebs, Klassifizierungssysteme}

Es gibt 2 Haupttypen von Krankheiten der Prostata beim erwachsenen Mann: die Benigne

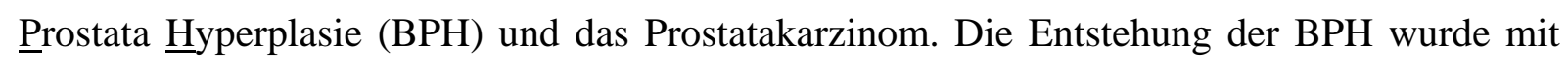
der Funktion des Enzyms 5- $\alpha$-Reduktase in Verbindung gebracht. Bei der Reduktion von Testosteron durch die 5- $\alpha$-Reduktase entsteht Dihydrotestosteron (DHT). DHT ist 10-mal effizienter in seiner Wirkung als Testosteron und stimuliert die Proliferation von stromalen und glandulären Zellen [Hayward et al., 1997]. Auf der einen Seite besitzen BPH und Prostatakrebs einige gemeinsame Eigenschaften. Zum Beispiel steigt für beide Entitäten das Vorkommen mit steigendem Alter, und beide benötigen Androgene zum Wachstum. Auf der anderen Seite stellt die BPH weder eine prämaligne Läsion, noch einen Vorläufer des Prostatakarzinoms dar. Das Prostatakarzinom entwickelt sich von einer frühen androgen- 
abhängigen, organ-begrenzten Krankheit zu einer hoch invasiven, androgen-unabhängigen, metastasierenden Krankheit. Die Fähigkeit der Krebszellen, sich in entfernte Organe auszubreiten, ist die Hauptursache von Krebs-bezogenen Todesfällen. Die regionären Lymphknoten und das Knochensystem sind die Zielorgane für die Metastasenbildung. Über 70\% der Patienten, die an einem Prostatakarzinom versterben, besitzen Metastasen im Knochen [Zetter, 1990]. Die Prostata Intraepitheliale Neoplasie (PIN) ist der eigentliche Vorläufer des invasiven Adenokarzinoms. Die PIN ist durch Proliferation des luminalen Epithels (androgen-abhängig) charakterisiert und tritt in der Peripherie und in der Transitionalzone der Prostata auf. Im Verlauf der Progression entwickelt das Prostatakarzinom eine enorme Heterogenität und ein multifokales Muster. Um diese Komplexität des Prostatakarzinoms zu beschreiben, entwickelte Gleason ein Klassifizierungssystem, in dem das Endresultat die Summe der dominanten Formen und der sekundären Formen des Karzinoms ist. So kann der Grad zwischen 2 (1+1) und 10 (5+5) liegen und fortgeschrittene Prostatakarzinome korrelieren generell mit einem höheren Gleason score (Abb. 1.1) [Gleason, 1992].

\section{Verschiedene Stadien der Entwicklung und Progression von Prostatatumoren}

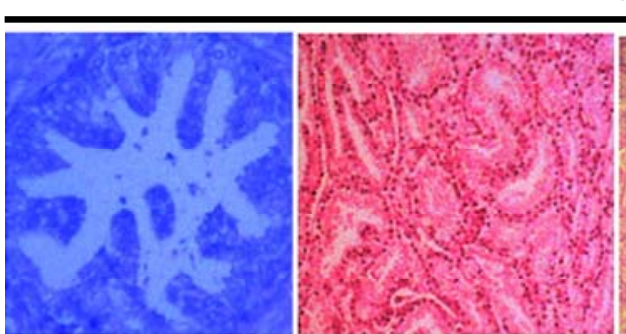

PIN

I

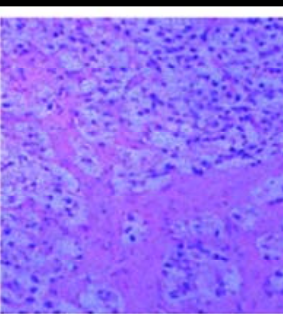

Gleason

Score 4

V
Gleason

Score 1

II

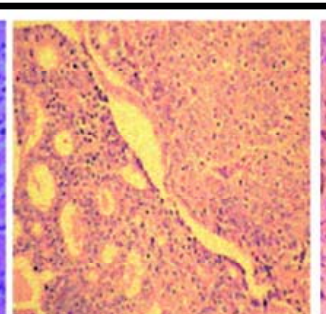

Gleason

Score 5+3

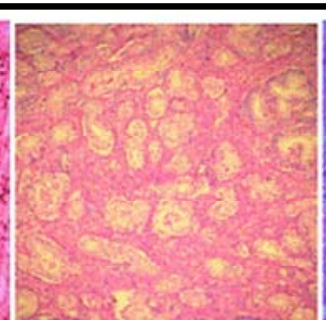

Gleason

Score 2

III

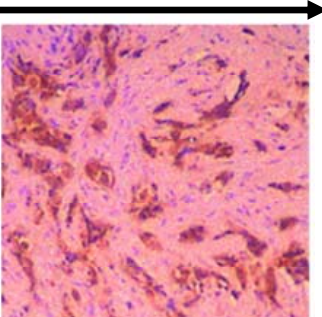

Metastasen

VI

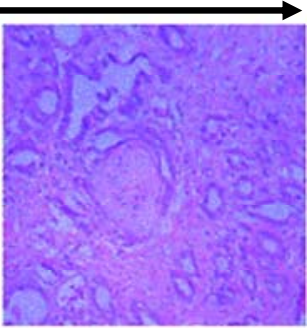

Gleason

Score 3

IV 
Abb. 1.1: Das Klassifizierungssystem des Prostatakarzinoms und von hochgradiger PIN. In den einzelnen Abbildungen sind Hämalaun/Eosin-gefärbte Gewebeschnitte verschiedener Tumormuster dargestellt [Karan et al., 2003]. I: Die mikropapilläre Form von hochgradiger PIN. Tafel II zeigt ein gut differenziertes Karzinom mit gleichgroßen Drüsen. Tafel III zeigt ein Gleason-Muster 2 mit relativ gleichgroßen und gleichförmigen Drüsen. Tafel IV zeigt die Variabilität in der Größe von malignen Drüsen und ein infiltrierendes Muster, welches typisch für Gleason Score 3 ist. Im Zentrum befinden sich perineurale Invasionen. Tafel V zeigt vereinigte Drüsen mit einem klaren Zytoplasma, welches typisch für Gleason Score 4 ist. Tafel VI stellt in der rechten Hälfte das Gleason-Muster 5 und in der linken Hälfte das Gleason-Muster 3 dar. Tafel VII zeigt ein metastasierendes Prostatakarzinom, welches den Knochen involviert.

Ein Klassifizierungssystem für die verschiedenen Stadien des Prostatakarzinoms ist die von der Union internationale contre le cancer vorgeschlagene TNM-Klassifikation maligner Tumoren. Dabei beschreibt T (Tumor) die Ausdehnung des Primärtumors, N (Nodulus) das Fehlen bzw. das Vorhandensein regionärer Lymphknotenmetastasen und M (יㅡetastase) das mögliche Auftreten von Fernmetastasen. Im Stadium T1 handelt es sich um histologisch zufällig entdeckte Prostatakarzinome. Im T2-Stadium ist der Tumor auf die Prostata begrenzt, im Stadium T3 hat er sich über die Prostatakapsel hinaus ausgebreitet und kann z. B. in den Harnblasenhals oder die Samenblasen infiltriert sein. Im T4-Stadium liegt eine Tumorinfiltration in benachbarte Organe vor, wie z. B. in die Beckenwand oder das Rektum [Böcking et al., 1993]. Die N- und M-Stadien entsprechen der bei anderen Karzinomen üblichen Einteilung.

\subsection{Leupaxin als Mitglied der Paxillin-Proteinfamilie}

Leupaxin wurde durch random screening einer Makrophagen-cDNA-Bibliothek von Lipsky et al. [1998] als ein zytoplasmatisches Protein identifiziert, das in hämatopoetischen Zellen exprimiert wird. Es zeigt ausgeprägte Homologien zu dem focal adhesion-Protein Paxillin. Aufgrund dieser Verwandschaft zu Paxillin und seiner hauptsächlichen Expression in Leukozyten wurde das Protein Leupaxin (LPXN) genannt. Wie auch das androgen receptor associated protein $\underline{55} \mathrm{kDa}$ (ARA55) wird Leupaxin zur Paxillin-Proteinfamilie gezählt [Brown et al., 2004].

Das wichtigste gemeinsame Merkmal der Paxillin-Proteinfamilie ist dessen konservierte Domänenstruktur (Abb. 1.2), denn alle drei Mitglieder enthalten vier (ARA55 und Leupaxin) 
bzw. fünf (Paxillin) LD-Motive im N-terminalen Bereich und vier LIM-Domänen im Cterminalen Bereich des Proteins. Die LD-Motive stellen kurze konservierte Leucin-reiche Aminosäuresequenzen dar, die im N-terminalen Bereich ein invariantes Leucin ( $\underline{\mathrm{L}})$-Aspartat (D)-Paar enthalten. Die LIM-Domänen umfassen ca. 50 Aminosäuren und enthalten fünf konservierte Cysteine und zwei Histidine, die zusammen Zink-bindende Module bilden. Die LIM-Domänen wurden erstmals in den Homöodomänen-Transkriptionsfaktoren Lin-11, Isl-1

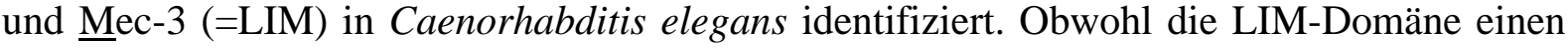
typischen DNA-bindenden Charakter besitzt, ist diese Domäne vor allem für Protein-ProteinInteraktionen verantwortlich. Bis zum jetzigen Zeitpunkt wurde nur für ARA55 eine Interaktion mit DNA in Zink-abhängiger Weise in vitro nachgewiesen [Nishiya et al., 1998]. Im Bereich der LIM-Domänen liegt auch die höchste Homologie zwischen den Mitgliedern der Paxillin-Proteinfamilie. So zeigen Leupaxin und Paxillin eine 70\%ige Homologie im Cterminalen Bereich auf Aminosäure-Ebene. Die Homologie der individuellen LIM-Domänen von Paxillin und Leupaxin liegt zwischen 67\% und 76\% [Lipsky et al., 1998], von Paxillin und ARA55 bei 62\% [Shibanuma et al., 1997; Matsuya et al., 1998].

Ein weiteres Merkmal der Paxillin-Proteinfamilie ist die subzelluläre Lokalisation der Mitglieder in sog. focal adhesion sites. Diese Zellstrukturen entstehen, wenn Mitglieder der Integrinfamilie der transmembranen Rezeptoren an ihre entsprechenden Liganden in der extrazellulären Matrix (z.B. Fibronektin, Laminin, Vitronektin) binden und sich in der Plasmamembran in Gruppen sammeln. Da die Rezeptoren keine intrinsische enzymatische Aktivität aufweisen, binden an den zytoplasmatischen Teil der Integrine intrazelluläre Signalmoleküle sowie Strukturproteine, um die von außen eingehenden Signale effektiv in das Zellinnere zu leiten. Diese makromolekularen Adhäsionskomplexe werden als focal adhesion sites bezeichnet. Für die Lokalisation von Paxillin und ARA55 in den focal adhesion sites ist jeweils die LIM3-Domäne mit Unterstützung der LIM2-Domäne verantwortlich [Brown et al., 1996; Fujita et al., 1998]. Durch die Phosphorylierung von Serin-/Threonin-Resten in den LIM2/3-Domänen von Paxillin wird die Lokalisation in den focal adhesion sites reguliert und somit auch die Zelladhäsion an Fibronektin [Brown et al., 1998]. Da sowohl die LD-Motive als auch die LIM-Domänen Protein-Protein-Interaktionen vermitteln, stellen die Mitglieder der Paxillin-Proteinfamilie Plattformen zur Koordination von Integrin- und Wachstumsfaktoren-induzierten Signalwegen an den focal adhesion sites dar, die die Reorganisation des Zytoskeletts, die Zelladhäsion, die Zellmotilität sowie den Zellzyklus beeinflussen (siehe auch Abb. 1.3). 


\section{Paxillin-Proteinfamilie}
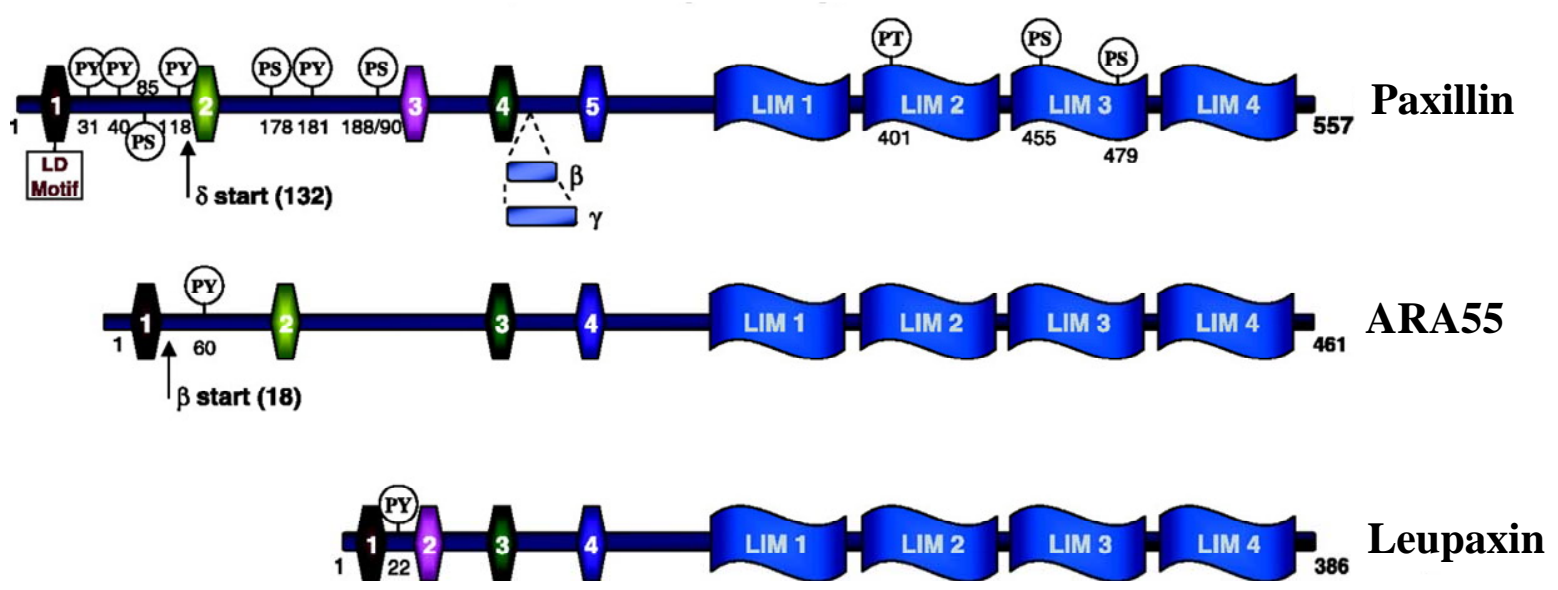

Abb. 1.2: Schematische Darstellung der LD-Motive und LIM-Domänen von Leupaxin, ARA55 und Paxillin (modifiziert nach Brown et al. [2004]). Die Proteine Leupaxin und ARA55 bestehen jeweils aus vier LD-Motiven (fünf LD-Motive bei Paxillin) im N-terminalen Bereich und vier LIM-Domänen im C-terminalen Bereich der Aminosäuresequenz. Die konservierten LD-Motive sind jeweils mit der gleichen Farbe gekennzeichnet. Die Mitglieder der Paxillin-Proteinfamilie können an unterschiedlichen Stellen phosphoryliert werden (PY=Phosphorylierung eines Tyrosinrestes, PS=Phosphorylierung eines Serinrestes, PT=Phosphorylierung eines Threoninrestes). Die Zahlen beschreiben die Aminosäurepositionen der phosphorylierten Aminosäuren.

Für Paxillin und ARA55 wurden bereits eingehende Untersuchungen zur Expression und Funktion der Proteine durchgeführt. Paxillin wurde zuerst als 68 kDa großes focal adhesionProtein [Turner et al., 1990] beschrieben, dessen Funktion in der Integration und Verbreitung von Signalen ausgehend von Integrinen und Wachstumsfaktoren hin zur effektiven Zellmigration liegt. Die Zellmotilität stellt einen komplexen vielstufigen Prozess dar, der eine Koordination des Membrantransportes und der Reorganisation des Aktin- und TubulinZytoskelett-Netzwerks benötigt, um eine Vorwärtsbewegung der Zelle zu ermöglichen. Paxillin ist durch dessen Phosphorylierungen und multipotente Assoziationen ein wichtiger Vermittler zwischen den beteiligten Proteinfamilien. Das Protein Paxillin wird an vielen Tyrosin-, Serin- und Threonin-Resten in Antwort auf die Zelladhäsion und/oder durch Stimulation von verschiedenen Wachstumsfaktoren und Zytokinen phosphoryliert (Abb. 1.2). Die Tyrosin-Phosphorylierung generiert Bindungsstellen für SH2 (SRC homology domain)Domänen enthaltende Proteine wie z.B. CRK [Bellis et al., 1995; Schaller et al., 1995; Turner 
et al., 1998]. Die Assoziation von CRK mit Paxillin ist wichtig für die Koordination der Integrin-vermittelten Zellmotilität [Petit et al., 2000]. Dagegen beeinflusst die Phosphorylierung der Serin- und Threonin-Reste eher die Konformation von Paxillin, wodurch allosterisch die Interaktionsfähigkeit mit spezifischen Bindungspartnern gefördert oder inhibiert wird.

Das zweite Mitglied der Paxillin-Proteinfamilie, ARA55, wurde zunächst als TGF $\beta$-und Wasserstoffperoxid-induzierbares Gen (daher der zweite Name hydrogen peroxide inducible clone 5 (Hic-5)) beschrieben. Es wurde festgestellt, dass ARA55 eine wichtige Rolle in der negativen Regulation des Zellwachstums spielt, inklusive des Alterungsprozesses und der TGFß-Signaltransduktion [Shibanuma et al., 1994; Zhang et al., 2000]. Später wurde ARA55 als AR-Koaktivator von Fujimoto et al. [1998] charakterisiert. In dieser Studie wurde auch gezeigt, dass ARA55 die transkriptionelle Aktivität des AR in Anwesenheit des Agonisten DHT oder der Antagonisten Östradiol $\left(\mathrm{E}_{2}\right)$ oder Hydroxyflutamid verstärkt. Die Phosphorylierung von ARA55 durch die Kinase PYK2 (proline rich tyrosine $(\underline{Y})$ kinase 2) verringert die AR-Aktivität, da phosphoryliertes ARA55 nicht mit dem AR interagieren kann [Wang et al., 2002]. Dass nicht nur ARA55, sondern auch Paxillin einen direkten Einfluss auf die Genexpression hat, zeigte eine Studie, bei der die Interaktion von Paxillin und AR sowie die Liganden-unabhängige Aktivierung des AR durch Paxillin nachgewiesen wurden [Kasai et al., 2003]. Weiterhin wurde gezeigt, dass Paxillin und ARA55 in die Transaktivierung des Glukokortikoid (GR)- und des Progesteronrezeptors (PGR), nicht aber des Östrogenrezeptors (ER) involviert sind [Fujimoto et al., 1999; Yang et al., 2000; Kasai et al., 2003]. Welcher Transportmechanismus die für die Transaktivierung notwendige Kernlokalisation von Paxillin und ARA55 vermittelt, ist noch unbekannt. Jedoch wurde für beide Proteine ein sog. Kernexportsignal (nuclear export signal $=$ NES) im Bereich der LD-Motive identifiziert [Thomas et al., 1999]. Eine Inhibition des zellulären Exportin 1-vermittelten Exportmechanismus durch Leptomycin B lässt zudem beide Proteine im Kern akkumulieren [Aoto et al., 2002; Woods et al., 2002; Shibanuma et al., 2003]. Für ARA55 wurden redoxsensitive Mechanismen zur Regulation der Lokalisation im Nukleus identifiziert, was den ersten Hinweis auf eine normal-physiologische Funktion des Kern-Zytoplasma-shuttling der Paxillin-Proteine gab ([Shibanuma et al., 2003] und Abb. 1.3). Bei der Suche nach den Zielgenen der Paxillin-Proteinfamilie haben einige Studien ARA55 mit der Regulation von $c$ fos in Verbindung gebracht [Shibanuma et al., 1997; 2002; 2003]. Zudem konnte eine ARA55-Regulierung des Promotors vom Cdk (cycline dependent kinase)-Inhibitor p21WAF/CIP1 über die Sp1-Bindungsstelle identifiziert werden [Shibanuma et al., 2004]. 
Durch den Besitz einer Vielzahl von Protein-Protein-Interaktiondomänen könnten die Proteine der Paxillin-Familie im Zellkern, ähnlich wie an den focal adhesion sites, Plattformen für die Bildung von Proteinkomplexen darstellen, die für die Transkription bestimmter Zielgene notwendig sind.

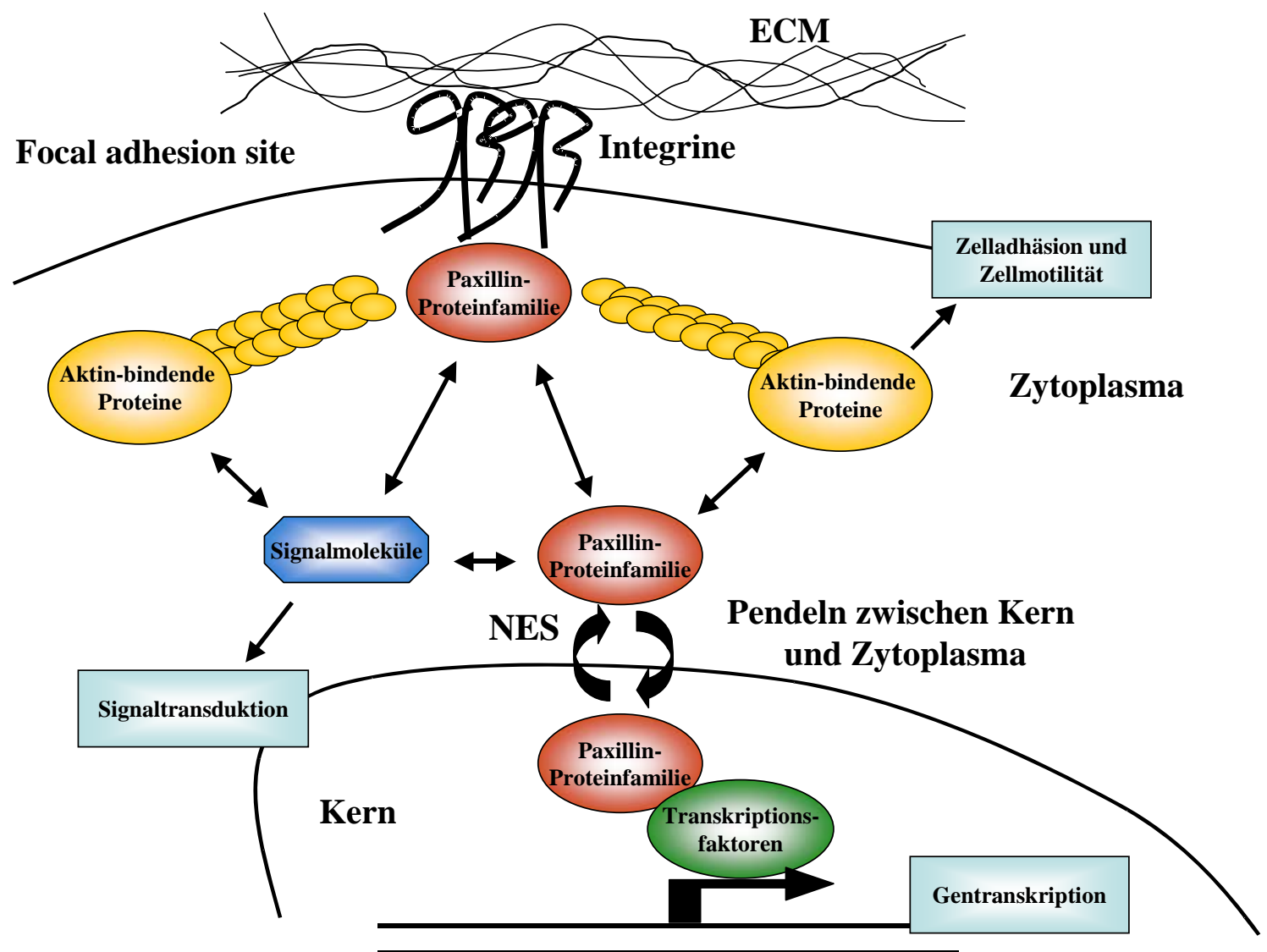

Abb. 1.3: Multiple Funktionen der Paxillin-Proteinfamilie, modifiziert nach Wang et al. [2003]. Im Normalzustand sind die Proteine der Paxillin-Familie an den focal adhesion sites lokalisiert, die durch Bindung von Integrinen an die extrazelluläre Matrix (ECM) entstehen. Dort interagieren sie mit verschiedenen Integrinen, Aktin-bindenden Proteinen und Signalmolekülen, um Zelladhäsion, Motilität und Signaltransduktion zu kontrollieren. Zusätzlich pendeln die Paxillin-Proteine zwischen Zytoplasma und Zellkern. Der Mechanismus des nukleären Imports ist nicht bekannt. Der Kernexport wird über ein intrinsisches Kernexportsignal (nuclear export signal $=\mathrm{NES}$ ) in den Proteinen vermittelt. Im Zellkern interagieren die Paxillin-Proteine wahrscheinlich mit Transkriptionsfaktoren, welche die Genexpression beeinflussen. 
Über die mögliche Funktion von Leupaxin gibt es bisher nur wenige Untersuchungen. Aus der Literatur ist jedoch bekannt, dass Leupaxin mit der zytoplasmatischen Tyrosinkinase PYK2 in lymphoiden Zellen interagiert. Mit Hilfe eines Phospho-Tyrosin-spezifischen Antikörpers konnte gezeigt werden, dass Leupaxin phosphoryliert wird [Lipsky et al., 1998]. Welche Kinase für diese Phosphorylierung verantwortlich ist, ist jedoch noch unbekannt. Weitere Interaktionspartner von Leupaxin wurden bisher nur in murinen Osteoklasten (Knochenabbauzellen) beschrieben. Darunter befinden sich Proteine, die bereits als Interaktionspartner von Paxillin bekannt sind z.B. FAK (focal adhesion kinase), PTP-PEST (protein tyrosine phosphatase) und p95PKL (paxillin kinase linker). In den Osteoklasten stellt Leupaxin ein wichtiges Adaptorprotein bei der Bildung von Adhäsionszonen dar. Weiterhin führt eine Zerstörung der Assoziation von Leupaxin mit dem podosomalen Signalkomplex zur Inhibition der Migrations- und Resorptionsfähigkeit der Osteoklasten [Gupta et al., 2003]. Mittels Mikrodissektion und anschließender Atlas ${ }^{\mathrm{TM}}$-Array-Hybridisierung wurde Leupaxin in vorhergehenden Studien als überexprimiertes Gen im humanen Prostatakarzinom im Vergleich zu normalem Prostatagewebe identifiziert [Voigt, 2003]. Eine Analyse der Leupaxin-Genexpression in anderen Tumoren mit Hilfe des Cancer Profiling Arrays zeigte, dass die Leupaxin-Genexpression nur in den hormon-abhängigen Tumoren wie Prostata-, Brust- und Uterustumoren hochreguliert vorliegt [Voigt, 2003]. Leupaxin wurde aufgrund seiner hohen Homologie zu Paxillin und ARA55 der Paxillin-Proteinfamilie zugeordnet, deren Mitglieder zum einen als Koaktivatoren von Steroidhormonrezeptoren fungieren, zum anderen aber auch direkt in die Zellmotilität involviert sind. Weiterhin wurde bereits gezeigt, dass die Mitglieder dieser Proteinfamilie unterschiedliche, zum Teil gegensätzliche Funktionen ausüben und sich nicht gegenseitig funktionell ersetzen können [Brown et al., 2004]. Diese Gegebenheiten machen Leupaxin zu einem putativen Kandidaten für ein in die Proliferation und Invasivität der Krebszellen involviertes Protein. Es gibt bisher keine Veröffentlichungen über die Rolle von Leupaxin als Interaktionspartner oder Koaktivator des AR und anderer Steroidhormonrezeptoren und den Einfluss von Leupaxin auf die Initiation und/oder Progression des Prostatakarzinoms. 


\subsection{Ziele der Arbeit}

In der voliegenden Dissertation sollte der Einfluss von Leupaxin auf die Initiation und Progression des Prostatakarzinoms untersucht werden. Weiterhin sollte die Funktion von Leupaxin in Prostatakarzinomzellen in vitro und in vivo analysiert werden. Die einzelnen Ziele waren:

- Immunhistochemische Analyse von humanen Prostatakarzinomen auf die Expression von Leupaxin

- Expression und subzelluläre Lokalisation von Leupaxin in humanen Prostatakarzinomzelllinien

- Nachweis eines putativen Kernexportsignales in der Leupaxin-Aminosäuresequenz

- Analyse der Interaktionen von Leupaxin mit den Steroidhormonrezeptoren AR, GR und PGR

- in vitro-Analysen zur Funktion von Leupaxin

o Herunterregulierung der Leupaxin-Expression in den PCa-Zelllinien LNCaP, PC-3 und DU 145 mittels RNA-Interferenz

o Untersuchung des Einflusses von Leupaxin auf Apoptose, Proliferation, Invasivität und Migrationsfähigkeit der PCa-Zelllinien

o Analysen zum Einfluss von Leupaxin auf die Expression adhäsions-relevanter Gene mittels eines Zelladhäsions-Arrays

o Identifizierung der Leupaxin-involvierenden Signalwege mit Hilfe eines Phospho-MAPK-Arrays

o Induzierbare Überexpression von Leupaxin in der PCa-Zelllinie LNCaP

o Charakterisierung Leupaxin-überexprimierender LNCaP-Zellklone (subzelluläre Lokalisation, AR-Aktivierung, Proliferation, Invasion, Adhäsion)

- In vivo-Analyse zur Funktion von Leupaxin mit Hilfe eines Mausmodells zur Prostataspezifischen Überexpression von Leupaxin

o Generierung und Etablierung von transgenen Leupaxin-Mauslinien

o Untersuchung der Integrationen des Leupaxin-Konstrukts und Expression des transgenen Leupaxins

o Histologische Analysen der Prostatae in verschiedenen Altersstadien der transgenen Leupaxin-Mauslinien 


\section{Material und Methoden}

\subsection{Chemikalien und Reagenzien}

Alle Substanzen, die nicht aufgeführt sind, wurden von den Firmen Roth (Karlsruhe) und Sigma-Aldrich (Deisenhofen) bezogen.

\begin{tabular}{|c|c|}
\hline Chemikalien & Hersteller \\
\hline Acrylamid/Bisacrylamid 40\% (29:1) & Carl Roth GmbH, Karlsruhe \\
\hline Adeninsulfat & AppliChem GmbH, Darmstadt \\
\hline Agar & Carl Roth GmbH, Karlsruhe \\
\hline Agarose & Invitrogen, Karlsruhe \\
\hline Aminosäuren & Biomol, Hamburg \\
\hline Ammoniumsulfat & Carl Roth GmbH, Karlsruhe \\
\hline Ampicillin & Sigma-Aldrich, Deisenhofen \\
\hline Ampuwa & Fresenius AG, Bad Homburg \\
\hline Adenosintriphosphat (ATP) & Biomol GmbH, Hamburg \\
\hline Bacto-Trypton & Carl Roth GmbH, Karlsruhe \\
\hline Chloroform & Baker, Deventer, NL \\
\hline Dextransulfat & GE Healthcare, München \\
\hline Dimethyldicarbonat (DMPC) & Sigma-Aldrich, Deisenhofen \\
\hline Dimethylsulfoxid (DMSO) & Carl Roth GmbH, Karlsruhe \\
\hline Dithiothreitol (DTT) & Biomol, Hamburg \\
\hline D-Luciferin (freie Säure, synthetisch) & PJK, Kleinblittersdorf \\
\hline dNTPs (100 mM) & Invitrogen, Karlsruhe \\
\hline Entwickler & Kodak, Darmstadt \\
\hline Ethidiumbromid & Sigma-Aldrich, Deisenhofen \\
\hline Ethylendiamin-tetraacetat (EDTA) & ICN, Aurora, USA \\
\hline $\begin{array}{l}\text { Ethylenglycol-bis }(\beta \text {-aminoethyl)-N,N,N',N'- } \\
\text { tetraacetat (EGTA) }\end{array}$ & Carl Roth GmbH, Karlsruhe \\
\hline Fixierer & Kodak, Darmstadt \\
\hline G418 & Merck, Darmstadt \\
\hline Glukose & Carl Roth GmbH, Karlsruhe \\
\hline Glycerol & Carl Roth GmbH, Karlsruhe \\
\hline
\end{tabular}




\begin{tabular}{|c|c|}
\hline Chemikalien & Hersteller \\
\hline Glycin & Carl Roth GmbH, Karlsruhe \\
\hline Glycylglycin & Carl Roth GmbH, Karlsruhe \\
\hline Hefeextrakt & Carl Roth GmbH, Karlsruhe \\
\hline Hygromycin & Merck, Darmstadt \\
\hline Isopropyl- $\beta$-D-thiogalactopyranosid (IPTG) & Biomol, Hamburg \\
\hline Kanamycin & Sigma-Aldrich, Deisenhofen \\
\hline (N-Morpholino )-Propansulfonsäure (MOPS) & Carl Roth GmbH, Karlsruhe \\
\hline$\beta$-Mercaptoethanol & Serva, Heidelberg \\
\hline Natriumdodecylsulfat (SDS) & Serva, Heidelberg \\
\hline NuPAGE TM MES Running buffer (20x) & Invitrogen, Karlsruhe \\
\hline NuPAGE тм LDS Sample buffer (4x) & Invitrogen, Karlsruhe \\
\hline OligoFectamine $\mathrm{TM}^{\mathrm{TM}}$ & Invitrogen, Karlsruhe \\
\hline Orange-G & Sigma-Aldrich, Deisenhofen \\
\hline Penicillin/Streptomycin & PAN, Aidenbach \\
\hline Phenol & Invitrogen, Karlsruhe \\
\hline PMSF & Sigma-Aldrich, Deisenhofen \\
\hline p-Nitrophenyl- $\alpha$-D-Galactopyranosid (PNP- $\alpha$-Gal) & MP Biomedicals, Eschwege \\
\hline Radioaktiv markierte Reagenzien: [ $\left.{ }^{32} \mathrm{P}\right]$-dCTP & GE Healthcare, München \\
\hline Rapid-Hyb Hybridisierungspuffer & GE Healthcare, München \\
\hline RNase-Inhibitor & MBI, St. Leon-Rot \\
\hline RNA-Längenstandard & Invitrogen, Karlsruhe \\
\hline Roti ${ }^{\circledR}$ Fect & Carl Roth GmbH, Karlsruhe \\
\hline Roti ${ }^{\circledR}-$ Nanoquant & Carl Roth GmbH, Karlsruhe \\
\hline S.O.C. Medium & Invitrogen, Karlsruhe \\
\hline Simply Blue Safe Stain & Invitrogen, Karlsruhe \\
\hline N,N,N',N'-Tetramethylethylenediamine (TEMED) & Carl Roth GmbH, Karlsruhe \\
\hline Tris & Carl Roth GmbH, Karlsruhe \\
\hline Triton X-100 & Fluka, Deisenhofen \\
\hline Tween 20 & Merck, Darmstadt \\
\hline VectaShield mit DAPI & VectorLab, Burlingame, USA \\
\hline $\begin{array}{l}\text { 5-Bromo-4-Chloro-3-indolyl a-D-galactopyranosid } \\
\text { (X- } \alpha \text {-Gal) }\end{array}$ & Biomol, Hamburg \\
\hline Zellkulturmedien & PAN, Aidenbach \\
\hline
\end{tabular}




\subsection{Biochemikalien und Enzyme}

\begin{tabular}{ll}
\hline Biochemikalien & Hersteller \\
\hline Albumin Fraktion V & Biomol, Hamburg \\
Aprotinin & Sigma-Aldrich, Deisenhofen \\
Fetales Kälberserum (SeraPlus) & PAN, Aidenbach \\
MangoTaq-DNA-Polymerase & Bioline, Luckenwalde \\
Lachsspermien-DNA & Sigma-Aldrich, Deisenhofen \\
Leupeptin & Sigma-Aldrich, Deisenhofen \\
Pepstatin A & Sigma-Aldrich, Deisenhofen \\
PfuUltra-HF-DNA Polymerase & Stratagene, La Jolla, USA \\
Phalloidin, FITC- oder TRITC-markiert & Sigma-Aldrich, Deisenhofen \\
Platinum-Taq-DNA Polymerase & Invitrogen, Karlsruhe \\
Proteinase K & Carl Roth GmbH, Karlsruhe \\
Restriktionsenzyme & Invitrogen, Karlsruhe \\
Reverse Transkriptase SuperScript II & Invitrogen, Karlsruhe \\
RNase A & Invitrogen, Karlsruhe \\
T4-DNA-Ligase & Promega, Mannheim \\
\hline
\end{tabular}

\subsection{Gebrauchswaren}

Nicht aufgeführte Gebrauchswaren wurden von den Firmen Schütt und Omnilab-Krannich (Göttingen), sowie Sarstedt (Nümbrecht) bezogen.

6-, 12- oder 24well-Zellkultur-Platten

384well-Platten, weiß

flachbödige 96well-Mikrotiterplatten

Blottingpapier GB 002, 003, 004

CentriSart I

FALCON culture slides

PVDF-Membran

Einmalfilter Minisart
Corning Inc., New York, (USA)

ABgene, Hamburg

Greiner, Nürtingen

Schleicher \& Schüll, Dassel

Sartorius, Göttingen

Becton Dickinson GmbH, Heidelberg

Macherey \& Nagel, Düren

Sartorius, Göttingen 


\begin{tabular}{ll}
\hline Gebrauchswaren & Hersteller \\
\hline & \\
NML (Porengröße 0,20 und 0,45 $\mu \mathrm{m}$ ) Filterpapier 0858 & Schleicher \& Schüll, Dassel \\
Hybond C Membran & GE Healthcare, München \\
Membranfilter & Millipore, Morlsheim \\
Petrischalen & Greiner Nunc., Nürtingen \\
Pipettenspitzen & Sarstedt, Nürnbrecht \\
Reaktionsgefäße & Sarstedt, Nürnbrecht \\
Quarz-Küvetten & Hellma, Mühlheim \\
Röntgenfilme (Hyperfilm ${ }^{\mathrm{TM}}$-MP) & GE Healthcare, München \\
Sterilfilter & Sartorius, Göttingen \\
Objektträger Superfrost ${ }^{\circledR P l u s}$ & Schütt, Göttingen \\
Zellkulturflaschen & Greiner Nunc., Nürtingen
\end{tabular}

\subsection{Sterilisationsverfahren}

Gebrauchswaren, Lösungen und Kulturmedien wurden bei $121^{\circ} \mathrm{C}$ und 1,5 Bar autoklaviert oder über Nacht bei $220^{\circ} \mathrm{C}$ hitzesterilisiert. Hitzeempfindliche Lösungen wurden steril filtriert. Wässrige Lösungen für RNA-Präparationen und RNA-Analysen wurden mit 1 \%o (v/v) Dimethyldicarbonat versetzt, für 12 bis 24 h bei RT inkubiert und anschließend autoklaviert.

\subsection{Gebrauchsfertige Reaktionssysteme}

\begin{tabular}{ll}
\hline Reaktionssystem & Hersteller \\
\hline $\begin{array}{l}\text { DYEnamic ET-Terminator-Mix } \\
\text { CellTiter } 96^{\circledR}{ }^{\circledR} Q_{\text {ueous }} \text { Non-Radioactive Cell }\end{array}$ & GE Healthcare, München \\
Proliferation Assay (MTS) & Promega, Mannheim \\
Chemiluminescent Reporter Assay for $\beta$ - & Tropix, Bedford, USA \\
Galactosidase, Galacto-Light ${ }^{\mathrm{TM}}$ & \\
DirectPCR tail reagent & Peqlab, Erlangen \\
ECL Plus & GE Healthcare, München \\
EZ4U Proliferationsassay & Biozol, Echingen
\end{tabular}


Reaktionssystem

Micro Spin ${ }^{\mathrm{TM}}$-S200 HR Säulen

Montage $^{\mathrm{TM}}$ PCR Centrifugal Filter Devices

OneStep RT-PCR-Kit

Plasmid Midi Kit Nucleobond AX100

Plasmid Midi Kit

Protein G Immunoprecipitation Kit

QuantiTect ${ }^{\mathrm{TM}}$ SYBR ${ }^{\circledR}-$ Green PCR Master Mix

QIA Ex II Gel Extraction Kit

Rediprime ${ }^{\mathrm{TM}}$ II Random Prime-Labeling System

RNeasy Mini Kit

Tri-Reagent ${ }^{\mathrm{TM}}$

\section{Hersteller}

GE Healthcare, München

Millipore, Schwalbach

Qiagen, Hilden

Macherey \& Nagel, Düren

Invitrogen, Karlsruhe

Sigma-Aldrich, Deisenhofen

Qiagen, Hilden

Qiagen, Hilden

GE Healthcare, München

Qiagen, Hilden

Sigma-Aldrich, Deisenhofen

\subsection{Lösungen}

Lösungen für den routinemäßigen Gebrauch wurden nach [Sambrook et al., 1989] angesetzt.

Die benötigten Chemikalien wurden den Erfordernissen gemäß in bidestilliertem oder DEPCbehandeltem Wasser gelöst und nach Bedarf autoklaviert oder steril filtriert.

\begin{tabular}{|c|c|}
\hline Lösung/ Puffer & Zusammensetzung \\
\hline \multirow[t]{3}{*}{ Alkalische-Phosphatase-Färbelösung } & $45 \mu \mathrm{l}$ NBT (75 mg/ml in DMF) \\
\hline & $35 \mu \mathrm{l}$ BCIP (50 mg/ml in DMF) \\
\hline & in $10 \mathrm{ml} \mathrm{AP-Puffer}$ \\
\hline \multirow[t]{3}{*}{ AP-Puffer } & $100 \mathrm{mM} \mathrm{NaCl}$ \\
\hline & $50 \mathrm{mM} \mathrm{MgCl}_{2}$ \\
\hline & 100 mM Tris/HCl pH 9.5 \\
\hline \multirow[t]{2}{*}{ Assay-Puffer ( $\alpha$-Gal-Assay) } & 2 Vol 1x NaOAc-Puffer \\
\hline & 1 Vol PNP- $\alpha$-Gal-Lösung \\
\hline \multirow[t]{2}{*}{ Blockpuffer I (Western Blot) } & 1x PBS \\
\hline & 2-5\% Magermilchpulver \\
\hline \multirow[t]{2}{*}{ Blockpuffer II (Western Blot) } & 1x TBS/0,1\% Tween 20 \\
\hline & 5\% Magermilchpulver \\
\hline \multirow[t]{2}{*}{ Blockpuffer III (Immunhistochemie) } & 1x PBS \\
\hline & $3 \%$ BSA \\
\hline
\end{tabular}




\begin{tabular}{|c|c|}
\hline Lösung/ Puffer & Zusammensetzung \\
\hline \multirow[t]{3}{*}{ Coomassie-Lösung } & $30 \%(v / v)$ Methanol \\
\hline & 10\% (v/v) Essigsäure \\
\hline & 0,05\% (w/v) Coomassie-Brilliant Blau R250 \\
\hline \multirow[t]{3}{*}{ Glycinpuffer (1x) } & 1,44\% (w/v) Glycin \\
\hline & $0,3 \%(w / v)$ Tris \\
\hline & $0,1 \%(w / v)$ SDS \\
\hline \multirow[t]{3}{*}{ Glycylglycin-Puffer } & 25 mM Glycylglycin pH 7.8 \\
\hline & $15 \mathrm{mM} \mathrm{MgSO}_{4}$ \\
\hline & 4 mM EGTA \\
\hline \multirow[t]{4}{*}{ 10x IP-Puffer } & $500 \mathrm{mM}$ Tris $\mathrm{pH} 7.55$ \\
\hline & $1,5 \mathrm{M} \mathrm{NaCl}$ \\
\hline & 5\% Natriumdeoxycholat \\
\hline & $10 \%$ NP-40 (oder IGPAL) \\
\hline \multirow[t]{2}{*}{ Kaliumphosphat (1M) } & $0,17 \mathrm{M} \mathrm{KH}_{2} \mathrm{PO}_{4}$ \\
\hline & $0,72 \mathrm{M} \mathrm{K}_{2} \mathrm{HPO}_{4}$ \\
\hline \multirow[t]{3}{*}{ Luciferin-Arbeitslösung (für 50 Proben) } & $1 \mathrm{ml}$ Luciferin-Stock \\
\hline & 4 ml Glycylglycinpuffer (pH 7.8) \\
\hline & $40 \mu \mathrm{l} 1 \mathrm{M}$ DTT \\
\hline \multirow[t]{4}{*}{ Luciferin-Assay-Buffer (LAB) (für eine Probe) } & $165 \mu \mathrm{l}$ Glycylglycinpuffer pH 7.8 \\
\hline & $35 \mu \mathrm{l} 100 \mathrm{mM}$ Kaliumphosphat \\
\hline & $2,2 \mu \mathrm{l} 100 \mathrm{mM}$ DTT \\
\hline & $2,2 \mu \mathrm{l} 100 \mathrm{mM}$ ATP \\
\hline \multirow[t]{3}{*}{ Luciferinstock } & 55 mg DTT \\
\hline & 35,7 ml Glycylglycinpuffer (pH 7.8) \\
\hline & 10 mg Luciferin \\
\hline \multirow[t]{9}{*}{ Lysispuffer für Proteine (Zellkultur) } & $150 \mathrm{mM} \mathrm{NaCl}$ \\
\hline & $1 \mathrm{mM}$ EDTA \\
\hline & 50 mM Tris-HCl, pH 7.4 \\
\hline & $1 \% \mathrm{NP}-40$ \\
\hline & 0,25\% Natriumdeoxycholat \\
\hline & Pepstatin A $(1 \mu \mathrm{g} / \mathrm{ml})$ \\
\hline & Leupeptin $(1 \mu \mathrm{g} / \mathrm{ml})$ \\
\hline & Aprotinin $(1 \mu \mathrm{g} / \mathrm{ml})$ \\
\hline & PMSF (1 mM) \\
\hline \multirow[t]{3}{*}{ Lysispuffer II für Proteine (Transaktivierungsassay) } & 100 mM Kaliumphosphat pH 7.8 \\
\hline & $1 \mathrm{mM}$ DTT \\
\hline & $0,2 \%$ Triton X-100 \\
\hline
\end{tabular}




\begin{tabular}{|c|c|}
\hline Lösung/ Puffer & Zusammensetzung \\
\hline \multirow[t]{3}{*}{ Lysispuffer III für Proteine (Organe) } & 1\% Triton \\
\hline & 150mM HEPES \\
\hline & 1mM EDTA \\
\hline \multirow{3}{*}{ MOPS-Puffer (10x) } & $50 \mathrm{mM}$ Natriumacetat \\
\hline & 10 mM EDTA \\
\hline & 200 mM MOPS (pH 7.0) \\
\hline 1 x NaOAc-Puffer ( $\alpha$-Gal-Assay) & 0,5 M NaOAc (pH 4,5) \\
\hline \multirow[t]{2}{*}{ PNP- $\alpha$-Gal-Lösung } & 30,1 mg PNP- $\alpha$-Gal-Lösung \\
\hline & $5 \mathrm{ml} \mathrm{H} \mathrm{H}_{2} \mathrm{O}$ \\
\hline 10 x Stop-Lösung ( $\alpha$-Gal-Assay) & $1 \mathrm{M} \mathrm{Na}_{2} \mathrm{CO}_{3}$ \\
\hline \multirow[t]{3}{*}{ P1 Puffer (Plasmid-Minipräparation) } & 50 mM Tris-HCl, pH 8.0 \\
\hline & 10 mM EDTA \\
\hline & $100 \mu \mathrm{g} / \mathrm{ml}$ RNase A \\
\hline \multirow[t]{2}{*}{ P2 Puffer (Plasmid-Minipräparation) } & $200 \mathrm{mM} \mathrm{NaOH}$ \\
\hline & $1 \%$ SDS \\
\hline P3 Puffer (Plasmid-Minipräparation) & 3 M Kaliumacetat (pH 5.5) \\
\hline \multirow[t]{4}{*}{ 10x PBS } & $1,37 \mathrm{M} \mathrm{NaCl}$ \\
\hline & $81 \mathrm{mM} \mathrm{Na}_{2} \mathrm{HPO}_{4}$ \\
\hline & $27 \mathrm{mM} \mathrm{KCl}$ \\
\hline & $14,7 \mathrm{mM} \mathrm{KH}_{2} \mathrm{PO}_{4}$ \\
\hline \multirow[t]{2}{*}{ Sammelgelpuffer } & 0,5 M Tris/HCl pH 6.8 \\
\hline & $0,4 \%$ SDS \\
\hline \multirow[t]{2}{*}{ SSC (20x) } & $3 \mathrm{M} \mathrm{NaCl}$ \\
\hline & 0,3 M Natriumcitrat, $\mathrm{pH} 7.0$ mit $\mathrm{NaOH}$ \\
\hline \multirow[t]{4}{*}{ Stop-Mix I } & 95\% Formamid \\
\hline & 20 mM EDTA \\
\hline & 0,05\% Bromphenolblau \\
\hline & 0,05\% Xylencyanol \\
\hline \multirow[t]{3}{*}{ Stop-Mix II } & 15\% Ficoll 400 \\
\hline & 200 mM EDTA \\
\hline & 0,1\% Orange G \\
\hline \multirow[t]{2}{*}{ 50x TAE-Puffer } & 2 M Tris-Acetat, $\mathrm{pH} 8.3$ \\
\hline & 0,05 M EDTA \\
\hline \multirow[t]{3}{*}{ TBE-Puffer (5x) } & 445 mM Tris/HCl, pH 8.0 \\
\hline & 445 mM Borsäure \\
\hline & 10 mM EDTA \\
\hline
\end{tabular}




\begin{tabular}{|c|c|}
\hline Lösung/ Puffer & Zusammensetzung \\
\hline \multirow[t]{2}{*}{ 10x TBS } & $1,37 \mathrm{M} \mathrm{NaCl}$ \\
\hline & 100 mM Tris/HCl, pH 7.6 \\
\hline \multirow[t]{2}{*}{ TE-Puffer } & 10 mM Tris-HCl, $\mathrm{pH} 80$ \\
\hline & $1 \mathrm{mM}$ EDTA \\
\hline \multirow[t]{3}{*}{ Transferpuffer (Western Blot) } & 25 mM Tris $\mathrm{pH} 8.3$ \\
\hline & 150 mM Glycin \\
\hline & 20\% Methanol \\
\hline \multirow[t]{2}{*}{ Trenngelpuffer } & 1,5 M Tris/HCl pH 8.8 \\
\hline & $0,4 \%$ SDS \\
\hline \multirow[t]{2}{*}{ Trypsin/EDTA-Lösung } & 0,05\% Trypsin \\
\hline & $0,02 \%$ EDTA in PBS \\
\hline \multirow[t]{2}{*}{$20 \times$ Turbo-Puffer } & $0,2 \mathrm{M} \mathrm{NaOH}$ \\
\hline & mit festem $\mathrm{H}_{3} \mathrm{BO}_{3}$ auf $\mathrm{pH} 8.0$ \\
\hline Waschlösung I (Southern Blot) & $2 \mathrm{xSSC}$ \\
\hline \multirow[t]{2}{*}{ Waschlösung II (Southern Blot) } & $0,2 x \mathrm{SSC}$ \\
\hline & $0,1 \%$ SDS \\
\hline \multirow[t]{2}{*}{ Waschlösung III (Southern Blot) } & $0,1 \mathrm{x}$ SSC \\
\hline & $0,1 \%$ SDS \\
\hline \multirow[t]{2}{*}{ Waschlösung IV (Western Blot) } & 1x TBS/PBS \\
\hline & 2\% Magermilchpulver \\
\hline X-Gal-Stammlösung & 20 mg X-Gal/ml N.N.-Dimethyl-formamid \\
\hline
\end{tabular}

\subsection{Medien, Antibiotika, Agarplatten}

\subsubsection{Medien für Bakterien}

$\begin{array}{lll}\text { LB (Luria-Bertani)-Medium: } & 1 \% & \text { Trypton } \\ & 0,5 \% & \text { Hefeextrakt } \\ 1 \% & \mathrm{NaCl} \\ & \mathrm{pH} 7.0\end{array}$

Die Medien wurden mit bidestilliertem Wasser angesetzt, autoklaviert und bei $4^{\circ} \mathrm{C}$ aufbewahrt. Für die Selektion wurden der jeweiligen Resistenz entsprechend Ampicillin

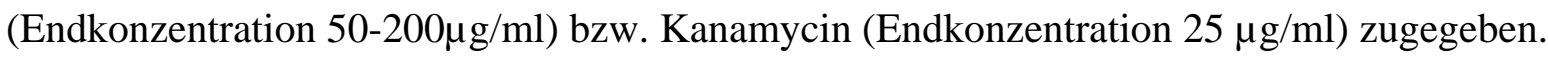




\subsubsection{Medien für Hefen}

YPDA-Medium (Vollmedium): $20 \mathrm{~g} / \mathrm{l}$ Pepton

$10 \mathrm{~g} / \mathrm{l}$ Hefeextrakt

2\% Glukose

20 mg/l Adeninhemisulfat

pH 5.8 mit $\mathrm{HCl}$

SD-Medium:

1,7 g/l Hefe-Stickstoff-Basis ohne Aminosäuren

$5 \mathrm{~g} / \mathrm{l}$ Ammoniumsulfat

10\% sterile Mangel-Nährlösung

2\% Glukose

10 x Mangel-Nährlösung:

In Abhängigkeit vom gewünschten Selektivmedium wurden von den folgenden Aminosäuren eine oder mehrere ausgelassen.

$\begin{array}{lc}200 \mathrm{mg} / \mathrm{l} \text { Adeninsulfat } & 200 \mathrm{mg} / \mathrm{l} \text { Methionin } \\ 200 \mathrm{mg} / \mathrm{l} \text { Arginin } & 500 \mathrm{mg} / \mathrm{l} \text { Phenylalanin } \\ 200 \mathrm{mg} / \mathrm{l} \text { Histidin } & 2000 \mathrm{mg} / \mathrm{l} \text { Threonin } \\ 300 \mathrm{mg} / \mathrm{l} \mathrm{Isoleucin} & 200 \mathrm{mg} / \mathrm{l} \text { Tryptophan } \\ 1000 \mathrm{mg} / \mathrm{l} \text { Leucin } & 300 \mathrm{mg} / \mathrm{l} \text { Tyrosin } \\ 300 \mathrm{mg} / \mathrm{l} \text { Lysin } & 200 \mathrm{mg} / \mathrm{l} \text { Uracil } \\ 1500 \mathrm{mg} / \mathrm{l} \text { Valin } & \end{array}$

Die Medien wurden mit bidestilliertem Wasser angesetzt, autoklaviert und bei $4^{\circ} \mathrm{C}$ aufbewahrt.

\subsubsection{Agarplatten}

Zur Herstellung von Agarplatten wurde dem LB-, SD- oder YPDA-Medium vor dem Autoklavieren 1,5\% (w/v) Agar zugefügt, nach dem Autoklavieren auf $55^{\circ} \mathrm{C}$ abgekühlt, ggf. 
mit den unten angegebenen Reagenzien versetzt und in Petrischalen gegossen. Nach dem Aushärten wurden die Agarplatten bei $4^{\circ} \mathrm{C}$ aufbewahrt.

Ampicillin : Endkonzentration $50 \mu \mathrm{g} / \mathrm{ml}$

Kanamycin: Endkonzentration $25 \mu \mathrm{g} / \mathrm{ml}$

\subsubsection{Medien für eukaryontische Zellkulturen}

Die zur Kultur eukaryontischer Zellen verwendeten Medien wurden käuflich erworben (PAN, Aidenbach), vor Gebrauch mit fetalem Kälberserum (FKS) und Antibiotika (Penicillin/Streptomycin) versetzt und sterilfiltriert. Für die Zellkultur wurden folgende Medien verwendet:

Medium für PC-3-, LNCaP- und

DU 145-Zellen:

RPMI 1640 (PAN)

$100 \mu \mathrm{g} / \mathrm{ml}$ Streptomycin

100 U/ml Penicillin

10\% FKS

Medium für Daudi-Zellen:

RPMI 1640 (PAN)

$100 \mu \mathrm{g} / \mathrm{ml}$ Streptomycin

100 U/ml Penicillin

15\% FKS

Medium für LNCaP-Klone:

RPMI 1640 (PAN)

$100 \mu \mathrm{g} / \mathrm{ml}$ Streptomycin

$100 \mathrm{U} / \mathrm{ml}$ Penicillin

$10 \%$ FKS

0,2 $\mathrm{mg} / \mathrm{ml} \mathrm{G418} \mathrm{und/oder}$

0,2 mg/ml Hygromycin

Medium für NIH 3T3-Zellen:

DMEM (PAN)

2 mM L-Glutamin

$10 \%$ FKS

$100 \mu \mathrm{g} / \mathrm{ml}$ Streptomycin

100 U/ml Penicillin 
Zur Langzeitlagerung der Zellen in flüssigem Stickstoff wurde das entsprechende Medium mit 8-10\% DMSO versetzt.

\subsection{Biologisches Material}

\subsubsection{Bakterienstämme}

Für die Transformation von Plasmiden in kompetente Bakterienstämme wurde der Bakterienstamm Escherichia coli DH5 $\alpha$ [Hanahan, 1983] von Invitrogen (Karlsruhe) verwendet.

\subsubsection{Eukaryontische Zelllinien}

Daudi Humane B-Lymphoblasten-Zelllinie (Burkitt-Lymphom), ATCC, Rockville, USA [Klein et al., 1968; Ohsugi et al., 1980]

DU 145 Humane Prostataadenokarzinom-Zelllinie, ATCC, Rockville, USA Androgen-unabhängige Zellen [Mickey et al., 1977; Stone et al., 1978]

LNCaP Humane Prostataadenokarzinom-Zelllinie, ATCC, Rockville, USA Androgen-abhängige Zellen [Horoszewicz et al., 1983]

NIH 3T3 Mausfibroblasten, ATCC, Rockville, USA

[Jainchill et al., 1969]

PC-3 Humane Prostataadenokarzinom-Zelllinie, ATCC, Rockville, USA Androgen-unabhängige Zellen [Kaighn et al., 1979; Ohnuki et al., 1980]

\subsubsection{Mausstämme}

Die verwendeten Mäuse des Stammes FVB stammten aus institutseigenen Beständen, dem Max-Planck-Institut für experimentelle Medizin (Göttingen) oder wurden von der Firma 
Charles River (Hannover) bezogen. Die Haltungsbedingungen bestanden aus einem zwölfstündigen Hell-Dunkel-Rhythmus bei $22^{\circ} \mathrm{C}$ und $55 \pm 5 \%$ relativer Luftfeuchtigkeit. Tierfutter wurde von der Firma ssniff-Spezialdiäten (Soest) bezogen.

\subsubsection{Synthetische Oligonukleotide}

\subsubsection{Synthetische DNA-Oligonukleotide}

Für die Sequenzierung von Konstrukten bzw. die Generierung von cDNA-Produkten wurden synthetische Oligonukleotide von den Firmen Invitrogen (Karlsruhe) und Operon (Köln) verwendet. Enthalten die Oligonukleotide nicht sequenzspezifische Schnittstellen für Restriktionsenzyme, sind diese in der nachfolgenden Tabelle grau hervorgehoben.

Vektor-spezifische Primer:

\begin{tabular}{|c|c|}
\hline GFPC1-TOP+ & 5’-GAT CAC ATG GTC CTG CTG GAG TTC GT-3’ \\
\hline GFPC1-R+ & 5'-GTA AAA CCT CTA CAA ATG TGG TAT GG-3’’ \\
\hline pGADT7F & 5'-TCG ATG ATG AAG ATA CCC CAC CAA ACC-3' \\
\hline pGADT7R & 5'-AGA TGG TGC ACG ATG CAC AGT TGAA GTG-3’ \\
\hline pGBKT7F & 5'-TCA TCG GAA GAG AGT AGT AAC AAA GG-3' \\
\hline pGBKT7R & 5'-CTA AGA GTC ACT TTA AAA TTT GTA TAC AC-3' \\
\hline CMV-V1-Fw & 5'-GGT AGG CGT GTA CGG TGG GAG GTC TAT-3' \\
\hline EGFP-V1-Rev & 5’-GTC CTC GAT GTT GTG GCG GAT CTT G-3’ \\
\hline EGFP-V2-Fw & 5'-CCA CAA CGT CTA TAT CAT GGC CGA CA-3’ \\
\hline SP6new & 5'-TTA GGT GAC ACT ATA GAA TAC TCA AGC-3' \\
\hline T3new & 5'-TTA ACC CTC ACT AAA GGG AAC AAA AGC-3’ \\
\hline T7new & 5'-AAT ACG ACT CAC TAT AGG GCG AAT TGG-3' \\
\hline pTRE-Hyg-Rev & 5'-CTA ACG GAT TCA CCA CTC CAA G-3' \\
\hline pTRE-Fw & 5’-GCA GAG CTC GTT TAG TGA ACC GTC AGA-3’ \\
\hline
\end{tabular}

Androgenrezeptor(AR)-spezifische Primer:

AR3FPN

AR3RPN

AR1FP

ARRP1

ARFP2
5’-CCG GAT CCC CGA CTA TTA CTT TCC ACC CCA GAA GAC C-3’

5'-CCC TGC AGT CAC TGG GTG TGG AAA TA-3'

5’-GGA GGA TCC ATG GAA GTG CAG TTA GGG CTG GGA AGG G-3’

5'-CTC GAG CTG CCC ATA GCG GCA CTG CGC CGC CGC AGC-3'

5'-GGA GGA TCC GGC AAG AGC ACT GAA GAT ACT GCT GAG-3’ 


$\begin{array}{ll}\text { ARRP2 } & \text { 5'-CTC GAG CTG TCT GGG TTG TCT CCT CAG TGG GGC TG-3’' } \\ \text { AR3RP } & \text { 5'-CTC GAG CTG TCA CTG GGT GTG GAA ATA GAT GGG CTT G-3' } \\ \text { AR_RP2046 } & \text { 5'-GGG AAT ACT CAG CAG TAT CTT CAG TGC-3' } \\ \text { AR_3243F } & \text { 5'-GAG AGA CAG CTT GTA CAC GTG GTC AAG-3' } \\ \text { AR_RP3260 } & \text { 5'-GTGTACAAGCTGTCTCTCTCCCAGTTC-3' } \\ \text { ARfl-V1-Fw } & \text { 5'-AGA TCT ATG GAA GTG CAG TTA GGG CTG GGA AGG-3' } \\ \text { ARfl-V1-Rev } & \text { 5'-CCG CGG CTG GGT GTG GAA ATA GAT GGG CTG AC-3' }\end{array}$

\section{Leupaxin-spezifische Primer:}

$\begin{array}{ll}\text { LPXN-left } & \text { 5'-AGA AGC ACT TAC CAG ACA AGC AG-3' } \\ \text { LPXN-right } & \text { 5'-ACA CTG AAG GAA GAT GCA AAG AG-3' } \\ \text { LPXN-FPAD(LD) } & \text { 5'-CTT GGG AAT TCG ACA TGG AAG AGT TAG ATG CC-3' } \\ \text { LPXN-FPAD(LIM) } & \text { 5'-GCA GAA TTC GGC ATT GCC ACA GTG CCC AAG GGC-3' } \\ \text { LPXN-V2-Fw } & \text { 5'-AAG CTT CAA TGG AAG AGT TAG ATG CCT TAT TGG-3' } \\ \text { LPXN-V2-Rev } & \text { 5'-AGA TCT TTA CAG TGG GAA GAG CTT ATT GAA GCA AGG-3' } \\ \text { LD3-Fw } & \text { 5'-CAG CAG CTC GAG AGT TGG ATG AGC TCA TGG CTC ACC TG-3' } \\ \text { NES-Fw } & \text { 5'-TGC CGG CTC GAG TCG TGT ATA CTA CCA ATA TCC AGG AG-3' } \\ \text { mLD3-Fw } & \text { 5'-GCT CAG TTG GAT GAG GCC ATG GCT CAC CTG AC-3' } \\ \text { LPXNmLD3_L1_F } & \text { 5'-GCT CAG GCG GAT GAG GCC ATG GCT CAC CTG AC-3' } \\ \text { LPXNmLD3_L3_F } & \text { 5'-CAG TTG GAT GAG GCC ATG GCT CAC GCC ACT GAG ATG CAG G-3' } \\ \text { LPXN(LD4)_F } & \text { 5'-GAA GCA CTT ACC AGA CAA GCA GAA TTC CAA GG-3' } \\ \text { LPXNmLD4(L1+3) } & \text { 5'-GCC TCC GCG GAC TCA ATG CTT GGG GGT GCG GAG CAG-3' } \\ \text { LPXNmLD4(L2) } & \text { 5'-GCC TCC CTG GAC TCA ATG GCT GGG GGT CTG GAG CAG-3' } \\ \text { LPXN(LD)-Fw-E } & \text { 5'-CTT GGG AAT TCG ACA ATG GAA GAG TTA GAT GCC-3' } \\ \text { LPXN(LD)-Rev } & \text { 5'-GGC TCG AGG GCA ATG CCA AGG TCC TGC AAT TC-3' } \\ \text { LPXN(LIM)-Fw-2 } & \text { 5'-GCA GAA TTC TGG CAT TGC CAC AGT GCC CAA GGG CCA TTG-3' } \\ \text { LPXN(LIM)-Rev-E } & \text { 5'-CAG TTG CTC GAG CAG TGG GAA GAG CTT ATT GAA GC-3' } \\ \text { LPXN_AXXAA 5' } & \text { 5'-CTG CAG TTA CAG TGG GGC AGC CTT ATT GGC GCA AGG TTG } \\ & \text { ACA ATA GGT CTT G-3' } \\ \text { LPXN-663F } & \text { 5'-CTT TGA GCG GAG TGG CTT GGC CTA CTG-3' } \\ \text { LPXN-689R } & \text { 5'-CAG TAG GCC AAG CCA CTC CGC TCA AAG-3' }\end{array}$

\section{Progesteronrezeptor (PGR)-spezifische Primer:}

$\begin{array}{ll}\text { PGR-V1-Fw } & \text { 5'-GAA TTC TCA TGA CTG AGC TGA AGG CAA AGG GTC C-3' } \\ \text { PGR-V1-Rev } & \text { 5'-CTG CAG CTT TTT ATG AAA GAG AAG GGG TTT CAC C-3' } \\ \text { PGR-GFP-Fw-EcoRI } & \text { 5'-GAA TTC CAT GAC TGA GCT GAA GGC AAA GGG TCC-3' } \\ \text { PGR-KT7-Fw-EcoRI } & \text { 5'-GAA TTC ATG ACT GAG CTG AAG GCA AAG GGT CC-3' } \\ \text { PGR-Fw-Stu } & \text { 5'-GCC CGC TCT AAA GAT AAA GGA GGA G-3' } \\ \text { PGR-Rev-Stu } & \text { 5'-GAG GAG GAC GCA GAC GAG ACT GA-3' }\end{array}$




$\begin{array}{ll}\text { PGR-Rev-Pst } & \text { 5'-CTG CAG ACT TTT TAT GAA AGA GAA GGG GTT TCA CC-3' } \\ \text { PGR-Fw-1752 } & \text { 5'-AGT TCT AGT CCC CCA GAA AAG GAC AG-3' } \\ \text { PGR-Fw-2984 } & \text { 5'-GCT CTA CCC TGC ACT CGG CCT CAA C-3' } \\ \text { PGR-Fw-3381 } & \text { 5'-AAT AAA GTC AGA GTT GTG AGA GCA CTG GAT G-3' } \\ \text { PGR-Rev-3911 } & \text { 5'-GAG GAA CTC TTC TTG GCT AAC TTG AAG C-3' } \\ \text { PGR-Rev-3440 } & \text { 5'-GCT TAG GGC TTG GCT TTC ATT TGG AAC-3' }\end{array}$

\section{Glukokortikoidrezeptor (GR)-spezifische Primer:}

$\begin{array}{ll}\text { GR-Sst-Rev } & \text { 5'-CCG CGG CTT TTG ATG AAA CAG AAG TTT TTT GAT ATT TCC-3' } \\ \text { GR-Xho-Fw } & \text { 5'-CTC GAG GAT GGA CTC CAA AGA ATC ATT AAC TCC-3' } \\ \text { hGR-546 } & \text { 5'-AGA GTT CAG CAT CCA CTG CTG TGT C-3' } \\ \text { hGR-902 } & \text { 5'-GAT AAT GGA GAT CTG GTT TTG TCA AGC-3' } \\ \text { hGR-1321 } & \text { 5'-GAG ACC AGA TGT AAG CTC TCC TCC ATC-3' }\end{array}$

\section{Gycerinaldehyd-3-Phosphat-Dehydrogenase (GAPDH)-spezifische Primer:}

GAPDH-Fw 5'-CCA GCA AGA GCA CAA GAG GAA GAG-3'

GAPDH-Rev 5'-AGC ACA GGG ATA CTT TAT TAG ATG-3'

Probasin-spezifische Primer:

rPb-Pr-fw

5'-GAT ATC CAG AAA AGC TTC CAC AAG TGC ATT TAG CCT CTC CAG-3'

rPb-Pr-rev

5'-GAA TTC CTC TGT AGG TAT CTG GAC CTC ACT GAC AAG G-3’

Genotypisierungsprimer:
LPXN-LD1-rev
5'-GAA GGT GGT GGT GAT TCC TTT GGC TC-3'
rPb-423-fw
5'-CTC TGC ACC TTG TCA GTG AGG TCC AG-3’

Catenin, delta 1- spezifische Primer:
CTNND1-Fw
5'-TGG ACG TGA CCA GGA TAA CAA GAT-3'
CTNND1-Rev
5'-GGC GTG GCT TAC AGT CTT CAT TAG-3'
CTNND1-1A-Fw
5'-CCA AGA AGG GCA AAG GGA AAA AAC C-3'
CTNND1-1A-Rev
5'-GCT AAA TCT TCT GCA TCA AGG GTG TTG-3' 
Urokinase-type plasminogen activator receptor (uPAR)-spezifische Primer:

$\begin{array}{ll}\text { uPAR-Fw } & 5^{\prime} \text {-TGA AGA ACA GTG CCT GGA TG-3' } \\ \text { uPAR-Rev } & 5^{\prime} \text {-TGT TGC AGC ATT TCA GGA AG-3' }\end{array}$

Plasminogen activator inhibitor (PAI)-2-spezifische Primer:

PAI-2-Fw 5'-ACA GGG AGA ACT GGA CAT GG-3'

PAI-2-Rev 5'-TCT GAG GCA CAC AGC TCA TC-3'

Maspin-spezifische Primer:

Maspin-Fw 5'-GTC ACA GTG GAC TAA TCC CAG C-3'

Maspin-Rev 5'-GCA CCT CTA TGG AAT CCC CA-3’

Fibronektin-spezifische Primer:

Fibronektin-Fw 5'-CCT GTT GGC ACT GAT GAA GAA C-3'

Fibronektin-Rev $\quad$ 5'-ACG AGT CAT CCG TAG GTT GGT T-3'

\title{
2.8.4.2 Synthetische RNA-Oligonukleotide
}

Die synthetischen siRNA-Oligonukleotide wurden von der Firma Eurogentec (Seraing, Belgien) bzw. Invitrogen (Karlsruhe) bezogen. Sie wurden als Duplex (D)-Oligonukleotide geliefert.

\author{
Humanes Leupaxin „D-LPXN“ \\ Zielsequenz: \\ 5'-UAUUCCAACCCAGCUCCUC-3' \\ Erster Strang: \\ 5'-UAUUCCAACCCAGCUCCUCdTdT-3’ \\ Zweiter Strang: \\ 5’-GAGGAGCUGGGUUGGAAUAdTdT-3'
}


Humanes Leupaxin „D-LPXNst“

Zielsequenz

GGCGCAGCUCGUGUAUACUACCAAU

Erster Strang:

GGCGCAGCUCGUGUAUACUACCAAU

Zweiter Strang:

AUUGGUAGUAUACACGAGCUGCGCC

Luciferase (Photinus pyralis) „D-Luc“

Zielsequenz:

5'-CGUACGCGGAAUACUUCGA -3’

Erster Strang:

5'-CGUACGCGGAAUACUUCGAdTdT -3'

Zweiter Strang:

5'-UCGAAGUAUUCCGCGUACGdTdT -3'

\subsubsection{Synthetische DNA-Oligonukleotide für quantitative real time PCR-Experimente}

Die synthetischen Oligonukleotid-Primer für die quantitativen real time PCR-Analysen wurden von der Firma Qiagen (Hilden) bezogen.

Humanes $\beta$-Aktin:

$\beta$-Aktin Fw:

5'-TCACCCACACTGTGCCCATCTACGA-3'

$\beta$-Aktin Rev:

5'-GGTAACCGTTACTCGCCAAGGCGAC-3'

$\beta$-Aktin Sonde:

5'-TEXAS RED-ATGCCCTCCCCCATGCCATCCTGCGT-BHQ-3'

Humanes Leupaxin:

Leupaxin Fw:

5'-ACGCTCCACCCTTCAGGACA-3'

Leupaxin Rev:

5'-GACATTGAGCTCCTGGATATTGG-3’

Leupaxin Sonde:

5' - FAM-ACACAAGTCCCTTGCCGGCG-TAMRA-3' 


\subsubsection{Antikörper}

\begin{tabular}{|c|c|}
\hline Primärantikörper & Hersteller \\
\hline $\begin{array}{l}\text { anti-AKT1/2/3 (S473), polyklonaler Antikörper, } \\
\text { Kaninchen (\#7985-R) }\end{array}$ & Santa Cruz Biotechnology, Heidelberg \\
\hline $\begin{array}{l}\text { anti-Phospho-Akt(Thr308), polyklonaler } \\
\text { Antikörper, Kaninchen (\#9275) }\end{array}$ & New England Biolabs GmbH, Frankfurt a.M. \\
\hline anti-AKT, monoklonaler Antikörper, Maus & Santa Cruz Biotechnology, Heidelberg \\
\hline $\begin{array}{l}\text { anti-AR (Ab-2), polyklonaler Antikörper, } \\
\text { Kaninchen }\end{array}$ & Neomarkers, Westinghouse, USA \\
\hline $\begin{array}{l}\text { anti-cmyc Tag (clone 4A6), monoklonaler } \\
\text { Antikörper IgG1, Maus }\end{array}$ & Upstate-Chemicon, Hampshire, UK \\
\hline $\begin{array}{l}\text { anti-ERK1/2, polyklonaler, Antikörper, } \\
\text { Kaninchen (\#9102) }\end{array}$ & New England Biolabs GmbH, Frankfurt a.M. \\
\hline $\begin{array}{l}\text { anti-Phospho-ERK1/2(Thr202/Tyr204), } \\
\text { polyklonaler Antikörper, Kaninchen (\#9101) }\end{array}$ & New England Biolabs GmbH, Frankfurt a.M. \\
\hline $\begin{array}{l}\text { anti-GFP, N-terminal (G1544), polyklonaler } \\
\text { Antikörper, Kaninchen }\end{array}$ & Sigma-Aldrich, Deisenhofen \\
\hline $\begin{array}{l}\text { anti-LPXN (C und G), monoklonaler Antikörper, } \\
\text { Maus }\end{array}$ & ICOS Corp., Bothell, USA \\
\hline $\begin{array}{l}\text { anti-MEK1/2, polyklonaler Antikörper, } \\
\text { Kaninchen (\#9122) }\end{array}$ & New England Biolabs GmbH, Frankfurt a.M. \\
\hline $\begin{array}{l}\text { anti-Phospho-MEK1/2(Ser217/221), polyklonaler } \\
\text { Antikörper, Kaninchen (\#9121) }\end{array}$ & New England Biolabs GmbH, Frankfurt a.M. \\
\hline $\begin{array}{l}\text { anti-myc epitop tag, polyklonaler Antikörper, } \\
\text { Kaninchen }\end{array}$ & Dunn Labortechnik, Asbach \\
\hline $\begin{array}{l}\text { anti-c-Raf, polyklonaler Antikörper, Kaninchen, } \\
\text { (\#9422) }\end{array}$ & New England Biolabs GmbH, Frankfurt a.M. \\
\hline anti-Phospho-Raf(Ser259), polyklonaler & New England Biolabs GmbH, Frankfurt a.M. \\
\hline Antikörper, Kaninchen (\#9421) & \\
\hline $\begin{array}{l}\text { anti- } \alpha \text {-Tubulin (clone B-5-1-2), monoklonaler } \\
\text { Antikörper, Maus }\end{array}$ & Sigma-Aldrich, Deisenhofen \\
\hline anti-p120 ${ }^{\mathrm{CTN}}$ (NT), Klon 6H11, monoklonaler & Invitrogen, Karlsruhe \\
\hline
\end{tabular}

Antikörper, Maus 


$\begin{array}{ll}\text { Sekundärantikörper } & \text { Hersteller } \\ \begin{array}{l}\text { anti-Kaninchen IgG, Alkalische Phosphatase } \\ \text { konjugiert (A-3687), Ziege }\end{array} & \text { Sigma-Aldrich, Deisenhofen } \\ \begin{array}{l}\text { anti-Kaninchen IgG (H+L), HRP (horse radish } \\ \text { peroxidase) konjugiert, Ziege }\end{array} & \text { Dianova, Hamburg, Jackson ImmunoResearch } \\ \begin{array}{l}\text { anti-Kaninchen IgG, Cy3 konjugiert (C2306) } \\ \text { anti-Kaninchen IgG, FITC konjugiert }\end{array} & \text { Sigma-Aldrich, Deisenhofen } \\ \text { anti-Maus IgG, Alkalische Phosphatase } & \text { Sigma-Aldrich, Deisenhofen } \\ \text { konjugiert (A-3688) } & \text { Sigma-Aldrich, Deisenhofen } \\ \text { anti-Maus IgG (H+L), HRP konjugiert, kaninchen } & \text { Dianova, Hamburg, Jackson ImmunoResearch } \\ \text { anti-Maus IgG, Cy3 konjugiert (C2181) } & \text { Sigma-Aldrich, Deisenhofen } \\ \text { anti-Maus IgG, FITC konjugiert } & \text { Sigma-Aldrich, Deisenhofen }\end{array}$

\subsubsection{Plasmide und Vektoren}

\begin{tabular}{ll}
\hline Plasmid/Vektor & Herkunft \\
\hline pAR-IRES-EGFP & \\
& I. Litvinov, John Hopkins University School of Medicine, \\
pBluescript SK (+/-) & Baltimore, USA \\
pBluescript KS(+/-) & Stratagene, La Jolla, USA \\
pCMV- $\beta$-Gal & Stratagene, La Jolla, USA \\
pEGFP-C1 & G. C. Shevelev, Moskau \\
pGADT7 & Clontech, Palo Alto, CA, USA \\
pGBKT7 & Clontech, Palo Alto, CA, USA \\
pGEM-Teasy & Clontech, Palo Alto, CA, USA \\
MMTV-Luc & Promega, Wisconsin, USA \\
pRShGR & Dr. R. Schüle, Molekulare Gynäkologie, Universität \\
& Freiburg \\
& R.M. Evans, Ph.D., Salk Institute for Biological Studies, \\
& San Diego, USA \\
& I. Litvinov, John Hopkins University School of Medicine, \\
Baltimore, USA
\end{tabular}




\begin{tabular}{ll}
\hline Plasmid/Vektor & Herkunft \\
\hline \multirow{2}{*}{ pSG5-PGR1 } & Pierre Chambon Ph.D., Institut de Genetique et de \\
& Biologie Moleculaire et Cellulaire, Université Louis \\
& Pasteur, Strasbourg \\
& Pierre Chambon Ph.D., Institut de Genetique et de \\
pSG5-PGR2 & Biologie Moleculaire et Cellulaire, Université Louis \\
& Pasteur, Strasbourg \\
& Clontech, Palo Alto, CA, USA \\
pTet-On & Clontech, Palo Alto, CA, USA \\
TK-Hyg & Clontech, Palo Alto, CA, USA \\
pTRE & Novagen, Bad Soden \\
pTriEX-1.1 Neo &
\end{tabular}

\subsubsection{Verwendete Konstrukte und Plasmide}

Für die Amplifikation der zu klonierenden Fragmente wurde die PfuUltra-DNA-Polymerase verwendet, da sie eine proofreading-Aktivität besitzt. Alle neu amplifizierten Fragmente wurden zuerst in pGEM-Teasy kloniert (2.10.5) und dort entsprechend komplett durchsequenziert. Erst dann erfolgte die Klonierung in den Zielvektor unter Verwendung der in der nachfolgenden Tabelle angegebenen Restriktionsenzyme. 


\begin{tabular}{|c|c|c|c|c|}
\hline \multirow[b]{2}{*}{ Konstrukt } & \multirow[b]{2}{*}{ Vektor } & \multirow{2}{*}{$\begin{array}{c}\text { Insert } \\
\text { Nukleotid- } \\
\text { position/ } \\
\text { Datenbank-Nr. }\end{array}$} & \multicolumn{2}{|c|}{ Beschreibung } \\
\hline & & & $\begin{array}{c}\text { Amplifikation: Primer/ } \\
\text { Template }\end{array}$ & $\begin{array}{c}\text { Klonierung/ } \\
\text { Verwendete } \\
\text { Restriktionsenzyme }\end{array}$ \\
\hline \multirow[b]{2}{*}{$\begin{array}{l}\text { GFP-LPXN- } \\
\text { LIM }\end{array}$} & \multirow[b]{2}{*}{ pEGFP-C1 } & \multirow{2}{*}{$\begin{array}{c}\text { 510-1251/ } \\
\text { NM_004811 }\end{array}$} & \multicolumn{2}{|c|}{ enthält die vier LIM-Domänen von Leupaxin } \\
\hline & & & $\begin{array}{l}\text { LPXN-LIM-Fw2 und } \\
\text { LPXN-LIM-RevE/ } \\
\text { cDNA Daudi }\end{array}$ & $\begin{array}{c}\text { EcoRI / XhoI aus } \\
\text { pGEM-Teasy-LPXN- } \\
\text { LIM }\end{array}$ \\
\hline \multirow[b]{2}{*}{$\begin{array}{l}\text { GFP-LPXN- } \\
\text { LD }\end{array}$} & \multirow[b]{2}{*}{ pEGFP-C1 } & \multirow[b]{2}{*}{$\begin{array}{c}\text { 94-536/ } \\
\text { NM_004811 }\end{array}$} & \multicolumn{2}{|c|}{ enthält die vier LD-Motive von Leupaxin } \\
\hline & & & $\begin{array}{l}\text { LPXN-LD-Fw und } \\
\text { LPXN-LD-Rev/ } \\
\text { cDNA Daudi }\end{array}$ & $\begin{array}{c}\text { EcoRI / XhoI aus } \\
\text { pGEM-Teasy-LPXN- } \\
\text { LD }\end{array}$ \\
\hline \multirow[b]{2}{*}{ GFP-LPXN } & \multirow[b]{2}{*}{ pEGFP-C1 } & \multirow[b]{2}{*}{$\begin{array}{c}\text { 94-1251/ } \\
\text { NM_004811 }\end{array}$} & \multicolumn{2}{|c|}{ enthält offenen Leserahmen von Leupaxin } \\
\hline & & & $\begin{array}{l}\text { LPXN-LD-Fw und } \\
\text { LPXN-LIM-RevE/ } \\
\text { cDNA Daudi }\end{array}$ & $\begin{array}{c}\text { EcoRI / XhoI aus } \\
\text { pGEM-Teasy-LPXN } \\
\text { (GFP) }\end{array}$ \\
\hline \multirow{2}{*}{$\begin{array}{l}\text { GFP-LPXN- } \\
\text { NES-LIM }\end{array}$} & \multirow[b]{2}{*}{ pEGFP-C1 } & \multirow{2}{*}{$\begin{array}{c}\text { 272-1251/ } \\
\text { NM_004811 }\end{array}$} & \multicolumn{2}{|c|}{$\begin{array}{l}\text { enthält cDNA von Leupaxin ab putativem NES } \\
\text { zwischen dem LD2- und LD3-Motiv }\end{array}$} \\
\hline & & & $\begin{array}{c}\text { NES-Fw und } \\
\text { LPXN-LIM-RevE/ } \\
\text { pEGFP-C1-LPXN }\end{array}$ & $\begin{array}{l}\text { XhoI aus pGEM-Teasy- } \\
\text { LPXN-NES }\end{array}$ \\
\hline \multirow[b]{2}{*}{$\begin{array}{l}\text { GFP-LPXN- } \\
\text { LD3-LIM }\end{array}$} & \multirow[b]{2}{*}{ pEGFP-C1 } & \multirow[b]{2}{*}{$\begin{array}{c}\text { 368-1251/ } \\
\text { NM_004811 }\end{array}$} & \multicolumn{2}{|c|}{ enthält cDNA von Leupaxin ab dem LD3-Motiv } \\
\hline & & & $\begin{array}{l}\text { LPXN-LD3-Fw und } \\
\text { LPXN-LIM-RevE/ } \\
\text { pEGFP-C1-LPXN }\end{array}$ & $\begin{array}{l}\text { XhoI aus pGEM-Teasy- } \\
\text { LPXN-LD3 }\end{array}$ \\
\hline \multirow[b]{2}{*}{$\begin{array}{l}\text { GFP-LPXN- } \\
\text { LD3mutL2- } \\
\text { LIM }\end{array}$} & \multirow[b]{2}{*}{ pEGFP-C1 } & \multirow[b]{2}{*}{$\begin{array}{c}\text { 368-1251; } \\
\text { c379g, t380c/ } \\
\text { NM_004811 }\end{array}$} & \multicolumn{2}{|c|}{$\begin{array}{l}\text { enthält cDNA von Leupaxin ab dem LD3-Motiv mit } \\
\text { Mutation L101A }\end{array}$} \\
\hline & & & $\begin{array}{l}\text { LPXN-mLD3-L2-Fw und } \\
\text { LPXN-LIM-RevE / } \\
\text { pEGFP-C1-LPXN-LD3- } \\
\text { LIM }\end{array}$ & $\begin{array}{c}\text { EcoRI aus pGEM- } \\
\text { Teasy-LPXN- } \\
\text { LD3mutL2 }\end{array}$ \\
\hline \multirow[b]{2}{*}{$\begin{array}{l}\text { GFP-LPXN- } \\
\text { LD3mutL1+ } \\
\text { 2-LIM }\end{array}$} & \multirow[b]{2}{*}{ pEGFP-C1 } & \multirow[b]{2}{*}{$\begin{array}{l}\text { 368-1251; t370g, } \\
\text { t371c, c379g, } \\
\text { t380c/ } \\
\text { NM_004811 }\end{array}$} & \multicolumn{2}{|c|}{$\begin{array}{l}\text { enthält cDNA von Leupaxin ab dem LD3-Motiv mit } \\
\text { Mutationen L98A, L101A }\end{array}$} \\
\hline & & & $\begin{array}{l}\text { LPXN-mLD3-L1-Fw und } \\
\text { LPXN-LIM-RevE / } \\
\text { pEGFP-C1-LPXN- } \\
\text { mLD3mutL2-LIM }\end{array}$ & $\begin{array}{c}\text { EcoRI aus pGEM- } \\
\text { Teasy-LPXN- } \\
\text { LD3mutL1+2 }\end{array}$ \\
\hline
\end{tabular}




\begin{tabular}{|c|c|c|c|c|}
\hline \multirow[b]{2}{*}{ Konstrukt } & \multirow[b]{2}{*}{ Vektor } & \multirow{2}{*}{$\begin{array}{c}\text { Insert } \\
\text { Nukleotid- } \\
\text { position/ } \\
\text { Datenbank-Nr. }\end{array}$} & \multicolumn{2}{|c|}{ Beschreibung } \\
\hline & & & $\begin{array}{c}\text { Amplifikation: Primer/ } \\
\text { Template }\end{array}$ & $\begin{array}{c}\text { Klonierung/ } \\
\text { Verwendete } \\
\text { Restriktionsenzyme }\end{array}$ \\
\hline \multirow{2}{*}{$\begin{array}{l}\text { GFP-LPXN- } \\
\text { LD3mutL2+ } \\
\text { 3-LIM }\end{array}$} & \multirow[b]{2}{*}{ pEGFP-C1 } & \multirow{2}{*}{$\begin{array}{l}\text { 368-1251; } \\
\text { c379g, t380c, } \\
\text { c391g, t392c, } \\
\text { g393c/ } \\
\text { NM_004811 }\end{array}$} & \multicolumn{2}{|c|}{$\begin{array}{l}\text { enthält cDNA von Leupaxin ab dem LD3-Motiv mit } \\
\text { Mutationen L101A, L105A }\end{array}$} \\
\hline & & & $\begin{array}{l}\text { LPXN-mLD3-L3-Fw und } \\
\text { LPXN-LIM-RevE / } \\
\text { pEGFP-C1-LPXN- } \\
\text { LD3mutL2-LIM }\end{array}$ & $\begin{array}{c}\text { EcoRI aus pGEM- } \\
\text { Teasy-LPXN- } \\
\text { LD3mutL2+2 }\end{array}$ \\
\hline \multirow[b]{2}{*}{$\begin{array}{l}\text { GFP-LPXN- } \\
\text { LD3mutL1- } \\
\text { 3-LIM }\end{array}$} & \multirow[b]{2}{*}{ pEGFP-C1 } & \multirow{2}{*}{$\begin{array}{l}\text { 368-1251; t370g, } \\
\text { t371c, c379g, } \\
\text { t380c, c391g, } \\
\text { t392c, g393c/ } \\
\text { NM_004811 }\end{array}$} & \multicolumn{2}{|c|}{$\begin{array}{l}\text { enthält cDNA von Leupaxin ab dem LD3-Motiv mit } \\
\text { Mutationen L98A, L101A, L105A }\end{array}$} \\
\hline & & & $\begin{array}{l}\text { LPXN-mLD3-L3-Fw und } \\
\text { LPXN-LIM-RevE / } \\
\text { pEGFP-C1-LPXN- } \\
\text { LD3mutL1+2-LIM }\end{array}$ & $\begin{array}{c}\text { EcoRI aus pGEM- } \\
\text { Teasy-LPXN- } \\
\text { LD3mutL1-3 }\end{array}$ \\
\hline \multirow[b]{2}{*}{$\begin{array}{c}\text { GFP-LPXN- } \\
\text { LD4-LIM }\end{array}$} & \multirow[b]{2}{*}{ pEGFP-C1 } & \multirow[b]{2}{*}{$\begin{array}{c}\text { 438-1251/ } \\
\text { NM_004811 }\end{array}$} & \multicolumn{2}{|c|}{ enthält cDNA von Leupaxin ab dem LD4-Motiv } \\
\hline & & & $\begin{array}{l}\text { LPXN-LD4-Fw und } \\
\text { LPXN-LIM-RevE / } \\
\text { pEGFP-C1-LPXN }\end{array}$ & $\begin{array}{l}\text { EcoRI aus pGEM- } \\
\text { Teasy-LPXN-LD4 }\end{array}$ \\
\hline \multirow{2}{*}{$\begin{array}{l}\text { GFP-LPXN- } \\
\text { LD4mutL2- } \\
\text { LIM }\end{array}$} & \multirow[b]{2}{*}{ pEGFP-C1 } & \multirow{2}{*}{$\begin{array}{c}\text { 469-1251; } \\
\text { c487g, t488c/ } \\
\text { NM_004811 }\end{array}$} & \multicolumn{2}{|c|}{$\begin{array}{l}\text { enthält cDNA von Leupaxin ab dem LD4-Motiv mit } \\
\text { Mutation L139A }\end{array}$} \\
\hline & & & $\begin{array}{l}\text { LPXN-mLD4-L2-Fw und } \\
\text { LPXN-LIM-RevE / } \\
\text { pEGFP-LPXN-LD4-LIM }\end{array}$ & $\begin{array}{c}\text { EcoRI aus pGEM- } \\
\text { Teasy-LPXN- } \\
\text { LD4mutL2 }\end{array}$ \\
\hline \multirow[b]{2}{*}{$\begin{array}{l}\text { GFP-LPXN- } \\
\text { LD4mutL1-3 }\end{array}$} & \multirow[b]{2}{*}{ pEGFP-C1 } & \multirow{2}{*}{$\begin{array}{l}\text { 469-1251; } \\
\text { c475g, t476c, } \\
\text { c496g, t497c/ } \\
\text { NM_004811 }\end{array}$} & \multicolumn{2}{|c|}{$\begin{array}{l}\text { enthält cDNA von Leupaxin ab dem LD4-Motiv mit } \\
\text { Mutationen L135A, L139A, L142A }\end{array}$} \\
\hline & & & $\begin{array}{l}\text { LPXN-mLD4-L1+3 und } \\
\text { LPXN-LIM-RevE / } \\
\text { pEGFP-C1-LPXN-LD4- } \\
\text { LIM }\end{array}$ & $\begin{array}{c}\text { EcoRI aus pGEM- } \\
\text { Teasy-LPXN- } \\
\text { LD4mutL1-3 }\end{array}$ \\
\hline \multirow[b]{2}{*}{$\begin{array}{l}\text { pGADT7- } \\
\text { LPXN }\end{array}$} & \multirow[b]{2}{*}{ pGADT7 } & \multirow[b]{2}{*}{$\begin{array}{c}\text { 94-1251/ } \\
\text { NM_004811 }\end{array}$} & \multicolumn{2}{|c|}{ enthält offenen Leserahmen von Leupaxin } \\
\hline & & & $\begin{array}{l}\text { LPXN-FPAD(LD) und } \\
\text { LPXN-LIM-Rev/ } \\
\text { cDNA Daudi }\end{array}$ & $\begin{array}{c}\text { EcoRI / XhoI aus } \\
\text { pGEM-Teasy- } \\
\text { LPXN(AD) }\end{array}$ \\
\hline \multirow[b]{2}{*}{$\begin{array}{l}\text { pGADT7- } \\
\text { LPXN-LD }\end{array}$} & \multirow[b]{2}{*}{ pGADT7 } & \multirow[b]{2}{*}{$\begin{array}{c}\text { 94-536/ } \\
\text { NM_004811 }\end{array}$} & \multicolumn{2}{|c|}{ enthält nur die vier LD-Motive von Leupaxin } \\
\hline & & & $\begin{array}{l}\text { LPXN-FPAD(LIM) und } \\
\text { LPXN-LIM-Rev/ } \\
\text { cDNA Daudi }\end{array}$ & $\begin{array}{c}\text { EcoRI / XhoI aus } \\
\text { pGEM-Teasy-LPXN- } \\
\text { LD(AD) }\end{array}$ \\
\hline
\end{tabular}




\begin{tabular}{|c|c|c|c|c|}
\hline \multirow[b]{2}{*}{ Konstrukt } & \multirow[b]{2}{*}{ Vektor } & \multirow{2}{*}{$\begin{array}{c}\text { Insert } \\
\text { Nukleotid- } \\
\text { position/ } \\
\text { Datenbank-Nr. }\end{array}$} & \multicolumn{2}{|c|}{ Beschreibung } \\
\hline & & & $\begin{array}{l}\text { Amplifikation: Primer/ } \\
\text { Template }\end{array}$ & $\begin{array}{c}\text { Klonierung/ } \\
\text { Verwendete } \\
\text { Restriktionsenzyme }\end{array}$ \\
\hline \multirow[b]{2}{*}{$\begin{array}{l}\text { pGADT7- } \\
\text { LPXN-LIM }\end{array}$} & \multirow[b]{2}{*}{ pGADT7 } & \multirow[b]{2}{*}{$\begin{array}{c}\text { 510-1251/ } \\
\text { NM_004811 }\end{array}$} & \multicolumn{2}{|c|}{ enthält nur die vier LIM-Domänen von Leupaxin } \\
\hline & & & $\begin{array}{l}\text { LPXN-FPAD(LIM) und } \\
\text { LPXN-LIM-Rev/ } \\
\text { cDNA Daudi }\end{array}$ & $\begin{array}{c}\text { EcoRI / XhoI aus } \\
\text { pGEM-Teasy-LPXN- } \\
\text { LIM(AD) }\end{array}$ \\
\hline \multirow{2}{*}{$\begin{array}{l}\text { pGADT7- } \\
\text { LPXN- } \\
\text { AXXAA }\end{array}$} & \multirow[b]{2}{*}{ pGADT7 } & \multirow{2}{*}{$\begin{array}{c}\text { 94-1251, t1231g, } \\
\text { t1232c, gct1240- } \\
\text { 2ctc, t1243g, } \\
\text { t1244c/ } \\
\text { NM_004811 }\end{array}$} & \multicolumn{2}{|c|}{$\begin{array}{c}\text { enthält offenen Leserahmen von Leupaxin mit } \\
\text { mutiertem FXXLF-Motiv (F380A, L383A, F384A) }\end{array}$} \\
\hline & & & $\begin{array}{l}\text { LPXN-LD-Fw und LPXN- } \\
\text { AXXAA/ } \\
\text { pGADT7-LPXN }\end{array}$ & $\begin{array}{c}\text { EcoRI aus pGEM- } \\
\text { Teasy-LPXN-AXXAA }\end{array}$ \\
\hline \multirow{2}{*}{$\begin{array}{l}\text { pGADT7- } \\
\text { LPXN-LIM- } \\
\text { AXXAA }\end{array}$} & \multirow[b]{2}{*}{ pGADT7 } & \multirow{2}{*}{$\begin{array}{c}\text { 510-1251, } \\
\text { t1231g, t1232c, } \\
\text { gct1240-2ctc, } \\
\text { t1243g, t1244c/ } \\
\text { NM_004811 }\end{array}$} & \multicolumn{2}{|c|}{$\begin{array}{l}\text { enthält nur die vier LIM-Domänen von Leupaxin mit } \\
\text { mutiertem FXXLF-Motiv (F380A, L383A, F384A) }\end{array}$} \\
\hline & & & $\begin{array}{l}\text { LPXN-LIM-Fw und LPXN- } \\
\text { AXXAA/ } \\
\text { pGADT7-LPXN-LIM }\end{array}$ & $\begin{array}{l}\text { EcoRI aus pGEM- } \\
\text { Teasy-LPXN-LIM- } \\
\text { AXXAA }\end{array}$ \\
\hline \multirow[b]{2}{*}{$\begin{array}{l}\text { pTriEx- } \\
\text { LPXN }\end{array}$} & \multirow[b]{2}{*}{$\begin{array}{l}\text { pTriEx1.1 } \\
\text { Neo }\end{array}$} & \multirow[b]{2}{*}{$\begin{array}{c}\text { 94-1251/ } \\
\text { NM_004811 }\end{array}$} & \multicolumn{2}{|c|}{ enthält offenen Leserahmen von Leupaxin } \\
\hline & & & - & $\begin{array}{c}\text { EcoRI / XhoI aus } \\
\text { pGEM-Teasy-LPXN } \\
\text { (GFP) }\end{array}$ \\
\hline \multirow[b]{2}{*}{$\begin{array}{l}\text { FPCA-V2- } \\
\text { LPXN }\end{array}$} & \multirow[b]{2}{*}{ FPCA-V2 } & \multirow[b]{2}{*}{$\begin{array}{c}\text { 94-1251/ } \\
\text { NM_004811 }\end{array}$} & \multicolumn{2}{|c|}{ enthält offenen Leserahmen von Leupaxin } \\
\hline & & & $\begin{array}{l}\text { LPXN-V2-Fw und } \\
\text { LPXN-V2-Rev/ } \\
\text { cDNA Daudi }\end{array}$ & $\begin{array}{l}\text { HindIII / BglII aus } \\
\text { pGEM-Teasy- } \\
\text { LPXN(V2) }\end{array}$ \\
\hline \multirow{2}{*}{$\begin{array}{c}\text { pTRE- } \\
\text { LPXNcmyc }\end{array}$} & \multirow{2}{*}{ pTRE } & \multirow{2}{*}{$\begin{array}{c}\text { 94-1251/ } \\
\text { NM_004811 }\end{array}$} & \multicolumn{2}{|c|}{$\begin{array}{l}\text { enthält offenen Leserahmen von Leupaxin mit } \\
\text { sechsfachem cmyc-Tag }\end{array}$} \\
\hline & & & - & $\begin{array}{l}\text { EcoRI aus pBS(SK)- } \\
\text { rPb-LPXNcmyc * }\end{array}$ \\
\hline \multirow{2}{*}{$\begin{array}{l}\text { PTRE- } \\
\text { LPXNcmyc- } \\
\text { Hyg }\end{array}$} & \multirow{2}{*}{ pTRE } & \multirow{2}{*}{$\begin{array}{c}\text { 94-1251/ } \\
\text { NM_004811 }\end{array}$} & \multicolumn{2}{|c|}{$\begin{array}{c}\text { enthält offenen Leserahmen von Leupaxin mit } \\
\text { sechsfachem cmyc-Tag, sowie Hygromycin- } \\
\text { Resistenzgen }\end{array}$} \\
\hline & & & - & $\begin{array}{l}\text { Hyg HindIII / ApaI aus } \\
\text { TK-Hyg blunt in pTRE- } \\
\text { LPXNcmyc HindIII }\end{array}$ \\
\hline
\end{tabular}




\begin{tabular}{|c|c|c|c|c|}
\hline \multirow[b]{2}{*}{ Konstrukt } & \multirow[b]{2}{*}{ Vektor } & \multirow{2}{*}{$\begin{array}{c}\text { Insert } \\
\text { Nukleotid- } \\
\text { position/ } \\
\text { Datenbank-Nr. }\end{array}$} & \multicolumn{2}{|c|}{ Beschreibung } \\
\hline & & & $\begin{array}{l}\text { Amplifikation: Primer/ } \\
\text { Template }\end{array}$ & $\begin{array}{c}\text { Klonierung/ } \\
\text { Verwendete } \\
\text { Restriktionsenzyme }\end{array}$ \\
\hline \multirow[b]{2}{*}{$\begin{array}{l}\text { pGBKT7- } \\
\text { ARwt-LBD }\end{array}$} & \multirow[b]{2}{*}{ pGBKT7 } & \multirow[b]{2}{*}{$\begin{array}{c}\text { 2766-3875/ } \\
\text { NM_000044 }\end{array}$} & \multicolumn{2}{|c|}{ enthält die Ligandenbindungsdomäne des Wildtyp-AR } \\
\hline & & & $\begin{array}{l}\text { AR3FPN und } \\
\text { AR3RPN/ } \\
\text { cDNA T-47D }\end{array}$ & $\begin{array}{c}\text { BamHI / PstI aus } \\
\text { pGEM-Teasy-ARwt- } \\
\text { LBD }\end{array}$ \\
\hline \multirow{2}{*}{$\begin{array}{l}\text { pGBKT7- } \\
\text { AR(T877A)- } \\
\text { LBD }\end{array}$} & \multirow[b]{2}{*}{ pGBKT7 } & \multirow{2}{*}{$\begin{array}{c}\text { 2766-3875; } \\
\text { a2991g/ } \\
\text { NM_000044 }\end{array}$} & \multicolumn{2}{|c|}{$\begin{array}{l}\text { enthält Ligandenbindungsdomäne des mutierten AR } \\
\text { aus LNCaP, T877A }\end{array}$} \\
\hline & & & $\begin{array}{l}\text { AR3FPN und } \\
\text { AR3RPN/ } \\
\text { cDNA LNCaP }\end{array}$ & $\begin{array}{c}\text { BamHI / PstI aus } \\
\text { pGEM-Teasy-ARmut- } \\
\text { LBD }\end{array}$ \\
\hline \multirow[b]{2}{*}{$\begin{array}{l}\text { FPVA-V1- } \\
\text { AR }\end{array}$} & \multirow[b]{2}{*}{ FPCA-V1 } & \multirow[b]{2}{*}{$\begin{array}{c}\text { 1116-3875/ } \\
\text { NM_000044 }\end{array}$} & \multicolumn{2}{|c|}{ enthält offenen Leserahmen des humanen AR } \\
\hline & & & $\begin{array}{l}\text { ARfl-V1-Fw und } \\
\text { ARfl-V1-Rev/ } \\
\text { pAR-IRES-EGFP }\end{array}$ & $\begin{array}{c}\text { BglII / SacII aus } \\
\text { pGEM-Teasy-AR-V1 }\end{array}$ \\
\hline \multirow{2}{*}{$\begin{array}{l}\text { FPCA-V1- } \\
\text { hGR }\end{array}$} & \multirow[b]{2}{*}{ FPCA-V1 } & \multirow{2}{*}{$\begin{array}{c}127-2458 / \\
\text { ENST000002315 } \\
09\end{array}$} & \multicolumn{2}{|c|}{ enthält offenen Leserahmen des humanen GR } \\
\hline & & & - & $\begin{array}{l}\text { XhoI / SacII aus } \\
\text { pEGFP-C1-hGR }\end{array}$ \\
\hline \multirow{2}{*}{$\begin{array}{l}\text { pGBKT7- } \\
\text { hGR }\end{array}$} & \multirow[b]{2}{*}{ pGBKT7 } & \multirow{2}{*}{$\begin{array}{c}127-2458 / \\
\text { ENST000002315 } \\
09\end{array}$} & \multicolumn{2}{|c|}{ enthält offenen Leserahmen des humanen GR } \\
\hline & & & $\begin{array}{l}\text { hGR-Fw und hGR-Rev/ } \\
\text { cDNA T-47D }\end{array}$ & $\begin{array}{l}\text { NcoI / SmaI aus pGEM- } \\
\text { Teasy-hGR }\end{array}$ \\
\hline \multirow[b]{2}{*}{ GFP-hGR } & \multirow[b]{2}{*}{ pEGFP-C1 } & \multirow{2}{*}{$\begin{array}{c}127-2458 / \\
\text { ENST000002315 } \\
09\end{array}$} & \multicolumn{2}{|c|}{ enthält offenen Leserahmen des humanen GR } \\
\hline & & & $\begin{array}{l}\text { hGR-Fw und hGR-Rev/ } \\
\text { cDNA T-47D }\end{array}$ & $\begin{array}{l}\text { SacII aus pGEM-Teasy- } \\
\text { hGR }\end{array}$ \\
\hline \multirow[b]{2}{*}{$\begin{array}{c}\text { pGEM- } \\
\text { Teasy-PGR- } \\
\text { N(V1) }\end{array}$} & \multirow[b]{2}{*}{$\begin{array}{l}\text { pGEM- } \\
\text { Teasy }\end{array}$} & \multirow[b]{2}{*}{$\begin{array}{c}\text { 1455-2815/ } \\
\text { NM_000926 }\end{array}$} & \multicolumn{2}{|c|}{ enthält 3’'-Hälfte der humanen PGR-cDNA } \\
\hline & & & $\begin{array}{l}\text { PGR-V1-Fw und PGR-Stu- } \\
\text { Rev } \\
\text { cDNA T-47D }\end{array}$ & - \\
\hline \multirow{2}{*}{$\begin{array}{c}\text { pGEM- } \\
\text { Teasy-PGR- } \\
\text { C(V1) }\end{array}$} & \multirow{2}{*}{$\begin{array}{l}\text { pGEM- } \\
\text { Teasy }\end{array}$} & \multirow{2}{*}{$\begin{array}{c}\text { 2600-4253/ } \\
\text { NM_000926 }\end{array}$} & \multicolumn{2}{|c|}{ enthält 5'- Hälfte der humanen PGR-cDNA } \\
\hline & & & $\begin{array}{l}\text { PGR-Stu-Fw und PGR-V1- } \\
\text { Rev }\end{array}$ & - \\
\hline \multirow[b]{2}{*}{$\begin{array}{c}\text { pGEM- } \\
\text { Teasy-PGR- } \\
\text { N+C(V1) }\end{array}$} & & & enthält offenen Leseral & en des humanen PGR \\
\hline & $\begin{array}{l}\text { pGEM- } \\
\text { Teasy }\end{array}$ & $\begin{array}{c}\text { 1455-4253/ } \\
\text { NM_000926 }\end{array}$ & - & $\begin{array}{c}\text { StuI / PstI aus pGEM- } \\
\text { Teasy-PGR-C(V1) in } \\
\text { pGEM-Teasy-PGR- } \\
\text { N(V1) }\end{array}$ \\
\hline
\end{tabular}




\begin{tabular}{|c|c|c|c|c|}
\hline \multirow[b]{2}{*}{ Konstrukt } & \multirow[b]{2}{*}{ Vektor } & \multirow{2}{*}{$\begin{array}{c}\text { Insert } \\
\text { Nukleotid- } \\
\text { position/ } \\
\text { Datenbank-Nr. }\end{array}$} & \multicolumn{2}{|c|}{ Beschreibung } \\
\hline & & & $\begin{array}{c}\text { Amplifikation: Primer/ } \\
\text { Template }\end{array}$ & $\begin{array}{c}\text { Klonierung/ } \\
\text { Verwendete } \\
\text { Restriktionsenzyme }\end{array}$ \\
\hline \multirow[b]{2}{*}{$\begin{array}{l}\text { FPCA-V1- } \\
\text { PGR }\end{array}$} & \multirow[b]{2}{*}{ FPCA-V1 } & \multirow[b]{2}{*}{$\begin{array}{c}\text { 1455-4253/ } \\
\text { NM_000926 }\end{array}$} & \multicolumn{2}{|c|}{ enthält offenen Leserahmen des humanen PGR } \\
\hline & & & - & $\begin{array}{c}\text { EcoRI / PstI aus } \\
\text { pGEM-Teasy-PGR- } \\
\text { N+C(V1) }\end{array}$ \\
\hline \multirow[b]{2}{*}{$\begin{array}{c}\text { pGEM- } \\
\text { Teasy-PGR- } \\
\text { N(KT7) }\end{array}$} & \multirow[b]{2}{*}{$\begin{array}{l}\text { pGEM- } \\
\text { Teasy }\end{array}$} & \multirow[b]{2}{*}{$\begin{array}{c}\text { 1455-2815/ } \\
\text { NM_000926 }\end{array}$} & \multicolumn{2}{|c|}{ enthält 3’'-Hälfte der humanen PGR-cDNA } \\
\hline & & & $\begin{array}{l}\text { PGR-KT7-Fw-EcoRI und } \\
\text { PGR-Stu-Rev } \\
\text { cDNA T-47D }\end{array}$ & - \\
\hline \multirow{2}{*}{$\begin{array}{c}\text { pGEM- } \\
\text { Teasy-PGR- } \\
\text { C(KT7) }\end{array}$} & \multirow{2}{*}{$\begin{array}{l}\text { pGEM- } \\
\text { Teasy }\end{array}$} & \multirow{2}{*}{$\begin{array}{l}\text { 2600-4253/ } \\
\text { NM_000926 }\end{array}$} & \multicolumn{2}{|c|}{ enthält 5'́ Hälfte der humanen PGR-cDNA } \\
\hline & & & $\begin{array}{c}\text { PGR-Stu-Fw und PGR-Pst- } \\
\text { Rev }\end{array}$ & - \\
\hline \multirow[b]{2}{*}{$\begin{array}{c}\text { pGEM- } \\
\text { Teasy-PGR- } \\
\text { N+C(KT7) }\end{array}$} & \multirow[b]{2}{*}{$\begin{array}{l}\text { pGEM- } \\
\text { Teasy }\end{array}$} & \multirow[b]{2}{*}{$\begin{array}{c}\text { 1455-4253/ } \\
\text { NM_000926 }\end{array}$} & \multicolumn{2}{|c|}{ enthält offenen Leserahmen des humanen PGR } \\
\hline & & & - & $\begin{array}{l}\text { StuI / PstI aus pGEM- } \\
\text { Teasy-PGR-C(KT7) in } \\
\text { pGEM-Teasy-PGR- } \\
\text { N(KT7) }\end{array}$ \\
\hline \multirow[b]{2}{*}{$\begin{array}{l}\text { pGBKT7- } \\
\text { PGR }\end{array}$} & \multirow[b]{2}{*}{ pGBKT7 } & \multirow[b]{2}{*}{$\begin{array}{l}\text { 1455-4253/ } \\
\text { NM_000926 }\end{array}$} & \multicolumn{2}{|c|}{ enthält offenen Leserahmen des humanen PGR } \\
\hline & & & - & $\begin{array}{c}\text { EcoRI / PstI aus } \\
\text { pGEM-Teasy-PGR- } \\
\text { N+C(KT7) }\end{array}$ \\
\hline \multirow[b]{2}{*}{$\begin{array}{c}\text { pGEM- } \\
\text { Teasy-PGR- } \\
\text { N(GFP) }\end{array}$} & \multirow[b]{2}{*}{$\begin{array}{l}\text { pGEM- } \\
\text { Teasy }\end{array}$} & \multirow[b]{2}{*}{$\begin{array}{l}\text { 1455-2815/ } \\
\text { NM_000926 }\end{array}$} & \multicolumn{2}{|c|}{ enthält 3’' -Hälfte der humanen PGR-cDNA } \\
\hline & & & $\begin{array}{c}\text { PGR-GFP-Fw-EcoRI und } \\
\text { PGR-Stu-Rev } \\
\text { cDNA T-47D }\end{array}$ & - \\
\hline \multirow{2}{*}{$\begin{array}{c}\text { pGEM- } \\
\text { Teasy-PGR- } \\
\text { C(GFP) }\end{array}$} & \multirow{2}{*}{$\begin{array}{l}\text { pGEM- } \\
\text { Teasy }\end{array}$} & \multirow{2}{*}{$\begin{array}{l}\text { 2600-4253/ } \\
\text { NM_000926 }\end{array}$} & \multicolumn{2}{|c|}{ enthält 5' - Hälfte der humanen PGR-cDNA } \\
\hline & & & $\begin{array}{c}\text { PGR-Stu-Fw und PGR-Pst- } \\
\text { Rev }\end{array}$ & - \\
\hline \multirow[b]{2}{*}{$\begin{array}{c}\text { pGEM- } \\
\text { Teasy-PGR- } \\
\text { N+C(GFP) }\end{array}$} & \multirow[b]{2}{*}{$\begin{array}{l}\text { pGEM- } \\
\text { Teasy }\end{array}$} & \multirow[b]{2}{*}{$\begin{array}{c}\text { 1455-4253/ } \\
\text { NM_000926 }\end{array}$} & \multicolumn{2}{|c|}{ enthält offenen Leserahmen des humanen PGR } \\
\hline & & & - & $\begin{array}{l}\text { StuI / PstI aus pGEM- } \\
\text { Teasy-PGR-C(V1) in } \\
\text { pGEM-Teasy-PGR- } \\
\text { N(GFP) }\end{array}$ \\
\hline
\end{tabular}




\begin{tabular}{|c|c|c|c|c|}
\hline \multirow[b]{2}{*}{ Konstrukt } & \multirow[b]{2}{*}{ Vektor } & \multirow{2}{*}{$\begin{array}{c}\text { Insert } \\
\text { Nukleotid- } \\
\text { position/ } \\
\text { Datenbank-Nr. }\end{array}$} & \multicolumn{2}{|c|}{ Beschreibung } \\
\hline & & & $\begin{array}{c}\text { Amplifikation: Primer/ } \\
\text { Template }\end{array}$ & $\begin{array}{c}\text { Klonierung/ } \\
\text { Verwendete } \\
\text { Restriktionsenzyme }\end{array}$ \\
\hline \multirow[b]{2}{*}{ GFP-hPGR } & \multirow[b]{2}{*}{ pEGFP-C1 } & \multirow[b]{2}{*}{$\begin{array}{c}\text { 1455-4253/ } \\
\text { NM_000926 }\end{array}$} & \multicolumn{2}{|c|}{ enthält offenen Leserahmen des humanen PGR } \\
\hline & & & - & $\begin{array}{c}\text { EcoRI / PstI aus } \\
\text { pGEM-Teasy-PGR- } \\
\text { N+C(GFP) }\end{array}$ \\
\hline \multirow[b]{2}{*}{ pBS(SK)-rPb } & \multirow[b]{2}{*}{ pBluescript } & \multirow[b]{2}{*}{$\begin{array}{l}-426 \text { bis }+28 / \\
\text { AY370611 }\end{array}$} & \multicolumn{2}{|c|}{ enthält Minimalpromotor des Ratten-Probasins } \\
\hline & & & $\begin{array}{c}\text { rPb-Pr-Fw und } \\
\text { rPb-Pr-Rev/ } \\
\text { genomische Ratten-DNA }\end{array}$ & $\begin{array}{l}\text { EcoRV / EcoRI aus } \\
\text { pGEM-Teasy-rPb }\end{array}$ \\
\hline \multirow{2}{*}{ rPb-Luc } & \multirow{2}{*}{ pGL3-basic } & \multirow{2}{*}{$\begin{array}{l}-426 \text { bis }+28 / \\
\text { AY370611 }\end{array}$} & \multicolumn{2}{|c|}{$\begin{array}{l}\text { enthält Minimalpromotor des Ratten-Probasins vor } \\
\text { dem Luciferase-Gen }\end{array}$} \\
\hline & & & - & $\begin{array}{l}\text { KpnI / SmaI aus } \\
\text { pBS(SK)-rPb }\end{array}$ \\
\hline \multirow[b]{2}{*}{ pTRE-Hyg } & \multirow[b]{2}{*}{ pTRE } & & \multicolumn{2}{|c|}{ enthält Hygromycin-Resistenzgen } \\
\hline & & & - & $\begin{array}{l}\text { Hyg HindIII / ApaI aus } \\
\text { TK-Hyg blunt in pTRE } \\
\text { HindIII }\end{array}$ \\
\hline
\end{tabular}

\subsubsection{Datenbanken}

\section{Verwendung}

Analyse von DNA- und Protein-

Sequenzen

Bioinformatik

\section{Programm}

BLAST-Programm [Altschul et al., 1990] (http://www.ncbi.nlm.nih.gov)

BLAT-Search [Kent et al., 2002] (http://genome.ucsc.edu/cgi-bin/hgBlat)

BCM Search Launcher (http://searchlauncher.bcm.tmc.edu/)

Ensembl v32 (http://www.ensembl.org/)

National Center for Biotechnology Information (http://ncbi.nlm.nih.gov/)

DCODE.org Comparative Genomics Center (http://www.dcode.org)

ClustalW und Boxshade (http://ch.embnet.org)

Analyse von humanen Proteinen Human Protein Reference Database (http://www.hrpd.org) 
Verwendung Programm

Restriktionsschnittstellen $\quad$ NEB Cutter 2.0 (http://tools.neb.com/NEBcutter2/index.php)

WEB Cutter 2.0 (http://rna.lundberg.gu.se/cutter2)

Auswahl von Oligonukleotiden Primer3 (http://frofo.wi.mit.edu/chi-bin/primer3/primer3_www.cgi)

\subsection{Isolierung und Aufreinigung von Nukleinsäuren}

\subsubsection{Minipräparation von Plasmid-DNA}

Zur schnellen Isolierung rekombinanter Plasmide wurde zunächst eine geringe Menge an Plasmid-DNA präpariert. Hierzu wurden $5 \mathrm{ml}$ einer angeimpften Übernachtkultur bei 5000 x g zentrifugiert und das Pellet in $250 \mu \mathrm{l}$ P1-Lösung resuspendiert. Nach Zugabe von $250 \mu \mathrm{l}$ P2 (modifizierte alkalische Lyse) und $250 \mu \mathrm{l}$ P3 (Neutralisierung) wurde die Probe bei 16000 x g zentrifugiert. Der Überstand wurde in ein neues Gefäß überführt, mit 0,7 Vol Isopropanol versetzt, und bei $16000 \mathrm{x}$ g wurde die Plasmid-DNA gefällt. Anschließend wurde das DNA-Pellet mit $500 \mu \mathrm{l}$ 70\% Ethanol gewaschen und nach dem Trocknen in 20-50 $\mu_{\mathrm{l}} \mathrm{H}_{2} \mathrm{O}$ aufgenommen.

\subsubsection{Herstellung von Bakterien-Glycerin-Stocks}

$1 \mathrm{ml}$ einer Bakteriensuspension wurden mit $100 \mu \mathrm{l}$ sterilem Glycerin versetzt, gut gemischt und bei $-80^{\circ} \mathrm{C}$ aufbewahrt.

\subsubsection{Midipräparation von Plasmid-DNA}

Zur Isolierung größerer Mengen hochreiner Plasmid-DNA wurde das Plasmid-Midi Kit der Firma Macherey \& Nagel (Düren) oder Invitrogen (Karlsruhe) verwendet. Die DNA wird dabei über Säulen aus dem Kit affinitätschromatographisch aufgereinigt. Die Aufarbeitung erfolgte nach dem Protokoll des Herstellers. Die mit dieser Methode isolierte Plasmid-DNA 
kann u.a. für die Transfektion von Zellinien, für Restriktionsanalysen, Hybridisierungsexperimente und zur Subklonierung oder Sequenzierung eingesetzt werden.

\subsubsection{Ethanolfällung von DNA aus wässrigen Lösungen}

[Sambrook et al., 1989]

Die Ethanolfällung wurde eingesetzt, um DNA zu konzentrieren und sie von Salzverunreinigungen zu befreien. Zur Fällung von Plasmid-DNA oder PCR-Produkten wurde der Ansatz mit 1/10 Vol 3 M Natriumacetat-Essigsäure, pH 5.2, und 3 Vol 96\% Ethanol versetzt. Die Präzipitation erfolgte durch Inkubation für 10 min bei RT oder für mehrere Stunden bei $-20{ }^{\circ} \mathrm{C}$. Der Ansatz wurde für $30 \mathrm{~min}$ bei $16000 \mathrm{x}$ g zentrifugiert und das Pellet mit 70\%igem Ethanol gewaschen. Anschließend wurde das Pellet getrocknet und in einem entsprechenden Volumen $\mathrm{H}_{2} \mathrm{O}$ aufgenommen.

\subsubsection{Phenol/Chloroform- Aufreinigung von Nukleinsäuren}

Die Phenol/Chloroform-Extraktion dient der Reinigung der DNA von Proteinen und Membranbestandteilen. Die zu extrahierenden DNA-Proben wurden mit gleichen Volumina Phenol versetzt und intensiv gemischt. Die Phasentrennung erfolgte durch Zentrifugation bei 16000 x g für 2-5 min. Die wässrige Phase wurde in ein neues Eppendorf-Gefäß überführt und die Extraktion nun mit 1 Vol Phenol/Chloroform/ Isoamylalkohol (25:24:1) wiederholt. Die sich in der wässrigen Phase befindende DNA wurde anschließend einer Ethanolfällung (2.9.4) unterzogen.

\subsubsection{Isolierung von Plasmid-DNA aus Hefe}

Zur Isolierung der Plasmid-DNA wurden etwa $1 \mathrm{~cm}^{2}$ Hefekolonien von SD/-LTH(A)+ $\alpha-G a l-$ Platten abgeschabt und in $50 \mu \mathrm{l}$ TE, pH 7.5 resuspendiert. Um die Hefezellen zu lysieren, wurden 50 U des yeast lytic enzyme zu der Lösung gegeben. Anschließend wurde über Nacht bei $37^{\circ} \mathrm{C}$ in einem Thermomixer unter Schütteln inkubiert. Nach Zugabe von $10 \mu \mathrm{l} 20 \%$ SDS wurde die Probe stark gevortext und das Lysat bis zum Einfrieren in einen $-20^{\circ} \mathrm{C}$ Tiefkühlschrank gestellt. Anschließend wurden je $150 \mu \mathrm{l}$ TE, pH 8.0, $100 \mu \mathrm{l}$ 1-Brom-3- 
Chlorpropan und $100 \mu$ l Phenol, pH 8.0, hinzugegeben. Nach starkem Vortexen wurde das Eppendorf-Gefäß 30-60 min in einem Thermomixer bei Raumtemperatur geschüttelt und hin und wieder gevortext. Anschließend wurde bei 16000 x g 10 min lang zentrifugiert und die obere Phase in ein sauberes Eppendorf-Gefäß überführt. Dazu wurden $10 \mu \mathrm{l} 10 \mathrm{M}$ Ammoniumacetat, $2 \mu \mathrm{l}$ Glycogen $(20 \mu \mathrm{g} / \mu \mathrm{l})$ und $600 \mu \mathrm{l}$ Ethanol (70\%) gegeben und das Gefäß vorsichtig geschwenkt. Nach 20-30 min Zentrifugieren bei 16000 x g wurde der Überstand vorsichtig abgenommen und verworfen. Das Pellet wurde bei $50^{\circ} \mathrm{C}$ getrocknet und dann in $20 \mu \mathrm{H} \mathrm{H}_{2} 0$ resuspendiert. Für eine PCR wurden $2 \mu \mathrm{l}$ der DNA- Lösung eingesetzt.

\subsubsection{Isolierung von Gesamt-RNA aus Zellkulturen}

Die Isolierung von Gesamt-RNA aus Zellkulturen erfolgte mit Hilfe des RNeasy Mini Kits der Firma Qiagen (Hilden) nach dem Protokoll des Herstellers. Die Ausbeute an RNA betrug zwischen 0,5 und 1,0 $\mu \mathrm{g} / \mu \mathrm{l}$.

\subsubsection{Konzentrationsbestimmung von Nukleinsäuren}

Die Konzentration von Nukleinsäuren wurde mit einem Spektralphotometer (Ultrospec 300pro, GE Healthcare, München) bestimmt. Nach Abgleichen der Nullwerte konnte das Absorptionsmaximum der gemessenen Nukleinsäuren (bei $260 \mathrm{~nm}$ ) bestimmt und gleichzeitig Verunreinigungen durch Proteine (bei $280 \mathrm{~nm}$ ) bzw. Salze (bei $320 \mathrm{~nm}$ ) festgelegt werden. Die Berechnung der Nukleinsäurekonzentration erfolgte über das Lambert'sche Gesetz.

Zur Bestimmung von niedrigen Konzentrationen wurde eine bestimmte Menge der DNA auf ein Agarosegel neben einem DNA-Standard (MassRuler, MBI) aufgetragen, bei dem für jede Bande die entsprechende Menge DNA bekannt ist. Nach dem Lauf wurde das Gel mit Ethidiumbromid gefärbt und die DNA unter UV-Licht sichtbar gemacht und fotografiert. Die zu bestimmenden Banden wurden mit Banden des Standards ähnlicher Größe verglichen und so die Konzentration der Probe bestimmt. 


\subsection{Klonierungstechniken}

\subsubsection{Spaltung von DNA mit Restriktionsendonukleasen}

Zur enzymatischen Spaltung von DNA wurde der Restriktionsansatz in einem Volumen von mindestens $10 \mu \mathrm{l}$ bei der für das Enzym optimalen Temperatur für 1-2 h oder über Nacht inkubiert, wobei pro $\mu$ g DNA 2-3 U des jeweiligen Restriktionsenzyms eingesetzt wurden. Für die simultane Spaltung mit zwei Restriktionsendonukleasen wurde ein Puffer eingesetzt, der beiden Enzymen eine ausreichende Aktivität erlaubte.

\subsubsection{Isolierung von DNA-Fragmenten aus Agarosegelen}

Die Isolierung von DNA-Fragmenten aus Agarosegelen erfolgte mit Hilfe des QIA EX II Gel Extraction-Kits (Qiagen, Hilden). Nach dem Lösen der Agarose wird die DNA selektiv an Partikel aus Silicagel in Anwesenheit von chaotropen Salzen gebunden und anschließend mit Wasser eluiert. Die über ein Agarosegel aufgetrennten DNA-Fragmente wurden mit einem sterilen Skalpell aus dem Gel geschnitten und nach dem Protokoll der Firma Qiagen weiterbehandelt.

\subsubsection{Dephosphorylierung von Plasmid-DNA}

Um eine Religation linearisierter Plasmid-DNA zu verhindern, wurde eine Dephosphorylierung durchgeführt. Endständige 5'-Phosphatgruppen des Vektors werden mit Hilfe des Enzyms Alkalische Phosphatase entfernt. Dazu wurde die DNA mit 2 U Alkalischer Phosphatase für $1 \mathrm{~h}$ bei $37^{\circ} \mathrm{C}$ inkubiert. Anschließend wurde die DNA mit Phenol/Chloroform aufgereinigt, mit 2,5 Vol Ethanol und 1/10 Vol $3 \mathrm{M}$ Natriumacetat (pH 4.8) gefällt und in $\mathrm{H}_{2} \mathrm{O}$ resuspendiert. 


\title{
2.10.4 Ligation von DNA-Fragmenten
}

Die Ligation wurde zur Verknüpfung von linearer Plasmid-DNA mit DNA-Fragmenten genutzt. Das Enzym T4-DNA-Ligase katalysiert dabei die Bildung von Phosphodiesterbindungen zwischen 3'-Hydroxyl- und 5'-Phosphatenden der linearisierten DNA, so dass rekombinante DNA-Moleküle entstehen. Es wurde folgender Ligationsansatz verwendet:

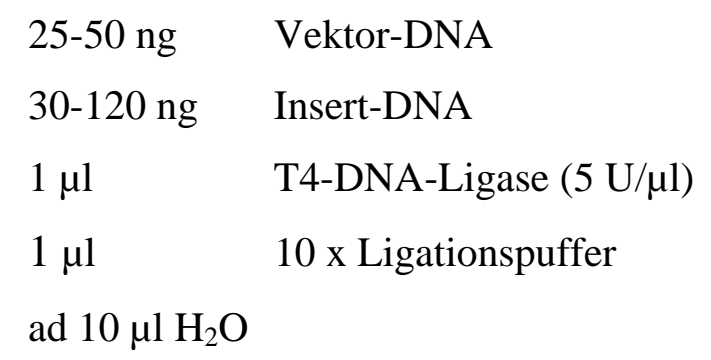

Der Ansatz wurde über Nacht bei $4^{\circ} \mathrm{C}$ inkubiert.

\subsubsection{Subklonierung von PCR- und RT-PCR-Produkten}

Taq- und andere Polymerasen besitzen eine terminale Transferase-Aktivität, die zu einer Addition von einem Nukleotid an das 3'-Ende von PCR-Produkten führt. In Anwesenheit aller 4 Nukleotide wird hauptsächlich dA angehängt. Diese terminale Transferase-Aktivität ist die Grundlage für die TA-Klonierungsstrategie. Für die Subklonierung von PCR- und RTPCR-Produkten wurde das pGEM-Teasy Vektor-System verwendet, welches 5’ T-Überhänge besitzt. Folgende Komponenten wurden gemischt:

\author{
50 ng pGEM-T Easy Vektor \\ PCR-Produkt (3:1, Insert: Vektor-Verhältnis) \\ $1 \mu \mathrm{l}$ T4-DNA-Ligase 10x Puffer \\ $1 \mu \mathrm{l}$ T4-DNA-Ligase \\ in einem Gesamtvolumen von $10 \mu \mathrm{l}$
}

Die Bestandteile wurden gemischt und über Nacht bei $4^{\circ} \mathrm{C}$ inkubiert. Die Produkte einer Ligation wurden anschließend in kompetente E. coli Bakterien transformiert (siehe 2.10.6). 
Die PfuUltra-HF-DNA-Polymerase besitzt keine terminale Transferase-Aktivität. Um nun PfuUltra generierte PCR-Produkte in den Vektor pGEM-Teasy zu klonieren, wurde ein sog. A-tailing durchgeführt, bei dem mit Hilfe einer zweiten Taq-Polymerase nachträglich ein dA an das PCR-Produkt angehängt wird. Dazu wurden folgende Komponenten gemischt:

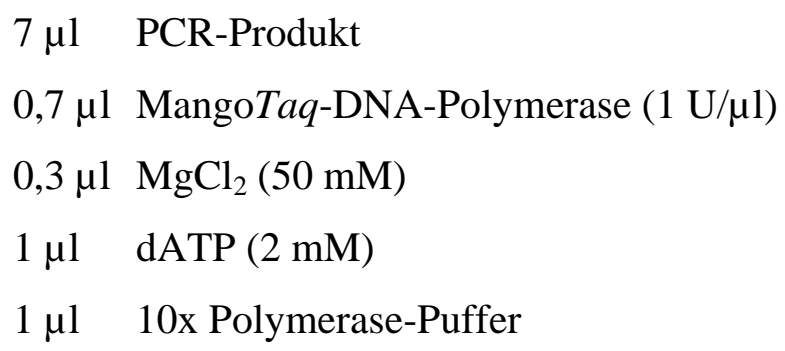

Der Ansatz wurde für 45 min bei $70^{\circ} \mathrm{C}$ inkubiert und anschließend 1-2 $\mu$ l direkt für die Ligation eingesetzt.

\subsubsection{Transformation kompetenter Zellen mit Plasmid-DNA}

[Hanahan, 1983]

Für die Transformation wurden zunächst die kompetenten Zellen auf Eis 5 min aufgetaut, 3-5 $\mu$ les Ligationsansatzes zu $50 \mu$ l kompetente Zellen hinzugefügt und für 20 min auf Eis inkubiert. Dann wurden die Zellen einem Hitzeschock bei $42^{\circ} \mathrm{C}$ für 1 min ausgesetzt und sofort wieder für 2 min auf Eis gestellt. Nach Zufügen von $1 \mathrm{ml}$ SOC-Medium wurde der Transformationsansatz für $1 \mathrm{~h}$ bei $37^{\circ} \mathrm{C}$ unter Schütteln inkubiert. Danach wurden $50-500 \mu \mathrm{l}$ der transformierten Zellen auf geeigneten Agarplatten ausgestrichen und über Nacht bei $37^{\circ} \mathrm{C}$ inkubiert.

\subsection{Gelelektrophorese}

\subsubsection{Gelelektrophorese von DNA}

Zur Auftrennung von DNA-Fragmenten wurden Agarose-Gelelektrophoresen durchgeführt. Je nach Größe der Fragmente wurden Gele mit 0,5-2,0\% (w/v) Agaroseanteil verwendet. Die Agarose wurde in $100 \mathrm{ml}$ 0,5x TBE-Puffer durch Kochen gelöst, mit Ethidiumbromid 
(Endkonzentration $0,5 \mu \mathrm{l} / \mathrm{ml}$ ) versetzt und in den Gelträger überführt. Nach vollständiger Verfestigung des Gels wurde die Elektrophorese in einer mit 0,5x TBE-Puffer gefüllten Gelkammer bei konstanter Spannung von 50-150 V durchgeführt. Bei der Verwendung sog. Turbo-Agarosegele wurde die Agarose in $1 \mathrm{x}$ Turbo-Gel-Puffer gelöst und wie oben beschrieben weiterbehandelt. Die Elektrophorese kann bei einer konstanten Spannung mit bis zu 300 V durchgeführt werden.

\subsubsection{Gelelektrophorese von RNA}

[Maniatis et al., 1980]

Um die Ausbildung von Sekundärstrukturen der RNA während der Gelelektrophorese zu verhindern, wurde der in 1x MOPS gelösten Agarose eine Formaldehyd-Lösung zugesetzt (Endkonzentration 6,6\%). Die RNA-Proben wurden vor der Auftrennung folgendermaßen behandelt:

$\begin{array}{ll}\mathrm{x} \mu \mathrm{l} & \text { RNA (5-6 } \mu \mathrm{g} \text { Gesamt-RNA) } \\ 2 \mu \mathrm{l} & \text { 10x MOPS } \\ 8 \mu \mathrm{l} & \text { deionisiertes Formamid } \\ 3 \mu \mathrm{l} & \text { Formaldehyd (37\%ige Lösung) } \\ 20 \mu \mathrm{l} & \text { Gesamtansatz }\end{array}$

Dieser Ansatz wurde dann bei $65^{\circ} \mathrm{C}$ für 10 min denaturiert und anschließend für 5 min auf Eis gestellt. Die RNA-Proben wurden mit 0,2 Vol Stop-Mix II mit Ethidiumbromid versetzt und bei $60 \mathrm{~V}$ 6-8 h gelelektrophoretisch aufgetrennt.

\subsubsection{Längenstandards}

Um die Größe von DNA- bzw. RNA-Fragmenten auf Agarosegelen zu bestimmen, wurden Längenstandards parallel mitgeführt.
1 kb DNA Ladder
Invitrogen, Karlsruhe
100 bp DNA Ladder
Invitrogen, Karlsruhe
MassRuler
MBI Fermentas, St. Leon-Rot 
$\lambda$-DNA/EcoRI/HindII

0.24-9.5 kb RNA Ladder
MBI Fermentas, St.Leon-Rot

Invitrogen, Karlsruhe

\subsection{Transfertechniken von Nukleinsäuren}

\subsubsection{Southern Blot-Analysen}

Zunächst wurden $30 \mu$ g genomische DNA mit dem entsprechenden Restriktionsenzym über Nacht geschnitten. Die anschließend im 1x TAE-Agarosegel aufgetrennten DNA-Fragmente wurden mit Hilfe des Southern-Blot-Verfahrens auf Nitrocellulosefilter übertragen. Der Transfer der DNA auf die Membran erfolgte über Nacht mit einem Turbo-Blotter (Schleicher \& Schüll, Dassel) nach dem Protokoll des Herstellers. Am nächsten Morgen wurden die Positionen der Geltaschen auf der Membran markiert. Der Filter wurde zur Fixierung der DNA mit Hilfe von UV-Licht auf der Membran fixiert.

\subsection{Radioaktive Markierung von DNA und Hybridisierung membran- gebundener RNA}

\subsubsection{Random Prime-Markierung}

[Feinberg et al., 1983]

Der RediPrime Kit II (GE Healthcare, München) wurde für die Markierung von DNAFragmenten mit $\alpha-\left[{ }^{32} \mathrm{P}\right]$-Isotopen verwendet. Die Methode basiert auf dem Prinzip des random priming, welches von Feinberg and Vogelstein entwickelt wurde. Der Reaktionsmix enthält dATP, dGTP, dTTP, Klenow Fragment (4-8 U) und zufällige Oligodeoxyribonukleotide, hauptsächlich 9-mere. 25-50 ng der Sonden-DNA wurden in einem Gesamtvolumen von $46 \mu$ bei $95^{\circ} \mathrm{C}$ für 3-5 min denaturiert. Die Probe wurde dann in das RediPrime ${ }^{\mathrm{TM}}$ Reaktionsgefäß überführt, gut gemischt, und zum Schluss wurden $4 \mu \mathrm{l}$ von $\alpha-\left[{ }^{32} \mathrm{P}\right]$-dCTP $(40 \mu \mathrm{Ci})$ zum Reaktionsmix zugegeben. Die Markierungsreaktion wurde bei $37^{\circ} \mathrm{C}$ 30-60 min durchgeführt. Die markierte DNA wurde anschließend mit Hilfe von MicroSpin S-200HR-Säulen (Amersham) aufgereinigt. Die spezifische Aktivität der DNAProbe wurde im Szintillationszähler (Tri-Carb 4530, Packard Instruments, Warrenville, USA) gemessen. Sie lag in der Regel zwischen 4 x $10^{8}$ und 5 x $10^{9} \mathrm{cpm} / \mu \mathrm{g}$ DNA. 


\subsubsection{Hybridisierung membrangebundener DNA mit radioaktiv markierten DNA- Sonden}

Die fixierten Nitrocellulosefilter mit darauf gebundener DNA wurden für mindestens $1 \mathrm{~h}$ bei $65^{\circ} \mathrm{C}$ in Rapid Hyb Puffer (Amersham) im Rollofen (Bachofer, Reutlingen) prähybridisiert. Anschließend wurden die denaturierte Sonde sowie $300 \mu \mathrm{l}$ Lachsspermien-DNA (10 mg/ml) zur Hybridisierungslösung gegeben. Die Hybridisierung erfolgte über Nacht unter denselben Bedingungen wie die Prähybridisierung. Die Filter wurden danach 15 min in Waschlösung I bei RT, 15 min in Waschlösung II bei $65^{\circ} \mathrm{C}$ und $2-5$ min in Waschlösung III bei $65^{\circ} \mathrm{C}$ gewaschen. Die noch feuchten Membranen wurden zur Auswertung mit einem Röntgenfilm in einer Autoradiographie-Kassette bei $-70^{\circ} \mathrm{C}$ oder mit einer Phosphor-Imagermembran (BioRad, Hercules, USA) bei RT exponiert. Die Phosphor-Imagermembran wurde anschließend in einem Phosphor-Imager (Personal Molecular Imager FX, Bio-Rad, Hercules, USA) mit Hilfe der Quantity One-Software analysiert.

\subsection{Polymerase-Kettenreaktion (PCR)}

[Saiki et al., 1985]

\subsubsection{PCR an Plasmid-DNA}

Die Methode wurde mit folgendem Reaktionsansatz durchgeführt:

$\begin{array}{rl}\mathrm{x} \mu \mathrm{l} & \text { template-DNA }(10-50 \mathrm{ng}) \\ 1 \mu \mathrm{l} & \text { Primer } 1(10 \mathrm{pmol} / \mu \mathrm{l} \text {, sequenzspezifisch }) \\ 1 \mu \mathrm{l} & \text { Primer } 2(10 \mathrm{pmol} / \mu \mathrm{l} \text {, sequenzspezifisch }) \\ 5 \mu \mathrm{l} & \mathrm{dNTPs}(2 \mathrm{mM}) \\ 5 \mu \mathrm{l} & \text { Taq-Polymerase Puffer }(10 \mathrm{x}) \\ 0,7 \mu \mathrm{l} & \text { MangoTaq-Polymerase }(1 \mathrm{U} / \mu \mathrm{l}) \\ \text { ad } 50 \mu \mathrm{l} & \mathrm{dH}_{2} \mathrm{O}\end{array}$

Die DNA-Amplifikation erfolgte mittels 30-40 Zyklen in einem Primus 96 Thermocycler der Firma MWG Biotech (High Point, NC, USA). Die Anzahl der Zyklen, die einzelnen Temperaturschritte und die jeweilige Dauer der Zyklen mussten für jedes DNA-Fragment und 
die dafür eingesetzten Primer neu gewählt werden. Ein Zyklus bestand aus folgenden Einzelschritten:

$\begin{array}{lll}95^{\circ} \mathrm{C} & 30-60 \mathrm{sec} & \text { Denaturierung } \\ 50-65^{\circ} \mathrm{C} & 30-90 \mathrm{sec} & \text { Annealing } \\ 72^{\circ} \mathrm{C} & 30-90 \mathrm{sec} & \text { Elongation }\end{array}$

Vor Beginn des ersten Zyklus wurde $1-3$ min bei $95^{\circ} \mathrm{C}$ denaturiert. Nach Beendigung der gewünschten Zyklen schloss sich ein letzter Elongationsschritt von 7 min bei $72^{\circ} \mathrm{C}$ an. 1/10 Vol des Ansatzes wurde mit Stop-Mix II gemischt und je nach Größe des PCR-Produkts auf ein 1-1,5\%iges Agarosegel aufgetragen und elektrophoretisch aufgetrennt.

\subsubsection{Reverse Transkription}

Um eine repräsentative Population von cDNA aus Gesamt-RNA zu erhalten, wurde die Reverse Transkription mit SuperScript II (Invitrogen, Karlsruhe) und oligo(dT)-Primern, die mit den poly(A) ${ }^{+}$-Sequenzen der mRNA paaren, durchgeführt. Es entsteht ein sog. cDNAStrang (für complementary DNA), der zur mRNA komplementär ist und später DNAabhängigen DNA-Polymerasen zugänglich gemacht werden kann.

Für die Reverse Transkription wurden 2-5 $\mu$ g RNA mit $1 \mu \mathrm{l}$ oligo(dT)-Primer $(0,5 \mu \mathrm{g} / \mu \mathrm{l})$ und $1 \mu \mathrm{dNTP}(10 \mathrm{mM})$ in $12 \mu \mathrm{l}$ Gesamtvolumen gemischt und $10 \mathrm{~min}$ bei $70^{\circ} \mathrm{C}$ inkubiert. Nach Zugabe von:

$$
\begin{aligned}
& 4 \mu \mathrm{l} \text { xx First Strand buffer } \\
& 2 \mu \mathrm{LTT}(0,1 \mathrm{M}) \\
& 1 \mu \mathrm{l} \text { RNase-Inhibitor }
\end{aligned}
$$

wurde die Probe 2 min bei $42^{\circ} \mathrm{C}$ inkubiert und $1 \mu$ l SuperScript II hinzugefügt. Die Reverse Transkription wurde 50 min bei $42^{\circ} \mathrm{C}$ durchgeführt. Anschließend wurde bei $70^{\circ} \mathrm{C}$ für 15 min die Reverse Transkriptase inaktiviert. 


\subsubsection{Quantitative real time PCR-Analysen}

Real time PCR bezeichnet ein PCR-Verfahren, bei dem während der PCR die Menge der entstandenen Produkte in Echtzeit gemessen wird. Die Messung der Produktzunahme geschieht anhand von Fluoreszenzlicht, welches in Abhängigkeit von der Produktmenge emittiert wird. Eine Möglichkeit zur Generierung produktabhängiger Fluoreszenz bieten dsDNA bindende Fluoreszenzfarbstoffe. Hier wurde der Cyaninfarbstoff SYBR $®-$ Green I, welcher als QuantiTect SYBR ${ }^{\circledR}-$ Green PCR Master Mix von der Firma Qiagen (Hilden) vertrieben wird, verwendet. Der Farbstoff bindet weitgehend sequenzunspezifisch in der kleinen Furche doppelsträngiger DNA, mit einer etwa 100fach höheren Affinität als Ethidiumbromid. Das derart gebundene SYBR ${ }^{\circledR}-G r e e n$ fluoresziert nach Anregung etwa 1000x stärker als der freie Farbstoff, weshalb SYBR®-Green sehr gut geeignet ist, die Akkumulation doppelsträngiger PCR-Produkte sichtbar zu machen [Morrison et al., 1998]. SYBR ${ }^{\circledR}-$ Green lässt sich in Gegenwart von doppelsträngiger DNA mit Blaulicht (480 nm) anregen und zeigt ein Emissionsspektrum mit einem Maximum bei $520 \mathrm{~nm}$.

Die Analyse wurde im 384well-Maßstab mit dem „ABI Prism 7900T Sequence Detection System" durchgeführt. Dieses System arbeitet mit einem Temperatur-Cycler und einem Laser, der zu jedem der 384 Reaktionsansätze gelenkt wird und diese anregt. Über ein ladungsempfindliches Detektionssystem erfolgte die Messung der Fluoreszenz jeder Probe, die durch an dsDNA gebundenes SYBR ${ }^{\circledR}-G r e e n$ emittiert wird. Die Daten wurden mit Hilfe der Sequenz-Detektionssystem-Software (SDS Version 2.1, PE Applied Biosystems) quantifiziert, exportiert und in Excel (Microsoft) ausgewertet. Die Reaktions-Ansätze enthielten je 0,25 $\mu \mathrm{M}$ der Oligonukleotide und $5 \mu$ l 2x QuantiTect ${ }^{\mathrm{TM}}$ SYBRß-Green PCRMaster-Mix (Qiagen, Hilden). Letzterer enthält die HotStarTaq ${ }^{\mathrm{TM}}$ DNA-Polymerase in einem

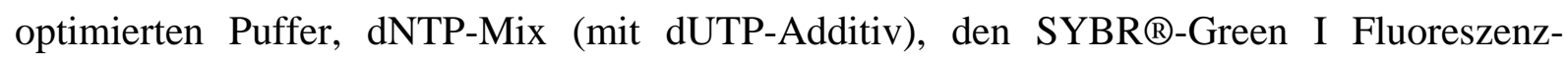
Farbstoff und ROX-Farbstoff als passive Referenz. Der ROX-Farbstoff soll die Korrektur minimaler Abweichungen erlauben, die durch Pipettier-Ungenauigkeiten oder FluoreszenzSchwankungen entstehen können.

Jedem Ansatz wurden entweder 25 ng genomische DNA (bei Kopienzahlbestimmung des

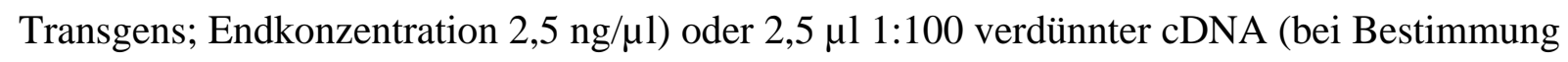
differentieller Genexpression) zugefügt. Für die Erstellung einer Standardkurve wurden Ansätze mitgeführt, die genomische DNA einer transgenen Maus der F1-Generation in den Endkonzentrationen $20 \mathrm{ng} / \mu \mathrm{l}, 10 \mathrm{ng} / \mu \mathrm{l}, 5 \mathrm{ng} / \mu \mathrm{l}, 2,5 \mathrm{ng} / \mu \mathrm{l}, 1,25 \mathrm{ng} / \mu \mathrm{l}$ und 0,625 ng/ $\mu \mathrm{l}$ 
enthielten. Um das Auftreten von unspezifischen Produkten auszuschließen, wurde nach Abschluss der Amplifikation eine Schmelzkurvenanalyse durchgeführt. Dabei wurde kontinuierlich die Fluoreszenz (F) bei steigender Temperatur (T) gemessen und die Steigung dF/dT (1. Ableitung) errechnet. Diese wurde gegen die Temperatur aufgetragen und damit die Maxima bei den primerspezifischen Schmelztemperaturen aufgezeigt. Zusätzliche Maxima verrieten unspezifische Produkte, z.B. Primer-Dimere. Folgendes Programm wurde für alle Primer verwendet:

$\left.\begin{array}{ll}50^{\circ} \mathrm{C} & 2 \mathrm{~min} \\ 95^{\circ} \mathrm{C} & 15 \mathrm{~min} \\ 94^{\circ} \mathrm{C} & 15 \mathrm{~s} \\ 58^{\circ} \mathrm{C} & 30 \mathrm{~s} \\ 72^{\circ} \mathrm{C} & 1 \mathrm{~min} 30 \mathrm{sec}\end{array}\right\} \begin{aligned} & \text { Aktivierung Taq } \\ & \text { Denaturierung } \\ & 95^{\circ} \mathrm{C}\end{aligned}$

Die relative Quantifizierung der initialen Kopienzahl erfolgt bei der real time PCR anhand des Verhältnisses der Kopienzahl des zu untersuchenden Testamplikons und eines Referenzamplikons, das unter identischen Bedingungen amplifiziert wird. Für die Genotypisierung wurde ein Pelota-spezifisches Primerpaar verwendet, da das Pelota-Gen genau eine Kopie im Mausgenom hat. Für die quantitativen Genexpressionsanalysen wurde als Referenz das housekeeping-Gen GAPDH (Glycerinaldehyd-3-Phosphat-Dehydrogenase) verwendet. Bei der Auswertung wird ein Signal-Schwellenwert definiert, bei welchem sich jede Einzelreaktion in der exponentiellen Phase befinden sollte. Der Zeitpunkt (in Zyklen), zu dem das Signal diesen Schwellenwert erreicht, wird als Schwellenwertzyklus oder $\mathrm{C}_{\mathrm{T}}$-Wert (threshold cycle) bezeichnet. Dieser $\mathrm{C}_{\mathrm{T}}$-Wert korreliert mit der Anzahl der Kopien, die für die Reaktion eingesetzt wurden. Wie in Abbildung 2.1 gezeigt, resultiert eine höhere oder niedrigere Start-Kopienzahl in einem signifikant früheren oder späteren Anstieg der Fluoreszenz-Emission. 


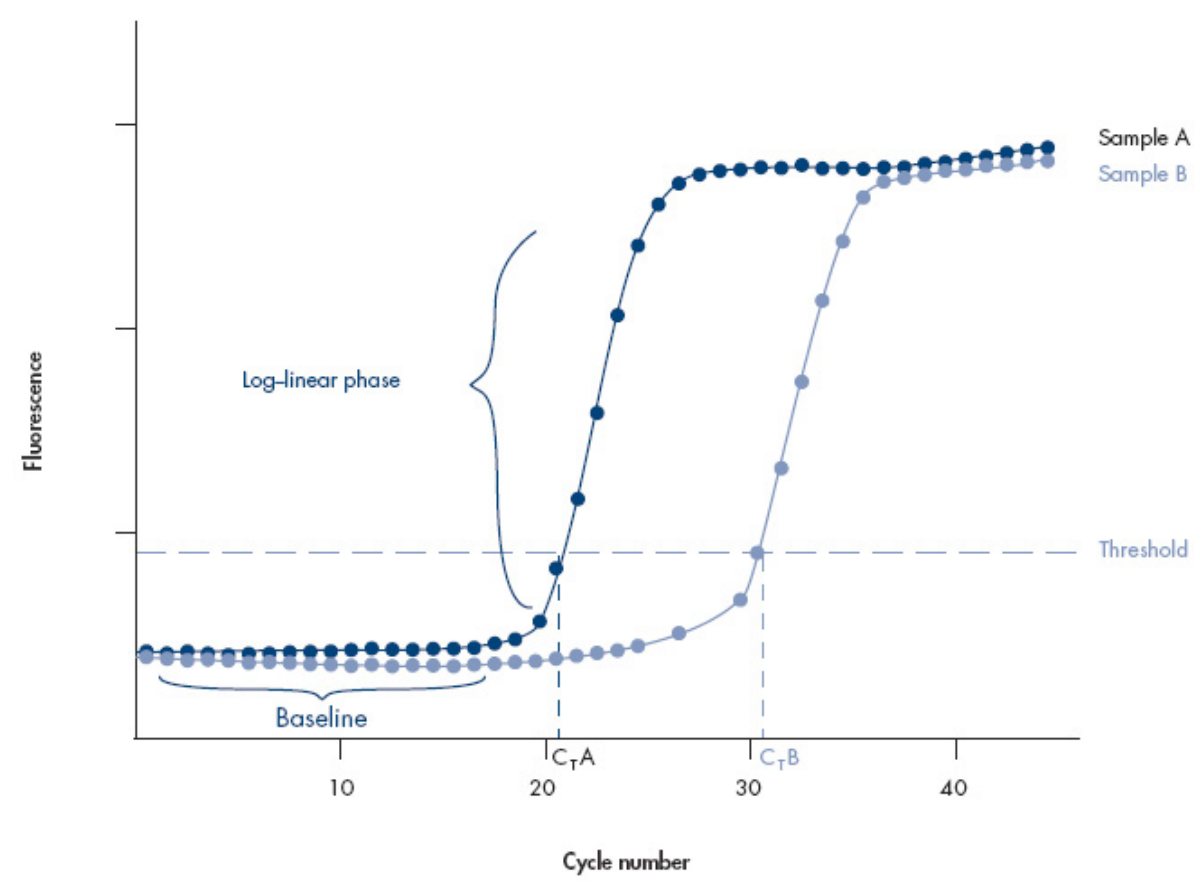

Abb. 2.1: Zunahme der Fluoreszenz zweier Proben (A und B) in Abhängigkeit von der PCR-ZyklusAnzahl. Probe A enthält eine größere Menge an Start-Kopien als Probe B und überschreitet den Schwellenwert daher bei einem früheren Zyklus als Probe A. $\mathrm{C}_{\mathrm{T}}$ : Schwellenwertzyklus. Quelle: QuantiTect SYBR®-Green PCR Handbook, Qiagen (2003).

Aus den Daten der Standardkurven für jedes Amplikon interpoliert das Programm SDS 2.1 die theoretisch eingesetzte DNA-Menge für Referenzamplikon und Testamplikon jeder Probe (cDNA oder Maus-DNA). Da für das Testamplikon und das Referenzamplikon einer Probe exakt gleiche DNA-Mengen für die Taqman-Analyse einsetzt werden, sollte das Verhältnis der durch das Programm interpolierten DNA-Menge von Testamplikon zu Referenzamplikon den Wert 1 ergeben. Im Falle einer homozygot transgenen Leupaxin-Maus, befindet sich doppelt soviel template-DNA für das Testamplikon wie für das Referenzamplikon in den Taqman-Ansätzen. Bei der Berechnung des Verhältnisses Testamplikon zu Referenzamplikon wird in diesem Fall ein Wert von ca. 2 erhalten. 


\subsection{Sequenzanalyse}

Die nichtradioaktive Sequenzierung basiert auf dem Prinzip des Kettenabbruchverfahrens, wobei vier Didesoxynukleotide zum Einsatz kommen, die jeweils mit verschiedenen Fluoreszenzfarbstoffen markiert sind, welche wiederum während der gel-elektrophoretischen Analyse über Laserabtastung automatisch detektiert werden. Die Sequenzreaktion wurde mit 100 ng/1000 bp Plasmid-DNA, 10 pmol sequenzspezifischem Primer und 2,5 $\mu$ l ET-Mix (DYEnamic ET terminator Cycle sequencing Kit der Firma Amersham, Freiburg) in einem Gesamtansatz von $10 \mu \mathrm{l}$ nach folgendem Programm durchgeführt:

$\left.\begin{array}{ll}95^{\circ} \mathrm{C} & 1 \mathrm{~min} \\ 95^{\circ} \mathrm{C} & 30 \mathrm{sec} \\ 60^{\circ} \mathrm{C} & 30 \mathrm{sec} \\ 60^{\circ} \mathrm{C} & 2 \mathrm{~min} \\ 60^{\circ} \mathrm{C} & 5 \mathrm{~min}\end{array}\right\} \quad \begin{aligned} & \text { Denaturierung } \\ & \text { Denaturierung } \\ & \text { Annealing } \\ & \text { Elongation } \\ & \text { Elongation }\end{aligned}$

Nach der Reaktion wurde der Ansatz mit $10 \mu \mathrm{l} \mathrm{H}_{2} \mathrm{O}$ aufgefüllt und über SephadexG50-Säulen aufgereingt. Die gelelektrophoretische Analyse erfolgte mit der automatischen Sequenzanlage MegaBACE ${ }^{\mathrm{TM}} 1000$ der Firma Molecular Dynamics (Amersham).

\subsection{Proteinchemische Techniken}

\subsubsection{Isolierung von Gesamtprotein aus Zellkulturen}

Einer dicht bewachsenen großen $\left(75 \mathrm{~cm}^{2}\right)$ Zellkulturflasche (Konfluenz $>80 \%$ ) wurde nach dem Waschen mit PBS $500 \mu$ l Lysis-Puffer zugefügt. Die adhärenten Zellen wurden mit einem Zellschaber vom Boden der Zellkulturflasche gelöst und in ein Eppendorf-Gefäß überführt. Suspensionszellen wurden bei 100 x g für 3 min zentrifugiert, mit PBS gewaschen und ebenfalls in $500 \mu$ l Lysis-Puffer aufgenommen. Nach einer Inkubation für 15 min auf Eis wurden unlösliche Bestandteile durch Zentrifugation bei 16000 x g für 10 min entfernt. Der die Zellproteine enthaltende Überstand wurde in ein sauberes Eppendorf-Gefäß überführt, die Proteinkonzentration (2.16.3) wurde bestimmt und das Lysat in geeigneten Aliquots bei $-80^{\circ} \mathrm{C}$ aufbewahrt. 


\subsubsection{Isolierung von Gesamt-Protein aus Organen der Maus}

Die direkt nach dem Abtöten der Mäuse entnommenen Organe wurden mit eiskaltem PBS gewaschen und zunächst in flüssigem Stickstoff eingefroren. Zur Isolierung der Proteine wurde zu den Organen $1 \mathrm{ml}$ Lysispuffer III gegeben, zu dem vorher frischer Proteaseschutz und 3,5 mM DTT hinzugefügt wurde. Mit Hilfe eines speziell für 1,5 ml Eppendorf-Gefäße angefertigten Mörsers wurde das Gewebe zerstoßen. Die nicht löslichen Bestandteile wurden 10 min bei 16000 x g abzentrifugiert. Der die Proteine enthaltende Überstand wurde in ein sauberes Eppendorf-Gefäß überführt und bis zur weiteren Verwendung als Aliquots bei $-80^{\circ} \mathrm{C}$ eingefroren.

\subsubsection{Konzentrationsbestimmung von Proteinen}

[Bradford, 1976]

Die Proteinkonzentration wurde nach der Methode von Bradford mit Hilfe von Roti®Nanoquant (Roth) bestimmt. Hierbei wird ausgenutzt, dass der Coomassie-Farbstoff BrilliantBlau in saurer Lösung an Proteine bindet, was eine Verschiebung des Absorptionsmaximums von 495 nm auf 595 nm zur Folge hat. Durch Mitführen einer BSA-Eichreihe (0-6,7 $\mu \mathrm{g} / \mathrm{ml}$ BSA) als interner Standard kann die Proteinkonzentration aus der Eichgeraden extrapoliert werden. $20 \mathrm{ml}$ des Farbstoffes (5x-Konz.) wurden mit 80 ml $\mathrm{H}_{2} \mathrm{O}_{\text {dd }}$ gemischt. Je $200 \mu \mathrm{l}$ dieser Arbeitslösung wurden zu $50 \mu$ l einer 1:100 Verdünnung der zu messenden Proteine gegeben. Die Messung der Extinktion erfolgte in flachbödigen 96well-Mikrotiterplatten, die in einem EL 800 Universal Microplate Reader (Bio-Tek Instruments Inc., Winooski, Vt.) bei 490/595 nm ausgewertet wurden. Es wurden je Probe drei Messungen durchgeführt und die Werte gemittelt.

\subsubsection{SDS-Polyacrylamidgelelektrophorese (SDS-PAGE)}

Zur Auftrennung der Proteine wurden Gradientengele (NuPAGE ${ }^{\mathrm{TM}}$ 4-12\% Bis-Tris Gel, Invitrogen, Karlsruhe) verwendet. Dieses Polyacrylamid-Gelsystem beruht auf dem SDSPAGE-Prinzip [Laemmli, 1970]. Durch die Verwendung von aufeinander abgestimmten Gelen und Puffern bei einem pH-Wert von 7.0 ist zum einen die Stabilität der Proteine, aber auch die der Gele erhöht, was zu einem besseren Ergebnis der Elektrophorese führt. 
Die Proteinproben wurden mit 0,4 Vol Probenpuffer (LDS Sample Buffer (4x), NuPAGE ${ }^{\mathrm{TM}}$, Invitrogen, Karlsruhe) versetzt, 10 min bei $70^{\circ} \mathrm{C}$ erhitzt und nach Abkühlen auf Eis auf das Gel aufgetragen. Die Elektrophorese erfolgte mit 1x MES-Puffer (Invitrogen) bei 150-180 V für ca. 1 h. Zur Bestimmung der Größe der aufgetrennten Proteine wurde parallel zu den Proteinproben ein vorgefärbter Proteinstandard (NuPAGEтм See Blue Plus2, Invitrogen) mitaufgetragen.

Für die Durchführung der Western Blot-Analysen in Abschnitt 3.6.7 wurden selbstgegossene SDS-Polyacrylamidgele nach dem von Laemmli eingeführten diskontinuierlichen Tris/HCl/Tris-Glycin-Puffersystem verwendet. Für Trenn- und Sammelgel wurden folgende Komponenten gemischt und die Gele nacheinander nach Zugabe von APS

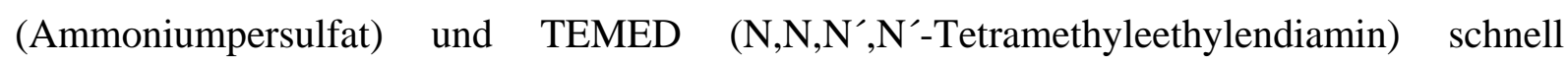
gegossen:

$\begin{array}{lll}\text { 12,5\% Trenngel: } & 12,5 \mathrm{ml} & \text { Acrylamid/Bis-Acrylamid (40\%, 29:1) } \\ & 10 \mathrm{ml} & \text { Trenngelpuffer } \\ & 17,5 \mathrm{ml} & \text { Wasser } \\ & 200 \mu \mathrm{l} & 10 \% \text { APS } \\ & 40 \mu \mathrm{l} & \text { TEMED } \\ & & \\ \text { 5\% Sammelgel: } & 1 \mathrm{ml} & \text { Acrylamid/Bis-Acrylamid (40\%, 29:1) } \\ & 2,5 \mathrm{ml} & \text { Sammelgelpuffer } \\ & 6,5 \mathrm{ml} & \text { Wasser } \\ & 50 \mu \mathrm{l} & 10 \% \text { APS } \\ & 10 \mu \mathrm{l} & \text { TEMED }\end{array}$

\subsubsection{Western Blot-Analysen von Proteinen auf PVDF-Membranen}

[Gershoni et al., 1982, 1983]

Eine auf die Größe des zu blottenden Polyacrylamidgels zugeschnittene PVDF-Membran (Macherey \& Nagel) wurde kurz (5-10 sec) in 100\% Methanol getaucht und anschließend in Transferpuffer für 10 min äquilibriert. Auf fünf ebenfalls auf die Größe zurechtgeschnittene Whatman GB003 Filter (Schleicher \& Schüll, Dassel), die in Transferpuffer getränkt wurden, 
wurde die PVDF-Membran und sofort das nach der elektrophoretischen Auftrennung der Proteine mit Wasser abgespülte Polyacrylamidgel gelegt. Fünf weitere mit Transferpuffer getränkte Filter wurden nach dem sandwich-Model oben aufgesetzt. Der Transfer wurde in einem Elektroblotter (Biometra, Göttingen) bei 100 mA für 1 - 2 h durchgeführt.

\subsubsection{Färbung von Polyacrylamidgelen}

Die SDS-Polyacrylamidgele wurden zwecks Proteinfärbung oder Kontrolle des Western BlotTransfers mit Coomassie-Lösung gefärbt, anschließend in $\mathrm{H}_{2} \mathrm{O}$ entfärbt und in Folie eingeschweißt.

\subsubsection{Inkubation von membrangebundenen Proteinen mit Antikörpern}

Um unspezifische Bindungsstellen abzublocken, wurde die Membran zunächst in 1x PBS mit 2-5\% Magermilchpulver (Blocklösung I) oder in 1x TBS-T mit 5\% Magermilchpulver (Blocklösung II) entsprechend Tabelle 2.I für $1 \mathrm{~h}$ bei RT inkubiert. Nach extensivem Waschen in Waschlösung IV erfolgte die Inkubation mit dem Primärantikörper bei einer für den jeweiligen Antikörper entsprechenden Verdünnung in Blocklösung I oder in 1x TBS$\mathrm{T} / 5 \%$ BSA bei $4^{\circ} \mathrm{C}$ über Nacht. Anschließend wurde die Membran 2x 5 min in Waschlösung gewaschen und mit einem entsprechenden Sekundärantikörper in einer Verdünnung von 1:2000 bis 1:10000 in Blocklösung für $2 \mathrm{~h}$ bei RT inkubiert. Wurde das System der colorimetrischen Alkalischen Phosphatase-Färbung angewendet, so wurde die Membran 2x 5 min in Waschlösung IV, 1x 5 min in 1x PBS bzw. TBS-T und 1x 5 min in AP-Puffer bei RT gewaschen. Zum Schluss wurden die Proteine auf der Membran durch Inkubation unter Lichtabschluss in $10 \mathrm{ml}$ Färbelösung (Alkalische Phosphatase-Färbelösung) sichtbar gemacht und die Reaktion mit Wasser oder $1 \mathrm{x}$ PBS gestoppt. Sollten die Proteine über Chemilumineszenz nachgewiesen werden, wurde die Membran nach Waschen mit Waschlösung III mindestens 2x 5 min in 1x PBS oder 1x TBS-T gewaschen, um Milchpulverrückstände zu entfernen. Anschließend wurde etwa $1 \mathrm{ml}$ der ECL PlusArbeitslösung hergestellt, indem Luminol/Enhancer-Lösung und die stabile Peroxid-Lösung der Firma Amersham 1:40 gemischt wurden. Die HRP setzt das Substrat der Arbeitslösung um. Die Produkte bilden ein lichtemittierendes Präzipitat um den AntigenAntikörperkomplex. Die Lösung wurde auf die Membran gegeben und 5 min inkubiert. 
Anschließend wurde die abgetropfte Membran in Plastik eingeschweißt und in eine Filmkammer gelegt. Der Film wurde in der Dunkelkammer aufgelegt und nach 60 sec entwickelt. Je nach Intensität der Banden konnte die Entwicklungszeit verlängert oder verkürzt werden.

Tab. 2.I: Übersicht über die verwendeten Antikörper-Verdünnungen sowie das Puffer-System.

\begin{tabular}{ccc}
\hline Antikörper & Verdünnung & Puffer-System \\
\hline anti-cmyc & $1: 800$ & \\
anti-Leupaxin & $1: 1600$ & PBS/ 2\%Magermilch \\
anti- $\alpha$-Tubulin & $1: 4000$ & PBS/ 2\% Magermilch \\
anti-AKT(Thr308) & $1: 2000$ & PBS/ 5\% Magermilch \\
anti-AKT1/2/3 (Ser473) & $1: 3000$ & TBS-T/5\% Magermilch \\
anti-AKT & $1: 3000$ & TBS-T/5\% Magermilch \\
anti-Phospho-ERK1/2(Thr202/Tyr204) & $1: 4000$ & TBS-T/5\% Magermilch \\
anti-ERK1/2 & $1: 4000$ & TBS-T/5\% Magermilch \\
anti-Phospho-MEK1/2(S217/S221) & $1: 4000$ & TBS-T/5\% Magermilch \\
anti-MEK1/2 & $1: 4000$ & TBS-T/5\% Magermilch \\
anti-Raf(Ser259) & $1: 4000$ & TBS-T/5\% Magermilch \\
anti-c-Raf & $1: 4000$ & TBS-T/5\% Magermilch \\
anti-GFP & $1: 1000$ & TBS-T/5\% Magermilch \\
anti-p120CTN (NT) & $1: 1000$ & TBS-T/5\% Magermilch \\
& & TBS-T/5\% Magermilch
\end{tabular}

\subsection{Zellbiologische Methoden}

\subsubsection{Zellkultur eukaryontischer Zellen}

Die adhärent wachsenden PC-3, LNCaP- und DU 145-Zellen wurden in käuflich erworbenem RPMI 1640-Medium, die NIH 3T3-Zellen wurden in DMEM-Medium jeweils mit Zusatz von 1,2\% Penicillin/Streptomycin und 10\% FKS in oberflächenbehandelten Gewebekulturflaschen kultiviert. Die Inkubation erfolgte im Brutschrank mit $5 \% \mathrm{CO}_{2}$ bei $37^{\circ} \mathrm{C}$. In Abhängigkeit von der Proliferationsrate wurden die Zellen ein- bis zweimal pro Woche geteilt. Die Zellen wurden dabei mit 1x DPBS (PAN) gewaschen und mit Trypsin-like Enzyme $^{\mathrm{TM}}$ (Invitrogen) so lange inkubiert, bis sich die Zellen vom Boden der Kulturflasche 
gelöst haben. Nach dem Ablösen der Zellen wurden 1:2 bis 1:5 Verdünnungen der Zellsuspension in frischem Medium hergestellt.

Die in Suspension wachsenden Daudi-Zellen wurden je nach Dichte der lebenden Zellen einbis zweimal pro Woche in 14 ml-Falcons überführt, bei $200 \mathrm{x}$ g für 3 min zentrifugiert, mit 1x DPBS gewaschen und in entsprechendem Medium in einer neuen Kulturflasche ausgesät.

\subsubsection{Kryokonservierung und Revitalisierung von eukaryontischen Zellen}

Die bis zu einer Konfluenz von $>80 \%$ gewachsenen Zellen wurden mit DPBS gewaschen, trypsiniert und anschließend in einer entsprechenden Menge Kulturmedium mit 8\% DMSO resuspendiert. Nach 7 Tagen Aufbewahrung bei $-70^{\circ} \mathrm{C}$ wurden sie in flüssigem Stickstoff konserviert. Zur Revitalisierung wurden die Zellen schnell aufgetaut, in vorgewärmtes Kulturmedium überführt und über Nacht inkubiert. Am nächsten Morgen wurde das Medium zur vollständigen Entfernung des DMSO gewechselt.

\subsubsection{Transfektion eukaryontischer Zellen}

Die Transfektion eukaryontischer Zellen erfolgte zum Nachweis der subzellulären Lokalisation von Fusionsproteinen, zum Nachweis der Kolokalisierung mit Hilfe von immunzytochemischen Experimenten und zum Nachweis von Interaktionen (Koimmunopräzipitation) und Transaktivierungen (Transaktivierungsassay) ausgewählter Proteine.

Das verwendete Transfektionsreagenz Roti ${ }^{\circledR}$-Fect (Carl Roth GmbH, Karlsruhe) stellt ein polykationisches Lipid dar. Es bildet mit der DNA einen stabilen Komplex aufgrund der entgegengesetzten Ladungen. Die DNA wird in diesem Fall nicht in den Liposomen verpackt, sondern lagert sich außen an. Beim Kontakt der Liposomen mit der Zellmembran wird die DNA in die Zelle aufgenommen, wobei der genaue Mechanismus noch nicht bekannt ist. Es wurden für die Transfektionsexperimente nur Zellen verwendet, die sich in einer permanenten Wachstumsphase befanden. Einen Tag vor der Transfektion wurden die Zellen auf entsprechenden Objektträgern (FALCON culture slides) oder Kulturflaschen so ausplattiert, dass am folgenden Tag eine Konfluenz von 70-90\% erreicht wurde. RPMI 1640-Medium ohne Zusätze wurde mit DNA und Transfektionsreagenz nach Vorschrift des Anbieters gemischt, bei RT 45 min inkubiert und vorsichtig auf die Zellen, die vorher mit PBS 
gewaschen und mit Kulturmedium ohne Antibiotika bedeckt worden waren, aufgetropft. Nach 3-4 h wurde zu dem Transfektionsmedium Kulturmedium mit Antibiotikazusatz gegeben. Am nächsten Tag wurde das Transfektionsmedium komplett gegen normales Kulturmedium ausgetauscht und die Zellen zwecks Proteinexpression 24-36 h unter Kulturbedingungen inkubiert.

\subsubsection{Stabile Transfektion von eukaryontischen Zellen}

Für die stabilen Transfektionen wurde wie unter 2.17.3 beschrieben vorgegangen. Nach $24 \mathrm{~h}$ wurden dann die LNCaP-Zellen trypsiniert und in zwei bis drei 6well-Platten ausplattiert. Dem Medium wurde zur Selektion nach Transfektion des Tet-On-Plasmids 0,3 mg/ml G418 und nach Transfektion der pTRE-Konstrukte zusätzlich noch 0,2 mg/ml Hygromycin zugegeben. Die Selektion wurde über einen Zeitraum von 14 Tagen durchgeführt, wobei nach Bedarf das Medium ausgetauscht wurde. Die gut sichtbaren Klone wurden mit einer Pipette vorsichtig aufgesaugt und in 24well-Platten überführt, wo sie zur weiteren Charakterisierung gezüchtet wurden.

\subsubsection{Anfertigung von Zytospin-Präparaten}

Um Zellen auf einem Objektträger zu fixieren, kann neben der Kultivierung auch die Methode der Zytospin-Präparation verwendet werden. Dazu wurden in einem speziellen Rotor (Sigma, Rotor 11234) 7x 105 Zellen auf einen Objektträger bei 90 x g für 7 min zentrifugiert. Nach dem Trocknen über Nacht wurden die Zellen anschließend für immunhistochemische Experimente verwendet oder die Zytospin-Präparate bei $-20^{\circ} \mathrm{C}$ in Aluminiumfolie gewickelt aufbewahrt. 


\subsubsection{Bestimmung der PSA-Konzentration im Kulturmedium von LNCaP-Zellen}

Für die Analyse der PSA-Sekretion von LNCaP-Zellen wurden diese mit Leupaxinspezifischer siRNA bzw. zur Kontrolle mit Luciferase-spezifischer siRNA transfiziert (siehe 2.20.2). Nach 24, 48 und 72 h wurde das Kulturmedium entnommen und für 5 min bei 16000x g abzentrifugiert. Die Messung der PSA-Menge erfolgte mit dem Elecsys ${ }^{\circledR S y s t e m ~}$ 2010 (Roche Diagnostics) in Zusammenarbeit mit Prof. Dr. Hubertus Jarry (Abteilung klinische und experimentelle Endokrinologie, Universität Göttingen). Die Messungen wurden in Doppelbestimmungen dreimal durchgeführt. Anschließend wurden die Werte gemittelt.

\subsection{Proliferationsassay}

In der Zellbiologie sind Proliferationstests eine häufig verwendete Methode zum Studium von Wachstumsfaktoren, Zytokinen und anderen in das Wachstumsverhalten der Zellen eingreifenden Substanzen oder Gene. Unter den verschiedenen Möglichkeiten, die Zellzahlen zu bestimmen, wurde ein Proliferationsassay (EZ4U-Kit, Biomedica, Wien oder CellTiter 96® AQueous Non-Radioactive Cell Proliferation Assay, Promega, Mannheim) gewählt, der auf der Entdeckung beruht, dass von lebenden Zellen schwach gefärbte Tetrazoliumsalze (MTS) in intensiv gefärbte Formazanderivate umgewandelt werden können. Diese Reduktion erfordert intakte Mitochondrien, die nach Absterben der Zelle innerhalb weniger Minuten inaktiv werden. Daraus ergibt sich eine Unterscheidungsmöglichkeit zwischen lebenden und abgestorbenen Zellen. Der Proliferationsassay wurde nach dem Protokoll des Herstellers

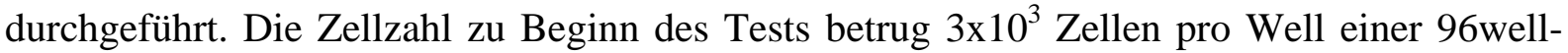
Platte. Die Messung des Farbumschlags des Chromophors erfolgte in einem Miktrotiterplatten-Lesegerät (EL 800 Universal Microplate Reader, BIO-TEK Instr. Inc.). Die Absorption wurde bei $450 \mathrm{~nm}$ gegen $620 \mathrm{~nm}$ (Referenzwellenlänge zum Abzug des Hintergrundes) im Abstand von 3, 24, 48, 72 und 96 h gemessen. 


\subsection{Invasionsassay}

Zur Bestimmung der Zellmigration wurden BioCoat Matrigel Invasion Chambers (Becton Dickinson, Bedford, MA) nach dem Protokoll des Herstellers verwendet. Sie stellen den Zellen die Bedingungen, die sie benötigen, um ihre invasive Eigenschaft in vitro zu zeigen. Sie bestehen aus einer BD Falcon ${ }^{\mathrm{TM}}$ TC Companion Platte mit Falcon ${ }^{\mathrm{TM}}$ Cell Culture Inserts, die eine PET-Membran (8 $\mu$ m Porengröße) mit einer dünnen Schicht Matrigel Basement Membrane Matrix enthalten. Diese stellt die Basalmembran in vitro dar. Die Matrigel-Schicht schließt die Poren der Membran, so dass nicht invasive Zellen nicht durch die Membran wandern können. Dagegen können invasive Zellen sich von der Matrigel-Matrix ablösen und durch die Matrigel-Matrix und die Poren der Membran wandern. Die Membran kann für Licht- und Elektronenmikroskopie verwendet werden und kann nach dem Färben der Zellen leicht entfernt werden.

Leupaxin-Duplex-siRNA und Luciferase-Duplex-siRNA transfizierte PC-3- und DU 145Zellen bzw. nicht stimulierte und für $48 \mathrm{~h}$ oder $>2$ Monate mit 0,1 $\mu \mathrm{g} / \mathrm{ml}$ Doxycyclin stimulierte LNCaP-Zellklone wurden im entsprechenden Kulturmedium jeweils in einer Konzentration von $5 \times 10^{4}$ Zellen/ml bzw. 4 x $10^{5}$ resuspendiert. $500 \mu$ dieser Zellsuspension wurden in den oberen Teil eines Inserts gegeben und für $22 \mathrm{~h}$ bzw. $48 \mathrm{~h}$ bei $37^{\circ} \mathrm{C}$ und $5 \% \mathrm{CO}_{2}$ inkubiert. Anschließend wurden nicht invasive Zellen von der oberen Oberfläche der Membran entfernt. Die Zellen von der unteren Seite der Membran wurden mit dem Diff-Quik Staining Set (Dade Behring GmbH, Marburg) gefärbt, und die invasiven Zellen wurden unter einem Mikroskop (BX60, Olympus Optical Co., Japan) bei 100-facher Vergrößerung gezählt. Die Daten entsprechen der Anzahl der aus fünf zufällig gewählten Sichtfelder gezählten, invasiven Zellen. Alle Experimente wurden in 3facher Wiederholung durchgeführt.

\subsection{Herunterregulierung der Genexpression mittels RNA-Interferenz}

Der Terminus RNA-Interferenz (RNAi) beschreibt die Verwendung von doppelsträngiger RNA, um spezifische mRNAs für die Degradierung zu markieren, wodurch die Expression der entsprechenden Gene verringert wird. RNAi ist eines aus einer breiten Klasse von RNAsilencing-Phänomenen, die in Pflanzen, Tieren und Pilzen gefunden worden sind [Cogoni et al., 2000; Elbashir et al., 2001a; Elbashir et al., 2001b; Tuschl, 2001]. 


\subsection{1 Überblick über den Mechanismus von RNAi}

Im ersten Schritt wird doppelsträngige RNA in 21-23 Nukleotide small interfering RNAs (siRNA) geteilt, welche auch als guide RNAs bezeichnet werden [Hammond et al., 2001; Sharp, 2001]. Das Enzym Dicer, ein Mitglied der RNase III-Familie der dsRNA-spezifischen Ribonukleasen, schneidet prozessiv die dsRNA (direkt oder über ein Transgen oder Virus eingeführt) in ATP-abhängiger Weise. Das sukzessive Schneiden degradiert die RNA in 1921 bp-Duplexe (siRNAs), die jedes einen 2-Nukleotid-Überhang am 3'-Ende besitzen [Hutvagner et al., 2002]. Im Effektor-Schritt binden die siRNA-Duplexe an einen Nuklease-

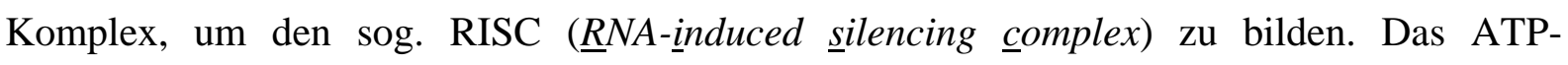
abhängige Entwinden der siRNA-Duplexe ist für die Aktivierung von RISC notwendig. Der aktive RISC geht gezielt gegen homologe Transkripte durch Basenpaarung vor und schneidet die mRNA 12 Nukleotide vom 3'-Terminus der siRNA [Hammond et al., 2001; Sharp, 2001]. In Säugerzellen führt das Einbringen langer doppelsträngiger RNA (>30 Nukleotide) zur Initiation einer antiviralen Antwort, die z.B. eine unspezifische Inhibierung der Proteinsynthese oder RNA-Degradation auslöst. Diese antivirale Antwort in Säugerzellen kann umgangen werden, indem synthetische siRNAs eingebracht oder siRNAs von Vektoren exprimiert werden (Abb. 2.2).

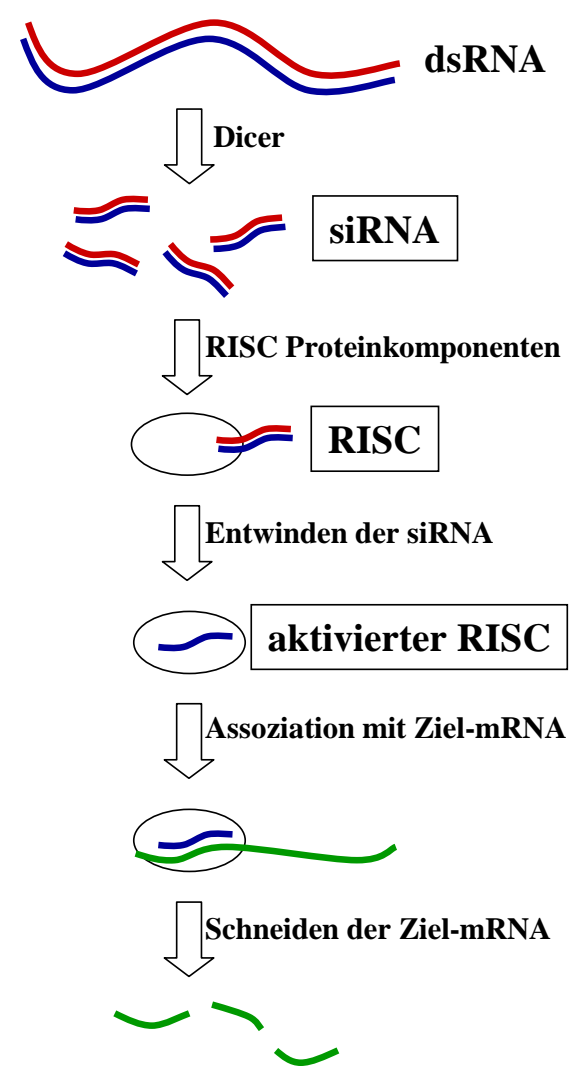


Abb. 2.2: Übersicht über den Mechanismus von RNAi [mod. nach www.ambion.com]. RNAi wird durch das Enzym Dicer initiiert, welches doppelsträngige RNA in 22-Nukleotide kleine small interfering RNAs (siRNAs) prozessiert. Die siRNAs werden dann in eine Multikomponenten-Nuklease (RISC) inkorporiert. RISC wird anschließend von einer latenten Form, die doppelsträngige siRNA enthält, in eine aktive Form durch Entwindung der siRNAs überführt. Der aktivierte RISC verwendet dann die entwundenen siRNAs als eine Schablone für die Substratselektion und die Ziel-mRNA wird geschnitten.

\subsubsection{Transfektion eukaryontischer Zellen mit siRNAs}

Die auf RNAi basierende Methode kann verwendet werden, um eine spezifische mRNA zur Degradierung zu markieren, wodurch es zur Verminderung der entsprechenden Genexpression (gene silencing) kommt. Es wurde ebenfalls gezeigt, dass sequenzspezifische einzelsträngige RNA-Oligonukleotide sowohl in sense- als auch in antisense-Orientierung als Negativkontrolle für dieses spezifische gene silencing eingesetzt werden können, da sie keinen Effekt auf die spezifische mRNA-Degradierung haben [Tuschl et al., 1999].

Transfektionen von PC-3-, LNCaP- und DU 145-Zellen wurden mit dem Transfektionsreagenz OligoFectamine ${ }^{\mathrm{TM}}$ (Invitrogen, Karlsruhe) durchgeführt, welches stabile Komplexe zwischen Lipiden und Oligonukleotiden bildet. So können die RNAMoleküle effizient in die Säugetier-Zellen aufgenommen werden. Die Transfektion wurde nach dem Protokoll des Herstellers mit genspezifischen siRNA-Duplex-Oligonukleotiden in einer Endkonzentration von $80 \mathrm{nM}$ im Transfektionsmedium durchgeführt. Als eine weitere Kontrolle wurden die PCa-Zellen mit siRNA-Duplex-Oligonukleotiden gegen das LuciferaseGen des Leuchtkäfers (Photinus pyralis; nicht-verwandte Sequenz) transfiziert (Sequenzen der Oligonukleotide siehe 2.8.4.2).

Für die Transfektion wurden die PCa-Zellen entweder in kleinen Kulturflaschen (22 cm2), 12well-Platten oder auf Objektträger mit Kulturflasche (FALCON culture slide) bis zu einer Konfluenz von 20\% (DU 145, PC-3) bzw. 40-50\% (LNCaP) kultiviert. Alle Angaben der nachfolgend beschriebenen Transfektion beziehen sich auf ein Well einer 12well-Platte oder Falcon culture clide; für kleine Kulturflaschen wurden die 3fachen Mengen verwendet. $3 \mu \mathrm{l}$ Duplex-siRNA $(20 \mu \mathrm{M})$ wurden mit $100 \mu \mathrm{l}$ Optimem I (Invitrogen) in einem 1,5 ml-Gefäß vermischt. $3 \mu$ l OligoFectamine ${ }^{\mathrm{TM}}$ wurde zu $20 \mu \mathrm{l}$ Optimem I in einem weiteren 1,5 ml-Gefäß gegeben und für 10 min bei RT inkubiert. Anschließend wurde die OligoFectamine-Lösung zu der RNA-Probe hinzugefügt und für 25 min bei RT inkubiert. Während dieser 
Inkubationszeit wurden die Zellen mit PBS gewaschen und $1 \mathrm{ml}$ Optimem I wurde in jedes Well gegeben. Anschließend wurde das Transfektionsgemisch (RNA/OligoFectamine ${ }^{\mathrm{TM}}$ in Optimem I) vorsichtig auf die Zellen gegeben und die Zellen bei $37^{\circ} \mathrm{C}$ und $5 \% \mathrm{CO} 2$ in einem Inkubator 8-12 h kultiviert. Nach Entnahme des Transfektionsmediums wurde normales Kulturmedium zu den Zellen gegeben und die Zellen unter den gleichen Bedingungen weiterkultiviert. Zu verschiedenen Zeitpunkten nach der Transfektion wurden die Zellen zur Isolierung von Proteinen, RNA und für immunhistochemische Experimente zur Verifizierung des gene silencing und zur Untersuchung der Effekte der jeweiligen Gen-Herunterregulierung verwendet.

\subsection{Assay zur Bestimmung der Adhäsion von Zellen}

Zur Bestimmung der adhäsiven Eigenschaften der Leupaxin-überexprimierenden LNCaPZellklone wurden sog. Adhäsionsassays durchgeführt. Dazu wurden die LNCaP-Zellklone für $48 \mathrm{~h}$ oder $>2$ Monate mit 0,1 $\mu \mathrm{g} / \mathrm{ml}$ Doxycyclin stimuliert bzw. unstimuliert kultiviert. Anschließend wurden die Zellen mit 0,3 mM EDTA in PBS vom Boden der Kulturschale gelöst, mit Kulturmedium ohne Serum durch Zentrifugation bei 200 x g gewaschen und die Zellzahl bestimmt. In eine 96well-Platte, die zuvor mind. $1 \mathrm{~h}$ bei $37^{\circ} \mathrm{C}$ mit $10 \mu \mathrm{g} / \mu \mathrm{l}$ Fibronektin, Rattenschwanz-Collagen oder $20 \mu \mathrm{g} / \mu \mathrm{l}$ BSA beschichtet worden ist, wurden je 1,5 bzw. 2 x $10^{4}$ Zellen in $100 \mu \mathrm{l}$ Gesamtvolumen zugegeben. Nach Inkubation für $30 \mathrm{~min}$ oder $1 \mathrm{~h}$ bei $37^{\circ} \mathrm{C}$ wurde das Medium entfernt und die adhärenten Zellen 2x mit PBS gewaschen. Die Zellen wurden mit 4\% Formaldehyd in PBS für 20 min fixiert und mit 0,1\% Kristallviolett für $1 \mathrm{~h}$ bei RT angefärbt. Nach zweimaligem Waschen mit $\mathrm{H}_{2} \mathrm{O}$ wurden die Zellen getrocknet und anschließend mit 0,2\%igem Triton X-100 für $1 \mathrm{~h}$ geschüttelt. Die Messung der Färbung erfolgte in einem Plattenphotometer bei 490 nm Wellenlänge.

\subsection{Bestimmung der Migrationsfähigkeit von Zellen}

Zur Bestimmung der Migrationsfähigkeit von PC-3- und DU 145-Zellen nach Herunterregulierung der Leupaxin-Expression wurde der sog. scratch-Assay oder auch Wundheilungsassay angewendet. 
Zunächst wurden die PC-3- und DU 145-Zellen mit Leupaxin-spezifischer bzw. zur Kontrolle mit Luciferase-spezifischer siRNA über Nacht transfiziert (2.20.2). Anschließend wurden die Zellen trypsiniert, gezählt und so ausplattiert, dass sie 24 h später eine Ein-Zellschicht am Boden einer 24well-Platte bildeten. Mit Hilfe einer sterilen, gelben Pipettenspitze wurde in diese Zellschicht eine Wunde eingeführt und das Kulturmedium zur Beseitigung der abgekratzten Zellen gewechselt. Die Wunde wurde mit Hilfe eines inversen Mikroskops dokumentiert. Alle 4 bis $8 \mathrm{~h}$ wurden die Zellen dann fotografiert und der Wundheilungsprozess dokumentiert. Der Assay wurde nicht über einen Zeitraum von mehr als 24 h ausgedehnt, da sonst der Fehler der Proliferation in die Ergebnisse der Migration eingehen kann.

\subsection{Soft-Agar-Assay zur Analyse des Verankerungs-unabhängigen Zellwachstums}

Zur Vorbereitung der 96well-Zellkulturplatten wurde in jedes Well $50 \mu$ l einer Basisschicht bestehend aus RPMI-Komplettmedium mit 0,6\% LMP (low melting point)-Agarose (Invitrogen) und gegebenenfalls 0,1 $\mathrm{\mu g} / \mathrm{ml}$ Doxycyclin gegossen und diese fest werden lassen. Die LNCaP-Zellklone mit induzierbarer Leupaxin-Expression bzw. die Kontroll-Zellklone mit integriertem Leerplasmid wurden für 48 h bzw. > 2 Monate mit 0,1 $\mu \mathrm{g} / \mathrm{ml}$ Doxycyclin stimuliert, trypsiniert und gezählt. Zum Ausplattieren wurde pro Well 1000 bzw. 1500 Zellen mit Komplettmedium, das mit 0,35\% LMP-Agarose versetzt war, in einem Gesamtvolumen von $50 \mu \mathrm{l}$ zugegeben. Die Zellen wurden anschließend für 7 Tage inkubiert, die Kolonien mit 0,1\% Kristallviolett gefärbt und in einem Plattenphotometer bei $490 \mathrm{~nm}$ Wellenlänge gemessen. Der Versuch wurde dreimal in Triplikaten wiederholt.

\subsection{Methoden zur subzellulären Lokalisierung eines Proteins}

\subsubsection{Immunzytochemische Färbung eukaryontischer Zellen}

Die PCa-Zellen wurden bis zu einer 80\%igen Konfluenz auf speziellen Objektträgern mit angehefteter Kulturflasche (FALCON culture slides) in entsprechendem Kulturmedium 
kultiviert. Die Zellen wurden einmal mit PBS gewaschen und in 3,7\% Formaldehyd in PBS für 20 min fixiert. Nach Permeabilisierung der Zellmembran für 15 min in 0,1\% Triton X-100 in PBS wurden die Zellen kurz in PBS gewaschen und 30 min bei RT mit 3\% BSA in PBS zur Blockierung unspezifischer Bindungsstellen inkubiert. Anschließend erfolgte die Inkubation mit dem Primärantikörper in entsprechender Konzentration in Blockpuffer über Nacht bei $4^{\circ} \mathrm{C}$ in einer feuchten Kammer. Die Zellen wurden 5 min in PBS gewaschen und mit dem jeweiligen Fluoreszenz-markierten Sekundärantikörper in entsprechender Verdünnung 2 h bei RT inkubiert. Nach intensivem Waschen in 1x PBS wurden die Präparate in Vectashield/ DAPI eingedeckt. Unter dem Mikroskop (BX60, Olympus) wurden die immunzytochemischen Präparate analysiert, fotografiert und mit dem analySIS-Programm CellF (soft imaging GmbH) bearbeitet.

\subsubsection{Subzelluläre Lokalisation von Fusionsproteinen}

Für die subzelluläre Lokalisation von Leupaxin und -varianten wurde der jeweilige Bereich in den pEGFP-C1-Vektor kloniert (Clontech, Heidelberg). Dabei wurde beachtet, dass sich der Leserahmen nicht verändert. Es entstand ein Fusionskonstrukt, bei dem Leupaxin und varianten an den C-Terminus der EGFP-kodierenden Sequenz gekoppelt sind. PCa-Zellen wurden auf speziellen Objektträgern mit aufgesetzter Kulturflasche (FALCON culture slide) kultiviert und gemäß 2.17.3 mit den pECFP-C1-Leupaxin-Konstrukten transfiziert. Nach einer 24- bis 36-stündigen Inkubation wurden die Zellen einmal mit PBS gewaschen und für 20 min in 4\% Formaldehyd in PBS fixiert. Nach kurzem Waschen in PBS wurden die Zellen mit VectaShield/DAPI eingedeckt. Unter einem Fluoreszenz-Mikroskop (BX60, Olympus) wurden die Zellen ausgewertet und fotografiert.

\subsection{Analysen von Zelltod und Apoptose}

\subsubsection{Immunzytochemische Färbung von eukaryontischen Zellen (Caspase-3)}

Diese Analysen wurden in Kooperation mit PD Dr. Stefan Schweyer aus der Abteilung der Pathologie, Georg-August-Universtität Göttingen, durchgeführt. 
In den apototischen Signalweg sind verschiedene Gruppen von Molekülen involviert. Ein Teil dieser Vermittler der Apoptose gehört zu den Aspartat-spezifischen Cysteinyl-Proteasen oder Caspasen. Ein Mitglied dieser Familie, Caspase-3 (CPP32, Apopain, YAMA), wurde als Schlüsselprotein in der Apoptose von Säugerzellen identifiziert [Kothakota et al., 1997].

Zur Bestimmung der Caspase-3-Aktivität wurden die Zellen auf Objektträger zentrifugiert (2.18.4), getrocknet und in Aceton fixiert. Anschließend wurden sie mit dem polyklonalen Kaninchen-Antikörper gegen die humane aktive Caspase-3 (clone AF835, R\&D Systems GmbH, Wiesbaden) inkubiert. Nach Inkubation mit einem biotinylierten Sekundärantikörper und mit Alkalischer Phosphatase gekoppeltem Streptavidin (Dako) wurden die Signale mit Fast Red (Dako) sichtbar gemacht. Die Zellen wurden anschließend mit Hämalaun gegengefärbt. Positive Zellen zeigen eine rote zytoplasmatische Färbung um den klar abgegrenzten Zellkern. Die Kontrollen wurden wie oben beschrieben gefärbt, wobei Primäroder Sekundärantikörper ausgelassen wurde. Als Positivkontrollen wurden Gewebeschnitte mit tophischer Gicht verwendet [Schweyer et al., 2000].

\subsection{6 yeast-two-hybrid-Experimente}

\subsection{1 yeast-two-hybrid-Screening}

[Fields et al., 1989]

Das yeast-two-hybrid-System wurde zur in vivo-Identifizierung von putativen Interaktionspartnern (AR, GR und PGR) von Leupaxin angewendet. Es basiert auf der Tatsache, dass viele eukaryontische Transkriptionsfaktoren aus zwei funktionell unabhängigen Domänen bestehen. So enthält der GAL4-Transkriptionsaktivator der Hefe eine DNA-Bindungsdomäne (DNA-BD) und eine transkriptionsaktivierende Domäne (AD). Die DNA-BD erkennt und bindet an eine als UAS (upstream activating sequence) bezeichnete Sequenz stromaufwärts von GAL4-responsiven Domänen. Die AD interagiert mit anderen Komponenten der Transkriptionsmaschinerie, die an der Initiation der Transkription beteiligt sind. Beide Domänen sind im Normalfall Teile eines einzigen Proteins und werden gleichermaßen zur Aktivierung eines Gens benötigt. Es wurde jedoch in vivo nachgewiesen, dass die Aktivierung auch dann möglich ist, wenn die Domänen auf zwei unterschiedlichen Proteinen lokalisiert sind. Diese Tatsache wird im yeast-two-hybrid-System ausgenutzt, in dem zwei verschiedene Klonierungsvektoren benutzt werden. Der eine Vektor trägt dabei die 
DNA-BD (pGBKT7), der andere die AD (pGADT7). Die auf Interaktion hin zu untersuchenden Proteine wurden durch Integration der entsprechenden Gensequenz in die Vektoren mit den entsprechenden Interaktionsdomänen fusioniert. So wurde die Ligandenbindungsdomäne des AR, sowie die vollständigen offenen Leserahmen von PGR und GR in den Vektor pGBKT7 (2.8.7) einkloniert. Der offene Leserahmen von Leupaxin, sowie die Fragmente LPXN-LD (enthält nur die vier LD-Motive) und LPXN-LIM (enthält die vier LIM-Domänen) wurden in den Vektor pGADT7 (2.8.7) eingebracht. Beide Plasmide wurden in den Hefestamm AH109 transformiert, in dem die Fusionsproteine exprimiert und in den Zellkern transportiert werden. Im Fall einer Interaktion beider Proteine kommt es zu einer Verbindung zwischen GAL4-DNA-BD und GAL4-AD und damit zu einer funktionellen Rekonstitution des GAL4-Transkriptionsaktivators. Dieser ist daraufhin in der Lage, die Transkription von Reportergenen (ADE2, MEL1, lacZ und HIS3), die stromabwärts der GAL4-Bindungsstellen lokalisiert sind, zu aktivieren, was die Proteininteraktion phänotypisch detektierbar macht (Abb. 2.3). Der Entzug von Leucin (L) bzw. Tryptophan (T) aus dem Nährboden selektiert die Hefezellen, die mit dem pGADT7- bzw. mit dem pGBKT7-Vektor transformiert worden sind. Für die Selektion auf die Proteininteraktion wird dem Nährboden zusätzlich noch Histidin (H; Reporter: HIS3) und Adenin (Reporter: ADE2) entzogen. Eine weitere Selektion kann durch Zugabe von X- $\alpha$-Gal (Reporter: MEL1) oder X-Gal (Reporter: lacZ) durchgeführt werden.

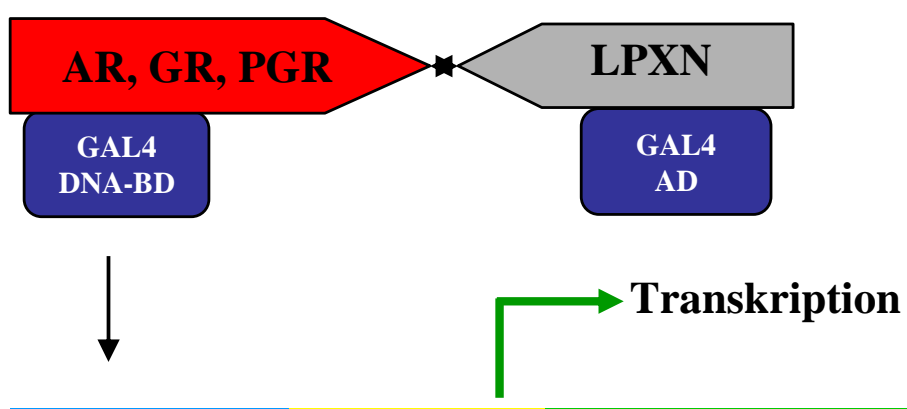

\section{GAL4 UAS Promotor MEL1, ADE2, HIS3- und lacZ}

Abb. 2.3: Schematischer Ablauf des yeast-two-hybrid-Systems. Die Interaktion zwischen AR, GR bzw. PGR und Leupaxin rekonstituiert den GAL4-Transkriptionsaktivator, was zur Expression der Reportergene MEL1, ADE2, HIS3 bzw. lacZ führt. 


\subsubsection{Transformation kompetenter Hefezellen mit Plasmid-DNA}

Es wurden 300 ml YPDA-Nährlösung mit 50 ml einer Übernachtkultur von AH109 beimpft und 2-3 h bei $30^{\circ} \mathrm{C}$ inkubiert, bis eine $\mathrm{OD}_{600}$ von $0,5 \pm 0,1$ erreicht wurde. Um kompetente Zellen zu generieren, wurde nach der Zellernte und Waschen mit sterilem Wasser das Pellet in 1,5 ml TE/Lithiumacetat-Lösung suspendiert. Das für die Transformation verfügbare Volumen belief sich auf 1,5 ml. $100 \mu$ ldieser Suspension wurden mit je 0,1 $\mu$ g Plasmid-DNA der verschiedenen Konstrukte pGADT7-LPXN und pGBKT7-AR, -GR oder -PGR und $100 \mu \mathrm{g}$ Lachsspermien-DNA $(10 \mu \mathrm{g} / \mu \mathrm{l}) \quad$ vermischt. Nach Zusatz von $600 \mu \mathrm{l}$ PEG/Lithiumacetat-Lösung wurde der Ansatz 30 min bei $30^{\circ} \mathrm{C}$ geschüttelt. Anschließend wurden $70 \mu \mathrm{LMSO}$ zugefügt und die Zellen 15 min lang einem $42^{\circ} \mathrm{C}$-Hitzeschock ausgesetzt. Die so behandelten Zellen wurden auf Eis abgekühlt, pelletiert und in 0,5 ml TEPuffer suspendiert. Von dieser Suspension wurden $250 \mu \mathrm{l}$ auf einem SD/-LTH Selektivnährboden ausgestrichen und bei $30^{\circ} \mathrm{C}$ für 3-4 Tage inkubiert.

\subsubsection{Interaktionsnachweis von Leupaxin und AR, GR und PGR über Selektion}

Durch die Selektion sollte gezeigt werden, dass das DNA-BD/AR (bzw. GR oder PGR)Fusionsprotein mit dem AD/LPXN-Fusionsprotein interagiert. Da der verwendete Hefestamm AH109 vier Reportergene (ADE2, HIS3, MEL1 (kodiert für $\alpha$-Galaktosidase) und lacZ (kodiert für $\beta$-Galaktosidase)) besitzt, die alle unter der Kontrolle des GAL4Transkriptionsaktivators stehen, jedoch verschiedene Promotoren haben, ist eine bis zu Vierfach-Selektion der erhaltenen Transformanten möglich. Die Selektion HIS3- und ADE2exprimierender Zellen erfolgte durch ihre Fähigkeit zum Wachstum auf SD/-LTHANährboden. Die hier erhaltenen Kolonien wurden darüber hinaus auf die Expression des MEL1-Gens bzw. auf die Aktivität der $\alpha$-Galaktosidase getestet. Dazu wurde auf die hochstringenten Platten (SD/-LTHA) X- $\alpha$-Gal ausgestrichen. Sofern das (künstliche) Substrat $\mathrm{X}-\alpha$-Gal durch die $\alpha$-Galaktosidase umgesetzt wurde, zeigten die entsprechenden Kolonien nach einigen Stunden eine Blaufärbung. 


\subsubsection{Quantitativer $\alpha$-Galaktosidase-Assay}

Der quantitative $\alpha$-Galaktosidase-Assay kann zur Detektion und Quantifizierung der $\alpha$ Galaktosidase-Aktivität von Hefe benutzt werden. Diese Aktivität beruht auf der Expression des MEL1-Reportergens.

In $3 \mathrm{ml} \mathrm{SD/-LTHA-Medium} \mathrm{wurden} \mathrm{Hefekolonien} \mathrm{resuspendiert} \mathrm{und} \mathrm{für} 48 \mathrm{~h}$ bei $30^{\circ} \mathrm{C}$ unter Schütteln inkubiert. Nach der Inkubationszeit wurde zunächst die $\mathrm{OD}_{600}$ bestimmt. Anschließend wurde $1 \mathrm{ml}$ der Kultur in ein Eppendorf-Gefäß gegeben und bei 16000x g für 2 min zentrifugiert. Der Überstand wurde in ein neues Gefäß gegeben. Davon wurden $16 \mu l$ zusammen mit $48 \mu \mathrm{l}$ frisch angesetztem Assay-Puffer als Triplikate auf eine 96well-Platte gegeben und für $60 \mathrm{~min}$ bei $30^{\circ} \mathrm{C}$ inkubiert. Anschließend wurden $136 \mu \mathrm{l}$ 10x Stop-Lösung dazu pipettiert und die optische Dichte bei 410 nm gemessen. Die Auswertung erfolgte mit folgender Formel:

$\mathrm{OD}_{410} \times \mathrm{V}_{\mathrm{f}} \times 1000 /\left[(\varepsilon \times \mathrm{b}) \times \mathrm{t} \times \mathrm{V}_{\mathrm{i}} \times \mathrm{OD}\right]$

$\mathrm{t} \quad=$ Inkubationszeit in $\min (60 \mathrm{~min})$

$\mathrm{V}_{\mathrm{f}} \quad=$ Endvolumen des Assays $(200 \mu \mathrm{l})$

$\mathrm{V}_{\mathrm{i}} \quad=$ Volumen des hinzugefügten Überstandes $(16 \mu \mathrm{l})$

$\mathrm{OD}_{600}=$ optische Dichte der Übernachtkultur

$(\varepsilon \times b)=$ molare Absorbtion von p-Nitrophenol aus $410 \mathrm{~nm} \times$ Lichtweg der Küvette $=10,5(\mathrm{ml} / \mu \mathrm{mol})$ bei $200 \mu \mathrm{l}$ Endvolumen

\subsection{Koimmunopräzipitation}

Mit Hilfe der Immunpräzipitation lassen sich Proteine gezielt aus einem Zelllysat isolieren. Hierzu werden spezifische Antikörper benutzt, die an eine Matrix gebunden sind. Die Proteine binden somit über den Antikörper an die Matrix und können durch Zentrifugation von den übrigen Proteinen getrennt werden. Als Matrix wird normalerweise an Agarose gebundenes Protein A, G oder L benutzt. Durch nachfolgende SDS-PAGE und Western BlotAnalysen lassen sich unter anderem Protein-Proteininteraktionen nachweisen (Koimmunopräzipitation). Hierfür werden zwei verschiedene Antikörper verwendet, die für 
die beiden zu untersuchenden Proteine spezifisch sind. Der eine Antikörper wird für die Immunpräzipitation verwendet und an die Matrix gebunden, der jeweils andere für die Western Blot-Analyse eingesetzt. Interagieren die beiden Proteine, so werden beide zusammen als Komplex an die Matrix gebunden und können aufgereinigt werden. Nach Auftrennung über SDS-PAGE kann mit dem zweiten Antikörper, der gegen das jeweils andere Protein gerichtet ist, die Interaktion nachgewiesen werden.

Zum Nachweis der Interaktion von Leupaxin mit dem AR wurde die PCa-Zelllinie LNCaP in zwei große Zellkulturflaschen so ausplattiert, dass sie am nächsten Tag eine 80-90\%ige Konfluenz erreicht haben. Die LNCaP-Zellen wurden mit den Vektoren pTriEx-LPXN und pSG5-AR transfiziert (2.17.3) und das Transfektionsmedium nach 4 h gegen Komplettmedium ausgetauscht. Nach 24 h Inkubation wurde zum Serumentzug erneut das Medium gewechselt und durch RPMI-Medium ohne FKS ausgetauscht. Anschließend wurden die Zellen der einen Flasche mit 100 nM DHT stimuliert, während die andere Flasche als nicht stimulierte Kontrolle verwendet wurde.

Zum Nachweis der Interaktion von Leupaxin mit den Steroidhormonrezeptoren GR und PGR wurde ein stabil transfizierter LNCaP-Zellklon (Abschnitt 2.17.4, K 44/49) verwendet, der Leupaxin bei Induktion mit Doxycyclin überexprimiert. Nach Ausplattieren des Zellklons 44/49 in je zwei große Zellkulturflaschen wurde eine Transfektion mit den entsprechenden Vektoren pEGFP-C1-hGR bzw. pEGFP-C1-hPGR (2.17.3) durchgeführt. Nach Serumentzug über Nacht wurde je eine Kulturflasche mit 100 nM Dexamethason (für GR) oder mit 100 nM $\mathrm{P}_{4}$ (für PGR) stimuliert. Die jeweils andere Flasche wurde als nicht stimulierte Kontrolle verwendet.

Die folgenden Koimmunopräzipitationen erfolgten für alle Interaktionsnachweise gleich nach einem veränderten Protokoll des Protein G-CoIP Kits der Firma Sigma-Aldrich:

Für die Zelllyse wurden 0,7 ml 1x IP Puffer, dem $5 \mu \mathrm{g} / \mathrm{ml}$ Aprotinin, Pepstatin und Leupeptin, $1 \mathrm{mM} \mathrm{Na}_{3} \mathrm{VO}_{4}, \mathrm{NaF}$ und PMSF beigefügt wurden, auf die Zellen gegeben. Das Lysat wurde 5 min auf Eis gestellt und anschließend bei $4^{\circ} \mathrm{C}$ für 10 min bei 12000 x g zentrifugiert. Der Überstand wurde in ein neues Eppendorf-Gefäß überführt und davon die Proteinkonzentration bestimmt. Pro Immunpräzipitation (IP) wurde mindestens $1 \mathrm{mg}$ Proteine benötigt. Die entsprechenden Mengen Proteinlösung und Antikörper wurden in ein Eppendorf-Gefäß gegeben und das Volumen der Lösung mit 1x IP Puffer auf $600 \mu$ l aufgefüllt.

Für AR:

$\alpha$-LPXN C/G $10 \mu \mathrm{g} / \mathrm{IP}$

Für GR und PGR: $\quad \alpha$-GFP $\quad 2 \mu \mathrm{g} / \mathrm{IP}$ 
Anschließend wurden die Ansätze über Nacht bei $4^{\circ} \mathrm{C}$ auf einem Rotationsschüttler inkubiert. Dann wurde die Protein-G- bzw. A-Agarose vorbereitet. Pro IP wurden je $30 \mu \mathrm{l}$ der ProteinAgarose (A und G) mit $1 \mathrm{ml}$ 1x IP-Puffer gewaschen, indem vorsichtig gevortext und anschließend bei 12000 x g zentrifugiert wurde. Der Überstand wurde vorsichtig abgenommen und der Waschschritt noch 2x wiederholt. Anschließend wurden die Agaroseperlen in $50 \mu \mathrm{l} \mathrm{1x}$ IP-Puffer aufgenommen und die Protein-G- und A-Agarose miteinander vermengt. Nach der Inkubation wurden von diesem Gemisch $60 \mu \mathrm{l}$ zu dem Protein-Antikörper-Gemisch gegeben und diese für weitere $2 \mathrm{~h}$ bei $4^{\circ} \mathrm{C}$ auf dem Rotationsschüttler inkubiert. Zur Präzipitation der Protein-Antikörper-Komplexe wurden die Ansätze für 15 sec bei 12000 x g zentrifugiert und der Überstand entnommen. Zum Waschen wurden jeweils $700 \mu \mathrm{l}$ des 1x IP-Puffers auf das Pellet gegeben, vorsichtig resuspendiert und erneut zur Präzipitation zentrifugiert. Der Waschschritt wurde 3x wiederholt. Anschließend wurde der NuPAGETMLDS Sample-buffer (4x) 1:1 mit PBS gemischt und $50 \mu$ davon auf jedes Pellet zur Elution der noch gebundenen Proteine gegeben. Diese wurden für 10 min bei $95^{\circ} \mathrm{C}$ unter leichtem Schütteln auf dem Thermomixer inkubiert und anschließend zentrifugiert. Der die eluierten Proteine enthaltende Überstand wurde entnommen und für die nachfolgende Western Blot-Analyse eingesetzt. Für den Nachweis der Leupaxin-ARInteraktion wurde ein Antikörper gegen AR eingesetzt, für GR und PGR der Leupaxinspezifische Antikörper.

\subsection{Transaktivierungsassay}

Um zu testen, ob Leupaxin eine aktivierende Funktion in Bezug auf die Steroidhormonrezeptoren AR, GR und PGR besitzt, wurden Transaktivierungsassays durchgeführt. Hierbei werden sog. Reportergene verwendet, z.B. Luciferase, deren Expression von Promotoren kontrolliert wird, die artifizielle oder natürliche Bindungsstellen des zu untersuchenden Transkriptionsfaktors aufweisen. Ist der Rezeptor in der Lage an die spezifische Bindungssequenz zu binden, wird die Transkriptionsrate der Luciferase beeinflusst, deren Aktivität leicht zu messen ist. In diesem Fall wurden zwei verschiedene Reporterkonstrukte verwendet. Das Konstrukt rPb-Luc enthält das Luciferase-Gen unter der Kontrolle des Minimalpromotors des Ratten-Probasins (2.8.7) und wurde für die Messung der Transaktivierung des AR eingesetzt. Probasin selbst ist ein AR-reguliertes Gen in der Prostata 
von Ratten und Mäusen und enthält sog. androgen response elements (AREs). Der Minimalpromotor des Ratten-Probasins wurde bereits von Greenberg et al. [1994] näher charakterisiert, und es wurde gezeigt, dass er spezifisch durch den Androgenrezeptor reguliert wird. Als zweites Reporterkonstrukt für die Messung der Aktivierung des AR sowie für GR und PGR wurde das Plasmid MMTV-Luc eingesetzt, welches uns freundlicherweise von Dr. R. Schüle (Molekulare Gynäkologie, Universität Freiburg) zur Verfügung gestellt wurde. Dieses Konstrukt enthält das Luciferase-Gen unter der Kontrolle des mouse mammary tumor virus (MMTV)-Promotors, von dem bekannt ist, dass er durch Steroidhormonrezeptoren wie AR, GR und PGR aktiviert wird. Wenn die Rezeptoren mit ihrem entsprechenden Liganden stimuliert werden, können sie an die hormon-responsiven Elemente in den beiden Promotoren rPb und MMTV binden, woraufhin die Transkription des Luciferase-Gens stattfindet. Zur Überprüfung der Transfektionseffizienz wird ein Kontrollplasmid kotransfiziert, dass nicht von der Aktivität des Rezeptors abhängt. Hier wurde das für $\beta$-Galaktosidase kodierende Plasmid pCMV- $\beta$-Gal (2.8.7) verwendet.

\subsubsection{Quantitativer Nachweis von Reporterenzymen}

Der quantitative Nachweis der Aktivität der Reporterenzyme Luciferase und $\beta$-Galaktosidase erfolgte über die Messung von Lichtemissionsreaktionen in RLUs (relative light units) in einem Luminometer (Typ LB 953, Fa. Berthold, Bad Wildbad). Das rekombinante Gen des Enzyms Luciferase aus dem Leuchtkäfer Photimus pyralis [de Wet et al., 1987] wird als Reportergen verwendet (Halbwertszeit in transfizierten Zellen ca. 3 h, [Thompson et al., 1993]), da die auf die Oxidation des Käfer-Luciferins zurückzuführende Biolumineszenzreaktion gut nachgewiesen werden kann. Nach der automatischen Injektion des Substrates durch das Luminometer startet die lichtemittiernde Reaktion in $<1$ sec und ist bei einer Zugabe von Substrat im Überschuss über einen bestimmten Zeitraum proportional zur Luciferase-Aktivität der Probe. Dies erlaubt eine indirekte Bestimmung der Transkription des Reportergens. In der ATP- und $\mathrm{Mg}_{2}{ }^{+}$-abhängigen Reaktion wird zunächst eine Acyl-AMP Zwischenstufe gebildet, die in Gegenwart von Sauerstoff zu Oxyluciferin oxidiert wird. Angeregtes Oxyluciferin fällt nachfolgend in den Grundzustand zurück, wobei ein Photon emittiert wird. 
Durch die Verwendung von Chemilumineszenzsubstraten ist eine Aktivitätsmessung der $\beta$ Galaktosidase im Luminometer möglich, was den linearen Bereich der Detektion erhöht und die Sensitivität gegenüber dem colorimetrischen Ansatz steigert.

\subsubsection{Luciferase-Messung}

Vor der Messung wurden die transfizierten Zellen mit Hilfe von $150 \mu$ l Lysispuffer II lysiert. In ein Well einer 96well-Platte wurden je $30 \mu \mathrm{l}$ Zelllysat und $200 \mu \mathrm{l}$ Luciferin-Assay-Puffer gegeben. Die Luciferin-Arbeitslösung wurde in einem eigenen Gefäß angesetzt, da diese automatisch vom Luminometer zu den Proben gegeben wurde. Hierbei musste immer für fünf Proben mehr angesetzt werden, da vor dem Messen der Schlauch des Luminometers mit der Arbeitslösung gespült wurde.

Zum Starten der Lichtreaktion wurden $100 \mu$ der Luciferin-Injektionslösung durch einen Injektor des Luminometers eingespritzt und die nachfolgende Lichtemission nach Verstreichen einer Vorlaufzeit von 20 sec über weitere 20 sec integriert.

\subsection{3 $\beta$-Galaktosidase-Messung}

[Jain et al., 1991]

Die Chemilumineszenzmessung der $\beta$-Galaktosidase-Aktivität erfolgte unter Verwendung von $10 \mu$ desselben Zellextrakts wie zur Luciferasebestimmung mit dem Galacto-Light-Kit (Fa. Tropix, Bedford, USA). Das als Stocklösung vorliegende chemilumineszente Substrat Galacton wurde 1:100 mit dem gelieferten Reaktionspuffer verdünnt und $70 \mu \mathrm{l}$ pro Well in das für „Schlauch 1“ vorgesehene Messröhrchen des Luminometers vorgelegt. Das Substrat und der Reaktionspuffer (Light Emission Accelerator) wurden automatisch durch das Luminometer zu den Proben injiziert. In einem Abstand von $30 \mathrm{sec}$ wurde eine erste Messung durchgeführt, daran schloss sich eine Inkubationszeit von 60 min bei Raumtemperatur an. Anschließend erfolgte eine weitere Messung. Die Inkubationszeit mit Reaktionspuffer sollte für jede Probe identisch sein, da die Signalintensität mit der Inkubationszeit variiert. Der durch das Luminometer injizierte Light Emission Accelerator enthält modifizierten „Emerald Lumineszenz-Verstärker“, der gleichzeitig den nichtenzymatischen Hintergrund reduzieren soll. 


\subsubsection{Auswertung der Reportergen-Messungen}

Die erhaltenen Werte aus der $\beta$-Galaktosidase-Messung spiegeln die Transfektionseffizienz wieder, da die Galaktosidase in den Zellen unabhängig von anderen Proteinen gebildet wird. Somit sind die erhaltenen Werte aus der Luciferase-Aktivität mit denen der $\beta$-GalaktosidaseMessung abzugleichen, indem die Werte der Luciferase- durch die der GalaktosidaseAktivität dividiert werden. Die so erhaltenen Werte wurden miteinander verglichen und die Aktivität der Luciferase mit der Aktivität von AR, GR bzw. PGR gleichgesetzt.

\subsection{Transgene Mäuse}

\subsubsection{Vorbereitung und Injektion des transgenen Leupaxin-Konstrukts}

Zur Herstellung weiterer transgener Mauslinien mit Prostata-spezifischer LeupaxinExpression wurde das Konstrukt pBS(SK)-rPb-Pr-hLPXN-cmyc-3’UTR-LPXN verwendet [Herr, 2005]. Das Leupaxin-Konstrukt wurde mit Hilfe der Restriktionsenzyme aus dem pBS(SK)-Vektor isoliert und über Gelelektrophorese aufgetrennt. Das DNA-Fragment wurde mit dem QiaExII Gel Extraction Kit (Qiagen) aus dem Agarosegel isoliert, anschließend zusätzlich Ethanol-präzipitiert und in den Mikroinjektionspuffer (5 mM Tris pH 7.4/ 0,1 mM

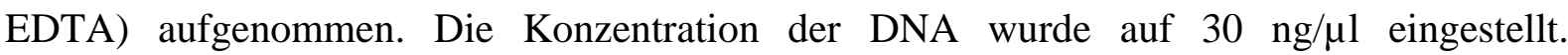
Anschließend wurde die DNA durch zweimaliges Zentrifugieren weiter aufgereinigt. In Zusammenarbeit mit Herrn Dr. Riedesel (MPI für Experimentelle Medizin, Göttingen) wurde die DNA nach erfolgter Aufreinigung in den männlichen Pronukleus von befruchteten Mäuseeizellen mikroinjiziert. Die Oozyten wurden dann scheinschwangeren Mäusen der Linie FVB reimplantiert.

\subsubsection{Isolierung genomischer DNA aus Organen}

Die Isolierung genomischer DNA der Maus für die Southern Blot- und Taqman-Analysen erfolgte aus der Schwanzspitze der Mäuse. Dabei wurden 0,5 bis $1 \mathrm{~cm}$ der Schwanzspitze von etwa 3 Wochen alten Mäusen in $700 \mu$ l Lysis-Puffer unter Zugabe von $30 \mu$ Proteinase K (10 $\mathrm{mg} / \mathrm{ml}$ ) bei $55^{\circ} \mathrm{C}$ über Nacht unter Schütteln inkubiert. Nach einer Phenol/Chloroform- 
Extraktion (1:1, siehe Abschnitt 2.9.5) wurde die DNA mit $500 \mu$ l Isopropanol und anschließender Zentrifugation (12000 x g, 10 min, RT) präzipitiert. Nach einem Waschschritt

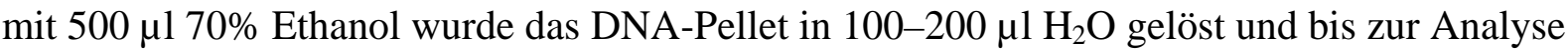
bei $4^{\circ} \mathrm{C}$ gelagert.

Für die Genotypisierung der Mäuse wurde das DirectPCR (tail) Reagent (PEQlab, Erlangen) zum Präparieren der genomischen DNA nach Herstellerangaben verwendet.

\subsubsection{Kopienzahlbestimmung bei transgenen Mäusen (T/- vs. T/T)}

Um zu bestimmen, welche Mäuse der $F_{2}$-Generation homozygot für das Leupaxin-Konstrukt sind, wurden Taqman-Analysen durchgeführt (siehe Abschnitt 2.14.3). Dazu wurde die Kopienzahl der heterozygot transgenen Elterntiere mit der der Nachkommen verglichen. Als homozygot wurden nur die transgenen Leupaxin-Mäuse deklariert, die die doppelte Kopienzahl im Vergleich zu den Elterntieren aufwiesen.

\subsection{Histologische Techniken}

Die folgenden histologischen Methoden wurden in Zusammenarbeit mit PD Dr. Bernhard Hemmerlein (Abteilung Pathologie, Universität Göttingen) durchgeführt.

\subsubsection{Fixierung des Gewebes}

Das frisch präparierte Material wurde direkt in Bouin'sches Fixativ gegeben und je nach Größe des Präparates für eine Stunde bis zu 2 Tagen bei RT fixiert. Mit Hilfe einer aufsteigenden Alkoholreihe (50\%, 70\%, 90\% und 96\%) wurde das Gewebe entwässert. Um das Ethanol vor der Einbettung in das Paraffin vollständig zu entfernen, wurde das Gewebe über Nacht in Methylbenzoat inkubiert. Für die Einbettung wurde das Paraffin im Wasserbad bei $58^{\circ} \mathrm{C}$ geschmolzen. Die Einbettung bestand aus mehreren Schritten, die sämtlich bei $58^{\circ} \mathrm{C}$ durchgeführt wurden. Für die Entfernung des Methylbenzoats wurde das Gewebe zweimal mit Benzol und zweimal in einem 1:1 Benzol/Paraffin-Gemisch jeweils für $1 \mathrm{~h}$ inkubiert. Zur vollständigen Durchdringung des Gewebes mit dem Paraffin wurde das Präparat anschließend 
zweimal für $1 \mathrm{~h}$ in Paraffin inkubiert. Im Anschluss daran wurde die auf $58^{\circ} \mathrm{C}$ temperierte Einbettungsform etwa zur Hälfte mit geschmolzenem Paraffin gefüllt, das Gewebe in die Form überführt und mit Paraffin aufgefüllt. Nach der Aushärtung über Nacht wurde der Paraffinblock aus der Form entnommen und bei $4^{\circ} \mathrm{C}$ gelagert.

\subsubsection{Vorbehandlung der Objektträger}

Die Objektträger wurden $20 \mathrm{~min}$ in $0,1 \mathrm{M} \mathrm{HCl}$ gekocht und danach $2 \mathrm{x} 5$ min in $\mathrm{H}_{2} \mathrm{O}$ gewaschen. Anschließend wurden die Objektträger für $30 \mathrm{~min}$ in $96 \%$ Ethanol gelegt, getrocknet und über Nacht in 1x Denhardt's Lösung inkubiert. Nach 20minütiger Fixierung in Ethanol/Eisessig (3:1) wurden die Objektträger in einer absteigenden Alkoholreihe (96\%, $70 \%$, 50\%, 30\% Ethanol, je $5 \mathrm{~min}$ ) rehydriert und über Nacht bei $70^{\circ} \mathrm{C}$ in $1 \%$ Organosilan $(\mathrm{pH} 3,4)$ inkubiert. Schließlich wurden sie $5 \times 5$ min in $\mathrm{H}_{2} \mathrm{O}$ gewaschen und über Nacht bei $100^{\circ} \mathrm{C}$ gebacken. In diesem Zustand können die beschichteten Objektträger bis zu sechs Monate aufbewahrt werden. Die Aktivierung der Objektträger erfolgte in 10\% Glutaraldehyd in PBS, pH 7,0, für 30 min. Anschließend wurden sie 5 min in $\mathrm{H}_{2} \mathrm{O}$ gewaschen, bevor die Aktivierung in 0,1 M Natrium-Perjodat 15 min unter dem Abzug stabilisiert wurde. Schließlich wurden die Objektträger $3 \mathrm{x}$ in PBS gewaschen und über Nacht bei $42^{\circ} \mathrm{C}$ getrocknet. Im aktivierten Zustand können die Objektträger mindestens 8 Wochen verwendet werden.

\subsubsection{Herstellung der Paraffinschnitte}

Die Paraffinblöcke mit dem fixierten Gewebe wurden zu Quadern geeigneter Größe zurechtgeschnitten und in das Mikrotom (JUNG RM 2035, Leica) eingespannt. Die Schnittdicke betrug 5-7 $\mu \mathrm{m}$. Mit Hilfe eines feinen Pinsels wurden die Schnitte auf $58^{\circ} \mathrm{C}$ warmes Wasser gelegt, mit einem Objektträger aufgenommen und getrocknet. Bis zur weiteren Verwendung wurden die Schnitte bei $4^{\circ} \mathrm{C}$ gelagert. 


\subsubsection{Immunlokalisierung von Proteinen in Paraffingewebeschnitten}

Zunächst wurden die Schnitte 2x 10 min in Xylol deparaffiniert, in einer absteigenden Alkoholreihe (100\% Ethanol für 1x 5 min und 1x 2 min, 96\%, 70\% Ethanol für je 5 min) rehydriert und in $\mathrm{H}_{2} \mathrm{O}$ (5 min) gespült. Die Gewebeschnitte wurden $45 \mathrm{~min}$ in einem Dampfgarer gekocht. Nach 20 min Abkühlzeit wurden sie für 5 min mit $\mathrm{H}_{2} \mathrm{O}$ gespült und kurz in $\mathrm{H}_{2} \mathrm{O}_{\text {dd }}$ getaucht. Die überschüssige Flüssigkeit wurde abgesaugt und unspezifische Bindungsstellen wurden 20 min mit 3\% $\mathrm{H}_{2} \mathrm{O}_{2}$ abgesättigt. Danach wurde erneut 5 min mit $\mathrm{H}_{2} \mathrm{O}$ gespült und die Gewebeschnitte kurz in $\mathrm{H}_{2} \mathrm{O}_{\text {dd }}$ und TBS getaucht. Anschließend wurde 20 min mit BSA geblockt. Auf das Präparat wurde der Primärantikörper (LPXN, Klon G, 1:500) gegeben und $2 \mathrm{~h}$ bei RT inkubiert. Unspezifische Antikörper-Bindungen wurden in TBS 3x 2 min abgewaschen. Der Zweitantikörper (HRP) wurde entsprechend den Firmenempfehlungen (DAKO EnVision) in TBS verdünnt. Nach 30 min Inkubation in einer feuchten Kammer wurden nicht gebundene Antikörper 3x 2 min in TBS ausgewaschen. Die DAB-Chromogen-Färbung erfolgte während einer Inkubationszeit von 15 min bei RT. Die Reaktion wurde mit TBS abgestoppt und die Gewebeschnitte anschließend 5 min in $\mathrm{H}_{2} \mathrm{O}$ gewaschen. Danach wurde 8 min mit Hämalaun gegengefärbt. Die Gewebeschnitte wurden für 10 min unter fließendem Leitungswasser gebläut und anschließend eingedeckelt.

\subsubsection{Der immunoreactive score zur Quantifizierung der Leupaxin-Expression in humanen Prostatakarzinomen}

Um die Expression von Leupaxin in humanen Prostatakarzinomen in Korrelation mit Tumorstadium, Gleason Score und Gleason-Muster der positiven Bereiche setzen zu können, mußte zunächst die Leupaxin-Expression quantifiziert werden. Dazu wurde ein additives Punktesystem (immunoreactive score $=$ IRS $^{\mathrm{LPXN}}$ ) verwendet, das sich aus der durchschnittlichen Signalstärke (dS) und der Anzahl Leupaxin-positiver Tumorzellen zusammensetzt (ALP; Tab. 2.II). Für die vergleichenden Analysen der LeupaxinImmunreaktivität mit dem Gleason Score und Gleason-Muster wurde der Fisher's exact test angewendet. 
Tab. 2.II: Zusammensetzung des IRS ${ }^{\mathrm{LPX}}$

\begin{tabular}{c|c|c|c|c}
\hline & 0 & 1 & 2 & 3 \\
\hline dS & negativ & niedrig & intermediär & hoch \\
\hline ALP & $\begin{array}{c}\text { keine LPXN- } \\
\text { positiven Zellen }\end{array}$ & $\begin{array}{c}0-10 \% \text { LPXN- } \\
\text { positive Zellen }\end{array}$ & $\begin{array}{c}10-50 \% \text { LPXN- } \\
\text { positive Zellen }\end{array}$ & $\begin{array}{c}>50 \% \text { LPXN- } \\
\text { positive Zellen }\end{array}$ \\
\hline
\end{tabular}

\subsection{Phospho-MAPK-Array}

Zur Analyse, in welche Signalwege Leupaxin involviert ist und welche Signalwege für die morphologischen Änderungen in androgen-abhängigen LNCaP-Zellen verantwortlich sind, wurde ein sog. Phospho-MAPK-Array (R\&D Systems, Wiesbaden) verwendet.

Der Phosho-MAPK-Array stellt ein Antikörper-Array zur Detektion spezifischer phosphorylierter Proteine des MAPK ( $\underline{\text { mitogen }}$ activated protein kinase) -Signalweges dar. Auf der Nitrocellulosemembran befinden sich in Duplikaten Fang- und Kontroll-Antikörper die gegen die 21 Mitglieder dieses Signaltransduktionswegs gerichtet sind (Abb. 2.4, 1.). Das zu untersuchende Zelllysat wird mit den Membranen inkubiert, wobei die phosphorylierten und nicht phosphorylierten Kinasen binden (Abb. 2.4, 2.), während nicht gebundenes Material weggewaschen wird. Anschließend wird ein Cocktail von biotinylierten Antikörpern zugegeben, die gegen die verschiedenen Phosphorylierungsstellen der Kinasen gerichtet sind (Abb. 2.4, 3.). Zur Detektion wird Streptavidin-gekoppelte HRP und ein ChemilumineszenzDetektionskit verwendet (Abb. 2.4). 


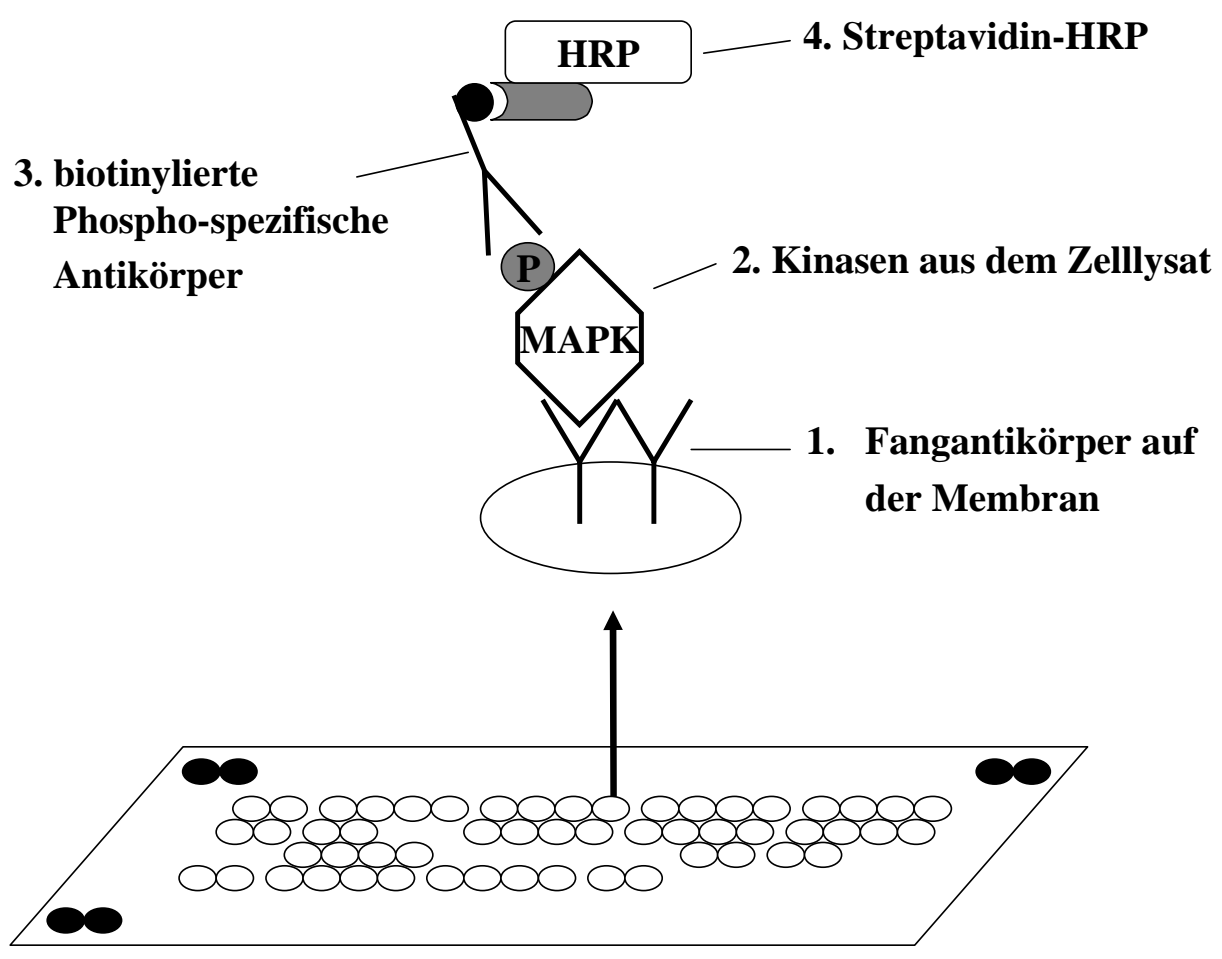

Abb. 2.4: Darstellung des Prinzips des Phospho-MAPK-Arrays. Die Kinasen im Zelllysat binden an die Fangantikörper (1. + 2.), die auf der Membran aufgespottet sind. Anschließend wird ein Cocktail bestehend aus biotinylierten Phospho-spezifischen Antikörpern zugegeben (3.). Die Detektion erfolgt mit Streptavidingekoppelter HRP und einem Chemilumineszenz-Kit (4.).

\subsubsection{Herstellung der zu untersuchenden Proteinlysate}

Zur Analyse des Phosphorylierungsstatus der Proteine des MAPK-Signalweges nach Herunterregulierung der Leupaxin-Expression wurden androgen-abhängige LNCaP-Zellen mit Leupaxin-spezifischer siRNA und zur Kontrolle mit Luciferase-spezifischer siRNA für $72 \mathrm{~h}$ transfiziert (2.20.2). Anschließend wurden die adhärenten und schwimmenden Zellen gesammelt und mit dem mitgelieferten Lysispuffer lysiert. Nach Zentrifugation bei $13000 \mathrm{x} \mathrm{g}$ für 5 min wurde der Proteingehalt des Zelllysats bestimmt (2.16.3) und eine Western BlotAnalyse zur Bestätigung der Leupaxin-Herunterregulierung mit einem Leupaxin-spezifischem Antikörper durchgeführt (2.16.5; 2.16.7). Insgesamt wurden drei verschiedene siRNATransfektionen durchgeführt und die Zelllysate mit bestätigter Leupaxin-Herunterregulierung zusammengeführt und erneut die Proteinkonzentration bestimmt. 


\subsubsection{Durchführung und Auswertung des Arrays}

Pro Probe (D-LPXNst und D-Luc) wurde $300 \mu \mathrm{g}$ Protein eingesetzt und der Array wurde nach Herstellerangaben durchgeführt. Nach der Entwicklung der Autoradiographie-Filme von unterschiedlichen Expositionszeiten wurde die mitgelieferte Schablone zur Kennzeichnung der Positiv- bzw. Negativkontrollen verwendet. Anschließend wurden die Filme eingescannt und mit Hilfe der QuantityOne Software ausgewertet, wobei jedem Signal die entsprechende Kinase sowie deren Phosphorylierungsstelle zugeordnet wurde. Zum Vergleich der beiden Array-Membranen wurden die Signale auf die Positivkontrollen normalisiert.

\subsection{Zelladhäsions-Array}

Um zu untersuchen, welche Gene für die morphologischen Änderungen und die Apoptose in LNCaP-Zellen bzw. für die Reduktion von Invasion und Migration in PC-3- und DU 145Zellen nach Herunterregulierung der Leupaxin-Expression verantwortlich sind, wurde ein Zelladhäsions-Array von der Firma SuperArray durchgeführt. Dieser Array enthält auf einer Nylonmembran cDNAs von 96 Genen, die für Zelladhäsions- und Extrazelluläre MatrixProteine kodieren. Diese ausgewählten Proteine spielen Schlüsselrollen in der Vermittlung von Zell-Zell-, Zell-Gewebe- und Zell-extrazelluläre Matrix-Interaktionen und sind in Zellwachstum, Zellteilung, Zelldifferenzierung, Migration und Apoptose involviert.

\subsubsection{Durchführung des Zelladhäsions-Arrays}

LNCaP- und PC-3-Zellen wurden zunächst mit Leupaxin-spezifischer (D-LPXN und DLPXNst) bzw. als Kontrolle mit Luciferase-spezifischer siRNA transfiziert, für 72 h inkubiert und anschließend einer RNA-Isolierung unterzogen (2.9.7). Um die RNA in radioaktivmarkierte cDNA-Proben umzuschreiben, wurde das Kit AmpoLabelling-LPR (SuperArray) verwendet. Für die Markierungsreaktion wurden jeweils $3 \mu \mathrm{g}$ RNA eingesetzt und nach dem Protokoll des Herstellers weiterbehandelt. Nach der radioaktiven Markierung wurden die Proben auf einem 1\%-TAE-Gel überprüft. Anschließend wurden zwei identische Zelladhäsionsarray-Membranen für $3 \mathrm{~h}$ bei $65^{\circ} \mathrm{C}$ in einem Rollofen prähybridisiert, die 
radioaktiv markierten Proben denaturiert und zu der Prähybridisierungslösung zugegeben. Die Hybridisierung fand bei $65^{\circ} \mathrm{C}$ über Nacht in einem Rollofen statt. Nach dem Waschen der Membranen nach Herstellerangaben wurden diese in Folie eingeschweißt und die Signale mit dem Phosphor-Imager dargestellt.

\subsubsection{Auswertung der Array-Daten}

Die über den Phosphor-Imager dargestellten Signale wurden mit Hilfe der QuantityOne Software ausgewertet. Anschließend wurden die Daten in die SuperArray-Software GEanalyzer eingespeist. Diese Software normalisiert die Werte gegen die auf der Membran vorhandenen housekeeping-Gene bzw. die durchschnittliche Signalstärke der Membran. Zudem wurden die Signale den entsprechenden Genen zugeordnet. In die späteren Analysen wurden nur Gene einbezogen, die eine Hoch- bzw. Herunterregulierung von einem Faktor über 1,5 zeigten. 


\section{Ergebnisse}

\subsection{Isolierung von Leupaxin als differentiell exprimiertes Gen im kapselinvasiven Prostatakarzinom}

Bereits in vorangegangenen Experimenten konnte mit Hilfe der Mikrodissektion und anschließender Atlas ${ }^{\mathrm{TM}}$-Array-Hybridisierung gezeigt werden, dass das Leupaxin-Gen im humanen kapselinvasiven Prostatakarzinom differentiell exprimiert wird. Die Überprüfung der aus dem Array erhaltenen Daten an weiteren acht Prostatakarzinomen mittels quantitativer real time RT-PCR zeigte in sechs Fällen eine erhöhte Leupaxin-Genexpression im zentralen Tumorgewebe gegenüber Normalgewebe. Bei den vier untersuchten Fällen mit kapselinvasiven Prostatatumorgewebeanteilen konnte eine Hochregulierung der LeupaxinGenexpression festgestellt werden, wobei in zwei dieser Fälle eine >2fach erhöhte Expression des Leupaxin-Gens nachgewiesen werden konnte [Voigt, 2003].

Um nun die zelluläre Expression von Leupaxin in humanen Prostatakarzinom-Präparaten zu untersuchen, wurden immunhistochemische Analysen mit einem Leupaxin-spezifischen Antikörper (Klon 283 G) durchgeführt. In Zusammenarbeit mit PD Dr. B. Hemmerlein (Abteilung Pathologie, Universitätsklinikum Göttingen) wurden insgesamt 59 radikale Prostatektomie- sowie neun Nadelbiopsie-Präparate auf die Expression von Leupaxin hin untersucht, wobei 13 Fälle (22\%) eine epitheliale Leupaxin-Expression ausschließlich in den Prostatakarzinom-Drüsen zeigten, nicht aber in Normalepithelzellen, hyperplastischen Drüsen oder Stromazellen (Tab. 3.I). Dabei wurden drei verschiedene Muster der LeupaxinExpression beobachtet. Das erste Muster zeigt eine starke und diffuse Leupaxin-Expression in jeder Prostatakarzinomzelle des Präparates (Abb. 3.1A). Im zweiten Muster ist die Expression von Leupaxin fokal auf bestimmte Tumorbereiche und -zellen beschränkt (Abb. 3.1B), und im dritten Muster ist keine Leupaxin-Expression in den Tumorepithelzellen zu erkennen (Abb. 3.1C). Den Tumor infiltrierende Lymphozyten und Makrophagen zeigten eine erwartet starke Leupaxin-Expression und dienten als interne Positivkontrolle. Aufgrund der meist fokalen Expression von Leupaxin konnte keine Expression in den Prostata-NadelbiopsiePräparaten beobachtet werden. 
Tab. 3.I: Ergebnisse der Expressionsanalyse von Leupaxin im humanen Prostatakarzinom mit Hilfe der Immunhistochemie. Aufgeführt sind die 13 Leupaxin-positiven Prostatakarzinom-Fälle aus insgesamt 59 untersuchten Prostatektomie-Präparaten.

\begin{tabular}{c|c|c|c|c}
\hline Fall & Tumorstadium & Gleason Score & IRSLPXN & Beschreibung \\
\hline 1 & pT3bN0Mx & 9 & $6(3+3)$ & diffus \\
2 & pT3bN1Mx & 9 & $3(2+1)$ & fokal \\
3 & pT3aN0Mx & 6 & $2(1+1)$ & fokal \\
4 & pT3aN0Mx & 7 & $3(2+1)$ & fokal \\
5 & pT2cN0Mx & 6 & $3(2+1)$ & fokal \\
6 & pT2bN0Mx & 6 & $2(1+1)$ & fokal \\
7 & pT2bN0Mx & 6 & $2(1+1)$ & fokal \\
8 & pT3aN1Mx & 8 & $5(3+2)$ & diffus \\
9 & pT2bN1Mx & 6 & $2(1+1)$ & fokal \\
10 & pT3aN0Mx & 6 & $2(1+1)$ & fokal \\
11 & pT3aN1Mx & 9 & $5(3+2)$ & diffus \\
12 & pT3bN1Mx & 8 & $5(3+2)$ & diffus \\
13 & pT3aN0Mx & 7 & $4(2+2)$ & fokal
\end{tabular}

Fall 1

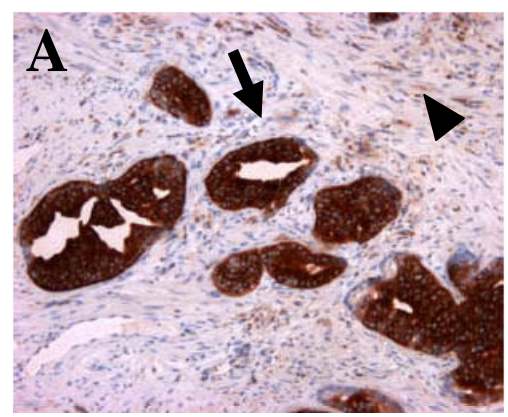

Fall 2

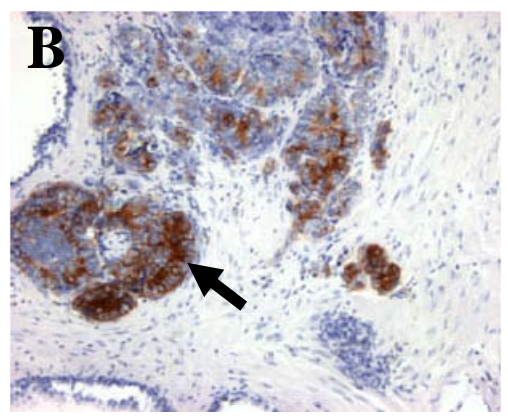

Fall 3

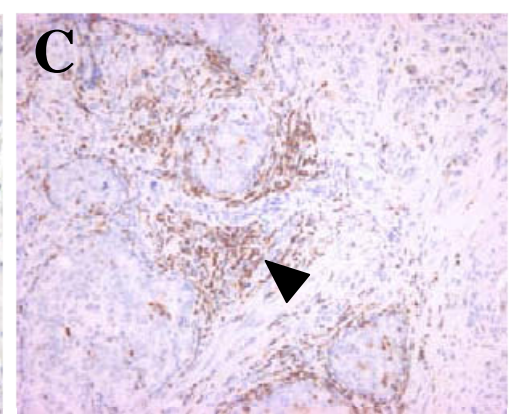

Abb. 3.1: Analyse der zellulären Expression von Leupaxin in humanen Prostatakarzinomen mittels Immunhistochemie. Gewebeschnitte von humanen Prostatektomie-Präparaten wurden mit einem Leupaxinspezifischen Antikörper (Klon 283G) gefärbt und mit Hämalaun gegengefärbt. A. Leupaxin ist in allen Zellen des Tumors (Pfeil) sowie in infiltrierenden Lymphozyten (Pfeilkopf) exprimiert. B. In diesem Fall zeigen nur einige wenige Bereiche des Karzinoms eine Leupaxin-Expression (Pfeil). Andere, auch in unmittelbarer Nachbarschaft gelegene Tumorbereiche zeigen keine Leupaxin-Expression. C. In diesem Fall konnte im Tumorepithel keine Expression von Leupaxin festgestellt werden. Allerdings sind hier besonders viele positiv gefärbte infiltrierende Lymphozyten (Pfeilkopf) zu sehen. Die Fälle 1 und 2 sind in Tab. 3.I aufgeführt; Fall 3: pT3bN1; Gleason Score 9. 
Um festzustellen, ob die Expression von Leupaxin in den Prostatakarzinomen mit dem Gleason Score des gesamten Tumors bzw. mit dem Gleason-Muster der Leupaxin-positiven Bereiche korreliert, wurde die Expression von Leupaxin in einem sog. immunoreactive score $\left(\right.$ IRS $\left.^{\text {LPXN }}\right)$ zusammengefaßt. Der IRS ${ }^{\text {LPXN }}$ stellt ein definiertes Punktesystem dar, das sowohl die Stärke der Leupaxin-Expression als auch den Anteil Leupaxin-positiver Prostatakarzinomzellen am Gesamttumor berücksichtigt (siehe 2.27.5). Ein Vergleich des IRS $^{\text {LPXN }}$ mit dem Gleason-Muster Leupaxin-positiver Tumorbereiche zeigt, dass ein hoher IRS $^{\text {LPXN }}$ signifikant mit einem Gleason-Muster von 4 und 5 assoziiert ist, wohingegen ein niedriger IRS ${ }^{\mathrm{LPXN}}$ mit einem Gleason-Muster von 2 und 3 korreliert $(\mathrm{p}=0,0008$, Fisher's exact test, Tab. 3.II). Auch der Vergleich des IRS ${ }^{\text {LPXN }}$ mit dem gesamten Gleason Score eines Prostatakarzinoms bestätigt diese Ergebnisse ( $\mathrm{p}=0,02$, Chi $^{2}$-Test, Tab. 3.III). Damit konnte gezeigt werden, dass die Leupaxin-Expression signifikant mit der Progression des Prostatakarzinoms korreliert.

Tab. 3.II: Vergleich des IRS ${ }^{\text {LPXN }}$ der Leupaxin-positiven Prostatakarzinome mit dem Gleason-Muster der positiven Tumorbereiche.

\begin{tabular}{cc|cc}
\hline & & \multicolumn{2}{|c}{ Gleason-Muster } \\
& & $1-3$ & $4-5$ \\
\hline \multirow{2}{*}{ IRS $^{\text {LPXN }}$} & niedrig (1-3) & 8 & 0 \\
& hoch (4-6) & 0 & 5 \\
\hline
\end{tabular}

Tab. 3.III: Vergleich des IRS ${ }^{\mathrm{LPXN}}$ der untersuchten Prostatakarzinome mit dem Gleason Score.

\begin{tabular}{ll|cc}
\hline & & \multicolumn{2}{|c}{ Gleason Score } \\
& negativ & $2-6$ & $>6$ \\
\hline \multirow{2}{*}{ IRS $^{\text {LPXN }}$} & niedrig (1-3) & 26 & 20 \\
& hoch (4-6) & 6 & 2 \\
& & 0 & 5 \\
\hline
\end{tabular}




\title{
3.2 Expression von Leupaxin in etablierten Prostatakarzinomzelllinien
}

Es wurde die Expression von Leupaxin in den etablierten Prostatakarzinom(PCa-)zelllinien LNCaP, PC-3 und DU 145 mittels Western Blot-Analyse untersucht. Wie in Abbildung 3.2A zu erkennen, exprimieren die androgen-abhängigen, nicht invasiven LNCaP-Zellen Leupaxin nur sehr schwach, wohingegen die androgen-unabhängigen, invasiven PC-3- und DU 145Zellen Leupaxin stark exprimieren. Als Positivkontrolle diente die Burkitt-LymphomZelllinie Daudi, die die stärkste Leupaxin-Expression zeigt (Abb. 3.2A). Um die Expression von Leupaxin in den verschiedenen PCa-Zelllinien zu quantifizieren, wurden die Western Blots densitometrisch ausgewertet. Im Vergleich zu den LNCaP-Zellen ist zu erkennen, dass die PC-3-Zellen eine 6fach und die DU 145-Zellen eine 2fach höhere Leupaxin-Expression zeigen (Abb. 3.2B). Demnach ist auch bei den PCa-Zelllinien festzustellen, dass die Leupaxin-Expression in den Zellmodellen des fortgeschritteneren Prostatakarzinoms (PC-3 und DU 145) stärker exprimiert ist als im Zellmodell des androgen-abhängigen, frühen Stadiums des Prostatakarzinoms (LNCaP).
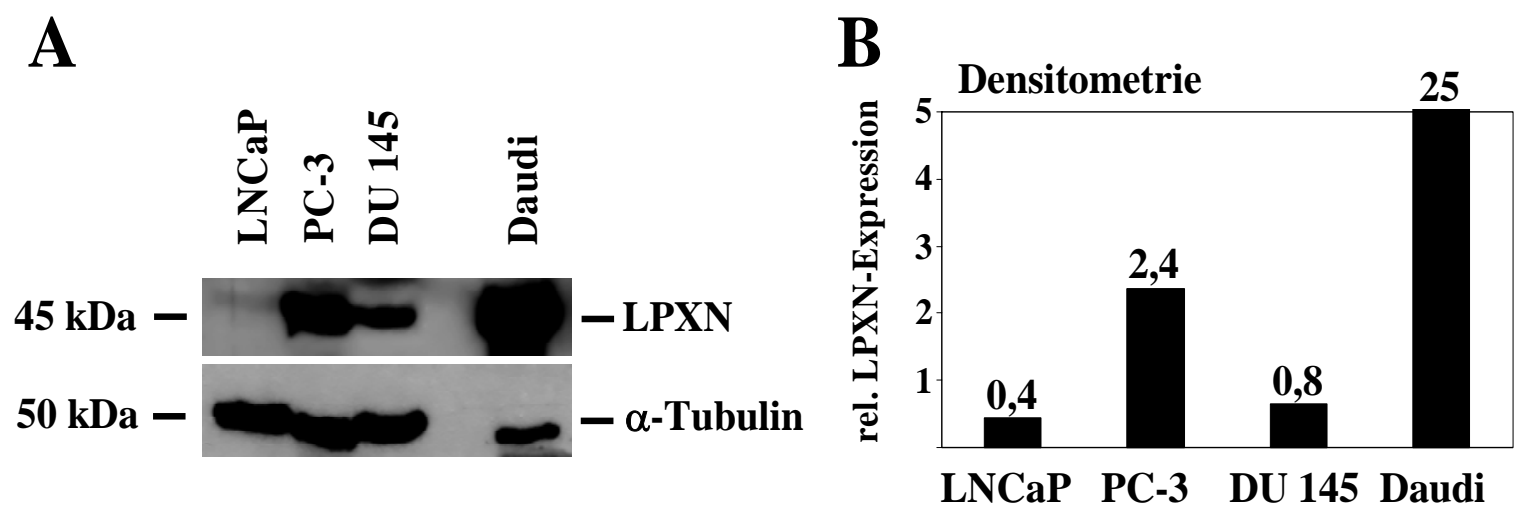

\begin{abstract}
Abb. 3.2: Expression von Leupaxin in etablierten Prostatakarzinomzelllinien. A. Aus den PCa-Zelllinien LNCaP, PC-3 und DU 145 sowie der Burkitt-Lymphom-Zelllinie Daudi (Positivkontrolle) wurden GesamtProteine isoliert und einer Western Blot-Analyse unterzogen. Verwendet wurde dazu ein Leupaxin-spezifischer Antikörper (283G), der eine spezifische Bande bei der für Leupaxin erwarteten Größe von 45 kDa darstellt. Zur Kontrolle der aufgetragenen Proteinmengen wurde ein Antikörper gegen $\alpha$-Tubulin verwendet. B. Densitometrische Auswertung des Western Blots. Der Western Blot wurde eingescannt und mit Hilfe des Phosphor-Imagers und der QuantityOne Software densitometrisch ausgewertet. Dargestellt wurde die relative Leupaxin-Expression, die sich aus dem Verhältnis der Bandenintensitäten des Leupaxin- und des $\alpha$-TubulinSignals ergibt.
\end{abstract}




\subsection{Subzelluläre Expression von Leupaxin in den PCa-Zelllinien}

Um die subzelluläre Expression von Leupaxin in den PCa-Zelllinien zu untersuchen, wurden diese auf Fibronektin-beschichteten Glasobjektträgern ausplattiert und fixiert. Zur Detektion von Leupaxin wurde eine Immunzytochemie mit einem Leupaxin-spezifischen Antikörper (siehe 2.21.1) durchgeführt. Wie in Abbildung 3.3 zu erkennen, lokalisiert Leupaxin in allen drei PCa-Zelllinien hauptsächlich in sog. focal adhesion sites, die sich am Ende der F-AktinFilamente (hier durch FITC-Phalloidin dargestellt) befinden. In 1-3\% der PCa-Zellen wurde eine zusätzliche nukleäre Lokalisation von Leupaxin beobachtet.

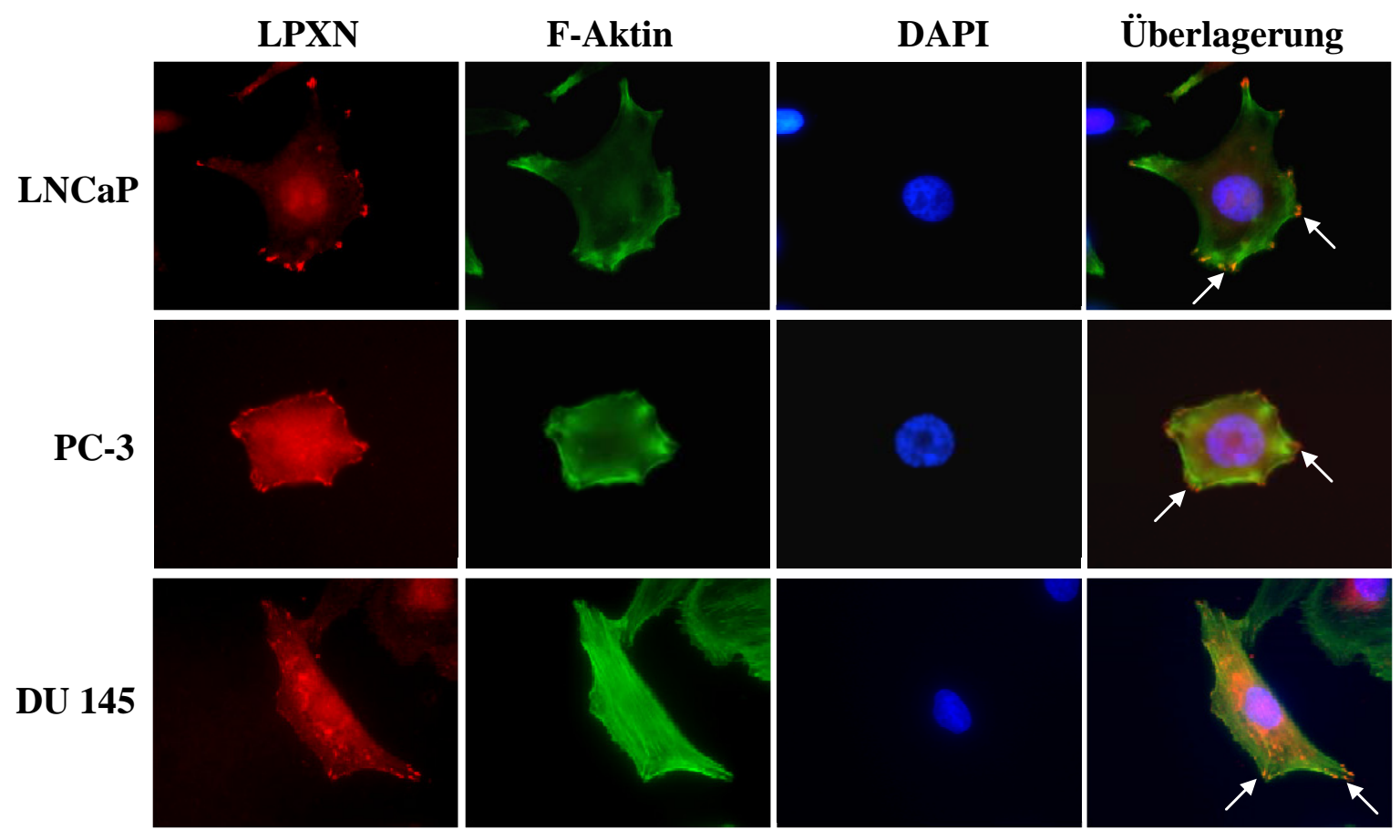

Abb. 3.3: Subzelluläre Lokalisation von Leupaxin in den PCa-Zelllinien. LNCaP-, PC-3- und DU 145Zellen wurden auf Fibronektin-beschichteten Objektträgern ausplattiert und für mind. 24 h inkubiert. Anschließend wurden sie fixiert und Leupaxin mit einem spezifischen Antikörper detektiert (rot). Zur Visualisierung des Zytoskeletts wurden die Zellen mit FITC-Phalloidin (grün, F-Aktin) behandelt. Die Kerne wurden mit DAPI dargestellt (blau). In der Überlagerung wurden die focal adhesion sites mit Pfeilen gekennzeichnet. Alle Bilder wurden mit einer 600fachen Vergrößerung aufgenommen. 


\subsection{Leupaxin enthält ein Kernexportsignal}

Bereits in vorangegengenen Experimenten konnte gezeigt werden, dass ein verkürztes Leupaxin-GFP-Fusionsprotein, welches nur die LIM-Domänen enthält (GFP-LPXN-LIM), nach der Transfektion in LNCaP-Zellen im Kern akkumuliert, wohingegen das GFPLeupaxin-Fusionsprotein, welches die vier LD-Motive enthält (GFP-LPXN-LD), ausschließlich eine zytoplasmatische Verteilung zeigt (Abb. 3.4A und [Voigt, 2003]). Zusätzlich deutet die in Abschnitt 3.3 beobachtete seltenere Lokalisation von Leupaxin im Kern darauf hin, dass Leupaxin sich möglicherweise zwischen Kern und Zytoplasma hin und her bewegt. Auch von den anderen Mitgliedern der Paxillin-Proteine ARA55 und Paxillin ist bekannt, dass sie unter bestimmten Bedingungen in den Kern wandern [Thomas et al., 1999b; Kasai et al., 2003].

Um zunächst zu zeigen, dass Leupaxin tatsächlich in den Kern wandert und aufgrund eines putativen Kernexportsignals (=ㅁuclear export signal (NES)) wieder heraustransportiert wird, wurde in LNCaP-Zellen das Fusionsprotein GFP-LPXN, welches die gesamte LeupaxinAminosäuresequenz enthält, überexprimiert. Anschließend wurde der normale zelluläre Exportmechanismus, der durch das Protein CRM1 (required for chromosome region maintenance oder Exportin 1) vermittelt wird, durch die Zugabe von Leptomycin B (LMB) inhibiert. Wie in Abb. 3.4B (unten) zu erkennen ist, akkumuliert das GFP-LPXNFusionsprotein im Kern der LNCaP-Zellen 6 h nach Zugabe von LMB ins Kulturmedium. 


\section{A}

GFP-LPXN-LD

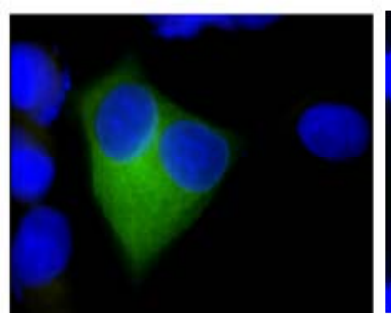

B

GFP-LPXN
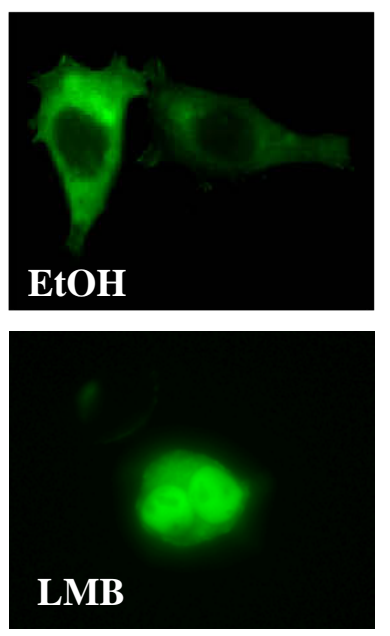

GFP-LPXN-LIM

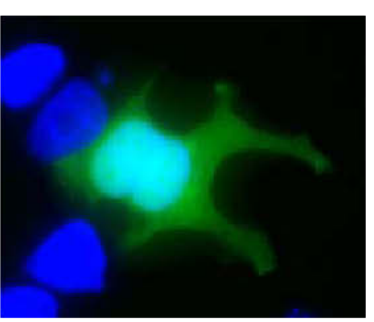

F-Aktin
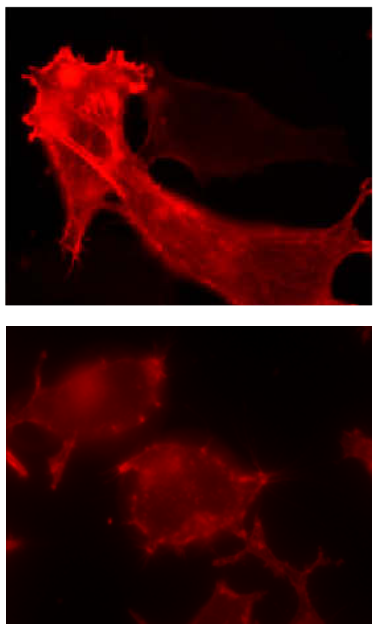

DAPI
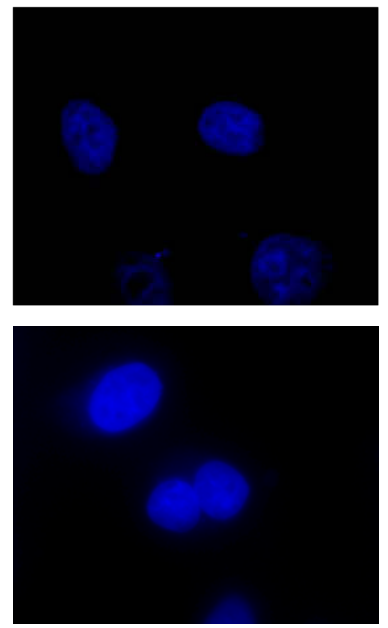

Überlagerung
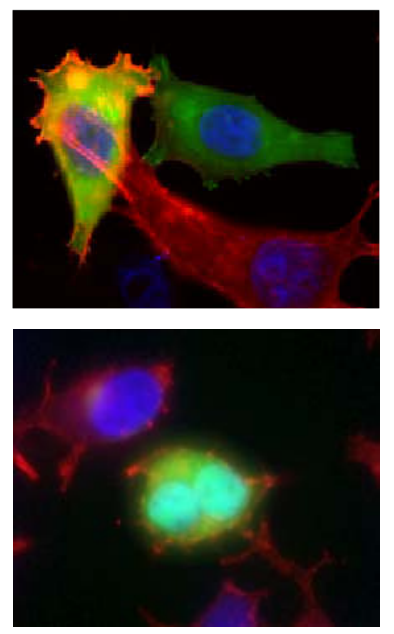

Abb. 3.4: Leupaxin pendelt zwischen Kern und Zytoplasma von PCa-Zellen. A. LNCaP-Zellen wurden mit den GFP-Fusionsproteinen GFP-LPXN-LD, welches nur die vier LD-Motive enthält, sowie GFP-LPXN-LIM, welches die vier LIM-Domänen umfasst, transfiziert, für $24 \mathrm{~h}$ inkubiert und anschließend fixiert. Die Kerne (blau) wurden mit DAPI angefärbt. Nur GFP-LPXN-LIM zeigt auch eine Kernverteilung des Fusionsproteins. B. Die mit GFP-LPXN transfizierten LNCaP-Zellen wurden vor der Fixierung mit EtOH (obere Reihe) bzw. mit dem Kernexport-Inhibitor LMB (untere Reihe) behandelt. Anschließend wurde zur Darstellung des Zytoskeletts das F-Aktin mit TRITC-Phalloidin (rot) und die Kerne (blau) mit DAPI angefärbt. Nur bei Zugabe von LMB konnte eine verstärkte Kernlokalisation von GFP-LPXN beobachtet werden. Alle Bilder wurden mit einer 600fachen Vergrößerung aufgenommen.

Nachdem nun gezeigt war, dass Leupaxin ein NES im Bereich seiner LD-Motive enthält, wurde die Aminosäuresequenz in diesem Bereich näher studiert und mit den Aminosäuresequenzen von Proteinen verglichen, bei denen das NES bereits experimentell nachgewiesen werden konnte. Nix et al. [1997] konstruierten aus den bekannten NES-Signalsequenzen eine Konsensussequenz (Abb. 3.5), die sie für Zyxin, einem Mitglied der LIM-Proteinfamlie, funktionell nachweisen konnten. ARA55 enthält ebenfalls ein funktionelles NES, welches auf 
das LD3-Motiv eingegrenzt wurde [Shibanuma et al., 2003]. Die Aminosäuresequenz von Leupaxin wurde daraufhin auf das Vorhandensein eines NES überprüft. Im Bereich zwischen den LD-Motiven 2 und 3 (Aminosäureposition 61-71, NP_004802) konnte eine entsprechende putative NES-Sequenz ermittelt werden (NES put., Abb. 3.5).

\begin{tabular}{|c|c|c|c|c|c|c|c|}
\hline & 1 & & 2 & & 3 & & 4 \\
\hline NES cons. & Hy & $X_{1-4}$ & Нy & $X_{2-3}$ & $\mathbf{L}$ & $\mathbf{X}$ & Нy \\
\hline NES put. & $\mathbf{V}$ & YTTN & I & $\mathbf{Q E}$ & $\mathbf{L}$ & $\mathbf{N}$ & $\mathbf{V}$ \\
\hline LD3 & L & DE & L & МАН & $\mathbf{L}$ & TE & $\mathbf{M}$ \\
\hline LD4 & $\mathbf{L}$ & DSM & $\mathbf{L}$ & GG & $\mathbf{L}$ & EQE & $\mathbf{L}$ \\
\hline
\end{tabular}

Abb. 3.5: Vergleich der NES-Konsensussequenz (NES cons.) mit Aminosäuresequenzen von Leupaxin. Das putative NES (NES put.) von Leupaxin ist zwischen den LD-Motiven 2 und 3 lokalisiert (Aminosäureposition 61-71). Das LD3- (Aminosäureposition 91-103) und das LD4- (Aminosäureposition 127139) Motiv von Leupaxin zeigen ebenfalls eine hohe Ähnlichkeit zur NES-Konsensussequenz. Die konservierten, hydrophoben Aminosäuren (Hy, 1-4) sind grau eingerahmt. X= jede Aminosäure.

Um nun das NES in Leupaxin funktionell nachzuweisen, wurde ein GFP-Fusionsprotein generiert, welches das putative NES-Motiv, die LD-Motive 3 und 4 sowie alle vier LIMDomänen umfasst (GFP-LPXN-NES-LIM). Ein zweites GFP-Fusionsprotein enthielt nur die LD-Motive 3 und 4 sowie die vier LIM-Domänen (GFP-LPXN-LD3-LIM). Nach der Transfektion in LNCaP-Zellen wurde die Anzahl der Zellen mit nukleärer Akkumulation der GFP-Fusionsproteine und die Gesamtzahl transfizierter Zellen bestimmt. Dabei wurde beobachtet, dass alle transfizierten Zellen keine Kernlokalisation der Fusionsproteine GFPLPXN-NES-LIM und GFP-LPXN-LD3-LIM zeigten, und somit das funktionelles NES nicht in der putativen NES-Sequenz liegen kann (Abb. 3.6). Da das NES von ARA55 im LD3Motiv liegt, wurden die konservierten Leucine 1 bis 3 von LD3 einzeln und in Kombination im GFP-Leupaxin-Fusionsprotein GFP-LPXN-LD3-LIM mutiert (GFP-LPXN-LD3mutL1-3LIM, Abb. 3.6A und B) und anschließend in LNCaP-Zellen überexprimiert. Die Anzahl der Zellen mit im Kern akkumulierten GFP-LPXN-Fusionsproteinen stieg auf 40\% an (Abb. 3.6A). Wurde das LD3-Motiv vollständig aus dem GFP-Fusionsprotein entfernt (GFP-LPXNLD4-LIM), erhöhte sich die Zahl der Zellen mit Kernlokalisation von GFP-LPXN-LD4-LIM 
auf ca. 50\%. Die Mutation von einem Leucin (L2) in diesem GFP-Leupaxin-Fusionsprotein (GFP-LPXN-LD4mutL2-LIM) als auch von allen drei Leucinen (L1-L3; GFP-LPXNLD4mutL1-3-LIM) führte sogar zur Akkumulation der überexprimierten GFPFusionsproteine in allen transfizierten LNCaP-Zellen (Abb. 3.6A und B). Somit konnte gezeigt werden, dass Leupaxin ein funktionelles NES enthält, welches hauptsächlich im LD4Motiv lokalisiert und an dem das LD3-Motiv mit beteiligt ist.

A

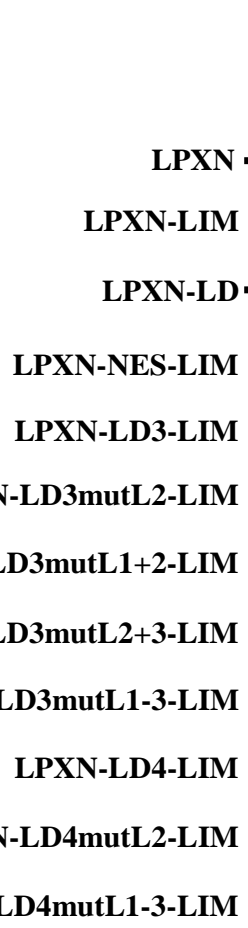

LD-Motive

LIM-Domänen
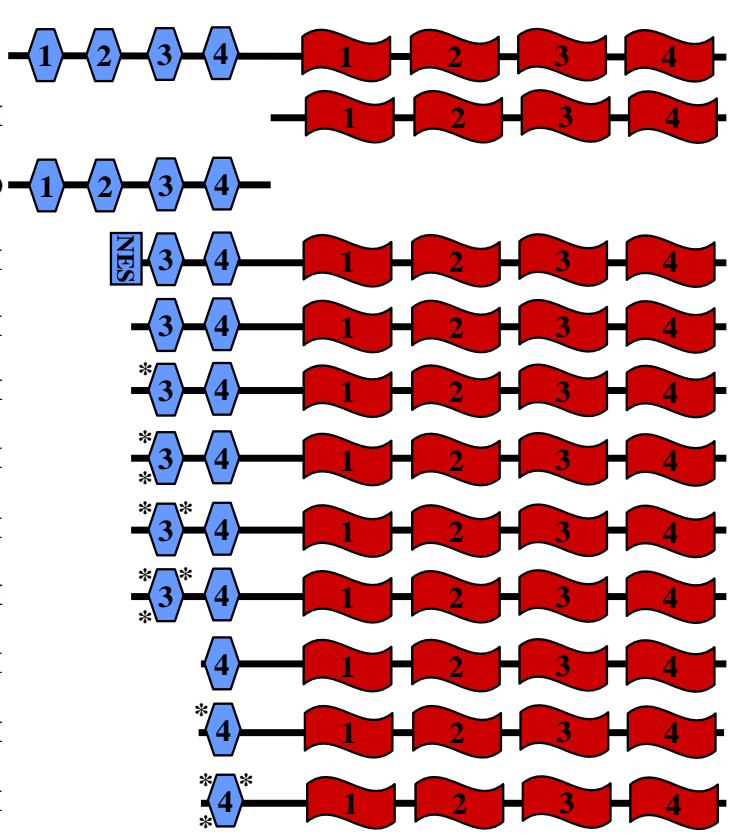

$\%$ transfizierter Zellen mit Kernlokalisation des GFPFusionsproteins

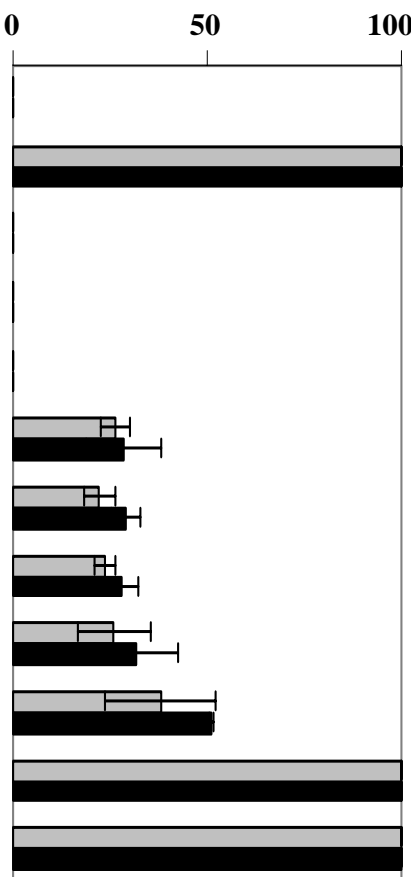


B
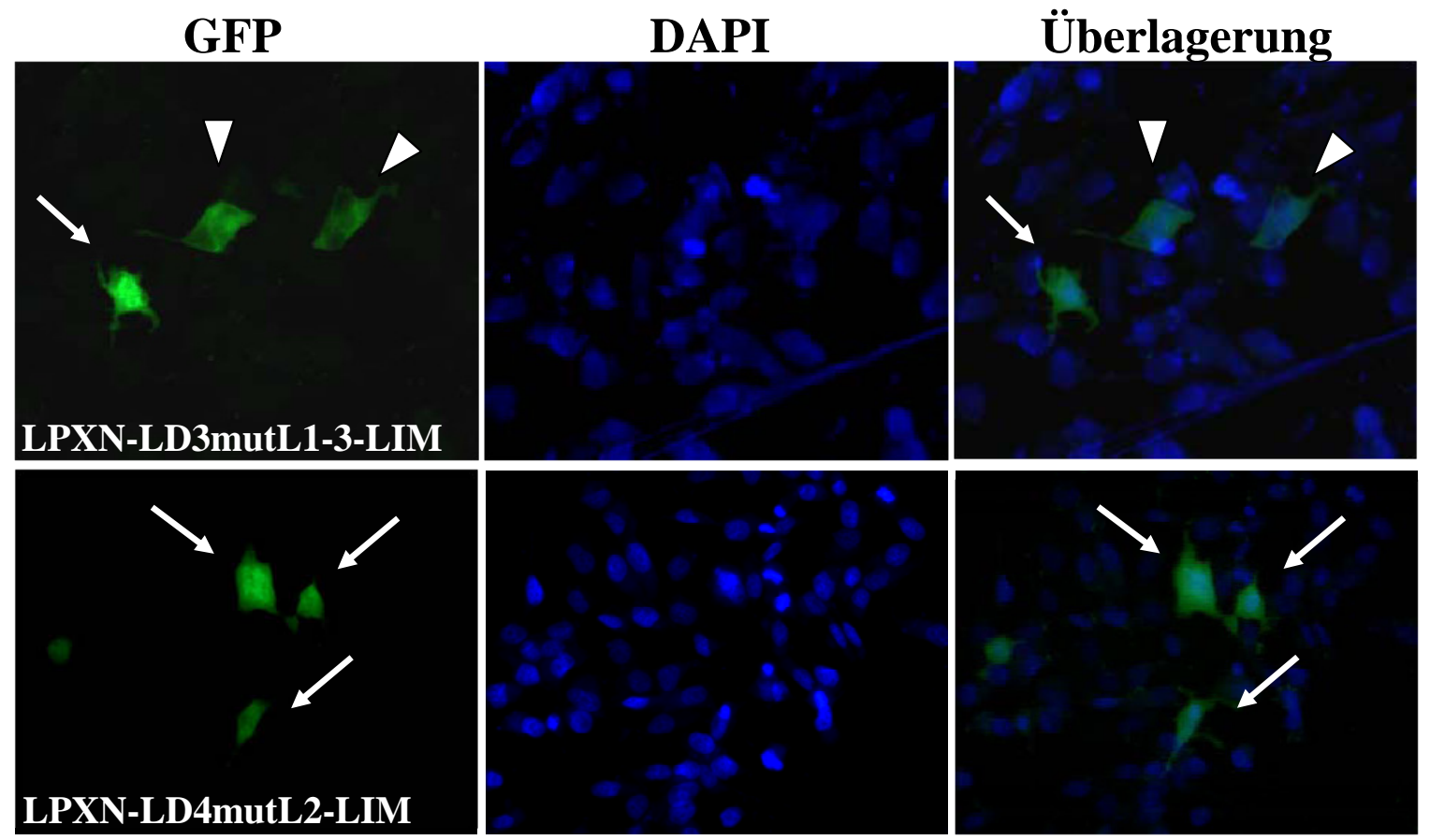

Abb. 3.6: Funktioneller Nachweis eines NES in Leupaxin. A. LNCaP-Zellen wurden mit den in der Abbildung angegebenen GFP-LPXN-Fusionsproteinen transfiziert und für $24 \mathrm{~h}$ inkubiert. Anschließend wurden die Zellen fixiert und die Kerne mit DAPI angefärbt. Unter einem Fluoreszenzmikroskop (600fache Vergrößerung) wurden die transfizierten Zellen insgesamt und die Zellen mit einer nukleären Akkumulation des GFP-Fusionsproteins gezählt und miteinander ins Verhältnis gesetzt. Die Sternchen kennzeichnen schematisch die substituierten Leucine. B. Beispiele für die Lokalisation der GFP-Leupaxin-Fusionsproteine. In der oberen Bildreihe ist die Lokalisation des Fusionsproteins GFP-LPXN-LD3mutL1-3-LIM dargestellt. Nur in ca. 30\% der Zellen ist eine zusätzliche Kernlokalisation (Pfeil) zu beobachten, während die restlichen Zellen eine ausschließlich zytoplasmatische Verteilung des Fusionsproteins zeigen (Pfeilkopf). In der unteren Reihe ist zu erkennen, dass das Fusionsprotein GFP-LPXN-LD4mutL2-LIM hingegen in allen Zellen eine nukleäre Lokalisation zeigt (Pfeile). Die Bilder wurden mit 200facher Vergrößerung aufgenommen.

\subsection{Interaktionen von Leupaxin mit Steroidhormonrezeptoren}

\subsubsection{Interaktion von Leupaxin mit dem Androgenrezeptor}

\subsubsection{Durchführung eines gerichteten yeast-two-hybrid-Experiments}

Im vorhergehenden Abschnitt wurde gezeigt, dass Leupaxin in den Nukleus von LNCaPZellen wandert, jedoch ist die Funktion von Leupaxin in diesen Zellen noch unklar. Aus 
neueren Studien ist allerdings bekannt, dass andere Mitglieder der Paxillin-Proteinfamilie, nämlich Paxillin und ARA55, mit dem Androgenrezeptor (AR) interagieren und als Transkriptionsaktivatoren für bestimmte Steroidhormonrezeptoren fungieren [Brown et al., 2004]. Daher wurde ein gerichtetes yeast-two-hybrid-Experiment durchgeführt, um eine mögliche Interaktion von Leupaxin mit dem AR zu analysieren (siehe 2.23). Der gesamte offene Leserahmen von Leupaxin wurde dazu in den Vektor pGADT7 (pGADT7-LPXN, siehe 2.8.7) und die Ligandenbindungsdomäne des AR (Aminosäureposition 551-920) in den Vektor pGBKT7 (pGBKT7-AR-LBD, siehe 2.8.7) einkloniert. Beide Konstrukte wurden anschließend in den Hefestamm AH109 transformiert (siehe 2.23.2/3) und auf -LTHA/ $\alpha$-Gal-Mangelplatten in An- und Abwesenheit des AR-Liganden Dihydrotestosteron (DHT) ausgestrichen. Zur Kontrolle der Transformationseffizienz wurden die transformierten Hefezellen auf -LT-Mangelplatten plattiert. Eine Interaktion von Leupaxin mit dem AR konnte unter hochstringenten Bedingungen nur in Anwesenheit von DHT beobachtet werden (Abb. 3.7). Weiterhin konnte kein Unterschied in der Bindungskapazität von Leupaxin zwischen dem Wildtyp-AR oder dem mutierten AR (T877A), der aus den LNCaP-Zellen isoliert worden ist, festgestellt werden (Abb. 3.7).

Um den mit dem AR interagierenden Bereich von Leupaxin näher einzuschränken, wurden zwei weitere Leupaxin-Konstrukte generiert. Das erste Konstrukt enthält in dem pGADT7Vektor nur die vier LD-Motive (pGADT7-LPXN-LD), das zweite enthält nur die vier LIMDomänen von Leupaxin (pGADT7-LPXN-LIM). Die Durchführung des yeast-two-hybridExperiments mit diesen beiden Leupaxin-Konstrukten ergab nur blau gefärbte Kolonien i) für das Konstrukt pGADT7-LPXN-LIM und ii) nur in Anwesenheit des Liganden DHT (Abb. 3.7). Damit tragen die LD-Motive nicht zur Interaktion von Leupaxin mit dem AR bei. 

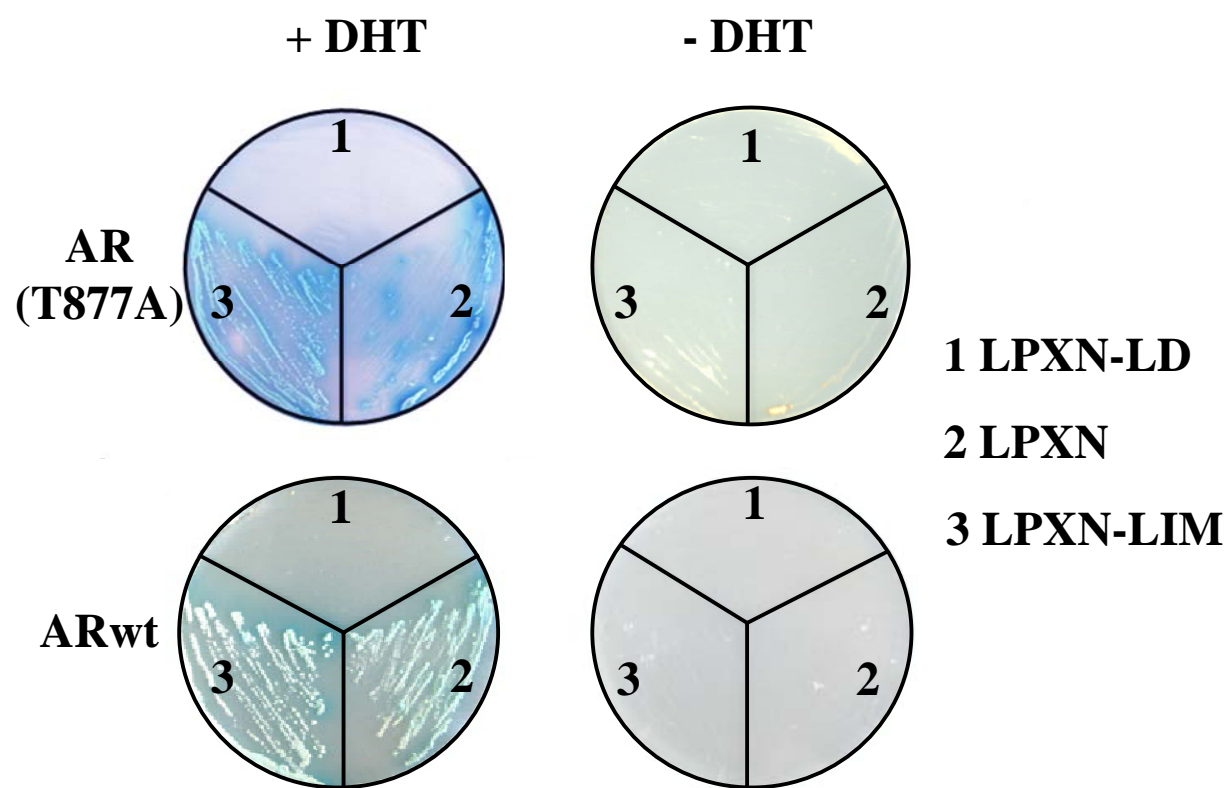

Abb. 3.7: Leupaxin interagiert über seine LIM-Domänen mit der Ligandenbindungsdomäne des AR in liganden-abhängiger Weise. In kompetente Hefezellen wurden gleichzeitig die Konstrukte pGBKT7-AR-LBD und pGADT7-LPXN bzw. pGADT7-LPXN-LIM oder pGADT7-LPXN-LD transformiert. Die Hefezellen wurden auf -LTHA/ $\alpha$-Gal-Mangelplatten ausgestrichen, die zuvor gegebenenfalls mit DHT (Endkonzentration $100 \mathrm{nM}$ ) behandelt wurden. Die Blaufärbung der Kolonien weist auf eine Interaktion zwischen Leupaxin und dem AR hin. Der AR interagiert folglich mit Leupaxin über die LIM-Domänen und diese Interaktion erfolgt liganden-abhängig, da kein Wachstum der Hefekolonien ohne DHT zu verzeichnen war.

\subsubsection{Bestätigung und Quantifizierung der Interaktion von Leupaxin und -varianten mit dem AR}

Zur Quantifizierung der Interaktion von Leupaxin mit dem AR wurde ein Flüssig- $\alpha$ Galaktosidase-Test mit den bereits oben genannten Konstrukten durchgeführt (siehe 2.26.4). Dieser Test zeigte, dass die Bindungskapazität der LIM-Domänen von Leupaxin mit dem AR in vitro stärker ist als die des full length-Leupaxins und die LD-Motive von Leupaxin nicht für eine Bindung an den AR ausreichen (Abb. 3.8).

Um regulatorische Elemente im Bereich der LIM-Domänen von Leupaxin zu identifizieren, die für die Interaktion von Leupaxin und dem AR verantwortlich sind, wurden Sequenzanalysen durchgeführt. Dabei wurde ein sog. FXXLF-Motiv am C-terminalen Ende von Leupaxin identifiziert, welches zwischen humaner (Aminosäureposition 380-384; NP_004802) und muriner (Aminosäureposition 380-384; NP_598913) Proteinsequenz 
konserviert ist. Frühere Studien hatten ergeben, dass das FXXLF-Motiv von ARKoregulatoren (z.B. ARA24, ARA70 und ARA55) verantwortlich für die Vermittlung der AR-spezifischen Interaktionen sind [He et al., 2002; Zhou et al., 2002]. Die Substitution dieses FXXLF-Motifs sowohl im full length-Leupaxin-Konstrukt (LPXN-AXXAA, siehe 2.8.7) als auch im Leupaxin-LIM-Konstrukt (LPXN-LIM-AXXAA, siehe 2.8.7) führte im Flüssig- $\alpha$-Galaktosidase-Test zu einer Reduktion der AR-Bindungskapazität der beiden mutierten Leupaxin-Proteine (Abb. 3.8).

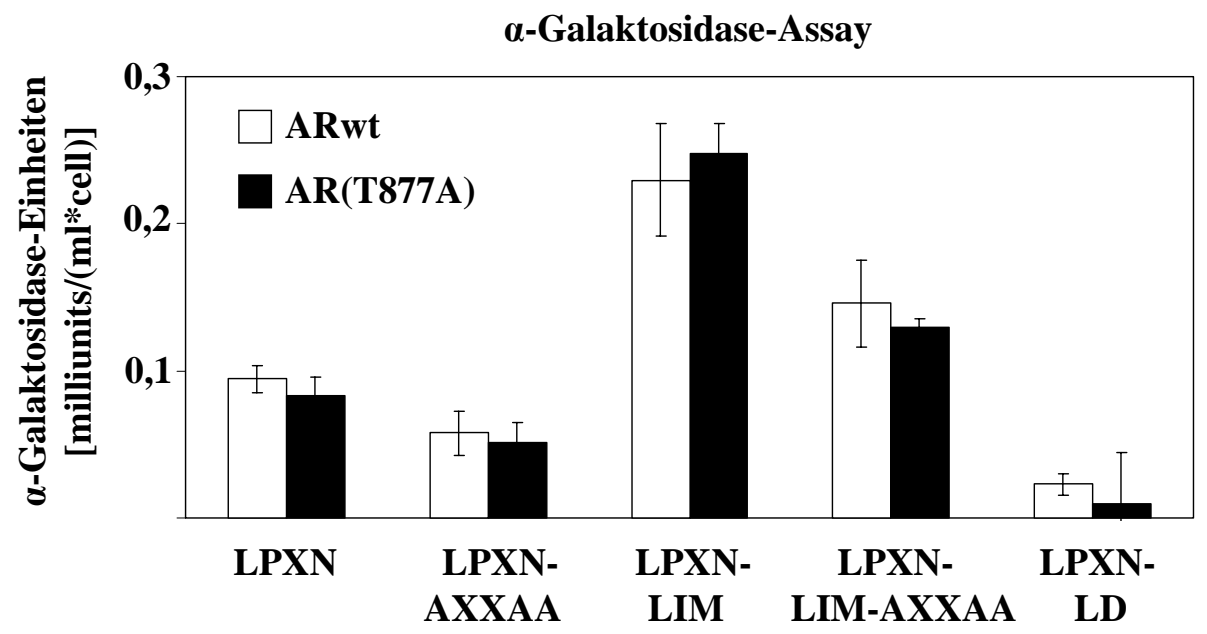

Abb. 3.8: Quantifizierung der Bindungskapazität von Leupaxin und -varianten an den AR. Die in der Abbildung angegebenen Leupaxin-Konstrukte wurden zusammen mit pGBKT7-AR-LBD (wt) bzw. pGBKT7AR-LBD (T877A) in kompetente Hefezellen transformiert. Nach Kultivierung der auf -LTHA-Mangelplatten gewachsenen Hefen (außer LPXN-LD: -LT) in -LTHA-Mangelmedium unter Zugabe von 100 nM DHT wurde die Umsatzrate von PNP- $\alpha$-Galaktose durch die $\alpha$-Galaktosidase, die nur bei einer Interaktion von Leupaxin (und -varianten) mit dem AR gebildet wird, gemessen. Es ist zu erkennen, dass die LIM-Domänen allein eine stärkere Bindungskapazität aufweisen als das vollständige Leupaxin-Protein. Wird jedoch bei beiden, LPXN als auch LPXN-LIM, das FXXLF-Motiv durch AXXAA ersetzt, ist eine Verminderung der Interaktion zu verzeichnen. Die LD-Motive zeigen in diesem Assay nur Hintergrundwerte.

\subsubsection{Bestätigung der Interaktion von Leupaxin mit dem AR mittels Koimmunopräzipitation}

Bisher wurde die Interaktion von Leupaxin mit dem AR nur in vitro in Hefezellen nachgewiesen. Um diese Interaktion auch in Säugerzellen zu bestätigen, wurde die Methode der Koimmunopräzipitation angewendet (siehe 2.27). Dazu wurden LNCaP-Zellen transient 
mit Plasmiden transfiziert, die die vollständigen offenen Leserahmen von Leupaxin und AR enthalten (pTriEx-LPXN und pSG5-AR, siehe 2.8.6 und 7). Nach 24 h wurde das Serum aus dem Medium entfernt und die Zellen über Nacht inkubiert. Vor der Isolierung des GesamtProteins wurde ein Teil der transfizierten LNCaP-Zellen mit 100 nM DHT für 6 h stimuliert, während der andere Teil unstimuliert blieb. Die Zelllysate wurden anschließend zur Immunpräzipitation der Proteinkomplexe mit einem Leupaxin-spezifischen Antikörper versetzt und über Nacht inkubiert. Nach Zugabe eines Protein A/G-Gemisches erfolgten die Präzipitation der Protein-Antikörper-Komplexe und mehrere Waschschritte der Präzipitate. Nach Elution der Proteine wurden diese über SDS-PAGE aufgetrennt und eine Western BlotAnalyse mit einem AR-spezifischen Antikörper durchgeführt (Abb. 3.9). Eine für den AR spezifische Bande bei 110 kDa wurde nur in Anwesenheit des Liganden DHT beobachtet, wohingegen in Abwesenheit von DHT sowie bei den Kontrollen (Zelllysate ohne Behandlung mit Primärantikörper) kein AR-Protein detektiert werden konnte. Somit ist gezeigt, dass Leupaxin mit dem AR auch in vivo interagiert, und dass diese Interaktion abhängig vom ARLiganden DHT ist.

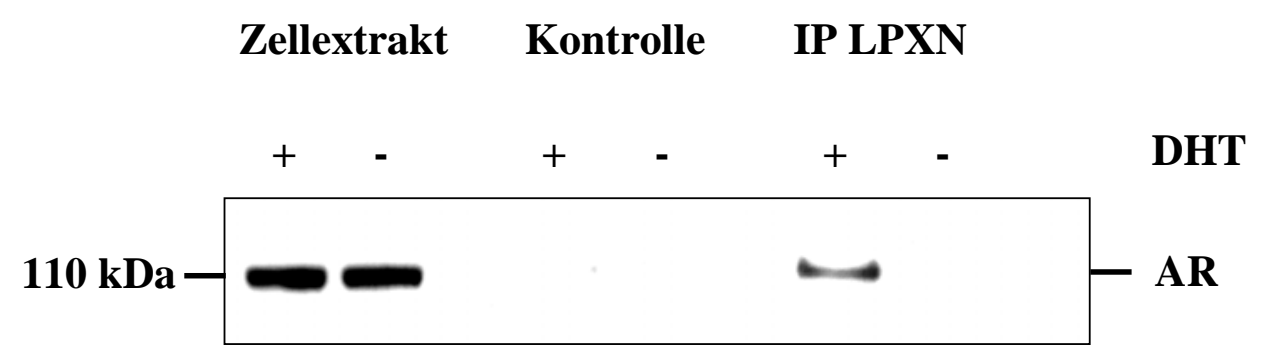

Abb. 3.9: Interaktionsnachweis von Leupaxin und AR mittels Koimmunopräzipitation. Mit den Zelllysaten von transient mit den Plasmiden pTriEx-LPXN und pSG5-AR transfizierten LNCaP-Zellen, die in An- bzw. Abwesenheit von DHT (100 nM) inkubiert wurden, wurde eine Immunpräzipitation mit einem Leupaxinspezifischen Antikörper durchgeführt. Anschließend wurden die eluierten Proteine einer Western Blot-Analyse mit einem AR-spezifischen Antikörper unterzogen. Dabei konnte eine distinkte Bande in der Größe des AR (110 kDa) nur in Anwesenheit von DHT detektiert werden. 


\subsubsection{Leupaxin erhöht die transkriptionelle Aktivität des AR}

Um die biologische Relevanz der Interaktion von Leupaxin mit dem AR zu analysieren, wurde ein Transaktivierungsassay durchgeführt (siehe 2.28). Um die Aktivität des AR messen zu können, wurden zwei verschiedene Reporterplasmide verwendet: MMTV-Luc und rPbLuc. Das Plasmid MMTV-Luc enthält vor dem Luciferase-Gen den mouse mammary tumor virus (MMTV)-Promotor, von dem bekannt ist, dass er durch Steroidhormonrezeptoren wie dem AR, aktiviert wird. Bei dem Plasmid rPB-Luc wurde der Minimalpromotor des RattenProbasins (rPb; [Greenberg et al. 1994]) vor das Luciferase-Gen kloniert. Probasin ist ein ARreguliertes Gen in der Prostata von Ratten und Mäusen und enthält bestimmte Nukleotidsequenzen, sog. androgen response elements (AREs), in dessen Promotorregion. Wird der AR durch DHT stimuliert, kann er an diese AREs binden und aktiviert somit die Transkription des nachfolgenden Gens, hier das Luciferase-Gen. Die Luciferase-Aktivität kann anschließend gemessen werden (2.28.2).

Sowohl LNCaP- als auch NIH 3T3-Zellen wurden mit den Vektoren pCMV- $\beta$-Gal, rPb-Luc bzw. MMTV-Luc und je nach Ansatz mit den Vektoren pEGFP-C1-LPXN, pEGFP-C1LPXN-LIM bzw. pEGFP-C1 jeweils in Triplikaten kotransfiziert (Konstrukte siehe 2.8.7). Der für die $\beta$-Galaktosidase kodierende Vektor pCMV- $\beta$-Gal wurde als Kontrolle zur Messung der Transfektionseffizienz verwendet. Bei der Transfektion der NIH 3T3-Zellen wurde zu dem oben genannten Plasmid-Cocktail zusätzlich noch der Vektor pSG5-AR zugesetzt, da diese Zellen nicht wie die LNCaP-Zellen über einen endogenen AR verfügen. Die transfizierten Zellen wurden für $36 \mathrm{~h}$ und gegebenenfalls unter Zugabe von $100 \mathrm{nM}$ DHT inkubiert und anschließend die Aktivitäten von Luciferase und $\beta$-Galaktosidase bestimmt (siehe 2.26.2 und 3).

Wie in Abbildung 3.10A und B deutlich zu erkennen ist, nimmt mit steigender Menge von GFP-LPXN die Aktivität des AR in liganden-abhängiger Weise bei Verwendung des Vektors MMTV-Luc sowohl bei den NIH 3T3-Zellen (Wildtyp-AR; Abb. 10A) als auch bei den LNCaP-Zellen (AR(T877A), Abb. 3.10B) zu. Die Negativkontrolle mit GFP allein zeigt keine erhöhte AR-Aktivität. Auch mit dem zweiten Reporterplasmid rPb-Luc ist bei Zugabe von Leupaxin ein Anstieg der AR-Transkriptionsaktivität zu verzeichnen (Abb. 3.10B und C). Die LIM-Domänen von Leupaxin alleine (GFP-LPXN-LIM) steigern zwar die Aktivität des AR, jedoch nicht in vollem Maße wie das vollständige GFP-Leupaxin-Fusionsprotein (Abb. 3.10A bis D). 
A

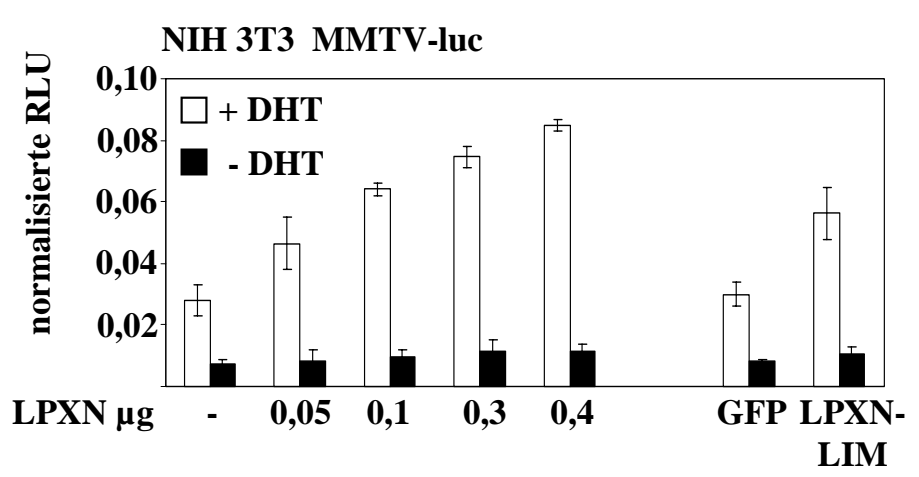

B

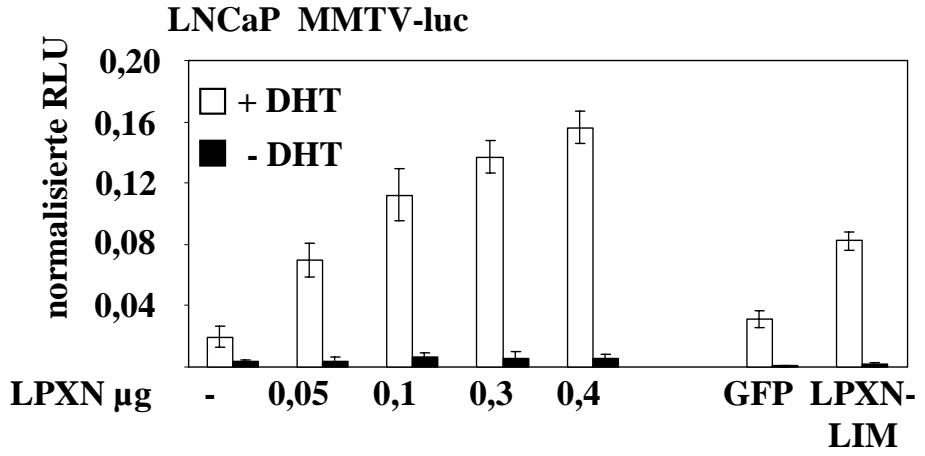

C

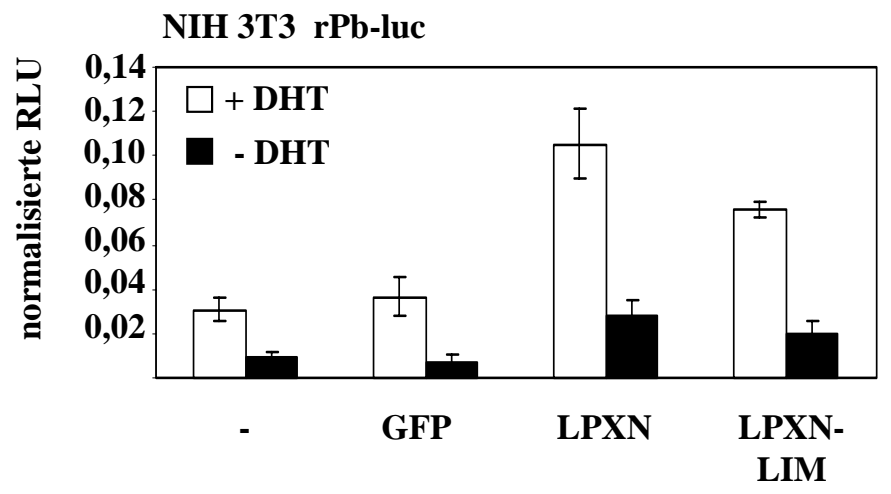

D

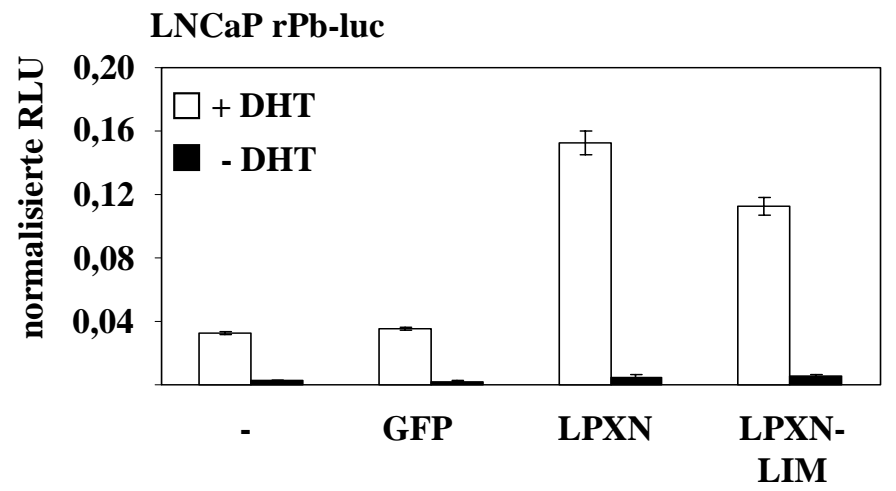

Abb. 3.10: Nachweis der AR-Koaktivierung durch Leupaxin mittels Transaktivierungsassays. Als Reporterplasmide für den Transaktivierungsassay dienten zwei verschiedene Promotoren (mouse mammary tumor virus = MMTV und Ratten-Probasin = rPb), die vor das Luciferase-Gen kloniert wurden. NIH 3T3- und LNCaP-Zellen wurden mit einem Plasmid-Cocktail transfiziert, der zum einen das Reporterplasmid MMTV-Luc (A und B; 0,2 $\mu \mathrm{g}$ ) bzw. rPb-Luc (C und D; 0,2 $\mu \mathrm{g}$ ), als auch pCMV- $\beta$-Gal (0,05 $\mu \mathrm{g}$ ) und die oben angegebenen Mengen GFP-LPXN enthielt. Für die NIH 3T3-Zellen wurde zusätzlich noch das Plasmid pSG5-AR (0,2 $\mu$ g), 
das die vollständige AR-cDNA enthält, zugegeben. GFP (0,4 $\mu$ g) diente als Negativkontrolle. Nach $36 \mathrm{~h}$ Inkubation und gegebenenfalls Stimulierung mit $100 \mathrm{nM}$ DHT wurde die Luciferase-Aktivität gemessen, die mit der Aktivität des AR gleichzusetzen ist. Zur Kontrolle der Transfektionseffizienz wurde außerdem die $\beta$ Galaktosidase-Aktivität bestimmt. Die in den Grafiken dargestellten Werte ergeben sich aus dem Quotienten der Luciferase- und der $\beta$-Galaktosidase-Aktivität und wurden als relative Lichteinheiten (= relative light units (RLU)) angegeben.

\subsubsection{Nachweis der Interaktion von Leupaxin mit dem AR mit Hilfe des BiFC-Assays}

Der Bimolecular fluorescence complementation assay (BiFC-Assay) ist eine neu entwickelte Methode zur Visualisierung von Protein-Proteininteraktionen direkt in der Zelle. Er gibt Auskunft über den Ort der Interaktion von zwei Kandidatenproteinen. Das Prinzip der Methode besteht in der Fragmentierung von fluoreszierenden Proteinen wie EGFP oder YFP (yellow fluorescence protein). Der für die Fluoreszenz von EGFP wichtige Aminosäurebereich liegt bei 157-158 [Ormo et al., 1996]. Nur wenn diese beiden Aminosäuren in unmittelbarer räumlicher Nähe zueinander stehen, kann das Protein grün fluoreszieren. Wird EGFP genau zwischen diesen beiden Aminosäuren getrennt, besitzen die beiden Einzelfragmente dann nicht die Fähigkeit der Fluoreszenz. Kommen sie jedoch in enge räumliche Nähe, wird die Fluoreszenz-Fähigkeit wiederhergestellt. Werden nun Proteine an die jeweiligen EGFP-Fragmente angehängt, kann deren Interaktionsfähigkeit in einer transfizierten Zelle sichtbar gemacht werden. Denn nur wenn die Kandidatenproteine miteinander interagieren, ist die räumliche Nähe der Aminosäuren 157 und 158 des EGFP in einer Zelle gewährleistet und ein grünes Signal wird unter dem Fluoreszenzmikroskop sichtbar (Abb. 3.11). Ein weiterer Vorteil dieser Methode besteht darin, dass auch schwächere Interaktionen sichtbar gemacht werden können, da einmal interagierende EGFP-Fragmente sich nicht mehr voneinander trennen und somit die Interaktion „fixiert“ ist. 


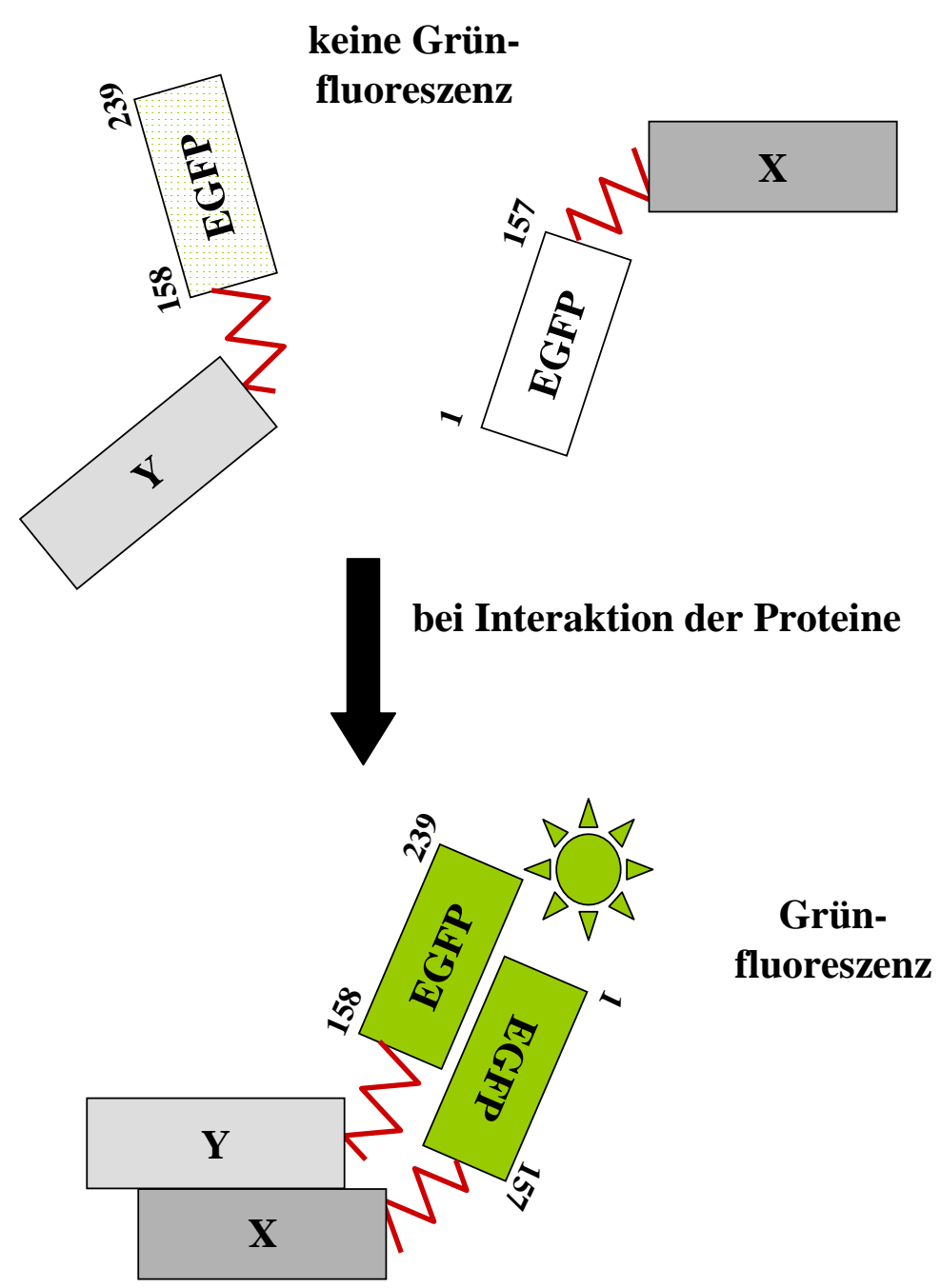

Abb. 3.11: Schematische Darstellung zur Funktionsweise des BiFC-Assays. Die beiden Kandidatenproteine $\mathrm{X}$ und $\mathrm{Y}$ werden als Fusionsproteine einmal mit dem N-terminalen Bereich des EGFP (Aminosäure 1-157) und einmal mit dem C-terminalen Bereich von EGFP (Aminosäure 158-239) überexprimiert. Findet keine Interaktion der Proteine statt, tritt auch keine Grünfluoreszenz auf (Bild oben), da die EGFP-Fragmente zu weit entfernt voneinander liegen. Können jedoch die beiden Kandidatenproteine $\mathrm{X}$ und $\mathrm{Y}$ miteinander interagieren, kommen die beiden EGFP-Fragmente in räumliche Nähe zueinander und die grünfluoreszierende Eigenschaft von EGFP ist wiederhergestellt.

Der hier vorgestellte BiFC-Assay wurde von Frau PD Dr. S. Hoyer-Fender (Abteilung Entwicklungsbiologie, Universität Göttingen) entwickelt und im Rahmen einer Informationsveranstaltung im Institut für Humangenetik vorgestellt. Die Funktionalität des Assays wurde mit einigen bekannten Interaktionspartnern überprüft (unveröffentliche Daten 
Dr. S. Hoyer-Fender). Die für diese Methode verwendeten Vektoren FPCA-V1, 2 und 3 wurden von Fr. Dr. S. Hoyer-Fender generiert und freundlicher Weise zur Verfügung gestellt. Der Vektor FPCA-V1 enthält den C-terminalen Bereich von EGFP (entspricht Aminosäure 158 bis 239), an den N-terminal der offene Leserahmen des AR einkloniert wurde (Abb. 3.12). Beide sind durch einen spacer getrennt, der die Bildung der Tertiärstruktur gewährleisten soll. In den Vektor FPCA-V2 wurde der offene Leserahmen von Leupaxin so einkloniert, dass der N-terminale Bereich von EGFP (entspricht Aminosäure 1 bis 157) Nterminal von Leupaxin liegt (Abb. 3.12). Auch hier werden die beiden Proteine durch einen spacer zur besseren Bildung der Tertiärstruktur getrennt.

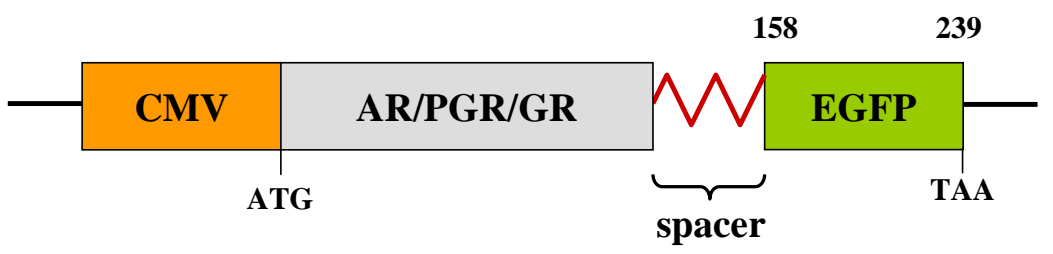

\author{
FPCA-V1-
} AR/PGR/GR

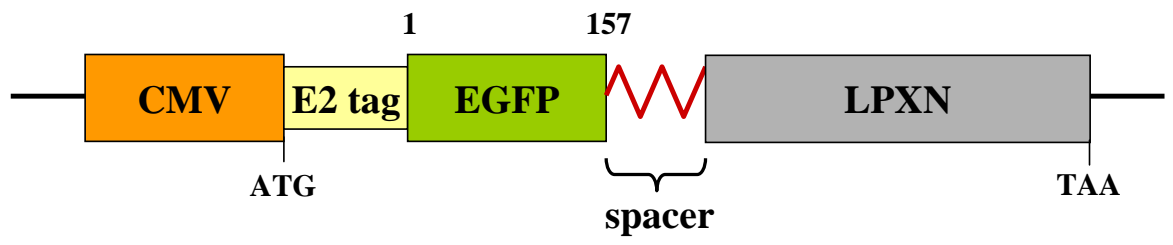

FPCA-V2-

LPXN

Abb. 3.12: Schematischer Überblick über die für den BiFC-Assay verwendeten Konstrukte (PD Dr. S. Hoyer-Fender). Der Vektor FPCA-V1 (Abb. oben) enthält den C-terminalen Bereich des EGFP (Aminosäure 158-239), an den die offenen Leserahmen von AR, PGR bzw. GR so kloniert wurden, dass sie im Fusionsprotein N-terminal von EGFP liegen. Der Vektor FPCA-V2 enthält den N-terminalen Bereich von EGFP gekoppelt an einen E2-Tag zur Detektion des Fusionsproteins mit einem E2-spezifischen Antikörper. Der offene Leserahmen von Leupaxin wurde so einkloniert, dass EGFP im resultierenden Fusionsprotein N-terminal von Leupaxin liegt.

Die beiden Konstrukte FPCA-V1-hAR und FPCA-V2-LPXN wurden anschließend in LNCaP-Zellen kotransfiziert. 36 h nach Stimulation mit 100 nM DHT wurden die Zellen fixiert und mit Vectashield/DAPI eingedeckt. Wie in Abbildung $3.13 \mathrm{zu}$ sehen, ist ein grünes Signal in den kotransfizierten LNCaP-Zellen zu beobachten, welches sowohl im Zytoplasma als auch im Nukleus lokalisiert ist. 

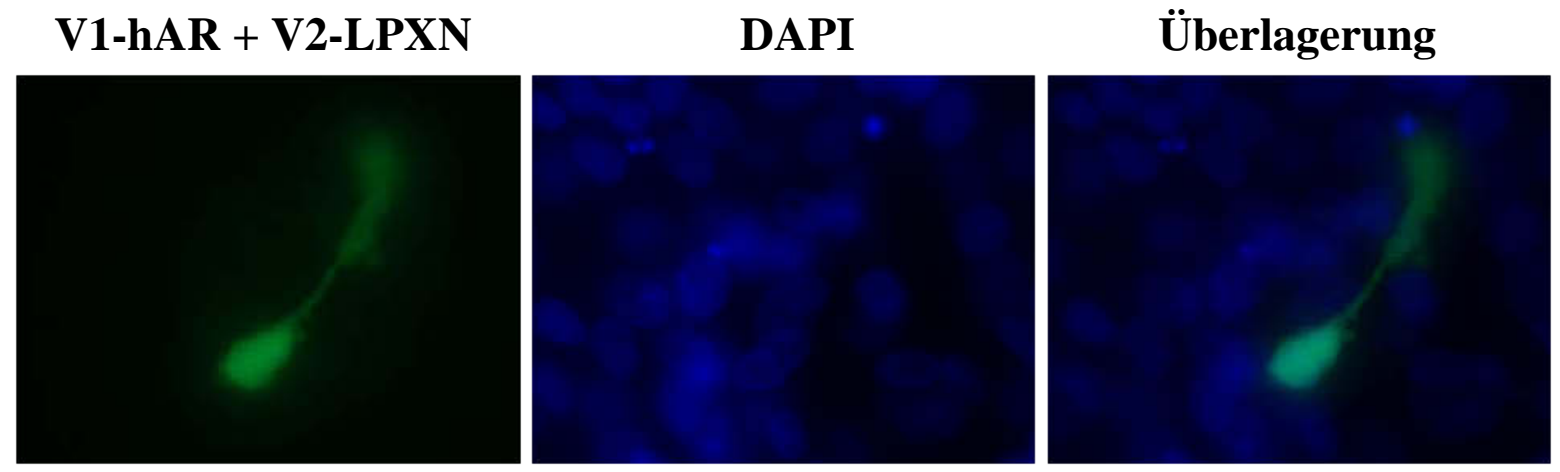

Abb. 3.13: Visualisierung der Interaktion von Leupaxin mit dem AR mit Hilfe des BiFC-Assays. LNCaPZellen auf Glasobjektträgern wurden mit den Konstrukten FPCA-V1-hAR und FPCA-V2-LPXN kotransfiziert, mit 100 nM DHT stimuliert und für 36 h inkubiert. Anschließend wurden die Zellen fixiert und die Kerne (blau) mit DAPI angefärbt. Die Bilder von grün fluoreszierenden Zellen wurden mit 600facher Vergrößerung aufgenommen.

\subsubsection{Interaktion von Leupaxin mit weiteren Steroidhormonrezeptoren}

Sowohl von Paxillin als auch von ARA55 ist bekannt, dass sie neben dem AR auch den Progesteron-(PGR), Glukokortikoid-(GR), Mineralkortikoid-(MR) und ARA55 auch den Östrogenrezeptor $\alpha(\mathrm{ER} \alpha)$ transaktivieren [Brown et al., 2004]. Nun stellte sich die Frage, ob auch Leupaxin an diese Steroidhormonrezeptoren bindet, oder ob es spezifische Unterschiede in der Bindungsfähigkeit der Mitglieder der Paxillin-Proteinfamilie bezüglich der verschiedenen Steroidhormonrezeptoren gibt.

Die Interaktion von Leupaxin mit den Östrogenrezeptoren $\alpha(E R \alpha)$ und $\beta(E R \beta)$ wurde bereits im Rahmen der Diplomarbeit von Frau A. Herr [2005] untersucht. Dabei konnte gezeigt werden, dass Leupaxin mit dem ER $\alpha$ in liganden-abhängiger Weise interagiert und diesen auch transaktiviert. Auch für den ER $\beta$ konnte in einem gerichteten yeast-two-hybridExperiment eine Bindung von Leupaxin an den ER $\beta$ beobachtet werden, die jedoch ligandenunabhängig ist. Die weiteren Untersuchungen zur Interaktion von Leupaxin mit dem ER $\beta$ werden derzeit von A. Büchner im Rahmen ihrer Diplomarbeit durchgeführt. 


\subsubsection{Interaktionsnachweis von Leupaxin mit dem Progesteron- und Glukokortikoidrezeptor mit Hilfe eines gerichteten yeast-two-hybrid- Experiments}

Zunächst wurde zum Nachweis der Interaktionen von Leupaxin mit den Steroidhormonrezeptoren PGR und GR ein gerichtetes yeast-two-hybrid-Experiment durchgeführt. Dazu wurden die vollständigen offenen Leserahmen des humanen PGR (NM_000926) und des humanen GR (NM_000176) in den Hefe-Vektor pGBKT7 einkloniert (siehe 2.8.7). Diese wurden zusammen mit den Leupaxin-Hefe-Konstrukten pGADT7-LPXN, pGADT7-LPXN-LD bzw. pGADT7-LPXN-LIM (siehe Abschnitt 3.5.1.1) in kompetente Hefezellen des Stammes AH109 kotransformiert und auf -LTHA/ $\alpha$-Gal-Mangelplatten ausgestrichen. Zur Untersuchung der Ligandenabhängigkeit wurde ein Teil der Mangelplatten zusätzlich mit dem PGR-Liganden Progesteron $\left(\mathrm{P}_{4}\right)$ bzw. dem GR-Liganden Dexamethason (Dex) behandelt. Zur Kontrolle der Transformationseffizienz wurden die Transformanten auf -LT-Mangelplatten plattiert.

Unter diesen hochstringenten Bedingungen konnte für den GR eine Interaktion mit Leupaxin sowohl in An- als auch in Abwesenheit von Dex beobachtet werden (Abb. 3.14 oben). Weiterhin konnte gezeigt werden, dass auch beim GR die Bindung an die LIM-Domänen von Leupaxin erfolgt, da bei LPXN-LD keine blauen Kolonien sichtbar sind. Die Interaktion von Leupaxin mit dem PGR ist gleichfalls liganden-unabhängig, da auch hier sowohl in An- als auch in Abwesenheit von $\mathrm{P}_{4}$ blau gefärbte Hefe-Kolonien unter hochstringenten Bedingungen wachsen konnten (Abb. 3.14 unten). 


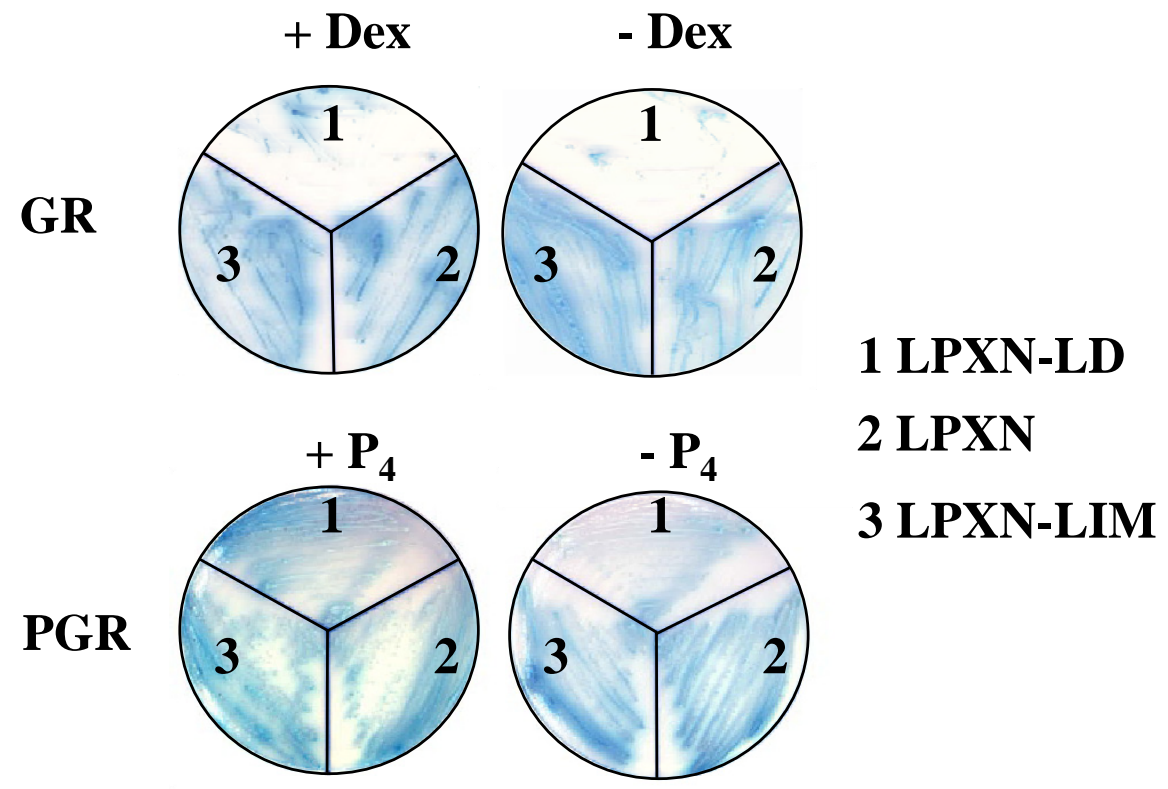

Abb. 3.14: Leupaxin interagiert in liganden-unabhängiger Weise sowohl mit dem GR als auch dem PGR. In kompetente Hefezellen wurden gleichzeitig die Konstrukte pGBKT7-hGR bzw. pGBKT7-PGR und pGADT7-LPXN bzw. pGADT7-LPXN-LIM oder pGADT7-LPXN-LD transformiert. Die transformierten Hefezellen wurden auf -LTHA/ $\alpha$-Gal-Mangelplatten ausgestrichen, die zuvor gegebenenfalls mit Dexamethason (Dex) bzw. Progesteron ( $\mathrm{P}_{4}$; Endkonzentrationen je $100 \mathrm{nM}$ ) behandelt wurden. Die Blaufärbung der Kolonien weist auf eine Interaktion zwischen Leupaxin und dem GR bzw. PGR hin. Der GR interagiert folglich mit Leupaxin über die LIM-Domänen, da kein Wachstum der Hefekolonien bei LPXN-LD zu verzeichnen ist. Beim PGR ist ein Wachstum der Hefezellen bei LPXN-LD zwar zu erkennen, jedoch ist die Blaufärbung der Kolonien schwächer. Somit interagiert auch der PGR hauptsächlich mit den LIM-Domänen von Leupaxin, aber die LDMotive scheinen einen Einfluss auf die Bindung zu besitzen.

\subsubsection{Bestätigung der Interaktion von Leupaxin mit GR und PGR mittels Koimmunopräzipitation}

Um die in den Hefen beobachtete Interaktion von Leupaxin mit dem GR und PGR in vivo zu verifizieren, wurde auch hier die Methode der Koimmunopräzipitation angewendet (siehe 2.27). Da weder für den GR noch für den PGR spezifische Antikörper zur Verfügung standen, wurden Konstrukte zur Expression der beiden Proteine als GFP-Fusionsproteine generiert (pEGFP-C1-hGR und pEGFP-C1-hGR, siehe 2.8.7). Anschließend wurden die Konstrukte transient in LNCaP-Zellen transfiziert, die das Fusionsprotein Leupaxin-cmyc überexprimieren können (siehe Abschnitt 3.6.8). Nach 24 h Inkubation wurde über Nacht das 
Serum entzogen und nachfolgend gegebenenfalls für 6 h mit $100 \mathrm{nM}$ Dex bzw. $\mathrm{P}_{4}$ stimuliert. Nach Isolierung der Gesamt-Proteine erfolgte die Immunpräzipitation mit einem GFPspezifischen Antikörper und dem Protein A/G-Gemisch. Die nach dem Waschen eluierten Proteine wurden über SDS-PAGE aufgetrennt und das Leupaxin-cmyc-Fusionsprotein mit dem Leupaxin-spezifischen Antikörper nachgewiesen. Wie in Abbildung 3.15 zu erkennen ist, konnte eine für Leupaxin-cmyc erwartete Bande bei ca. 63 kDa im Falle der GRKoimmunopräzipitation detektiert werden. Die Negativkontrolle ohne Primärantikörper zeigt keine entsprechende Bande. Diesem Ergebnis zufolge ist die Interaktion von Leupaxin mit dem GR unter Zugabe des Liganden Dex erhöht, da hier eine stärkere Bande detektiert wurde, obwohl gleiche Mengen Protein für die jeweiligen Reaktionen eingesetzt wurden (siehe Kontrolle Zellextrakt). Für den PGR konnte bis zum derzeitigen Zeitpunkt keine Interaktion mit Hilfe der Koimmunopräzipitation nachgewiesen werden.

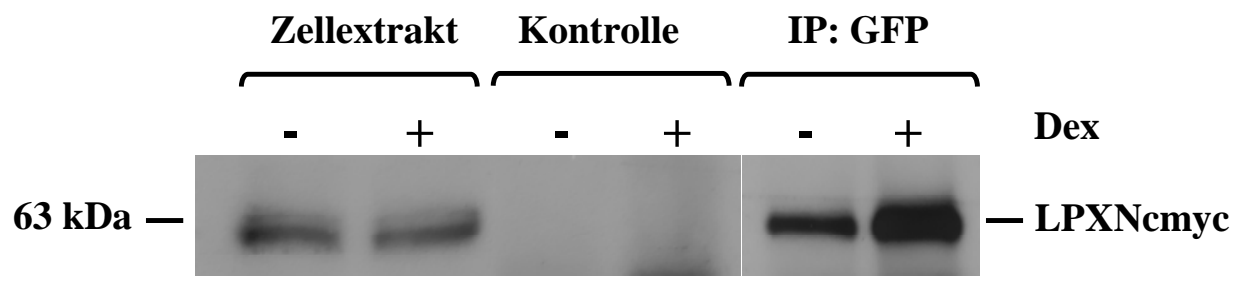

Abb. 3.15: Interaktionsnachweis von Leupaxin und GR mittels Koimmunopräzipitation. Die Immunpräzipitation erfolgte mit Zelllysaten von transient mit pEGFP-C1-hGR transfizierten LNCaP-Zellen, die das Fusionsprotein LPXNcmyc überexprimieren, und einem GFP-spezifischen Antikörper. Zur Stimulierung wurde nach Serumentzug über Nacht für 6 h 100 nM Dex ins Kulturmedium zugegeben. Die Western BlotAnalyse wurde mit einem Leupaxin-spezifischen Antikörper durchgeführt. Dabei konnte eine distinkte Bande in der Größe des Leupaxin-Fusionsproteins (LPXNcmyc, $63 \mathrm{kDa}$ ) sowohl in An- als auch in Abwesenheit von Dex detektiert werden.

\subsubsection{Leupaxin erhöht die transkriptionelle Aktivität sowohl vom GR als auch vom PGR}

Die Interaktion von Leupaxin und dem AR resultiert in einer erhöhten transkriptionellen Aktivität des AR unter Zugabe des Liganden DHT. Um nun festzustellen, ob auch die Interaktionen von Leupaxin und GR bzw. PGR zu einer erhöhten Transaktivierung der 
Steroidhormonrezeptoren führen, wurden Transaktivierungsassays durchgeführt. Als Reporterplasmid wurde für beide Steroidhormonrezeptoren das Konstrukt MMTV-Luc (Abschnitt 3.5.1.3) verwendet, da sowohl GR als auch PGR die Transkription des MMTVPromotors bei Stimulation mit dem entsprechenden Liganden aktivieren können [Thomas et al., 1999b]. NIH 3T3-Zellen wurden mit einem Plasmid-Cocktail bestehend aus pCMV- $\beta$-Gal (0,05 $\mu \mathrm{g})$, MMTV-Luc (0,2 $\mu \mathrm{g})$ pRS-hGR, pSG-PGR1, pEGFP-C1-PGR1 oder pSG-PGR2 (je 0,2 $\mu \mathrm{g}$ ) und verschiedenen Mengen GFP-LPXN transfiziert. Nach Stimulation mit $100 \mathrm{nM}$ Dex bzw. $\mathrm{P}_{4}$ für $36 \mathrm{~h}$ wurden die Zellen lysiert und die Aktivitäten von Luciferase und zur Kontrolle der Transfektionseffizienzen von $\beta$-Galaktosidase bestimmt. Die Ergebnisse von drei Transfektionen, die jeweils in Doppelbestimmungen durchgeführt wurden, sind in Abbildung 3.16 zusammengefaßt. Es ist zu erkennen, dass Leupaxin die Aktivität des GR und von beiden Isoformen des PGR um das 2fache erhöht. Dabei spielt es keine Rolle, ob die Liganden von GR oder PGR vorhanden sind. Allerdings ist die Aktivierung des GR und PGR durch Leupaxin nicht so stark ausgeprägt wie die Aktivierung des AR (siehe Abschnitt 3.5.1.3 Abb. 3.10).

A

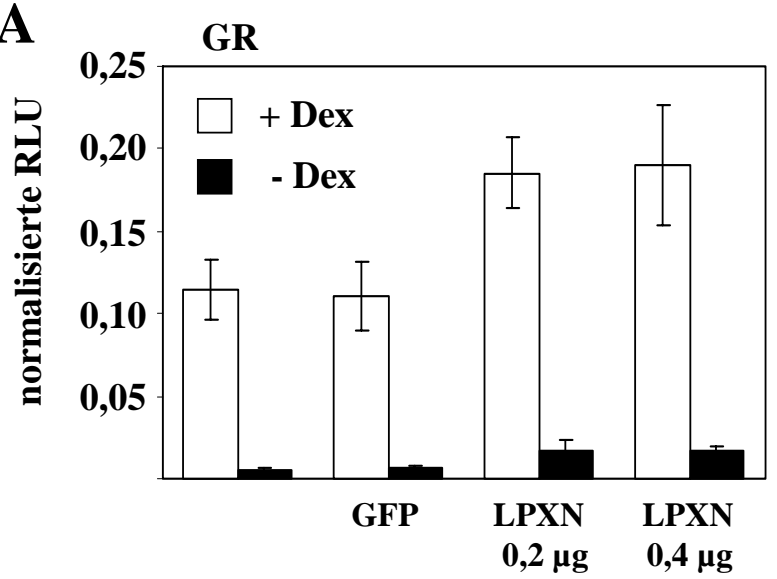

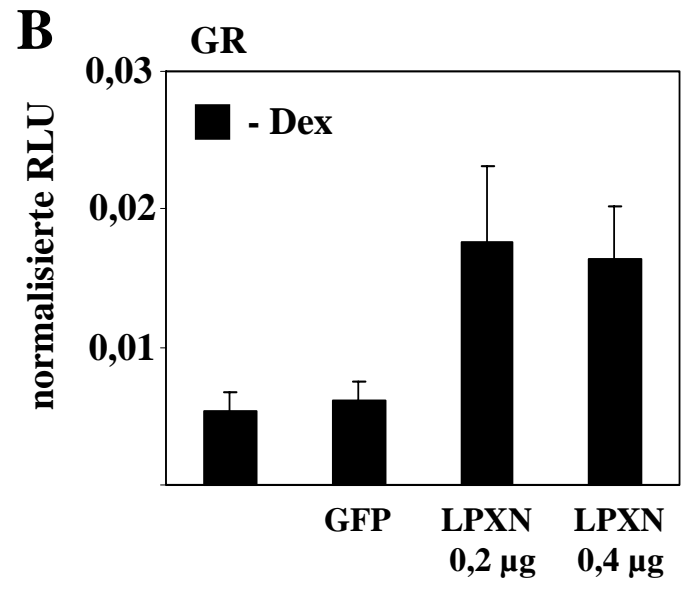

C

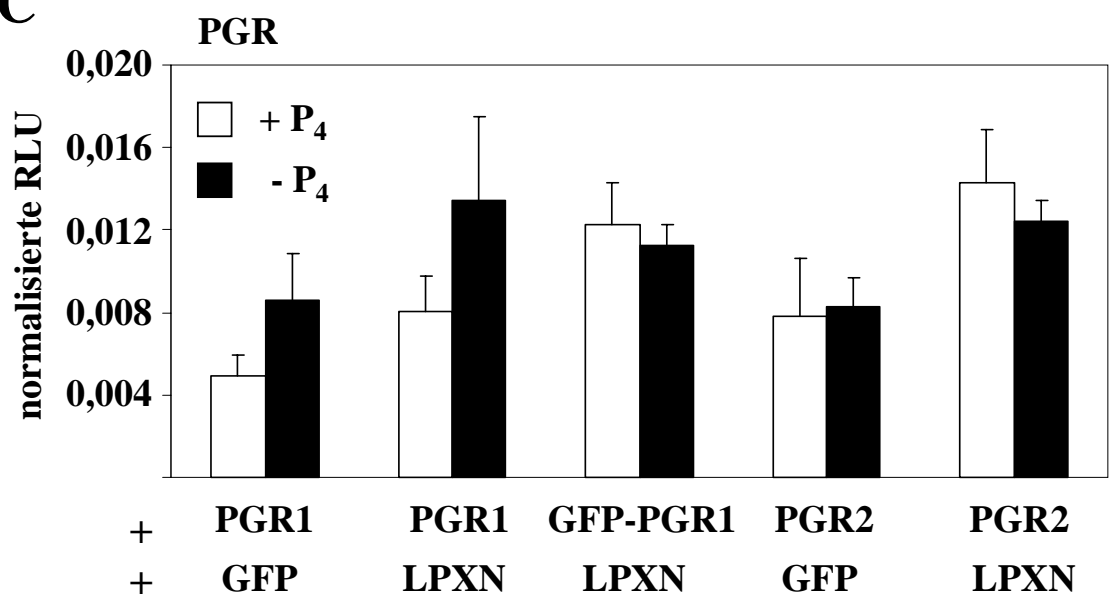


Abb. 3.16: Erhöhung der transkriptionellen Aktivität von GR und PGR durch Leupaxin. Als Reporterplasmid für die Transaktivierungsassays diente der Vektor MMTV-Luc. NIH 3T3-Zellen wurden mit einem Plasmid-Cocktail bestehend aus pCMV- $\beta$-Gal (0,05 $\mu \mathrm{g})$, MMTV-Luc $(0,2 \mu \mathrm{g})$, pRS-hGR, pSG5-PGR1, pEGFP-C1-PGR1 bzw. pSG5-PGR2 (je 0,2 $\mu \mathrm{g}$ ) und GFP-LPXN (0,4 $\mu \mathrm{g}$, wenn nicht anders angegeben) transfiziert und mit dem entsprechenden Liganden (je $100 \mathrm{nM}$ Dex für GR und $\mathrm{P}_{4}$ für PGR) stimuliert. GFP $(0,4 \mu \mathrm{g})$ diente als Negativkontrolle. Nach 36 h Inkubation wurde die Luciferase-Aktivität gemessen, die mit der Aktivität von GR bzw. PGR gleichzusetzen ist. Die Transfektionseffizienz wurde durch die Messung der $\beta$ Galaktosidase-Aktivität bestimmt. Die in den Grafiken dargestellten Werte ergeben sich aus dem Quotienten der Luciferase-Aktivität und der $\beta$-Galaktosidase-Aktivität und wurden als relative Lichteinheiten (= relative light units (RLU)) angegeben.

\subsubsection{Analyse der Interaktionen zwischen Leupaxin und GR bzw. PGR mit Hilfe des BiFC-Assays}

Um die Interaktion von Leupaxin mit den Steroidhormonrezeptoren GR und PGR mit Hilfe einer weiteren Methode zu analysieren, wurde der BiFC-assay angewendet (siehe Abschnitt 3.5.2.1). Dazu wurden jeweils die offenen Leserahmen von GR und PGR in den Vektor FPCA-V1 einkloniert (siehe 2.8.7). Anschließend erfolgte die Transfektion gemeinsam mit dem Konstrukt FPCA-V2-LPXN in LNCaP-, NIH 3T3- und COS-7-Zellen. Die Zellen wurden für 48 h mit dem entsprechenden Liganden (Dex bzw. $\mathrm{P}_{4} ; 100 \mathrm{nM}$ ) stimuliert und sofort in 4\% Formalin fixiert. Wie in Abbildung 3.17 ersichtlich ist, interagieren Leupaxin und GR im Zytoplasma miteinander. Für PGR konnte bisher noch keine Interaktion mit Hilfe des BiFC-Assays festgestellt werden.

$$
\text { V1-hGR + V2-LPXN }
$$

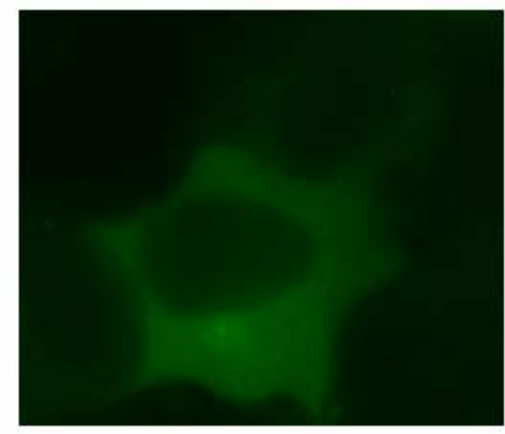

DAPI

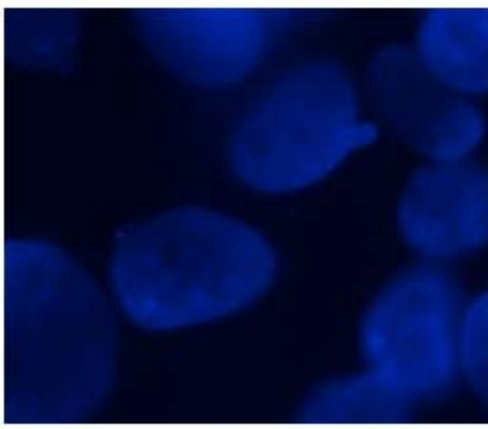

Überlagerung

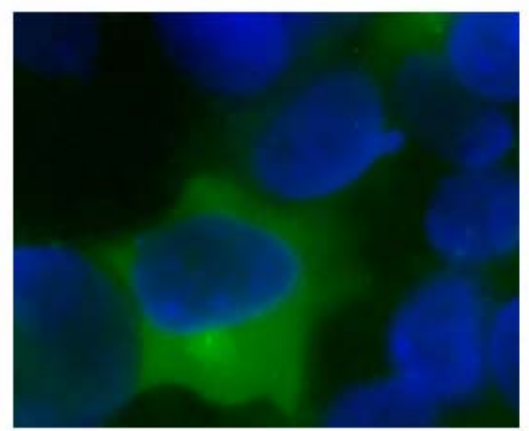

Abb. 3.17: Visualisierung der Interaktion von Leupaxin mit dem GR mit Hilfe des BiFC-Assays. COS-7Zellen auf Glasobjektträgern wurden mit den Konstrukten FPCA-V1-hGR und FPCA-V2-LPXN kotransfiziert, mit $100 \mathrm{nM}$ Dex stimuliert und für $24 \mathrm{~h}$ inkubiert. Anschließend wurden die Zellen fixiert und die Kerne (blau) 
mit DAPI angefärbt. Die Bilder von grün fluoreszierenden Zellen wurden mit 1000facher Vergrößerung aufgenommen.

\subsection{Analysen zur Funktion von Leupaxin}

\subsubsection{Herunterregulierung der Leupaxin-Expression in den PCa-Zelllinien mittels RNA-Interferenz}

Die Funktion von Leupaxin sollte durch Herunterregulierung der Expression in den PCaZelllinien untersucht werden. Dazu wurden die PCa-Zellen mit zwei verschiedenen Leupaxinspezifischen Duplex-siRNA-Oligonukleotiden transfiziert. Als „D-LPXN“ wird das DuplexsiRNA-Oligonukleotid bezeichnet, welches bereits in meiner vorangegangenen Diplomarbeit verwendet worden ist (Ziel: Nukleotidposition 157-175; NM_004811; siehe 2.8.4.2). Das zweite Duplex-siRNA-Oligonukleotid wird hier „D-LPXNst“ genannt und ist ein sog. „Stealth“-modifiziertes siRNA-Oligonukleotid (Ziel: Nukleotidposition 264-288; NM_004811; siehe 2.8.4.2). Die „stealth“-Modifizierung bewirkt laut Angaben der Firma, dass die siRNA-Oligonukleotide über einen längeren Zeitraum in der Zelle stabil vorliegen und die Herunterregulierung des Zielgens effizienter ist. Ein siRNA-Oligonukleotid, welches spezifisch für das Luciferase-Gen ist (D-Luc), wurde als Kontrolle für unspezifische Reaktionen der Zelle auf exogen eingebrachte Nukleinsäuren und auf Transfektionsreagenzien eingesetzt [Elbashir et al., 2002].

Erste Ergebnisse mit dem siRNA-Oligonukleotid D-LPXN hatten ergeben, dass die PCaZellen effizient mit den Oligonukleotiden transfiziert werden können (Transfektionsrate 85 bis 90\%), und dass auf RNA-Ebene eine Herunterregulierung der Leupaxin-Genexpression um bis zu 80\% in PC-3-Zellen erreicht wird [Voigt, 2003]. Zu dieser Zeit war der Leupaxinspezifische Antikörper und auch das zweite siRNA-Oligonukleotidpaar noch nicht verfügbar. In Abbildung 3.18 ist daher die Analyse der Herunterregulierung der Leupaxin-Expression in den PCa-Zelllinien LNCaP, PC-3 und DU 145 mittels Western Blot dargestellt. Der Blot wurde zudem densitometrisch mit Hilfe der QuantityOne Software ausgewertet. Es ist deutlich zu erkennen, dass das siRNA-Oligonukleotid D-LPXNst eine stärkere Herunterregulierung der Leupaxin-Expression in allen drei PCa-Zelllinien bewirkt. 


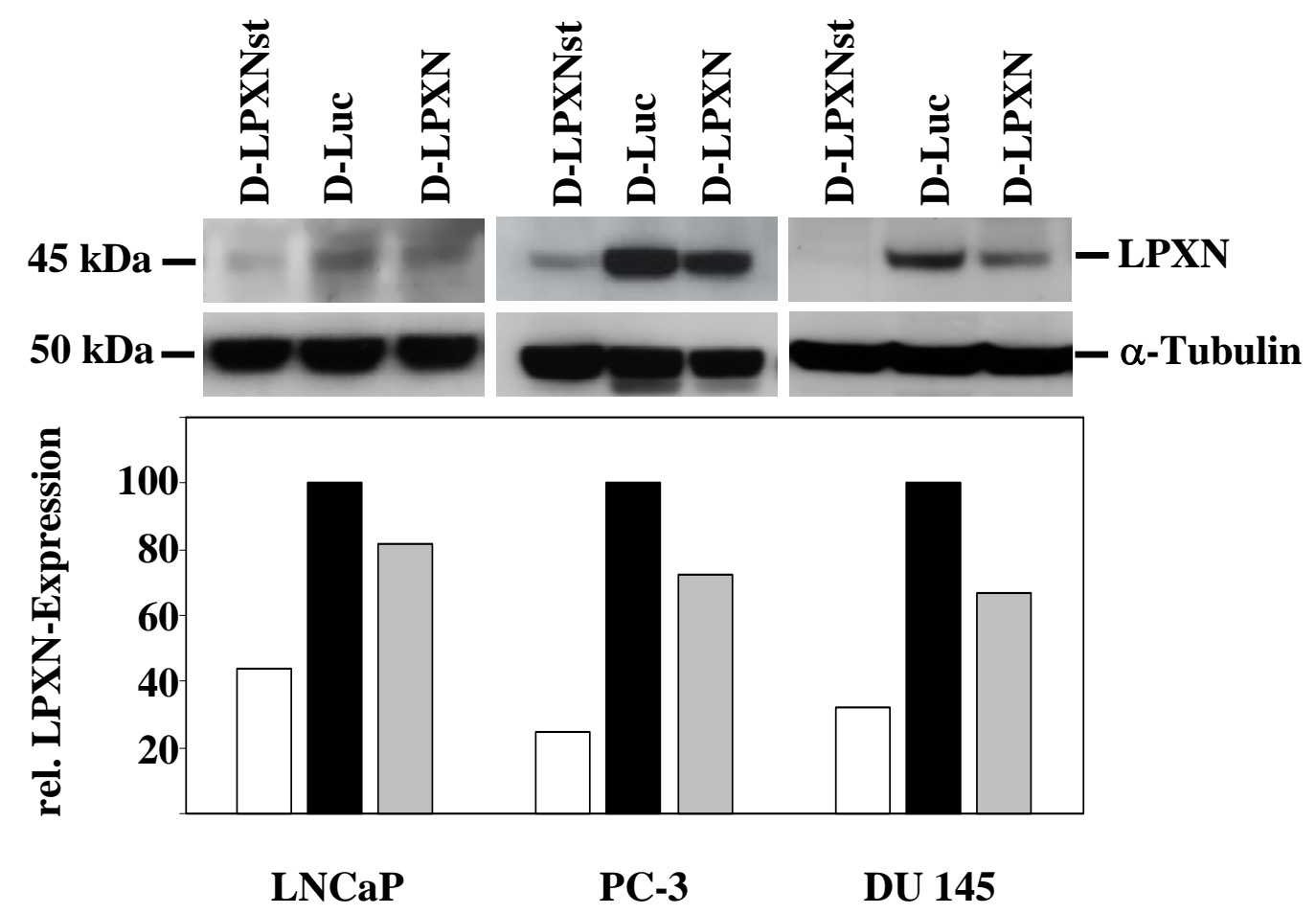

Abb. 3.18: Herunterregulierung der Leupaxin-Expression in den PCa-Zelllinien mittels spezifischer siRNA-Duplex-Oligonukleotide. LNCaP-, PC-3- und DU 145-Zellen wurden mit Leupaxin-spezifischer (DLPXNst und D-LPXN) und als Negativkontrolle mit Luciferase-spezifischer (D-Luc) Duplex-siRNA transfiziert. Nach 48 h Inkubation wurden die adhärenten und nicht adhärenten Zellen gesammelt, lysiert und GesamtProteine isoliert. Anschließend erfolgte die Auftrennung der Proteine über SDS-PAGE und der Nachweis von Leupaxin mit Hilfe eines Leupaxin-spezifischen Antikörpers (Abb. oben). Zur Quantifizierung wurde der Film eingescannt und die Bandenintensitäten mit Hilfe der QuantityOne Software ausgewertet (Abb. unten). Dargestellt wurde die relative Leupaxin-Expression, die sich aus dem Verhältnis der Bandenintensitäten des Leupaxin- und des $\alpha$-Tubulin-Signals ergibt.

\subsubsection{Induktion von Apoptose in androgen-abhängigen LNCaP-Zellen nach Herunterregulierung der Leupaxin-Expression}

In vorangegangenen Experimenten war gezeigt worden, dass androgen-abhängige LNCaPZellen nach Herunterregulierung der Leupaxin-Expression ihre Morphologie ändern. Ab 48 h nach Transfektion mit Duplex-siRNA gegen Leupaxin begannen die Zellen sich abzurunden und vom Boden der Zellkulturflasche abzulösen. Kontroll-transfizierte LNCaP-Zellen, sowie PC-3- und DU 145-Zellen mit herunterregulierter Leupaxin-Expression zeigten diese phänotypischen Reaktionen nicht [Voigt, 2003]. 
Um nun zu untersuchen, ob diese sich abrundenden LNCaP-Zellen apoptotisch werden, wurde ein Caspase-3-Assay durchgeführt, bei dem spezifisch die aktive Caspase-3 als Apoptosemarker nachgewiesen wird (siehe 2.22.1). Dazu wurden LNCaP-, PC-3- und DU 145-Zellen mit den siRNA-Oligonukleotiden D-LPXN bzw. D-Luc transfiziert und für $120 \mathrm{~h}$ inkubiert. Nach 72 und 120 h wurden die schwimmenden und adhärenten Zellen gesammelt, in PBS gewaschen und auf Objektträger zentrifugiert (siehe 2.17.5). Nach der Fixierung mit Aceton erfolgte die Detektion der aktiven Caspase-3 mit Hilfe eines spezifischen Antikörpers. Anschließend wurden die apoptotischen Zellen, die nun durch eine starke Rotfärbung erkennbar waren (Abb. 3.19A-F), unter dem Mikroskop mit Hilfe der AnalySIS Software ausgezählt. Eine geringere Zunahme apoptotischer Zellen ist bereits nach $72 \mathrm{~h}$ zu verzeichnen (ca. $10 \%$ ), nach $120 \mathrm{~h}$ sind es bereits 50\% apoptotische LNCaP-Zellen (Abb. 3.19G). Die kontroll-transfizierten LNCaP-, sowie D-LPXN-transfizierte PC-3- und DU 145-Zellen zeigten keine erhöhte Apoptoserate. 


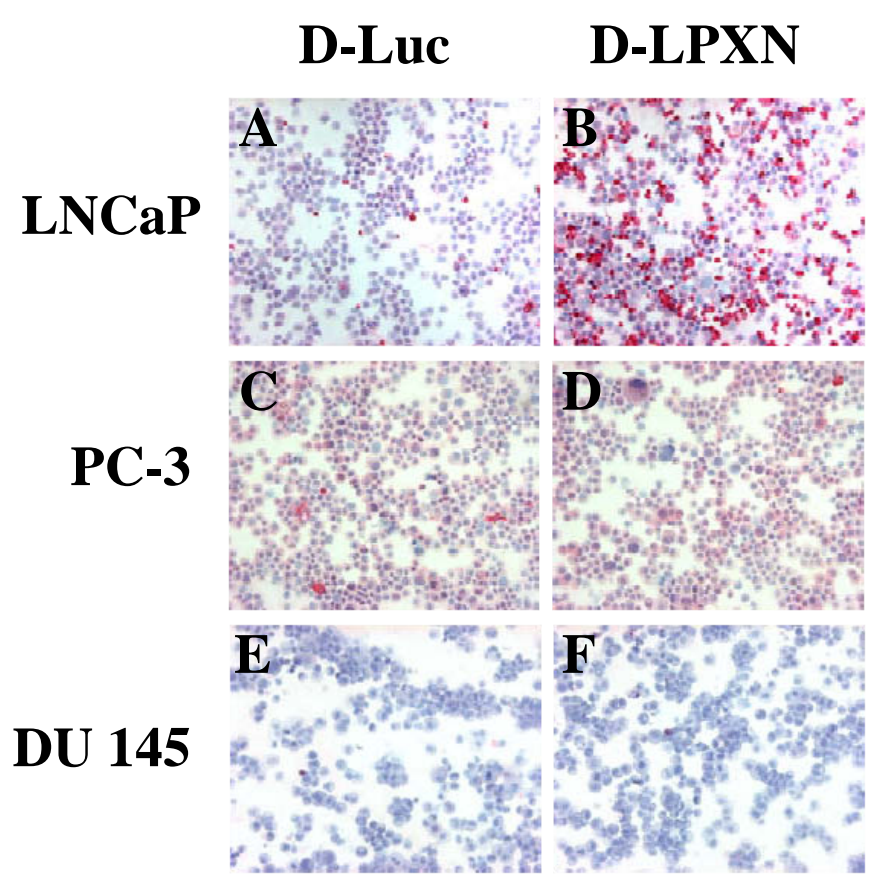

$120 \mathrm{~h}$

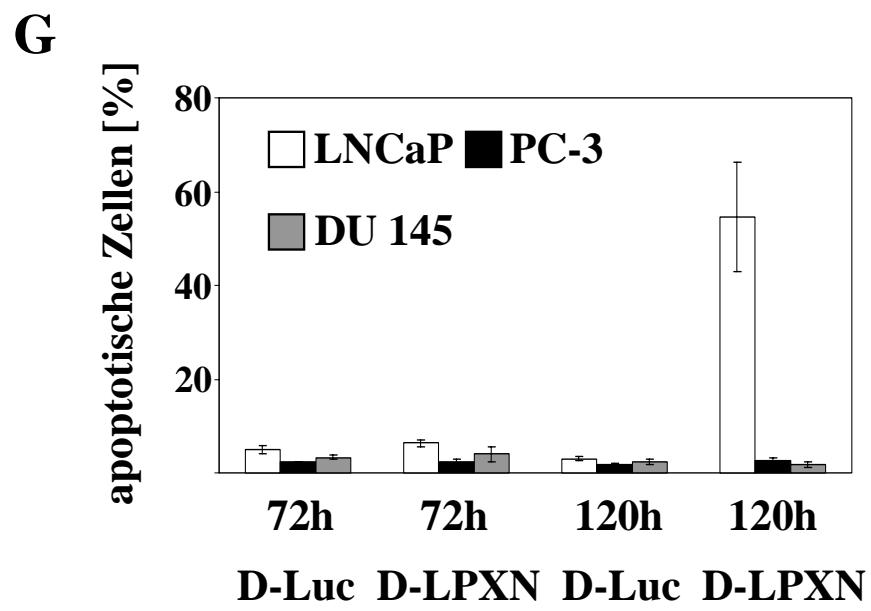

Abb. 3.19: Die Herunterregulierung der Leupaxin-Expression führt in androgen-abhängigen LNCaPZellen zur Induktion von Apoptose. LNCaP-, PC-3- und DU 145-Zellen wurden mit siRNA gegen Leupaxin (D-LPXN) und zur Kontrolle gegen Luciferase (D-Luc) transfiziert. Zu den angegebenen Zeitpunkten wurden die adhärenten und schwimmenden Zellen gesammelt und auf Objektträgern fixiert. Anschließend wurden apoptotische Zellen mit einem für aktive Caspase-3 spezifischen Antikörper markiert (rot). Die Gegenfärbung erfolgte mit Hämalaun. Zur Zählung der apoptotischen Zellen wurden fünf zufällig gewählte Felder bei einer 200fachen Vergrößerung fotografiert (A-F) und mit Hilfe der AnalySIS Software ausgewertet. G. Dargestellt wurde der Prozentsatz apoptotischer Zellen aus der Gesamtzahl der gezählten Zellen. Nur die androgenabhängigen LNCaP-Zellen zeigen eine Apoptoserate von 50\% $120 \mathrm{~h}$ nach Herunterregulierung der LeupaxinExpression, wohingegen bei den PC-3- und DU 145-Zellen auch nach $120 \mathrm{~h}$ keine erhöhte Apoptoserate im Vergleich zu den kontroll-transfizierten Zellen zu beobachten ist. 


\subsubsection{Reduktion der PSA-Bildung in LNCaP-Zellen mit verminderter Leupaxin- Expression}

Da LNCaP-Zellen im Gegensatz zu PC-3- und DU 145-Zellen androgen-abhängig sind und nur LNCaP-Zellen apoptotisch werden, wenn die Leupaxin-Genexpression reduziert wird, sollte nun untersucht werden, ob der AR eine verminderte Aktivität zeigt. Dazu wurde die Sekretion vom prostate specific antigen (PSA) der LNCaP-Zellen ins Medium gemessen (2.17.6). PSA stellt das Genprodukt von Kallikrein 3 dar, welches zwei funktionelle AREs und einen Enhancer mit einer funktionellen und stark affinen AR-Bindungsstelle in dessen Promotorregion besitzt, und damit ein stark AR-abhängiges Gen darstellt. Zur Messung der AR-Aktivität über PSA wurden LNCaP-Zellen mit der Leupaxin-spezifischen Duplex-siRNA D-LPXN und zur Kontrolle mit D-Luc transfiziert. Anschließend wurden die Zellen inkubiert und nach 24, 48 und 72 h das Medium zur Analyse der PSA-Sekretion entnommen. Die Messung der PSA-Konzentration im Kulturmedium erfolgte in Zusammenarbeit mit Prof. Dr. Hubertus Jarry (Abteilung Klinische und Experimentelle Endokrinologie, Universität Göttingen). In Abbildung 3.20 ist das Ergebnis aus drei verschiedenen Messungen zusammengefaßt. Bereits nach $24 \mathrm{~h}$ ist eine deutliche Abnahme der PSA-Sekretion zu beobachten, und nach $72 \mathrm{~h}$ wird in LNCaP-Zellen mit reduzierter Leupaxin-Expression nur noch 40\% der PSA-Menge im Vergleich zu den kontroll-transfizierten Zellen gebildet.

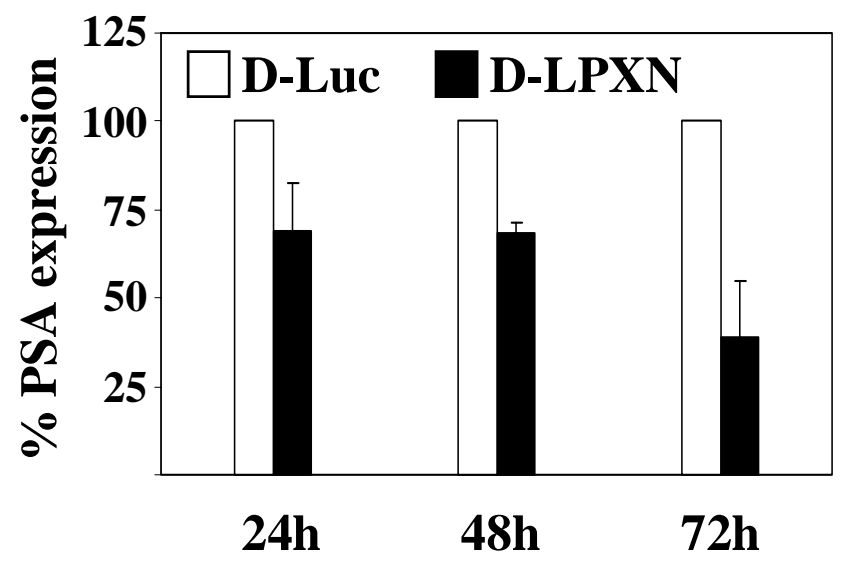

Abb. 3.20: Reduktion der PSA-Bildung nach Herunterregulierung der Leupaxin-Expression in androgenabhängigen LNCaP-Zellen. LNCaP-Zellen wurden mit siRNA gegen Leupaxin (D-LPXN) und zur Kontrolle gegen Luciferase (D-Luc) transfiziert. Zu den angegebenen Zeitpunkten wurde das Kulturmedium zur Messung der PSA-Konzentration entnommen. Die in der Grafik dargestellten Werte ergeben sich aus den Mittelwerten von drei unabhängigen Experimenten, die jeweils in einer Doppelbestimmung durchgeführt wurden. 


\subsubsection{Leupaxin hat keinen Einfluss auf die Proliferation von PCa-Zellen}

Ein möglicher Grund für die beobachtete stärkere Expression von Leupaxin in bestimmten fortgeschrittenen Prostatakarzinomen könnte eine erhöhte Proliferationsrate der Leupaxinpositiven Zellen sein. Um zu überprüfen, ob Leupaxin einen Einfluss auf die Proliferation von PCa-Zellen besitzt, wurde ein MTS-Assay nach Herunterregulierung der LeupaxinExpression durchgeführt.

Die PCa-Zelllinien LNCaP, PC-3 und DU 145 wurden mit siRNA gegen Leupaxin und zur Kontrolle gegen Luciferase transfiziert und die Zunahme der Lebendzellzahlen gemessen (siehe 2.18). Es konnte keine signifikante Reduktion der Proliferationsfähigkeit von PC-3und DU 145-Zellen festgestellt werden (Abb. 3.21). Die nach $72 \mathrm{~h}$ beobachtete Reduktion des Wachstums bei den Leupaxin-siRNA-transfizierten LNCaP-Zellen ist möglicherweise auf den Anstieg der Apoptoserate (siehe Abschnitt 3.6.2) zurückzuführen.
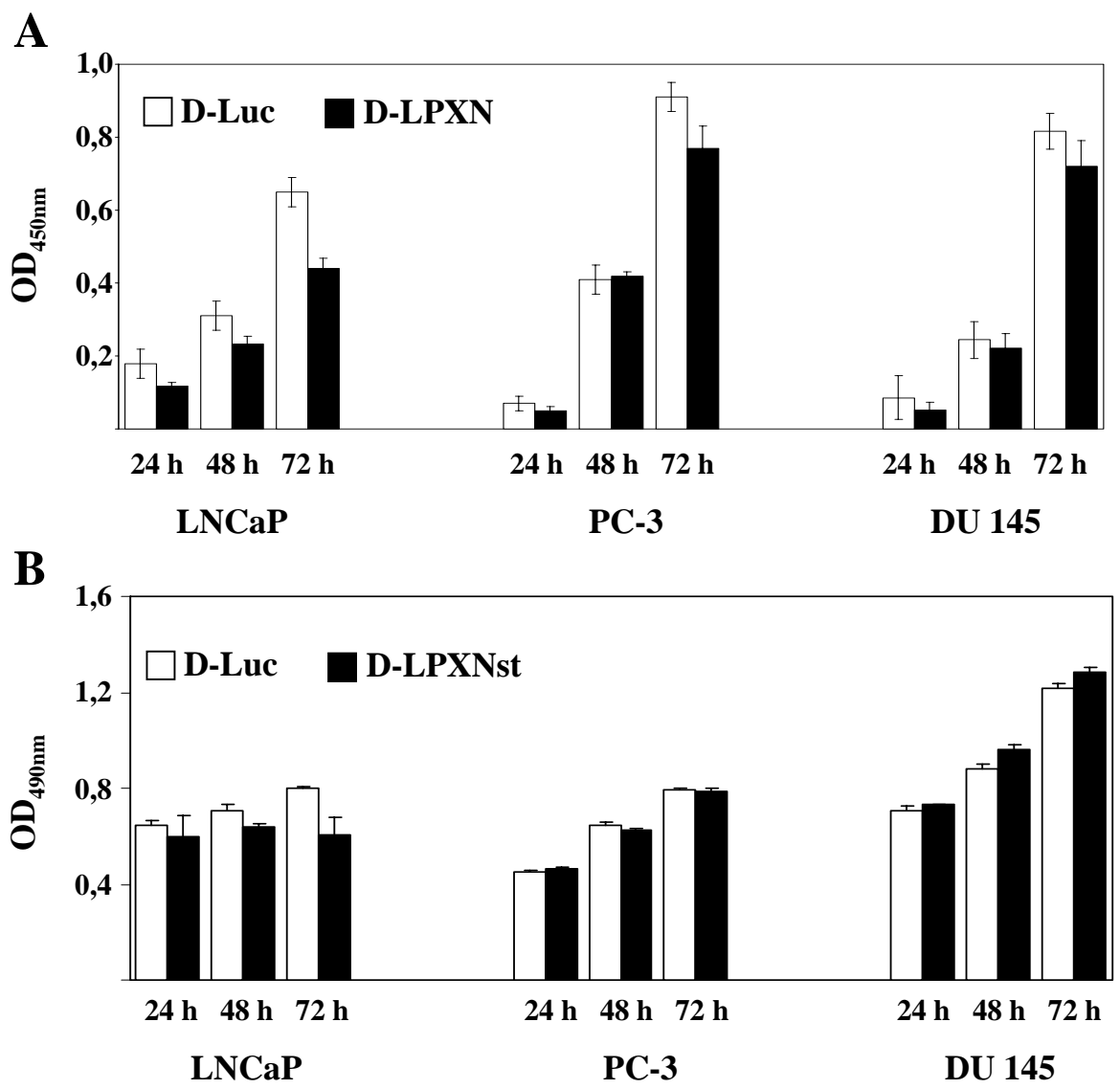

Abb. 3.21: Leupaxin hat keinen Einfluss auf die Proliferation von PCa-Zellen. Die PCa-Zelllinien LNCaP, PC-3 und DU 145 wurden mit siRNA gegen Leupaxin (A. D-LPXN; B. D-LPXNst) und zur Kontrolle gegen 
Luciferase (D-Luc) transfiziert und anschließend für die Messung der Proliferation ausplattiert. A. In diesem MTS-Assay (EZ4U, Biozol) wurde für die Herunterregulierung der Leupaxin-Expression das siRNAOligonukleotid D-LPXN verwendet. B. Das Wachstum der PCa-Zellen, die mit der Duplex-siRNA D-LPXNst behandelt worden sind, wurde mit dem MTS-Assay von Promega (CellTiter ${ }^{\circledR}$ non radioactive proliferation assay) bestimmt. Es ist bei beiden Assays deutlich zu erkennen, dass Leupaxin keinen Einfluss auf das Wachstumsverhalten von PC-3 und DU 145 hat. Der ab 48 h signifikante Unterschied in der Proliferation bei den LNCaP-Zellen ist auf den Beginn der morphologischen Veränderungen und die Apoptose-Induktion zurückzuführen.

\subsubsection{Reduktion der Invasivität und Migrationsfähigkeit von androgen-unabhängigen PC-3- und DU 145-Zellen nach Herunterregulierung der Leupaxin-Expression}

Da Leupaxin als differentiell exprimiertes Gen im humanen kapselinvasiven Prostatakarzinom identifiziert worden ist und dessen Expression mit der Progression der Tumoren korreliert (Abschnitt 3.1), stellte sich die Frage, ob Leupaxin direkt einen Einfluss auf die Invasion und Migration von PCa-Zellen ausübt. Daher wurde die Invasivität von androgen-unabhängigen PC-3- und DU 145-Zellen nach Herunterregulierung der LeupaxinExpression in vitro mit Hilfe des Matrigel-Invasions-Assays (siehe 2.19) analysiert. PC-3und DU 145-Zellen wurden dazu mit siRNA gegen Leupaxin (D-LPXN und D-LPXNst) bzw. als Kontrolle gegen Luciferase (D-Luc) über Nacht transfiziert. Anschließend wurden die Zellen in den oberen Teil eines Matrigel-Inserts gegeben, das eine mit Matrigel bedeckte Membran (8 $\mu$ m Poren) enthielt. Nach 22 h Inkubation wurden die invasiven Zellen aus dem unteren Teil des Inserts fixiert, Zellkern und Zytoplasma angefärbt und die invasiven Zellen unter dem Mikroskop gezählt (siehe 2.19). Wie in Abbildung 3.22A zu erkennen, zeigen PC3-Zellen eine um 70\% und DU 145-Zellen eine um bis zu 78 \% (für D-LPXNst) verminderte Fähigkeit der Invasion bei herunterregulierter Leupaxin-Expression im Vergleich zu den kontroll-transfizierten Zellen.

Die Fähigkeit der direkten Migration von PC-3- und DU 145-Zellen wurde mit Hilfe eines scratch-assays (auch Wundheilungsassay genannt, siehe 2.22) bestimmt. Nach der Transfektion der Zellen mit Leupaxin-spezifischer und Luciferase-spezifischer Duplex-siRNA (Kontrolle) wurden die Zellen so ausplattiert, dass sie am nächsten Tag eine geschlossene Zellschicht bildeten. Mit einer gelben Pipettenspitze wurde dann eine „Wunde“ in diese Zellschicht induziert und das Wachstum der Zellen über einen Zeitraum von 24 h unter einem inversen Mikroskop beobachtet und dokumentiert. Bereits nach $18 \mathrm{~h}$ ist ein deutlicher 
Unterschied im Migrationsverhalten von kontroll- und Leupaxin-siRNA-transfizierten PC-3und DU 145-Zellen zu beobachten (Abb. 3.22B). Während die Zellschichten der Kontrollzellen schon fast geschlossen sind, ist die Wunde bei den Zellen mit herunterregulierter Leupaxin-Expression kaum verändert.

A

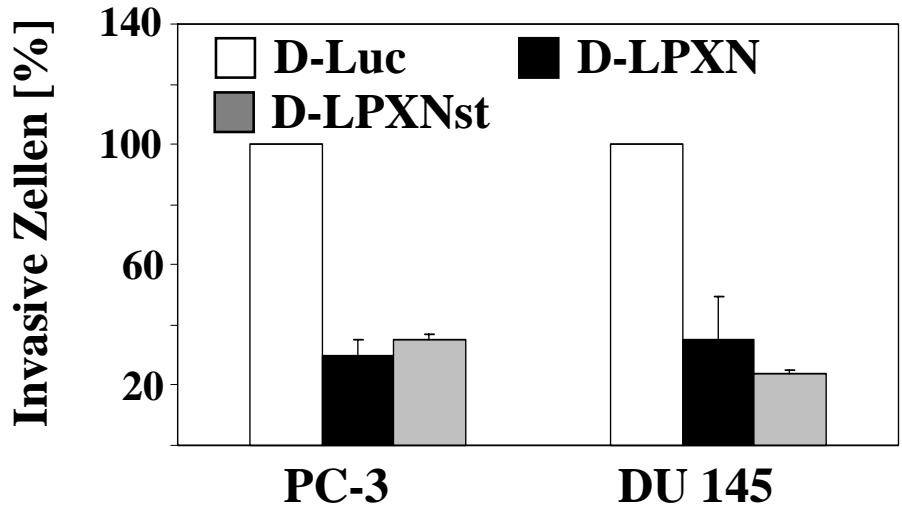

B

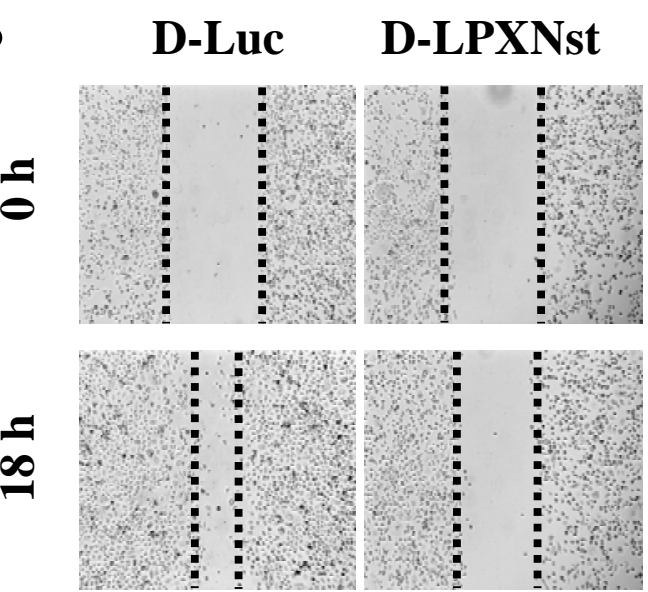

PC-3
D-Luc

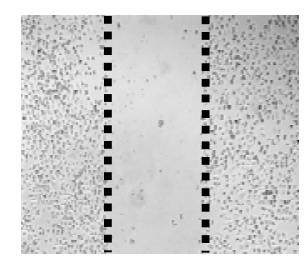

D-LPXNst

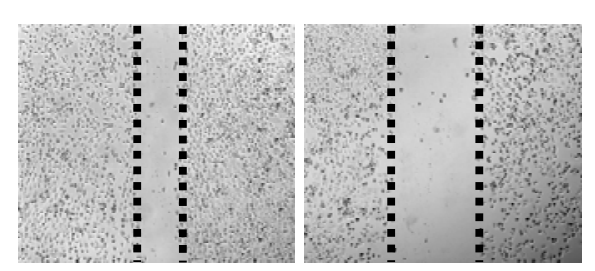

DU 145

Abb. 3.22: Reduktion der Invasivität und Migrationsfähigkeit von PC-3- und DU 145-Zellen nach Herunterregulierung der Leupaxin-Expression. A. Zur Bestimmung der Invasivität wurden gleiche Zellzahlen Kontroll- (D-Luc) und mit Leupaxin-siRNA (D-LPXN und D-LPXNst) transfizierter PC-3- und DU 145-Zellen auf eine mit Matrigel bedeckte Membran, die $8 \mu \mathrm{m}$ große Poren enthielt, ausplattiert und für $22 \mathrm{~h}$ inkubiert. Anschließend wurden die auf der oberen Seite der Membran befindlichen Zellen entfernt und die invasiven Zellen auf der unteren Seite der Membran fixiert und angefärbt. Unter einem Mikroskop wurden die invasiven Zellen in fünf zufällig gewählten Sichtfeldern gezählt. Zum besseren Vergleich der drei durchgeführten Transfektionen und Invasionsassays untereinander wurden die für die Kontrollen bestimmten 
Zellzahlen als 100\% gesetzt. B. In einem scratch-Assay wurde die direkte Migration von PC-3- und DU 145Zellen mit verminderter Leupaxin-Expression untersucht. In eine geschlossene Zellschicht von kontroll- (D-Luc) und Leupaxin-siRNA-(D-LPXNst) transfizierten PC-3- und DU 145-Zellen wurde mit einer gelben Pipettenspitze eine Wunde in die geschlossene Zellschicht eingefügt. Die Schließung der Wunde durch Migration umliegender Zellen wurde unter einem inversen Mikroskop bei 40facher Vergrößerung beobachtet und fotografiert. Nach $18 \mathrm{~h}$ ist ein deutlicher Unterschied zwischen den D-Luc- und D-LPXNst-transfizierten Zellen sowohl bei PC-3 als auch bei DU 145 zu verzeichnen.

\subsubsection{Analysen zum Einfluss von Leupaxin auf die Expression Adhäsions-relevanter Gene mittels eines Zelladhäsions-Arrays}

\subsubsection{Durchführung des Zelladhäsions-Arrays}

Aufgrund der Beobachtungen, dass Leupaxin in die Adhäsion/Apoptose von androgenabhängigen LNCaP-Zellen und in die Invasion und Migration von androgen-unabhängigen PC-3- und DU 145-Zellen involviert ist, stellte sich die Frage, welche Gene/Proteine für die Effekte nach der Leupaxin-Herunterregulierung verantwortlich sind. Da von Leupaxin in dieser Hinsicht keine Literaturdaten existieren, wurde eine cDNA-Array-Analyse durchgeführt (siehe 2.32). Auf dem verwendeten Zelladhäsions-Array sind 96 cDNAs von bekannten Genen aufgespottet, die in Invasion, Adhäsion und z.T. auch in Apoptose involviert sind. Für die Durchführung des Arrays wurden LNCaP- und PC-3-Zellen mit Leupaxin-spezifischer siRNA (D-LPXN) und zur Kontrolle mit Luciferase-spezifischer siRNA (D-Luc) transfiziert. $72 \mathrm{~h}$ nach der Transfektion wurde die Gesamt-RNA isoliert und mittels quantitativer RT-PCR auf die Herunterregulierung der Leupaxin-Expression hin untersucht. Anschließend erfolgte die radioaktive Markierung der Proben und die Hybridisierung mit zwei identischen Array-Membranen. Nachdem die Signale mit Hilfe des Phosphor-Imagers dargestellt worden waren, wurde die Analyse der Signalstärken mit Hilfe der QuantityOne Software und der SuperArray Software durchgeführt. Normalisiert wurde jeweils gegen die Signale von den auf der Membran befindlichen housekeeping-Genen $\beta$ Aktin, GAPDH, PPIA bzw. gegen die durchschnittlichen Signalstärke auf dem Blot für zwei verschiedene Expositionszeiten. Alle Ergebnisse wurden anschließend gemittelt.

Bei den LNCaP-Zellen mit herunterregulierter Leupaxin-Expression konnten vier differentiell exprimierte Gene identifiziert werden (Tab. 3.IV). Berücksichtigt wurden dabei nur Gene, die um den Faktor 1,5 hoch- bzw. herunterreguliert wurden. 
Tab. 3.IV: Ergebnisse des Zelladhäsions-Arrays für LNCaP-Zellen nach Herunterregulierung der Leupaxin-Expression (D-LPXN vs. D-Luc).

\begin{tabular}{|c|c|c|c|c|}
\hline Genbank & Symbol & Beschreibung & Faktor & \\
\hline NM_004363 & CEACAM5 & $\begin{array}{l}\text { Homo sapiens carcinoembryonic antigen-related cell } \\
\text { adhesion molecule } 5 \text { (CEACAM5), }\end{array}$ & 1,4 & 茜 \\
\hline AF062343 & CTNND1 & Catenin (cadherin-associated protein), delta 1 & 1,5 & $\stackrel{\frac{2}{3}}{\frac{2}{7}}$ \\
\hline M11233 & CTSD & Cathepsin D (lysosomal aspartyl protease) & 2,0 & 商 \\
\hline X02761 & FN1 & Fibronektin 1 & 2,2 & $\frac{1}{2}$ \\
\hline
\end{tabular}

Da die siRNA-Oligonukleotide D-LPXNst eine stärkere Herunterregulierung der LeupaxinExpression bewirken, wurde der Array mit RNA von LNCaP-Zellen, die mit der D-LPXNstsiRNA behandelt worden sind, wiederholt (Tab. 3.V).

Tab. 3.V: Ergebnisse des Zelladhäsions-Arrays für LNCaP-Zellen mit herunterregulierter LeupaxinExpression (D-LPXNst vs. D-Luc).

\begin{tabular}{|c|c|c|c|c|}
\hline Genbank & Symbol & Beschreibung & Faktor & \\
\hline NM_002211 & ITGB1 & $\begin{array}{c}\text { Integrin, beta } 1 \text { (fibronectin receptor, beta polypeptide, } \\
\text { antigen CD29 includes MDF2, MSK12), integrin a1 }\end{array}$ & 1,9 & \multirow{3}{*}{ 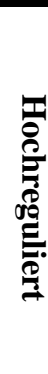 } \\
\hline AF062343 & CTNND1 & Catenin (cadherin-associated protein), delta 1 & 4,9 & \\
\hline AF060152 & ADAMTS1 & $\begin{array}{l}\text { A disintegrin-like and metalloprotease (reprolysin type) } \\
\text { with thrombospondin type } 1 \text { motif, 1; Meth } 1\end{array}$ & 1,8 & \\
\hline
\end{tabular}

Bei den PC-3-Zellen, die mit siRNA gegen Leupaxin behandelt worden sind, konnten acht herunterregulierte Gene und sechs hochregulierte Gene identifiziert werden (Tab. 3.VI). Hier wurden nur Gene berücksichtigt, die um den Faktor 2 differentiell exprimiert sind. 
Tab. 3.VI: Ergebnisse des Zelladhäsions-Array für PC-3

\begin{tabular}{|c|c|c|c|c|}
\hline Genbank & Symbol & Beschreibung & Faktor & \\
\hline AF060152 & ADAMTS1 & $\begin{array}{l}\text { A disintegrin-like and metalloprotease (reprolysin type) } \\
\text { with thrombospondin type } 1 \text { motif, 1; Meth } 1\end{array}$ & 2,0 & \\
\hline X02761 & FN1 & Fibronektin 1 & 3,3 & \\
\hline AF084467 & HPSE & Homo sapiens heparanase mRNA & 3,5 & ב \\
\hline Y00057 & ITGB2 & $\begin{array}{l}\text { Integrin, beta } 2 \text { (antigen CD18 (p95), lymphocyte } \\
\text { function-associated antigen 1; macrophage antigen } 1\end{array}$ & 2,2 & 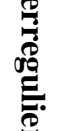 \\
\hline J05633 & ITGB5 & Integrin, beta 5 & 3,3 & $\Xi$ \\
\hline NM_002659 & PLAUR & $\begin{array}{l}\text { Human urokinase-type plasminogen activator receptor } \\
\text { (uPAR) }\end{array}$ & 2,0 & ֶֶ, \\
\hline M83248 & SPP1 & $\begin{array}{l}\text { Homo sapiens secreted phosphoprotein } 1 \text { (osteopontin, } \\
\text { bone sialoprotein I, early T-lymphocyte activation 1) } \\
\text { (SPP1), }\end{array}$ & 1,9 & z \\
\hline L38969 & THBS3 & Homo sapiens thrombospondin 3 (THBS3) gene; TSP-3 & 1,9 & \\
\hline M25280 & SELL & Selectin L (lymphocyte adhesion molecule 1) & 5,9 & 可 \\
\hline J02685 & SERPINB2 & Human plasminogen activator inhibitor (PAI-2) & 4,5 & 里 \\
\hline NM_002639 & SERPINB5 & protease inhibitor 5; maspin & 3,6 & $\stackrel{\stackrel{3}{2}}{\Xi}$ \\
\hline NM_003255 & TIMP2 & Tissue inhibitor of metalloproteinase 2 (TIMP2) & 3,4 & 文 \\
\hline M61916 & LAMB1 & Laminin B1 chain & 2,3 & $\theta_{1}$ \\
\hline X57766 & MMP11 & Human stromelysin-3 & 2,5 & Z \\
\hline
\end{tabular}




\subsubsection{2 Überprüfung der Daten aus dem Zelladhäsions-Array}

Die aus den Zelladhäsions-Arrays erhaltenen Daten sollten durch eine zweite unabhängige Methode bestätigt werden. Daher wurden quantitative real time RT-PCR-Analysen für die in den Tabellen 3.IV bis 3.VI grau hinterlegten Gene durchgeführt. Für die Gene Maspin, TIMP2, PAI-2 und uPAR konnte keine veränderte Expression weder für PC-3- noch für DU 145-Zellen mit verminderter Leupaxin-Expression festgestellt werden.

Weiterhin wurde das Gen CTNND1 untersucht, welches in beiden Zelladhäsions-Arrays von LNCaP (D-LPXN und D-LPXNst) identifiziert wurde. Das humane CTNND1-Gen besteht aus 21 Exons, die für bis zu 32 Protein-Isoformen als alternative Spleißprodukte kodieren. Identifiziert wurden 4 Hauptisoformen (1-4), die aufgrund von alternativen Startkodons entstehen, und weitere Isoformen, die sich durch alternatives Spleißen von 3 Exons unterscheiden (A, B und C). Mittels quantitativer RT-PCR konnte eine veränderte CTNND1Expression in LNCaP-, PC-3- und DU 145-Zellen 72 h nach Herunterregulierung der Leupaxin-Expression festgestellt werden (Abb. 3.23). Es wurden zwei verschiedene Primerpaare für die quantitative RT-PCR verwendet. Das Primerpaar CTNND1 amplifiziert jedes bekannte Transkript von CTNND1, wohingegen CTNND1-A nur die Transkripte amplifiziert, welche das sog. Exon A enthalten. Bei allen drei PCa-Zelllinien konnte gezeigt werden, dass die Expression von CTNND1 bzw. CTNND1-A 72 h nach Herunterregulierung der Leupaxin-Expression zunimmt.

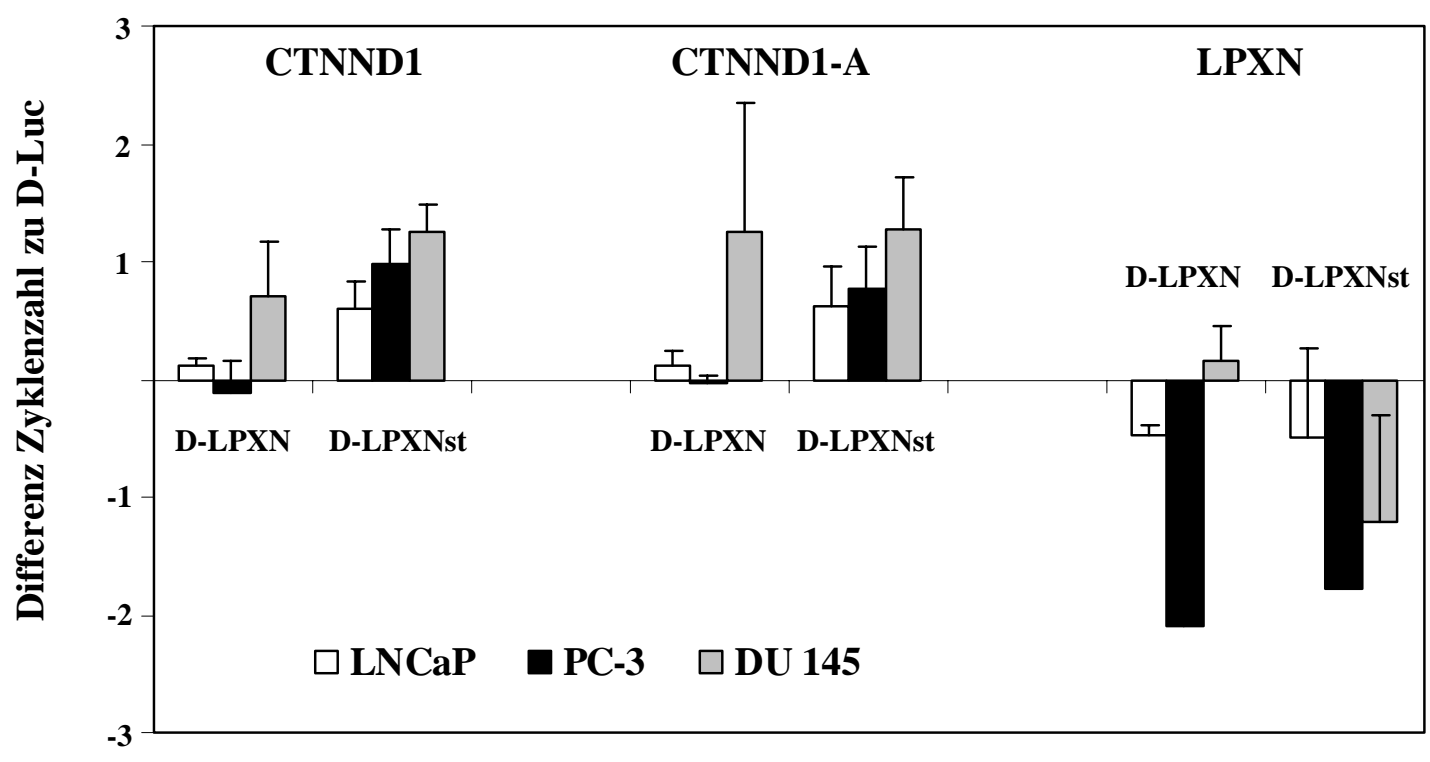


Abb. 3.23: Ergebnisse der quantitativen RT-PCR-Analysen zur Expression von CTNND1 in den PCaZellen mit reduzierter Leupaxin-Expression. Die Zelllinien LNCaP, PC-3 und DU 145 wurden mit siRNA gegen Leupaxin (D-LPXN und D-LPXNst) und zur Kontrolle gegen Luciferase (D-Luc) transfiziert und für $72 \mathrm{~h}$ inkubiert. Anschließend wurde die Gesamt-RNA isoliert, cDNA synthetisiert und quantitative real time PCRAnalysen mit spezifischen Primern durchgeführt. Es ist deutlich zu erkennen, dass sowohl CTNND1 als auch CTNND1-A in allen drei PCa-Zelllinien überexprimiert wird, wenn die Leupaxin-Expression herunterreguliert wurde. Zur Kontrolle der Transfektionen wurde auch die Expression von Leupaxin (LPXN) überprüft. Die in der Grafik angegebenen Werte ergeben sich aus den Mittelwerten von drei verschiedenen Transfektionen, die zweimal jeweils in Doppelbestimmungen über die quantitative real time PCR getestet worden sind. Zur Normalisierung wurde das housekeeping-Gen GAPDH verwendet. Dargestellt ist die Differenz der Zyklenzahl von D-Luc vs. D-LPXN bzw. D-LPXNst.

Um die Ergebnisse der quantitativen RT-PCR auf Proteinebene zu bestätigen, wurde ein Antikörper gegen CTNND1 erworben. Allerdings erkennt dieser Antikörper sowohl die Isoformen 1 als auch die Isoformen 2. Ein für die Isoform 1A spezifischer Antikörper ist nicht erhältlich. Daher wurden die anschließenden Western Blot-Analysen, die in Abbildung 3.24 dargestellt sind, mit diesem Antikörper durchgeführt. Dabei ist zu erkennen, dass sowohl in LNCaP- als auch in DU 145-Zellen nach Herunterregulierung der Leupaxin-Expression eine erhöhte Expression von CTNND1 zu verzeichnen ist. Für PC-3-Zellen konnte eine hochregulierte Expression von CTNND1 auf Proteinebene nicht verifiziert werden.

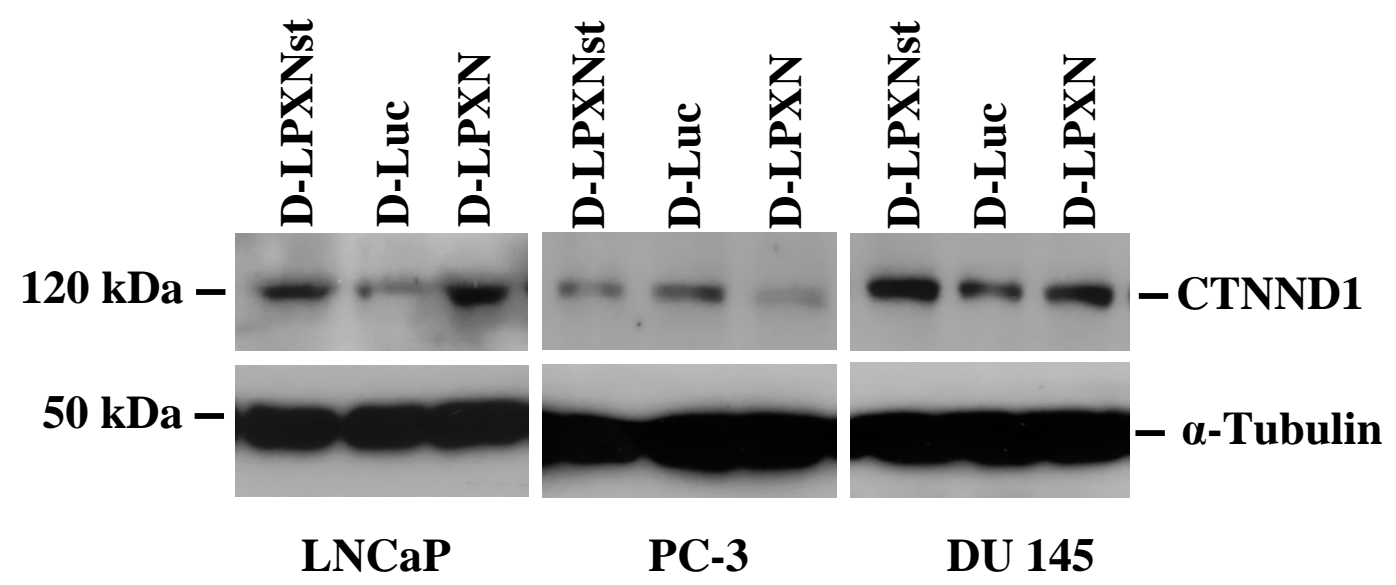

Abb. 3.24: Western Blot-Analyse zur Bestätigung der Hochregulierung der CTNND1-Expression in den PCa-Zelllinien mit reduzierter Leupaxin-Expression. LNCaP-, PC-3- und DU 145-Zellen wurden mit siRNA gegen Leupaxin (D-LPXN und D-LPXNst) und zur Kontrolle gegen Luciferase (D-Luc) transfiziert und für 72 h inkubiert. Nach der Isolierung von Gesamt-Proteinen wurden diese über SDS-PAGE aufgetrennt und ein Western Blot mit einem CTNND1-spezifischen Antikörper durchgeführt. In der für CTNND1 erwarteten Größe 
von 120 kDa konnte eine spezifische Bande detektiert werden. Bei den D-LPXN- und D-LPXNst-behandelten LNCaP- und DU 145-Zellen ist eine deutlich erhöhte Expression von CTNND1 zu verzeichnen.

\subsubsection{Analysen zur Phosphorylierung und Aktivität von Proteinen des MAPK (mitogen activated protein kinase)-Signalweges nach Herunterregulierung der Leupaxin- Expression}

\subsubsection{Durchführung des Phospho-MAPK-Arrays}

Aus der Literatur ist bekannt, dass Leupaxin mit der Tyrosinkinase PYK2 (proline rich tyrosine $(Y)$ kinase 2) und der Phosphatase PTP-PEST (protein tyrosine phosphatase-PEST) interagiert [Gupta et al., 2003]. Um einen genaueren Einblick zu erhalten, in welche Signalwege Leupaxin involviert ist und welche Signalwege bei Herunterregulierung der Leupaxin-Expression an- bzw. abgeschaltet werden, wurde ein sog. Phospho-MAPK (mitogen activated protein kinase)-Array durchgeführt (siehe 2.31). Auf diesem Array sind Antikörper aufgespottet, die gegen bestimmte phosphorylierte Aminosäuren von Proteinen des MAPKSignalweges gerichtet sind. Dieser Array wurde mit Gesamt-Protein von LNCaP-Zellen inkubiert, die für $72 \mathrm{~h}$ mit siRNA gegen Leupaxin (D-LPXNst) transfiziert worden waren. Eine zweite Membran wurde zur Kontrolle mit Protein von D-Luc transfizierten LNCaPZellen behandelt. Nach der Entwicklung der Signale wurden die Filme eingescannt und im Phosphor-Imager ausgewertet. Dabei wurden Unterschiede im Phosphorylierungsstatus von z.B. GSK-3ß, AKT2 und JNK2 festgestellt (Tab. 3.VII). 
Tab. 3.VII: Ergebnisse des Phospho-MAPK-Arrays von LNCaP-Zellen mit herunterregulierter LeupaxinExpression (D-LPXNst vs. D-Luc).

\begin{tabular}{|c|c|c|c|c|}
\hline \multirow[b]{2}{*}{ Phospho-Protein } & \multirow{2}{*}{$\begin{array}{c}\text { Phosphorylierungs- } \\
\text { stelle }\end{array}$} & \multicolumn{2}{|c|}{ Faktor* } & \\
\hline & & $30 \sec ^{\#}$ & $10 \min ^{\#}$ & \\
\hline GSK-3 $\alpha / \beta$ & S21/S9 & 1,3 & 1,1 & $\frac{T}{9}$ \\
\hline AKT 1 & S473 & 1,3 & 1,1 & $\underline{\underline{Q}}$ \\
\hline 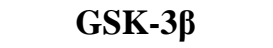 & S9 & 2,2 & 1,2 & $\stackrel{\text { oge }}{=}$ \\
\hline AKT3 & S472 & n.a. & 1,7 & $\Xi$ \\
\hline ERK1 & T202/Y204 & n.a. & 1,6 & \\
\hline JNK1 & T183/Y185 & n.a. & 2,7 & \\
\hline AKT 2 & S474 & 1,8 & 1,0 & \\
\hline JNK pan & $\begin{array}{l}\text { T183/Y185, } \\
\text { T221/Y223 }\end{array}$ & n.a. & 3,0 & 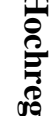 \\
\hline ERK2 & T185/Y187 & n.a. & 2,0 & $\frac{\bar{g}}{2}$ \\
\hline JNK3 & T221/Y223 & n.a. & 3,3 & \\
\hline JNK2 & T183/Y185 & 3,4 & 2,0 & \\
\hline MSK2 & S360 & n.a. & 1,1 & \\
\hline
\end{tabular}

* Faktor der Hoch- bzw. Herunterregulierung; n.a.= nicht auswertbar

\# Expositionszeit des Filmes

\subsubsection{2 Überprüfung der Ergebnisse des Phospho-MAPK-Arrays an PCa-Zellen mittels Western Blot-Analysen}

Zur Überprüfung der Array-Ergebnisse wurden Western Blot-Analysen (siehe 2.16) durchgeführt. Dazu wurden Antikörper eingesetzt, die spezifisch nur die phosphorylierten Formen der Proteine erkennen. Als Kontrolle dienten anschließend Antikörper, die sowohl die phosphorylierte als auch die nicht phosphorylierte Form der Proteine detektieren.

Zunächst wurde der Phosphorylierungsstatus der MAPK ERK1/2 (extracellular matrix regulated kinase 1/2 (p44/p42)) untersucht. Wie in Abbildung 3.25 dargestellt, zeigen die LNCaP-Zellen mit herunterregulierter Leupaxin-Expression eine Reduktion in der Phosphorylierung von ERK2 an der Aminosäureposition T202/Y204 schon 24 h nach der 
Transfektion mit den siRNAs D-LPXN und D-LPXNst im Vergleich zu den kontrolltransfizierten LNCaP-Zellen. Bei ERK1, welches nur sehr schwach phosphoryliert wird, ist hingegen kein eindeutiges Muster im Phosphorylierungsgrad zu erkennen. Die Expression von ERK1/2 hingegen ändert sich nicht bzw. nur sehr minimal (Abb. 3.25A, Mitte). Bei den PC-3- und DU 145-Zellen ist keine Veränderung im Phosphorylierungsgrad von ERK1/2 nach Herunterregulierung der Leupaxin-Expression zu erkennen. Zudem zeigen auch die PC3-Zellen insgesamt nur eine schwache Phosphorylierung von ERK1/2 (Abb. 3.25B).

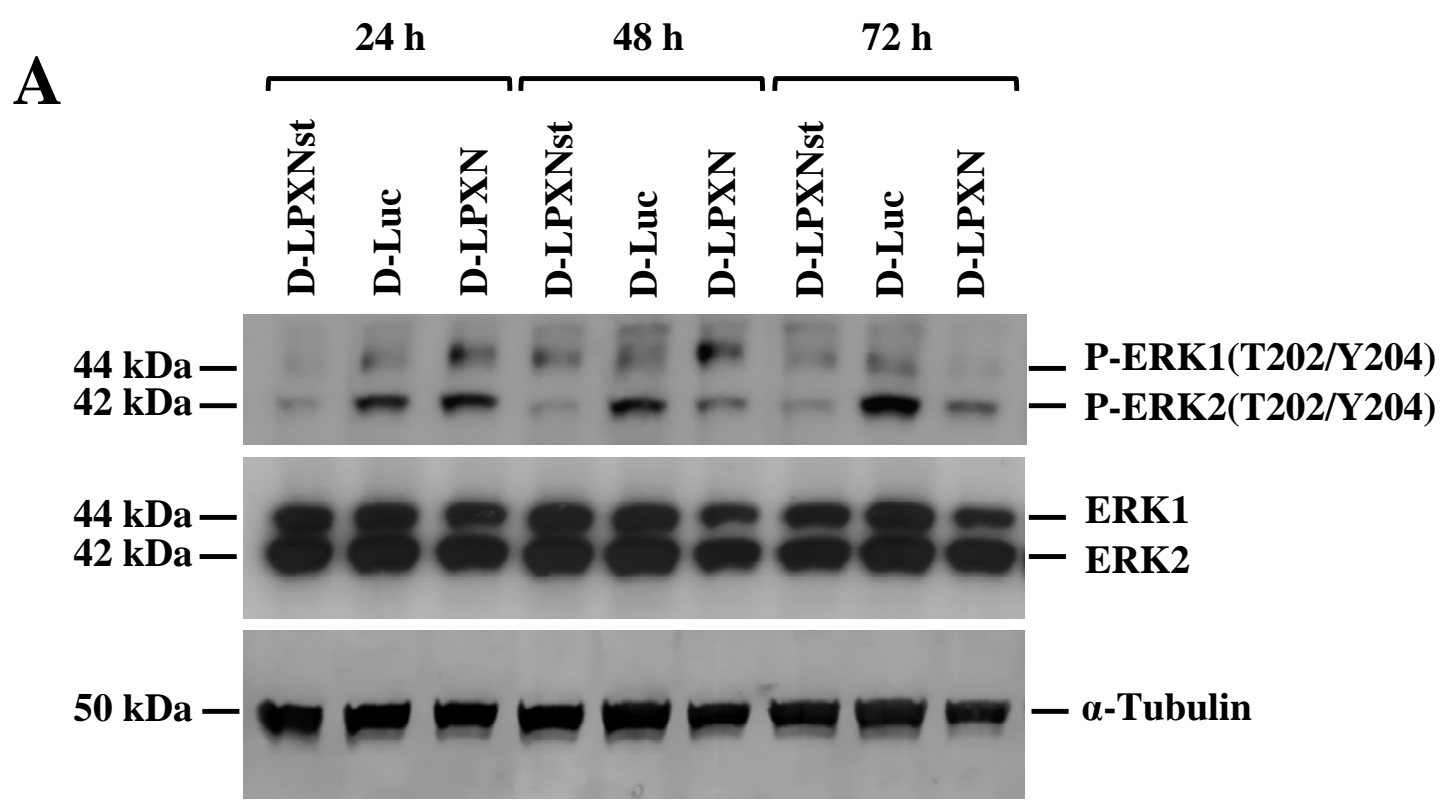

LNCaP

B
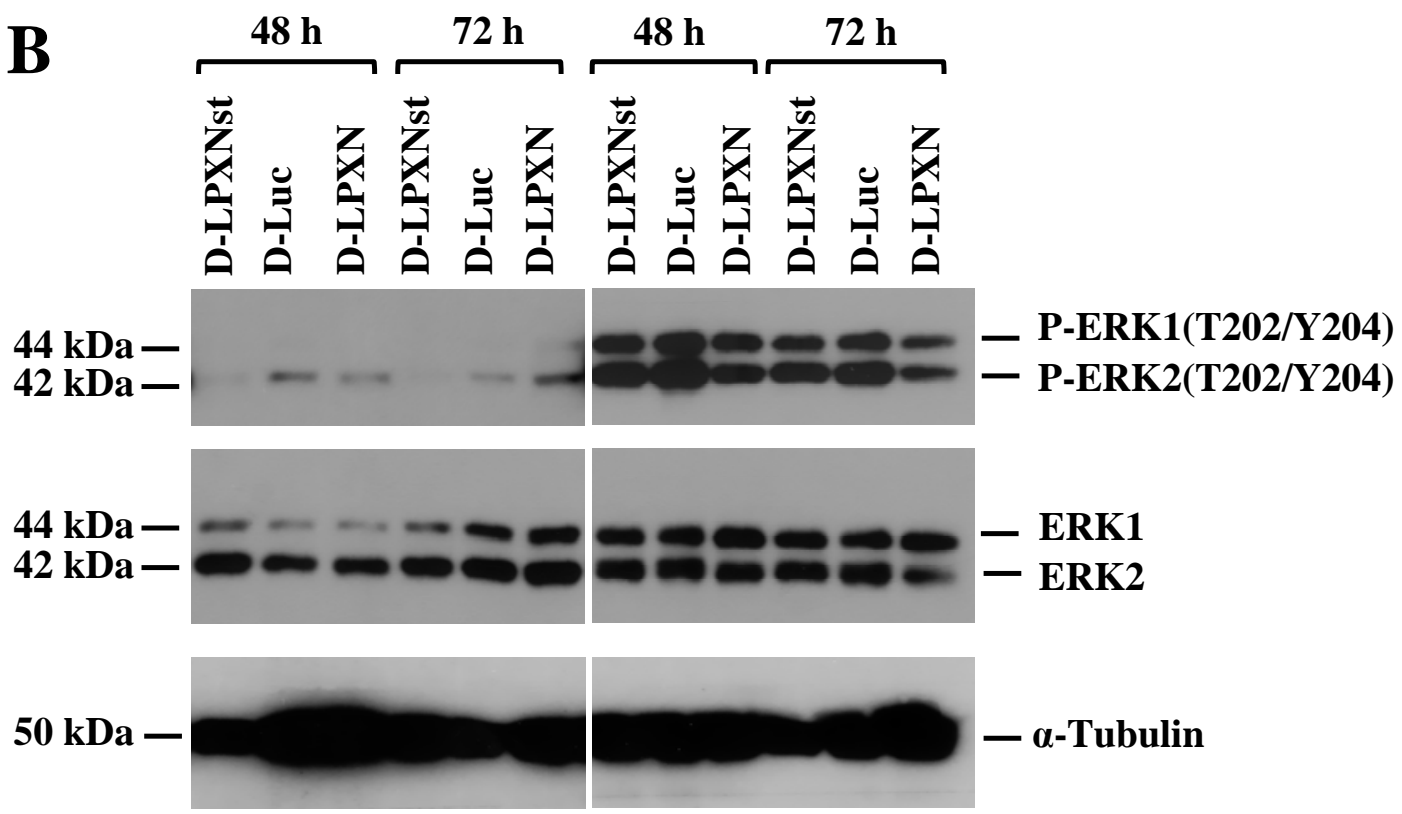

PC-3

DU 145 
Abb. 3.25: Western Blot-Analysen zur Phosphorylierung und Expression von ERK1/2 in LNCaP-, PC-3und DU 145-Zellen mit herunterregulierter Leupaxin-Expression. LNCaP- (A.), PC-3- und DU 145-Zellen (B.) wurden mit Leupaxin-spezifischer siRNA (D-LPXNst und D-LPXN) bzw. als Kontrolle mit Luciferasespezifischer siRNA (D-Luc) transfiziert. Nach den angegebenen Zeitpunkten wurde Gesamt-Protein isoliert und für die Western Blot-Analysen eingesetzt. Zunächst wurde ein Antikörper verwendet, der spezifisch für die Phosphorylierungs-Stelle T202/Y204 sowohl in ERK1 (P-ERK1) als auch in ERK2 (P-ERK2) ist. Zur Darstellung der Gesamt-ERK1/2-Menge im Zelllysat wurde ein Antikörper gegen unphosphoryliertes ERK1/2 eingesetzt, und ein Antikörper gegen $\alpha$-Tubulin diente zur Kontrolle der aufgetragenen Proteinmengen.

Verantwortlich für die Phosphorylierung von ERK1/2 ist die MAPK-Kinase MEK1/2 (MAP kinase or ERK kinase), welche z.B. an den Aminosäurepositionen S217/221 phosphoryliert und damit aktiviert wird. Um zu bestätigen, dass der MAPK-Signalweg in LNCaP-Zellen mit herunterregulierter Leupaxin-Expression eine geringere Aktivität aufweist, wurde auch der Phosphorylierungsgrad von MEK1/2 analysiert. In den Leupaxin-siRNA transfizierten LNCaP-Zellen konnte eine deutliche Reduktion in der Phosphorylierung von MEK1/2 an S217/S221 beobachtet werden, wohingegen die Expression von MEK1/2 unverändert blieb (Abb. 3.26).

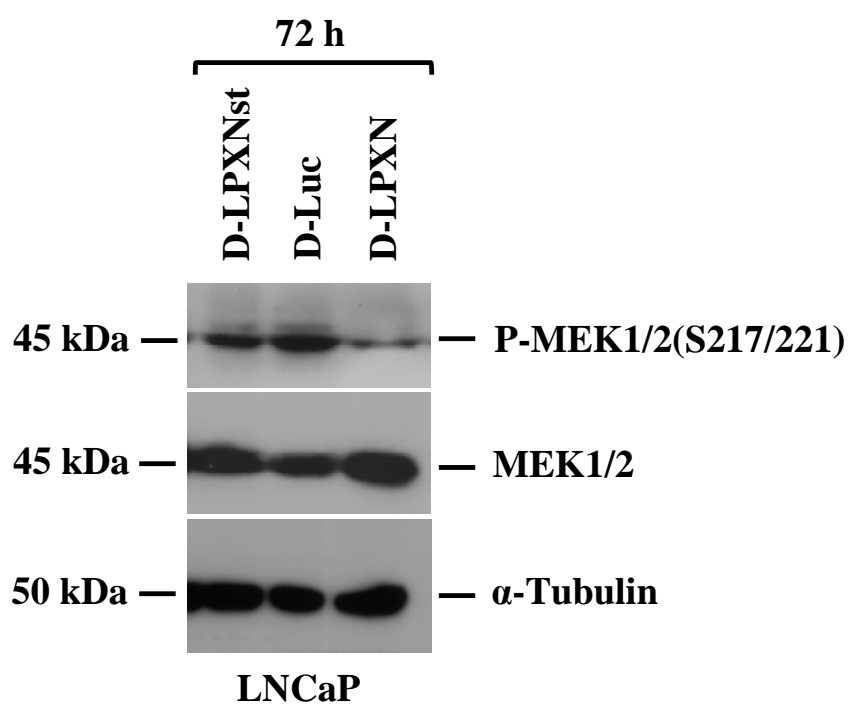

Abb. 3.26: Western Blot-Analyse zur Phosphorylierung und Expression von MEK1/2 in LNCaP-Zellen mit herunterregulierter Leupaxin-Expression. LNCaP-Zellen wurden mit Leupaxin-spezifischer siRNA (DLPXNst und D-LPXN) bzw. als Kontrolle mit Luciferase-spezifischer siRNA (D-Luc) transfiziert. Nach 72 h wurde Gesamt-Protein isoliert und für die Western Blot-Analyse eingesetzt. Zunächst wurde ein Antikörper verwendet, der spezifisch für die Phosphorylierungs-Stelle S217/221 von MEK1/2 ist. Zur Darstellung der 
Gesamt-MEK1/2-Proteinmenge im Zelllysat wurde ein Antikörper gegen unphosphoryliertes MEK1/2 eingesetzt, und ein Antikörper gegen $\alpha$-Tubulin diente zur Kontrolle der aufgetragenen Proteinmengen.

Da ERK1/2 und MEK1/2 am Ende des MAPK-Signalweges stehen, stellte sich nun die Frage, wie es zur reduzierten Phosphorylierung von ERK2 und MEK1/2 kommt, wenn Leupaxin herunterreguliert wird. Die Kinase AKT, welche u.a. den MAPK-Signalweg induziert, kann an den Aminosäurepositionen T308 bzw. S473 aufgrund unterschiedlicher Stimuli von außen phosphoryliert und damit aktiviert werden. Phosphoryliertes AKT selbst aktiviert z.B. die MAP-Kinase Kinase Kinase (MAP3K) c-Raf (RAF1, v-raf-1 murine leukemia viral oncogene homolog 1) durch die Phosphorylierung von c-Raf an Position S259. c-Raf wiederum phosphoryliert und aktiviert MEK1/2. Die Analyse der Aktivitäten von AKT und c-Raf erfolgte mit Hilfe Phospho-spezifischer Antikörper (P-AKT(T308), P-AKT(S473) und cRaf(S259)). Wie in Abbildung 3.27 dargestellt, ist weder bei den Phosphorylierungsstellen T308 und S473 von AKT (Abb. 3.27A), noch bei S259 von c-Raf (Abb. 3.27B) ein Unterschied im Phosphorylierungsgrad von LNCaP-Zellen mit verminderter LeupaxinExpression zu erkennen. Auch bei PC-3 und DU 145 konnte keine Veränderung der Phosphorylierung von AKT(S259) festgestellt werden (Abb. 3.28). Somit ist dieser Arm der Aktivierung des MAPK-Signalweges nicht an den Effekten der LeupaxinHerunterregulierung in LNCaP-, PC-3 und DU 145-Zellen beteiligt. 
A

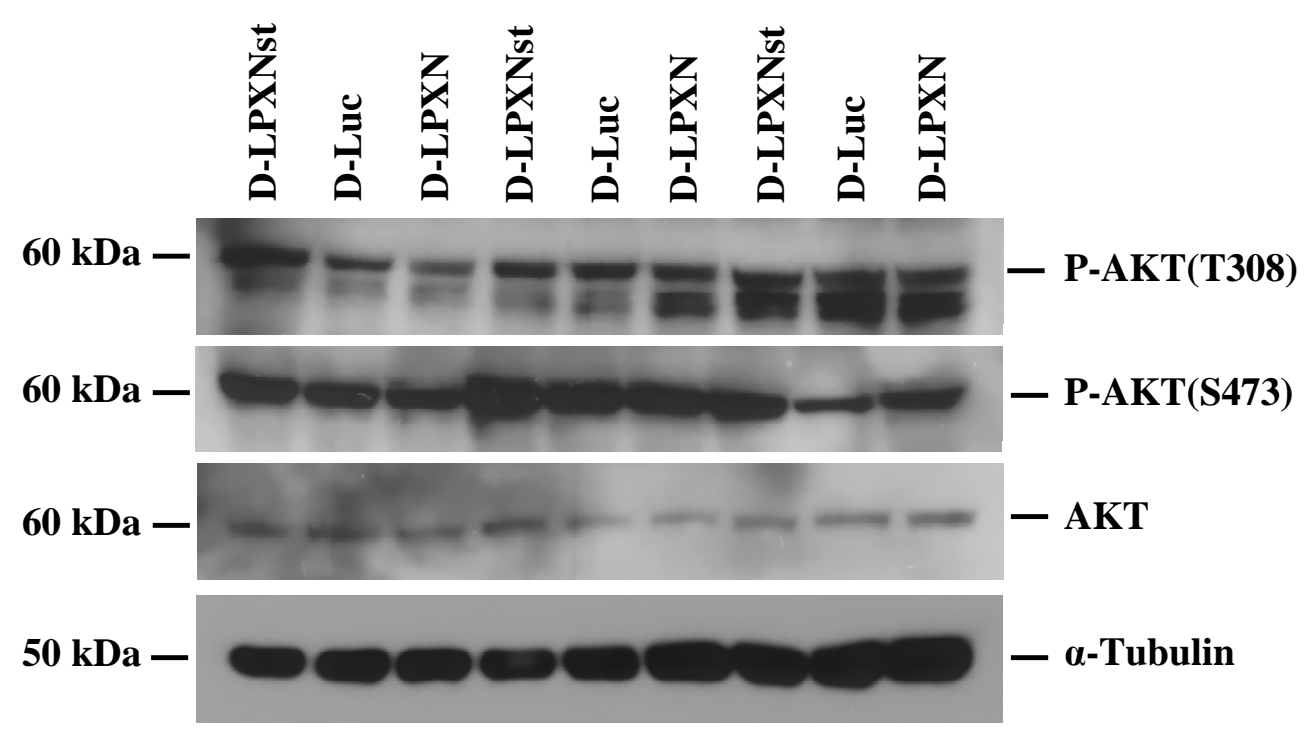

B

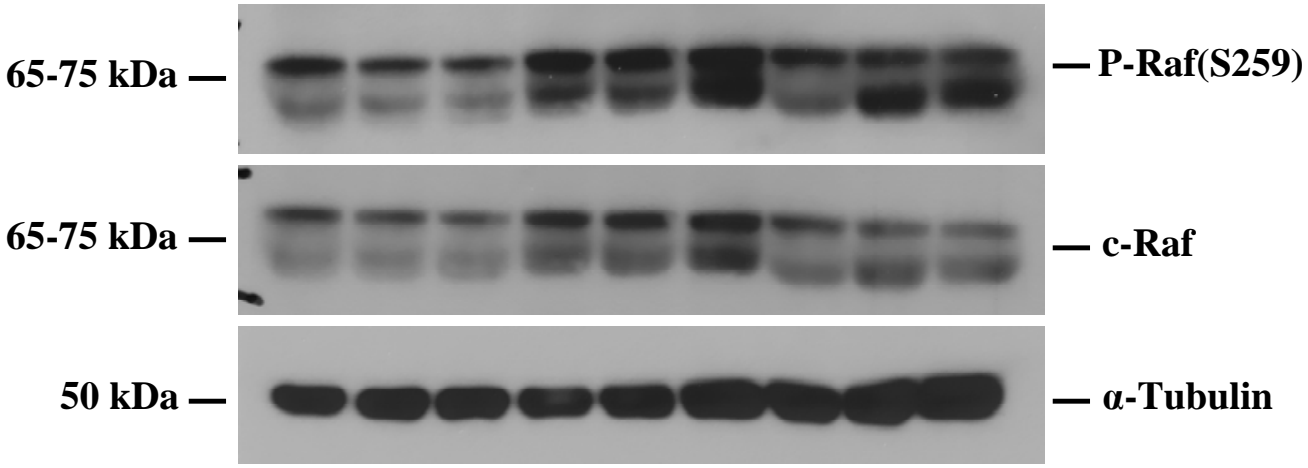

LNCaP

Abb. 3.27: Western Blot-Analyse zur Phosphorylierung und Expression von AKT und c-Raf in LNCaPZellen mit herunterregulierter Leupaxin-Expression. LNCaP-Zellen wurden mit spezifischer siRNA gegen Leupaxin (D-LPXNst und D-LPXN) bzw. als Kontrolle gegen Luciferase (D-Luc) behandelt. Nach den angegebenen Zeitpunkten wurde Gesamt-Protein isoliert und für die Western Blot-Analysen eingesetzt. A. Zunächst wurde ein Antikörper verwendet, der spezifisch für die Phosphorylierungs-Stellen T308 und S473 von AKT ist. Zur Darstellung der Gesamt-AKT-Proteinmenge im Zelllysat wurde ein Antikörper gegen unphosphoryliertes AKT eingesetzt. B. Die in A. verwendete Membran wurde mit einem Phospho-spezifischen Antikörper gegen Raf(S259) und anschließend mit einem Antikörper gegen das gesamte c-Raf rehybridisiert. Ein Antikörper gegen $\alpha$-Tubulin diente zur Kontrolle der aufgetragenen Gesamt-Proteinmengen bei A. und B. 


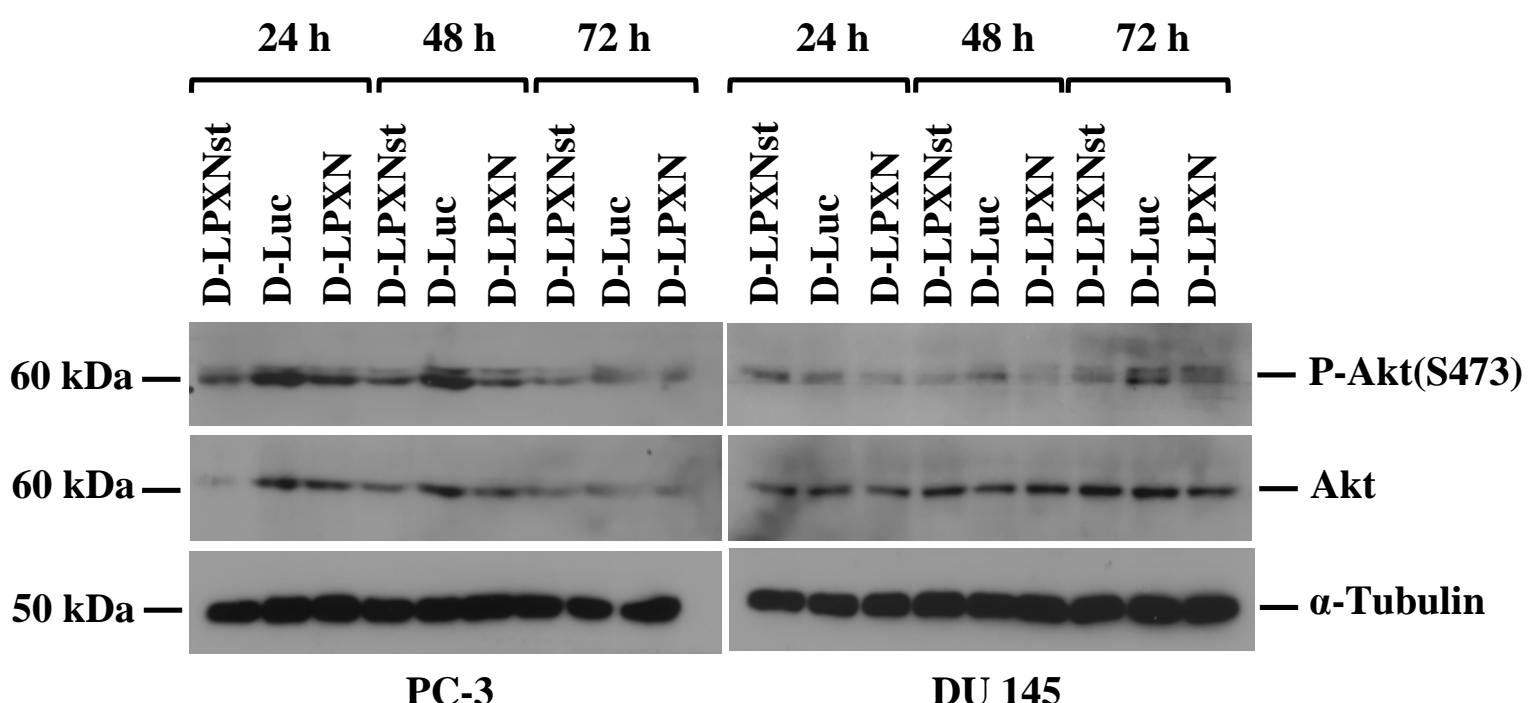

Abb. 3.28: Western Blot-Analyse zur Phosphorylierung und Expression von AKT in PC-3- und DU 145Zellen mit herunterregulierter Leupaxin-Expression. PC-3- und DU 145-Zellen wurden mit spezifischer siRNA gegen Leupaxin (D-LPXNst und D-LPXN) bzw. als Kontrolle gegen Luciferase (D-Luc) behandelt. Nach den angegebenen Zeitpunkten wurde Gesamt-Protein isoliert und für die Western Blot-Analysen eingesetzt. Zunächst wurde ein Antikörper verwendet, der spezifisch die Phosphorylierungs-Stelle S473 von AKT detektiert. Zur Darstellung der Gesamt-AKT-Menge im Zelllysat wurde ein Antikörper gegen unphosphoryliertes AKT eingesetzt. Ein Antikörper gegen $\alpha$-Tubulin diente zur Kontrolle der aufgetragenen Gesamt-Proteinmengen.

\subsection{8 Überexpression von Leupaxin in den PCa-Zelllinien Generierung von induzierbaren stabilen Transfektanten}

Für die Überexpression wurde das mit Doxycyclin induzierbare Tet-On-System von Clontech verwendet (Abb. 3.29), da aus Transfektionen mit Leupaxin unter einem konstitutiven Promotor (z.B. pEGFP-C1-LPXN) keine Klone isoliert werden konnten. 


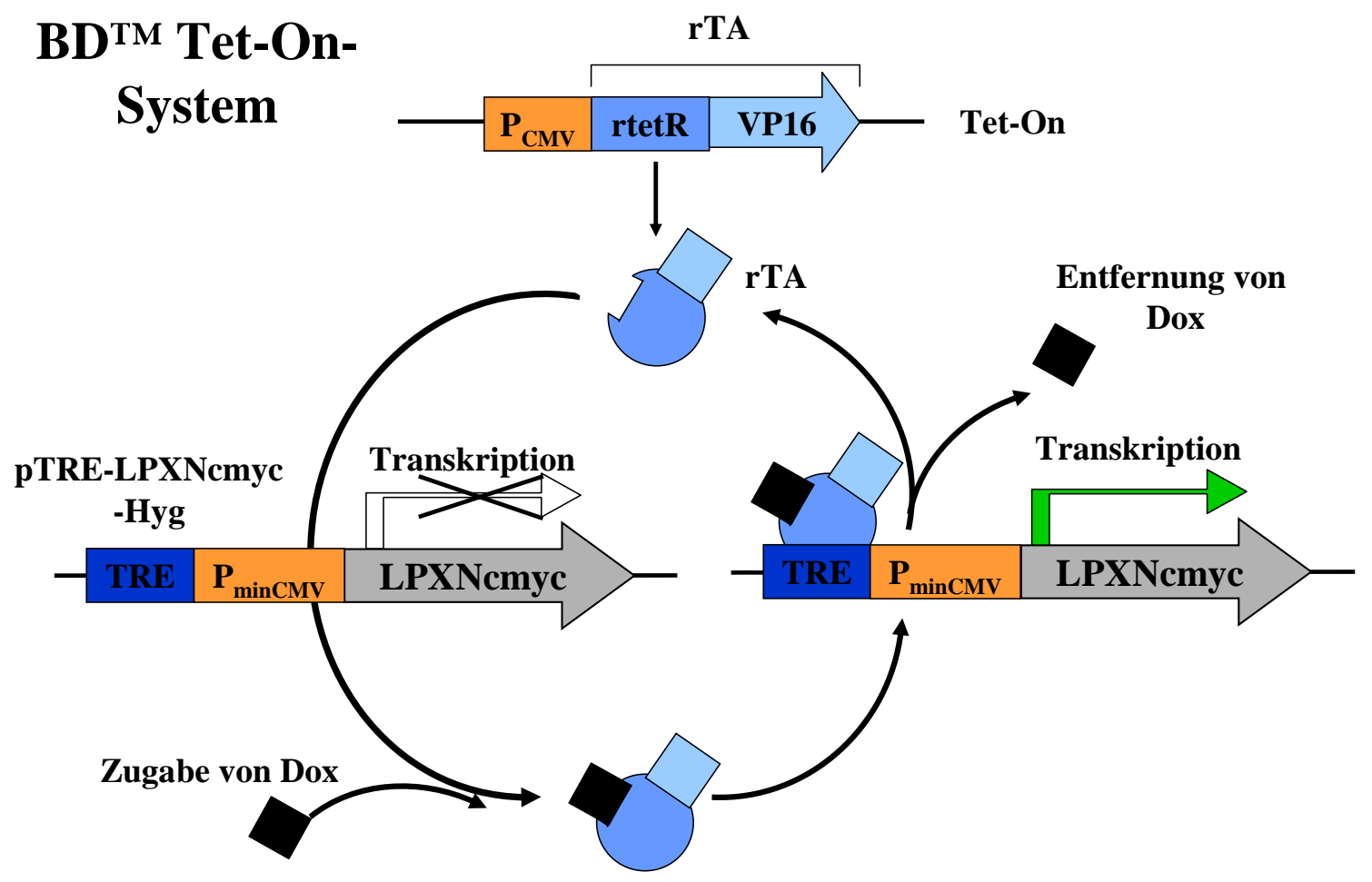

Abb. 3.29: Schematische Darstellung des zur induzierbaren Überexpression von Leupaxin verwendeten Tet-On-Systems. Für das Tet-On-System sind zwei stabile Transfektionen notwendig. Zunächst wird das Plasmid Tet-On in die Zellen eingebracht, welches für den Tet-Repressor (rTA) kodiert. Anschließend wird das Plasmid mit dem Kandidatengen (hier: pTRE-LPXNcmyc-Hyg) unter der Kontrolle des CMVMinimalpromotors mit Tetracyclin-responsiven Elementen (TRE) stabil in die Zellen transfiziert. Ohne Doxycyclin (Dox) kann der Tet-Repressor nicht an die TRE binden, und es findet keine Transkription statt. Wird jedoch Dox ins Medium zugegeben, bindet der Tet-Repressor an die TRE und kann so die Transkription des CMV-Minimalpromotors initiieren.

Für das Tet-On-System werden zwei stabile Transfektionen benötigt (Abb. 3.29, siehe 2.17.4). Zunächst wurde das Plamid Tet-On, welches den Tet-Repressor unter der Kontrolle des CMV-Promotors und das Neomycin-Resistenz-Gen enthält, in androgen-unabhänigige LNCaP-Zellen eingebracht. Die optimale Konzentration von G418 zur Selektion der positiven Klone wurde zuvor in einem Test bestimmt, bei dem LNCaP-Zellen in Anwesenheit von verschiedenen Konzentrationen G418 (0,05 bis 5 mg/ml) für zehn Tage inkubiert wurden. Anschließend wurde die Konzentration ausgewählt, bei der nach zehn Tagen alle Zellen abgestorben waren. Zur Selektion der positiven Zellen wurde G418 in einer Konzentration von $0,3 \mathrm{mg} / \mathrm{ml}$ verwendet. Nach der Isolierung der Klone wurden diese auf die Anwesenheit und Induzierbarkeit des Tet-Repressors geprüft. Dazu wurden die Klone in 24well-Platten 
ausplattiert und mit dem Vektor pTRE-Luc transient transfiziert. Dieser Vektor enthält das Luciferase-Gen unter dem CMV-Minimalpromotor mit Tetracyclin-responsiven Elementen (TRE), welcher auch später für das Leupaxin-Gen verwendet wurde. Nur wenn der TetRepressor gebildet wird und Doxycyclin im Medium vorhanden ist, kann die Transkription des Reportergens stattfinden (Abb. 3.29). Anschließend wurde die Luciferase-Aktivität gemessen (Abschnitt 2.28.2). Als Masterklone, die für die zweite stabile Transfektion verwendet werden sollten, wurden die Klone ausgewählt, die ohne Doxycyclin keine Aktivität und mit Doxycyclin eine mind. 20fache Induktion zeigten (Tab. 3.VIII). Die in Tabelle 3.VIII grau hervorgehobenen Klone 44 und 48 wurden zur weiteren stabilen Transfektion mit pTRELPXNcmyc-Hyg bzw. pTRE-Hyg als Kontrolle eingesetzt.

Tab. 3.VIII: Luciferase-Assay zum Test der Induzierbarkeit von LNCaP-Tet-On-Zellklonen.

\begin{tabular}{c|c|c|c|c|c|c}
\hline \multirow{2}{*}{ Klon Nr. } & \multicolumn{3}{|c|}{ 1. Test } & \multicolumn{2}{c}{ 2. Test } \\
\cline { 2 - 7 } & RLU & RLU & x-fache & RLU & RLU & x-fache \\
- Dox & Dox* & Induktion & - Dox & + Dox* & Induktion \\
\hline 2 & 474 & 7431 & 16 & 17 & 220 & 13 \\
6 & 249 & 5027 & 20 & 91 & 1573 & 17 \\
\hline 25 & 11 & 455 & 41 & 54 & 52 & 1 \\
40 & 158 & 15216 & 96 & 548 & 61417 & 112 \\
44 & 595 & 99294 & 167 & 169 & 31077 & 184 \\
45 & 360 & 69907 & 194 & 452 & 32383 & 72 \\
\hline 48 & 24 & 630 & 26 & 150 & 2349 & 16 \\
\hline 70 & 291 & 50511 & 174 & 66 & 11890 & 180 \\
\hline
\end{tabular}

*Doxycyclin wurde in einer Konzentration von $1 \mu \mathrm{g} / \mathrm{ml}$ verwendet.

Für die weitere stabile Transfektion wurden zwei Konstrukte generiert. Zum einen wurde in den Vektor pTRE, der den CMV-Minimalpromotor mit den Tetracyclin-responsiven Elementen enthält, der offene Leserahmen von Leupaxin mit einem zusätzlichen sechsfachen cmyc-Tag einkloniert. Weiterhin wurde zur Selektion der positiven Klone das HygromycinResistenz-Gen in den Vektor eingebracht (pTRE-LPXNcmyc-Hyg, siehe 2.8.7). Zur Kontrolle wurde der leere pTRE-Vektor mit dem Hygromycin-Resistenz-Gen verwendet (pTRE-Hyg, siehe 2.8.7). 
Die Masterklone wurden mit den Vektoren pTRE-LPXNcmyc-Hyg bzw. pTRE-Hyg transfiziert. Nach 2wöchiger Selektion mit 0,3 mg/ml Hygromycin wurden die LPXN-Klone mit verschiedenen Konzentrationen Doxycyclin stimuliert, Gesamt-Protein isoliert und Western Blot-Analysen zur Überprüfung der Induzierbarkeit und Expression des Fusionsproteins Leupaxin-cmyc durchgeführt (Abb. 3.30). Die Klone 44/12, 44/15, 44/49, 44/63 sowie 48/2 und 48/7 wurden für weitere Analysen verwendet.

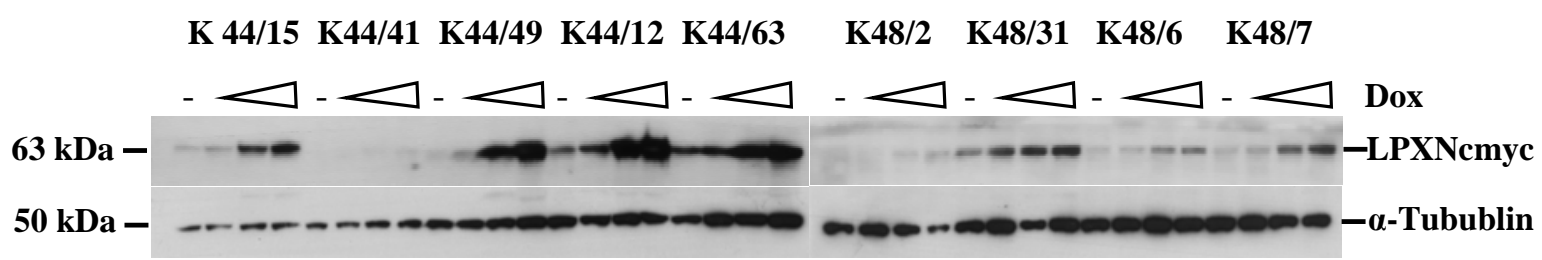

Abb. 3.30: Überprüfung der Expression des Leupaxin-cmyc-Fusionsproteins in den stabilen LNCaPTransfektanten. Die LNCaP-Zellklone wurden für 48 h mit 0, 0,01, 0,05 und $1 \mu \mathrm{g} / \mathrm{ml}$ Doxycyclin (Dox) stimuliert, Gesamt-Proteine isoliert und Western Blot-Analysen mit einem Leupaxin-spezifischen Antikörper durchgeführt. Zur Kontrolle der aufgetragenen Proteinmengen wurde ein Antikörper gegen $\alpha$-Tubulin verwendet. Die Zellklone vom Masterklon 44 waren stärker induzierbar als die des Masterklons 48.

Um die Kontroll-Zellklone (mit H gekennzeichnet) auf Integration des Leerplasmids pTREHyg zu überprüfen, wurde genomische DNA aus diesen Zellklonen isoliert (siehe 2.29.2) und eine PCR mit pTRE-Hyg-spezifischen Primern durchgeführt (pTRE-Hyg-Fw und pTRE-HygRev). Wie in Abbildung 3.31 ersichtlich, ist in den Klonen 44/4H, 44/9H, 48/3H und 48/10H das Leerplasmid integriert.

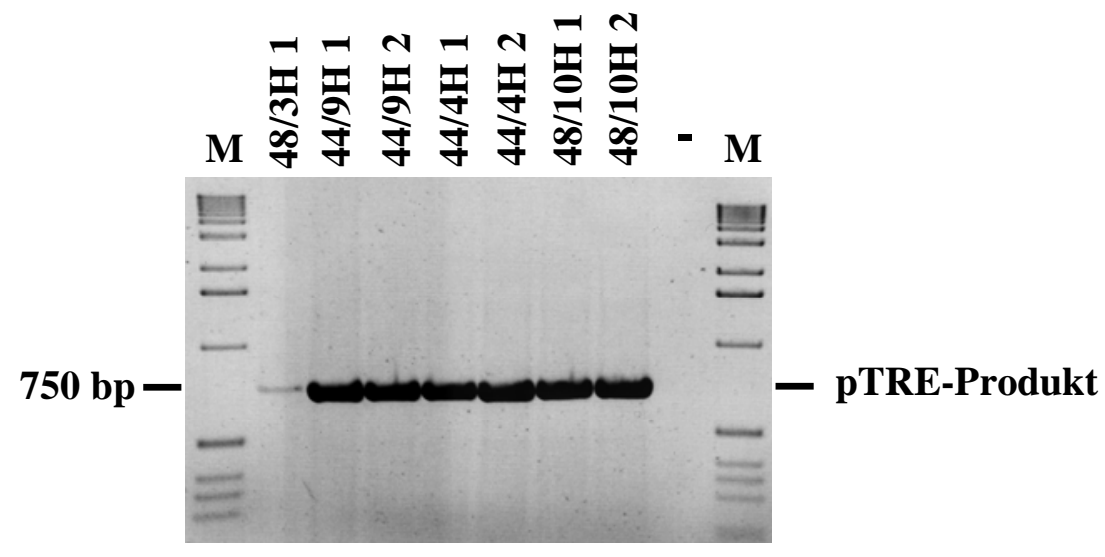


Abb. 3.31: PCR zur Überprüfung der Kontroll-Zellklone LNCaP-pTRE-Hyg. Von den LNCaP-Zellklonen, die stabil mit dem Plasmid pTRE-Hyg transfiziert worden sind, wurde je zweimal genomische DNA isoliert und eine PCR mit den Primern pTRE-Hyg-Fw und pTRE-Hyg-Rev durchgeführt und je $5 \mu$ l auf einem 1,2\%igen Agarose-Gel aufgetrennt. Das 750 bp große PCR-Produkt wurde bei allen Klonen in beiden DNA-Präparationen detektiert, wohingegen die Negativkontrolle mit H2O (-) keine Bande zeigt. Als Standard (M) wurde die 1kbLeiter verwendet.

\subsubsection{Charakterisierung der LNCaP-Klone mit induzierbarer Leupaxin-cmyc- Expression}

\subsection{Subzelluläre Lokalisation des Fusionsproteins Leupaxin-cmyc nach Stimulation mit Doxycyclin}

Um nachzuweisen, dass die Lokalisation des Fusionsproteins Leupaxin-cmyc mit der des endogenen Leupaxins übereinstimmt, wurde eine Immunfärbung mit den Antikörpern gegen cmyc und Leupaxin gleichzeitig durchgeführt. Die Überlagerung der beiden Färbungen in Abbildung 3.32 (hier als Beispiel Zellklon 44/49) zeigt deutlich, dass das Fusionsprotein im Zytoplasma und in den focal adhesion sites lokalisert ist.

LPXN

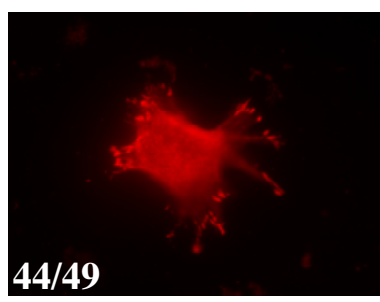

cmyc

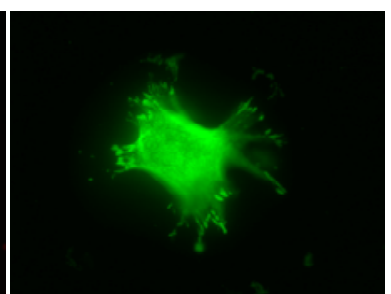

DAPI

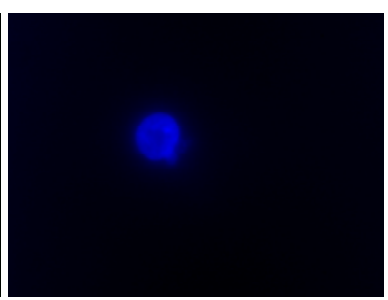

Überlagerung

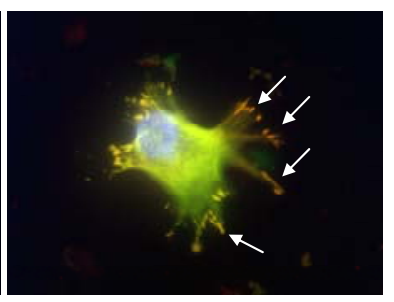

Abb. 3.32: Immunzytochemische Analyse zur subzellulären Lokalisation des Fusionsproteins Leupaxincmyc im LNCaP-Zellklon 44/49. Der Zellklon 44/49 wurde auf Glasobjektträgern ausplattiert und für 24 h mit $0,05 \mu \mathrm{g} / \mathrm{ml}$ Doxycyclin stimuliert. Anschließend wurden die Zellen fixiert und eine Immunfärbung mit den Antikörpern gegen Leupaxin (rot) und cmyc (grün) durchgeführt. Die Kerne (blau) wurden mit DAPI dargestellt. Die Bilder wurden mit 1000facher Vergrößerung aufgenommen. In der Überlagerung ist deutlich zu erkennen, dass das Fusionsprotein in den focal adhesion sites (Pfeile) lokalisiert ist. 


\subsection{Erhöhte Aktivität des AR nach Induktion der Leupaxin-cmyc-Expression}

Die Funktionalität des Fusionsproteins in den LNCaP-Zellklonen wurde anhand der Transaktivierung des AR untersucht (Abschnitt 3.5.2). Dazu wurden die LNCaP-Zellklone transient mit dem Reporterplasmid rPb-Luc sowie zur Kontrolle der Transfektionseffizienz mit dem Plasmid pCMV- $\beta$-Gal kotransfiziert. Anschließend wurde die Aktivität der Luciferase bestimmt, die der Aktivität des AR gleichgesetzt werden kann. Aus dem durchgeführten Transaktivierungsassay ist deutlich zu erkennen, dass stimulierte LNCaPZellklone eine um bis 2,5fach erhöhte AR-Aktivität besitzen im Vergleich zu den KontrollTransfektanten sowie normalen LNCaP-Zellen (Abb. 3.33).

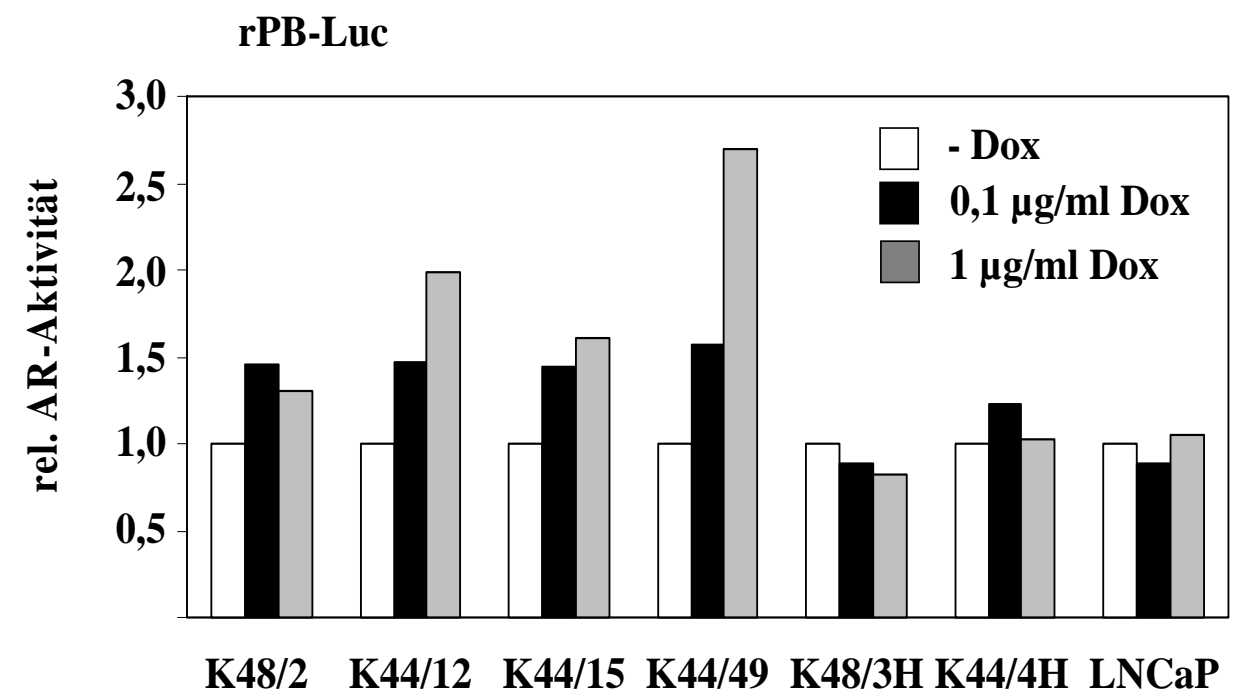

\footnotetext{
Abb. 3.33: Transaktivierungsassay zur Überprüfung der Aktivität des AR in Doxycyclin-stimulierten und unstimulierten LNCaP-Zellklonen. Als Reporterplasmid wurde rPb-Luc verwendet, welches zusammen mit pCMV- $\beta$-Gal in die aufgeführten LNCaP-Zellklone bzw. zur Kontrolle in normale LNCaP-Zellen kotransfiziert wurde. $24 \mathrm{~h}$ nach Stimulation mit Doxycyclin (Dox) wurden die Zellen geerntet und die Aktivitäten von Luciferase und $\beta$-Galaktosidase gemessen. Der Assay wurde dreimal in Doppelbestimmungen durchgeführt, die Normalisierung erfolgte über die $\beta$-Galaktosidase-Aktivitäten. Dargestellt ist das repräsentative Ergebnis eines Assays, bei dem die Werte für die unstimulierten Zellen gleich eins gesetzt wurden. Die AR-Aktivität nimmt um das bis zu 2,5fache im Zellklon 44/49 zu, während die Negativkontrollen (48/3H, 44/4H und LNCaP) keine deutliche Zunahme der AR-Aktivität zeigen.
} 


\subsection{Einfluss der Überexpression von Leupaxin auf die Proliferation von LNCaP- Zellen}

Bereits im Abschnitt 3.6.4 wurde gezeigt, dass Leupaxin keinen Einfluss auf die Proliferation von PCa-Zellen hat. Dieses Ergebnis sollte mit Hilfe der Leupaxin-überexprimierenden LNCaP-Zellklone überprüft werden. Daher wurden die Zellklone K48/2, K48/7, K44/12, K44/15, K44/49 und K44/63 sowie die Negativkontrollen K48/3H, K48/10H, K44/4H und K44/9H in 96well-Platten ausplattiert und die Zunahme lebender Zellen mit Hilfe des MTSAssays gemessen (siehe 2.18). Wie in Abbildung 3.34 beispielhaft für die Zellklone 48/2, 44/49 und 48/10H und LNCaP dargestellt, hat auch eine Überexpression von Leupaxin keinen Einfluss auf die Proliferation von LNCaP-Zellen.

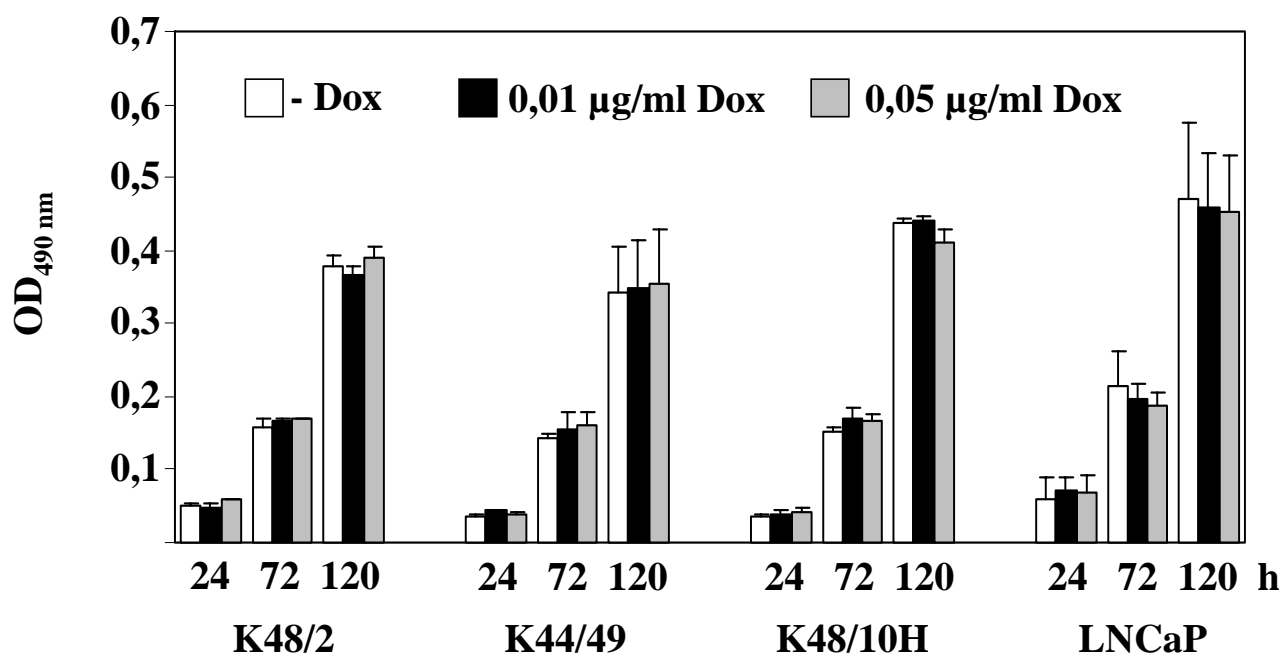

Abb. 3.34: Leupaxin hat keinen Einfluss auf die Proliferation von LNCaP-Zellen mit LeupaxinÜberexpression. Die LNCaP-Zellklone wurden in 96well-Platten ausplattiert und mit den angegebenen Konzentrationen Doxycyclin (Dox) stimuliert. Nach 24, 72 und 120 h wurde die Zellviabilität mit Hilfe des MTS-Assays gemessen. Der Proliferationsassay wurde dreimal in Doppelbestimmungen durchgeführt. Dargestellt ist das repräsentative Ergebnis eines Assays für die Leupaxin-LNCaP-Zellklone K48/2 und K44/49, sowie den Kontroll-LNCaP-Zellklon K48/10H und als Negativkontrolle für normale LNCaP-Zellen. Es ist keine Veränderung der Proliferationsfähigkeit für die LNCaP-Zellen mit Leupaxin-Überexpression zu beobachten. 


\subsection{Untersuchung der adhäsiven und invasiven Eigenschaften der Leupaxin- überexprimierenden LNCaP-Klone}

Da in den Abschnitten 3.1 und 3.6.5 gezeigt wurde, dass Leupaxin einen Einfluss auf die Progression von PCa und die Invasion von PCa-Zellen besitzt, wurden diese Fähigkeiten bei den Leupaxin-überexprimierenden LNCaP-Klonen überprüft. LNCaP-Zellen sind nichtinvasive Zellen und auch die Überexpression von Leupaxin für 48 h oder 2 Monate ändert nichts an dieser Eigenschaft, wie ein Matrigel-Invasionsassay (siehe 2.19) ergeben hat (Abb. 3.35A).

Weiterhin konnte kein Unterschied in der Adhäsion von LNCaP-Zellen mit LeupaxinÜberexpression im Vergleich zu LNCaP-Zellen mit endogener Leupaxin-Expression in verschiedenen Adhäsionsassays festgestellt werden (siehe 2.21). Die LNCaP-Zellklone wurden gegebenenfalls $48 \mathrm{~h}$ vor Beginn des Assays mit Doxycyclin stimuliert und anschließend in 96well-Platten ausplattiert, die mit Fibronektin, Collagen oder BSA beschichtet worden waren. Nach 30 und 60 min Inkubation wurden die adhärenten Zellen fixiert und mit Kristallviolett angefärbt. Die Messung erfolgte in einem Plattenphotometer bei 450 nm. Dabei wurden keine Unterschiede in der Adhäsivität zwischen den Leupaxinüberexprimierenden und den Kontroll-Zellklonen festgestellt (Abb. 3.35B). Die Untersuchung der Zellausbreitung (siehe 2.21) auf verschiedenen Oberflächen wie Fibronektin oder Glas kam zu demselben Ergebnis. Auch hier wurden Klone verwendet, die 48 h oder $>2$ Monate mit Doxycyclin stimuliert worden sind. 

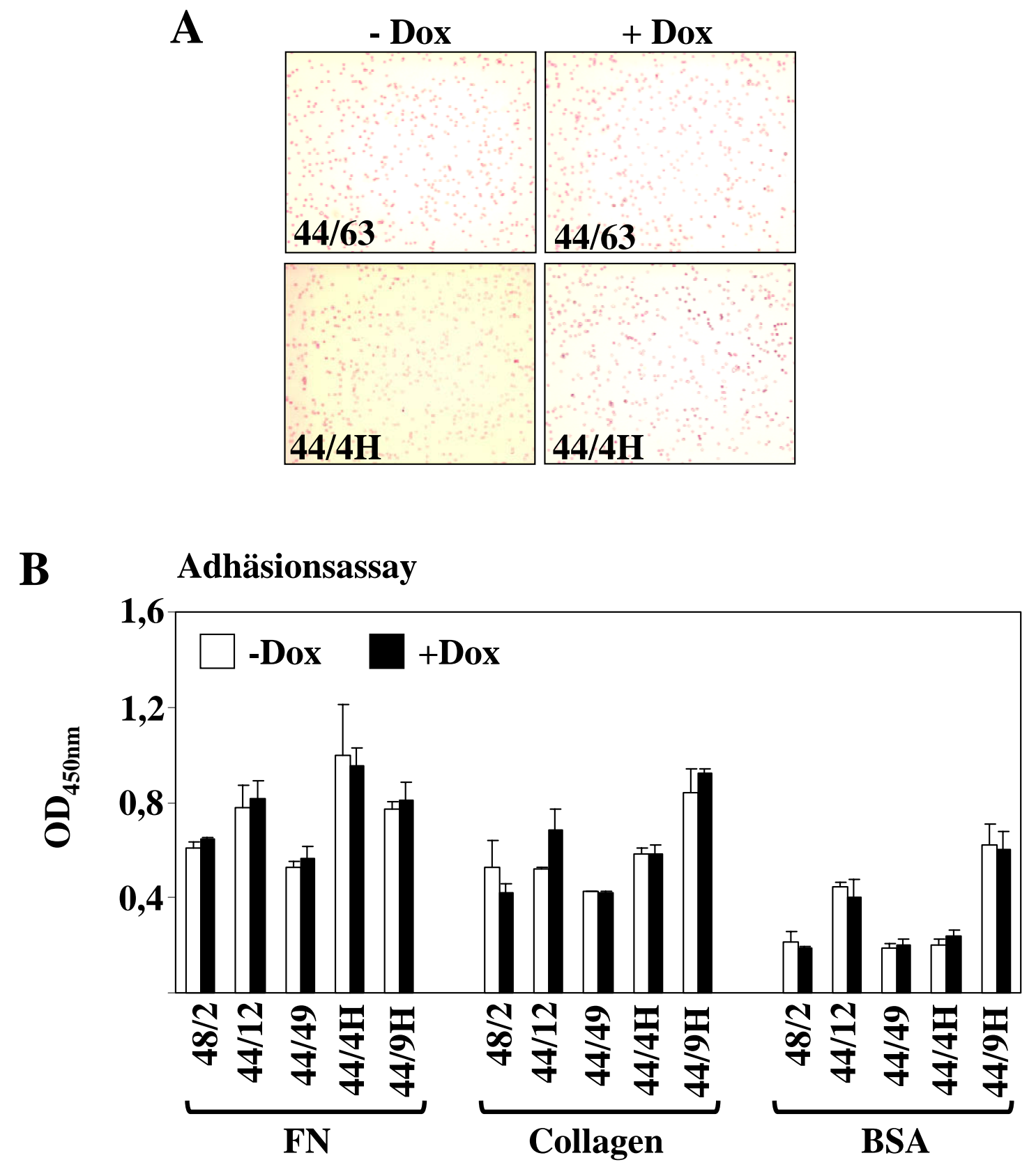

Abb. 3.35: Analysen zur Invasion und Adhäsion von Leupaxin-überexprimierenden LNCaP-Zellklonen.

A. Zur Bestimmung der Invasivität wurden gleiche Zellzahlen der für $>2$ Monate mit 0,1 $\mu$ g/ml Doxycyclin (Dox) stimulierten und der unstimulierten LNCaP-Zellklone 44/63 und 44/4H (Negativkontrolle) auf eine mit Matrigel bedeckte Membran mit $8 \mu \mathrm{m}$ großen Poren ausplattiert und für 48 h inkubiert. Anschließend wurden die auf der oberen Seite der Membran befindlichen Zellen entfernt und die invasiven Zellen auf der unteren Seite der Membran fixiert und angefärbt. Es wurden keine invasiven Zellen beobachtet. In der Abbildung sind die Membranporen erkennbar. B. Zur Bestimmung der adhäsiven Eigenschaften der mit Doxycyclin (Dox) stimulierten und unstimulierten LNCaP-Zellklone wurden jeweils 2x $10^{4}$ Zellen pro well einer 96well-Platte, die entweder mit Fibronektin (FN), Collagen oder zur Kontrolle mit BSA beschichtet worden waren, ausplattiert und für 30 min inkubiert. Anschließend wurden die adhärenten Zellen mit 4\% Formalin fixiert und mit 0,1\% 
Kristallviolett angefärbt. Die Messung erfolgte im Plattenphotometer bei $\mathrm{OD}_{450}$. Es ist kein eindeutiger Unterschied zwischen den Leupaxin-überexprimierenden LNCaP-Zellklonen 48/2, 44/12, 44/49 und den Kontroll-Zellklonen 44/4H und 44/9H zu erkennen.

\subsection{Mausmodell zur Prostata-spezifischen Überexpression von Leupaxin}

\subsubsection{Das Konstrukt zur Generierung einer transgenen Leupaxin-Maus}

Im Rahmen der Diplomarbeit von Frau A. Herr wurde ein Konstrukt zur Generierung einer transgenen Maus mit Prostata-spezifischer Überexpression des humanen Leupaxins hergestellt (Abb. 3.37). Um sicherzustellen, dass die Expression von Leupaxin stark und ausschließlich in der Prostata stattfindet, wurde der etablierte Minimalpromotor (-426 bp bis +28 bp) vom Probasin der Ratte gewählt. Von diesem Promotor ist bekannt, dass er in den dorsalen und ventralen Lappen der Maus-Prostata aktiv ist [Greenberg et al., 1994]. Zur besseren Detektion und Unterscheidung des transgenen Leupaxin-Proteins vom endogenen murinen Leupaxin wurde an den offenen Leserahmen vom humanen Leupaxin ein 6facher cmyc-Tag angehängt.

Die Expression des Konstruktes wurde vor der Injektion durch Transfektion in LNCaP-Zellen getestet. Weiterhin wurde die Funktionalität des Leupaxin-cmyc-Fusionsproteins mit Hilfe eines Transaktivierungsassays überprüft [Herr, 2005].

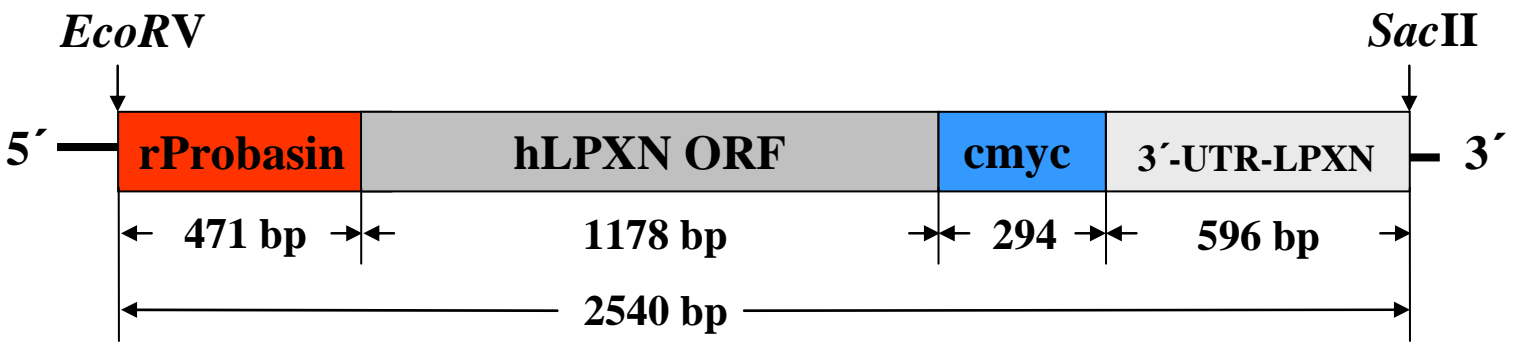

Abb. 3.37: Schematische Darstellung des Konstrukts zur Überexpression von Leupaxin in der Prostata der Maus, modifiziert nach Herr [2005]. Die gesamte Größe des Leupaxin-Konstruktes beträgt 2,54 kb (rProbasin: 471 bp, hLPXN: 1179 bp; cmyc: 294 bp; 3’UTR-LPXN: 596 bp). Mit Hilfe der Restriktionsenzyme EcoRV und SacII wurde das Konstrukt aus dem Klonierungsvektor pBluescript(SK) isoliert. 


\subsubsection{Generierung und Etablierung transgener Leupaxin-Mäuse}

Durch eine erste Injektion des Leupaxin-Konstrukts in den paternalen Vorkern der Oozyten von FVB-Mäusen konnte ein Founder-Tier (\#19) generiert werden [Herr, 2005]. Da theoretisch durch die zufällige Integration des Konstrukts ins Genom wichtige Gene zerstört werden können, was zu einem Transgen-unabhängigen Phänotyp führen kann, war die Etablierung weiterer transgener Mauslinien notwendig. Daher wurde eine zweite Injektion des Leupaxin-Konstrukts durchgeführt.

Aus der zweiten Injektion sind insgesamt 74 Nachkommen hervorgegangen, von denen sechs Mäuse als positiv getestet wurden (Abb. 3.38). Diese Tiere wurden anschließend mit WildtypFVB-Mäusen verpaart und ihre Nachkommen auf das Vorhandensein des Transgens getestet. Dabei wurde festgestellt, dass nur drei der Founder-Tiere (\#20, \#41 und \#61) transmittierten. Von diesen drei Founder-Tieren wurde je eine transgene Mauslinie etabliert.

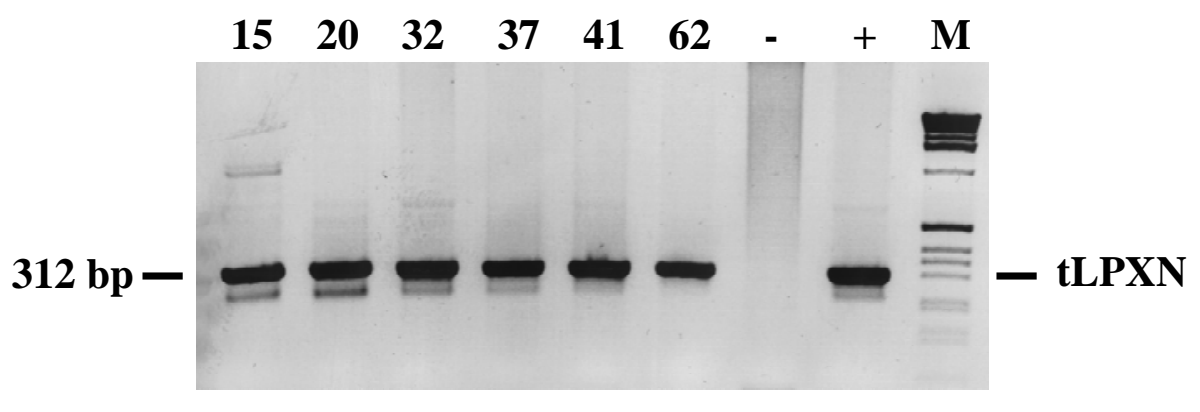

Abb. 3.38: Genotypisierungs-PCR der Founder-Tiere aus der 2. Injektion des Leupaxin-Konstrukts. Zur Genotypisierung wurde eine PCR an genomischer DNA aus Schwänzen mit den Primern rPb-Fw und LPXNLD1-Rev durchgeführt. Als Negativkontrolle diente genomische DNA einer Wildtyp-FVB-Maus (-), als Positivkontrolle $(+)$ wurde genomische DNA einer Maus der Linie 19 verwendet. Das erwartete PCR-Produkt besitzt eine Größe von 312 bp. M= DNA-Standard 1 kb-Leiter.

\subsubsection{Integration des Leupaxin-Transgens ins Mausgenom}

Um auszuschließen, dass das transgene Leupaxin-Konstrukt bei den Mauslinien \#19 und \#20 nicht mehrmals ins Genom integriert ist, wurden Taqman-(quantitative real time PCR-) und Southern Blot-Analysen durchgeführt. 
Für die Taqman-Analyse wurden positiv getestete Nachkommen der $F_{1}$-Generation zusammen mit dem jeweiligen Founder untersucht. Als Standard wurde die genomische DNA einer heterozygot transgenen Leupaxin-Maus (z.B. Founder-Tier) verwendet. Die relative Kopienzahl der Founder wurde anschließend mit der Kopienzahl der Nachkommen verglichen. Wenn eine einzige Integration des Konstrukts im Genom vorhanden ist, wird eine identische Kopienzahl sowohl bei den Founder-Tieren als auch bei den Nachkommen erwartet. In Abb. 3.39 ist das Ergebnis der Taqman-Analyse für die Mauslinien \#19 und \#20 zusammengefaßt. Bei beiden Mauslinien ist ersichtlich, dass sowohl die Founder-Tiere als auch die jeweiligen Nachkommen dieselbe relative Kopienzahl des Leupaxin-Konstrukts im Genom und damit beide Mauslinien nur eine Integration im Genom tragen. Da für beide Analysen derselbe DNA-Standard gewählt worden ist, kann auch geschlußfolgert werden, dass die Mauslinie \#20 etwa die doppelte Kopienzahl des Leupaxin-Konstrukts im Genom trägt als die Mauslinie \#19. Dies erklärt möglicherweise auch die stärkere Expression des transgenen Leupaxin-cmyc-Fusionsprotein (Abschnitt 3.7.5).

Linie 19

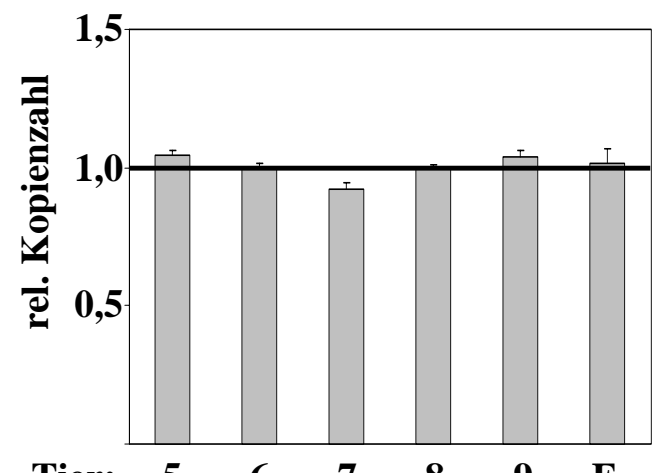

$\begin{array}{lllllll}\text { Tier: } & 5 & 6 & 7 & 8 & 9 & \text { F }\end{array}$
Linie 20

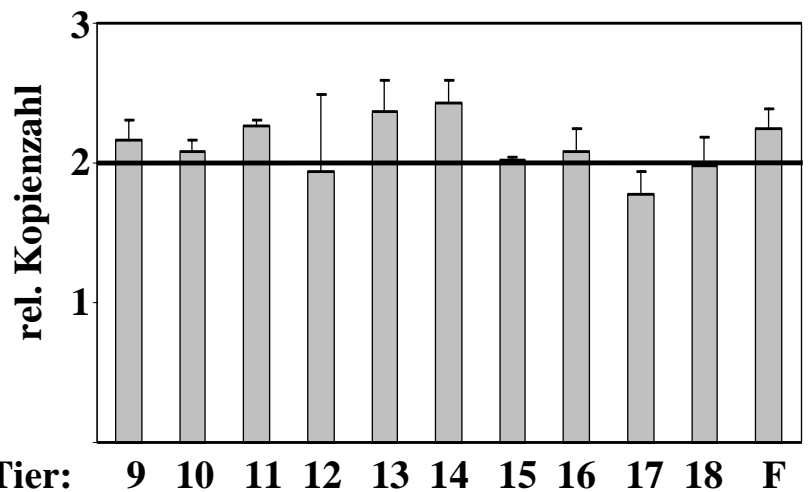

Abb. 3.39: Taqman-Analyse zur Bestimmung der Integrationszahl des transgenen Leupaxin-Konstrukts im Mausgenom. Die relative Kopienzahl des Leupaxin-Transgens im Genom der Nachkommen der $F_{1}$ Generation als auch der jeweiligen Founder-Tiere wurde mittels quantitativer real time PCR bestimmt. Als Standard wurde die genomische DNA einer heterozygot transgenen Leupaxin-Maus verwendet. Sowohl bei der Mauslinie \#19 (A.) als auch bei der Mauslinie \#20 (B.) ist dieselbe Kopienzahl des Founder-Tieres und der Nachkommen zu verzeichnen, so dass davon auszugehen ist, dass nur eine Integration ins Genom stattgefunden hat. 
Als zweite unabhängige Methode zur Bestimmung der Integration wurde eine Southern BlotAnalyse (2.12) durchgeführt. Die genomische DNA von Nachkommen der $F_{1}$-Generation wurde mit dem Restriktionsenzym BglII geschnitten, gelelektrophoretisch aufgetrennt und auf eine Membran übertragen. Als Sonde wurde ein 1097 bp langes Fragment gewählt, das mit dem Restriktionsenzym StuI aus dem Leupaxin-Konstrukt isoliert wurde (Abb. 3.40). Das DNA-Fragment enthält die Leupaxin-Sequenz ab Basenpaarposition 852, den cmyc-Tag und die Leupaxin-3’UTR bis Basenpaarposition 1949. BglII schneidet im Konstrukt genau einmal an der Position 2227 des Konstrukts (Abb. 3.40A). Die radioaktive Markierung und anschließende Hybridisierung mit der auf der Membran fixierten DNA erfolgte wie unter 2.13 beschrieben.

Bei den transgenen Mäusen werden zwei Banden pro Integration erwartet, wodurch neben der 2,6 kb großen Konstrukt-Bande eine weitere Bande pro Integration entstehen sollte. Die Größe der Nebenbanden hängt von der Entfernung der nächsten 3’ gelegenen BglIISchnittstelle zum integrierten Konstrukt ab (Abb. 3.40 B).

A

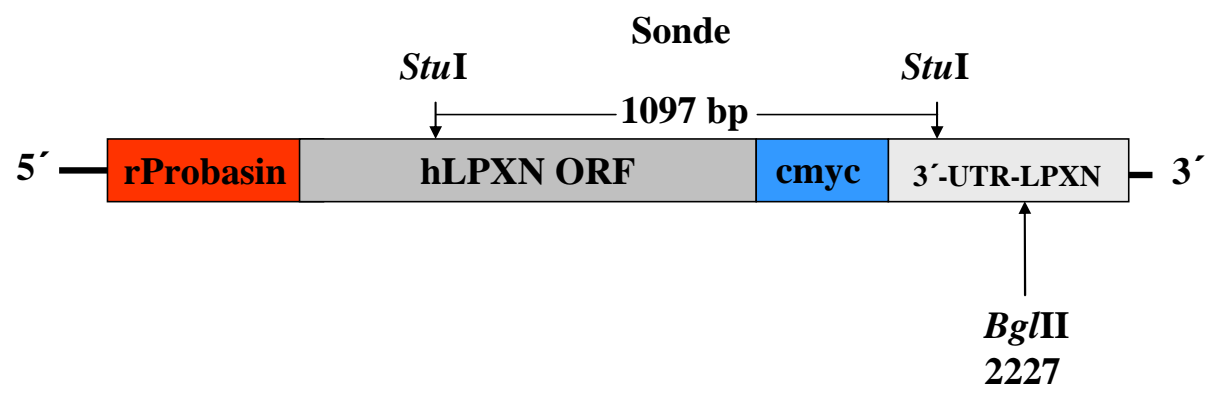

B

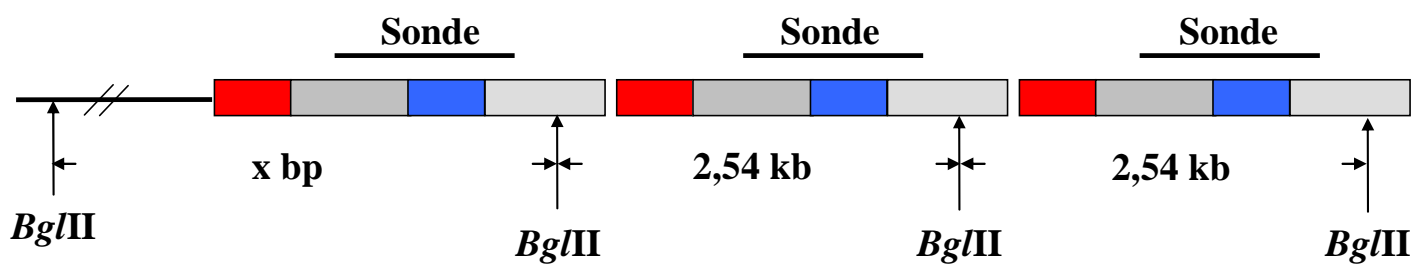

Abb. 3.40: Schematische Darstellung der Southern Blot-Strategie zur Überprüfung der Integrationszahl.

A. Dargestellt ist die Lage der Sonde im transgenen Konstrukt und die BglII-Schnittstelle. Die 1097 bp lange Sonde wurde mit dem Restriktionsenzym StuI aus dem transgenen Konstrukt isoliert und für die Hybridisierung eingesetzt. B. Dargestellt ist ein Abschnitt der Integration des Konstrukts im Genom mit den BglII-Schnittstellen sowie die verwendete Sonde und die erwarteten Größen der Banden bei der Southern Blot-Analyse. Die Farben korrespondieren mit A. 
Bei der Mauslinie \#19 konnte nur die Bande des Konstrukts bei 2,6 kb detektiert werden (Abb. 3.41A). Bei der Mauslinie \#20 ist auf dem Autoradiographie-Film die für das transgene Konstrukt erwartete Bande bei 2,6 kb zu sehen (Abb. 3.41B). Weiterhin wurden hier zwei weitere Banden im Bereich zwischen 4 und $3 \mathrm{~kb}$ sichtbar, die eigentlich auf zwei Integrationsorte im Genom hinweisen. Da jedoch alle Nachkommen dasselbe Bandenmuster zeigen, ist eine zweite Integration im Genom auszuschließen. Damit konnten die Ergebnisse aus der Taqman-Analyse mittels Southern Blot-Analyse bestätigt werden.

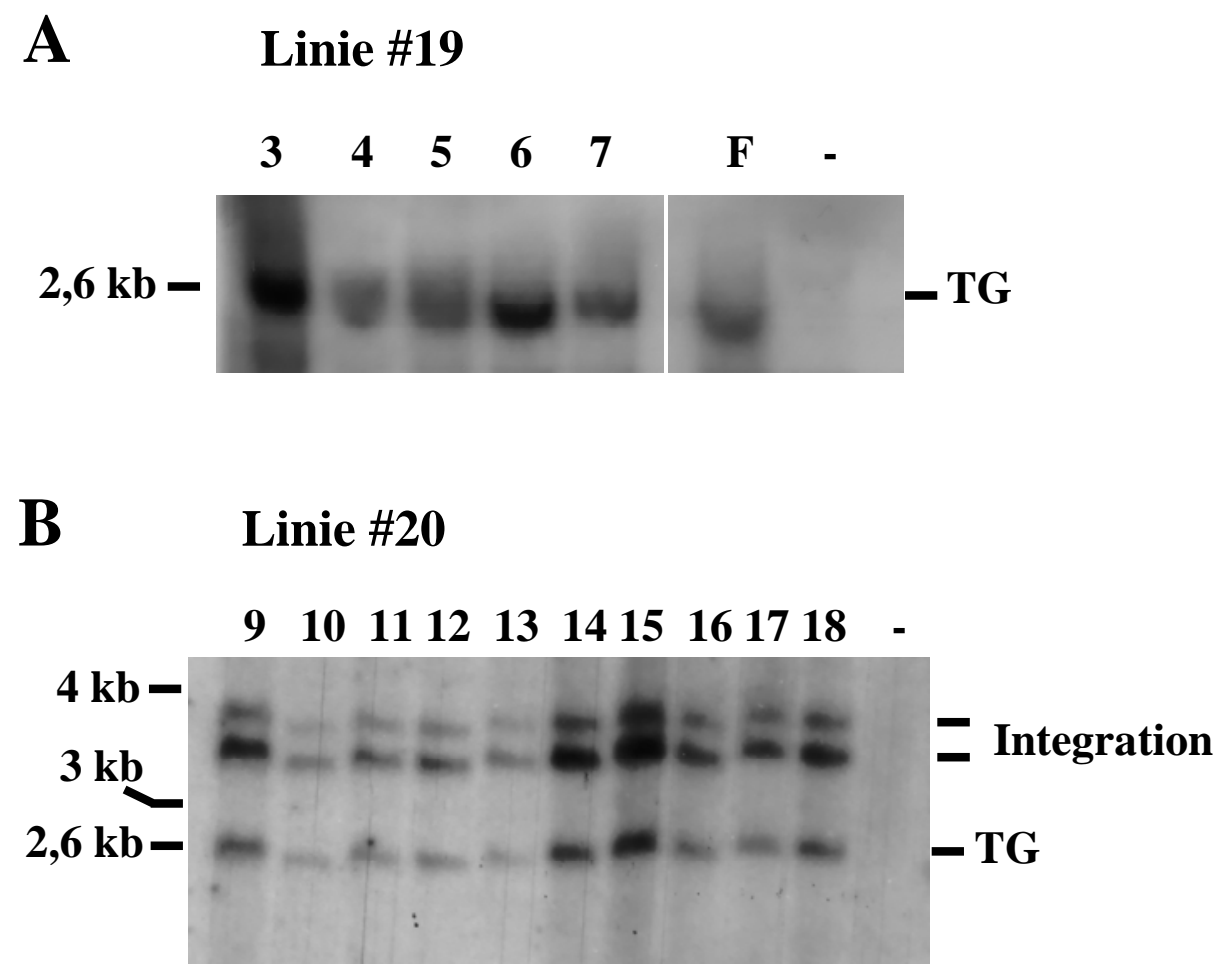

Abb. 3.41: Southern Blot-Analyse zur Überprüfung der Integrationszahl des transgenen Konstrukts im Genom. Die genomische DNA einer Kontroll-FVB-Maus (-) sowie von Nachkommen der $F_{1}$-Generation wurde mit dem Restriktionsenzym BglII geschnitten und eine Southern Blot-Analyse mit einer Leupaxin-cmycspezifischen Sonde durchgeführt. A. Bei der Mauslinie \#19 (Tiere 3-7) wurde nur die Konstruktbande von 2,6 kb detektiert. F=Founder-Tier. B. Neben der erwarteten Konstruktbande bei 2,6 kb traten zwei weitere Banden bei den Nachkommen der Mauslinie \#20 (Tiere 9-18) auf. Da jedoch kein Unterschied im Bandenmuster zwischen den Tieren zu beobachten ist, ist nur von einem Integrationsort auszugehen. 


\subsubsection{Verpaarung und Etablierung von homozygot transgenen Leupaxin-Mauslinien}

Zur Etablierung der beiden transgenen Mauslinien \#19 und \#20 wurden die Tiere untereinander so verpaart, dass homozygot transgene Mäuse entstehen. Dies hat den Vorteil, dass nach Etablierung keine Genotypisierungen mehr durchzuführen sind. Weiterhin kann eine schwache Expression wie in der Mauslinie \#19 (Abschnitt 3.7.5) dadurch erhöht werden, dass nun die doppelte Dosis des Transgens vorliegt. Zur Bestimmung des Genotyps der $\mathrm{F}_{2^{-}}$ Generation wurden Taqman-Analysen durchgeführt, wobei ein homozygot transgenes Tier sich durch die doppelte Kopienzahl im Vergleich zu den Elterntieren auszeichnet (Abb. 3.42; Beispiel für Mauslinie \#20).

\section{Linie \#20}

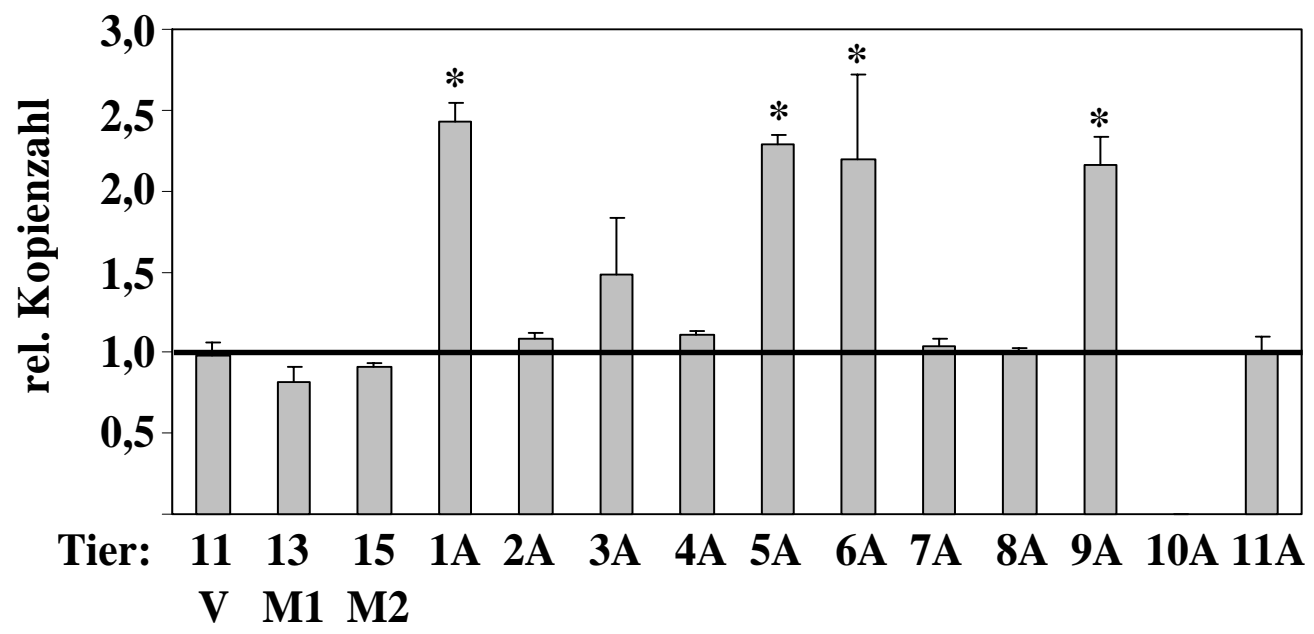

Abb. 3.42: Beispiel für eine Taqman-Analyse zur Überprüfung des Genotyps bei der Generierung von homozygot transgenen Leupaxin-Mäusen. Die relative Kopienzahl des Leupaxin-Transgens im Genom der Nachkommen der $\mathrm{F}_{2}$-Generation wurde mittels quantitativer real time PCR bestimmt. Als Standard wurde die genomische DNA der heterozygot transgenen Elterntiere $(11,13,15)$ verwendet. Homozygot transgene Leupaxin-Mäuse $\left(^{*}\right)$ zeigen die doppelte relative Kopienzahl des Transgens im Vergleich zu den Elterntieren. Maus 10A ist ein Wildtyp-Tier. V= Vater, M=Mutter. 


\subsection{5 Überprüfung der Expression des Leupaxin-Transgens in vivo}

Je ein acht Wochen altes männliches transgenes Tier von den Mauslinien \#19, \#20, \#41 und \#62 wurde getötet und die Prostata herauspräpariert. Anschließend wurde Gesamt-Protein isoliert und eine Western Blot-Analyse mit einem cmyc-spezifischen Antikörper zur Überprüfung der Expression des Transgens durchgeführt. Dabei stellte sich heraus, dass die Mauslinien \#41 und \#62 das transgene Leupaxin-cmyc-Fusionsprotein nicht exprimieren (Abb. 3.43A), sie wurden daher nicht in weitere Analysen einbezogen. Die Mauslinie \#19 (Abb. 3.43B) exprimiert das Transgen nur sehr schwach im Vergleich zur Mauslinie \#20 (Abb. 3.43C), die eine sehr starke Bande in der für das transgene Leupaxin-cmycFusionsprotein erwarteten Größe von 63 kDa zeigt. Aus den Western Blot-Analysen geht weiterhin hervor, dass die Expression des Transgens Prostata-spezifisch ist.

A

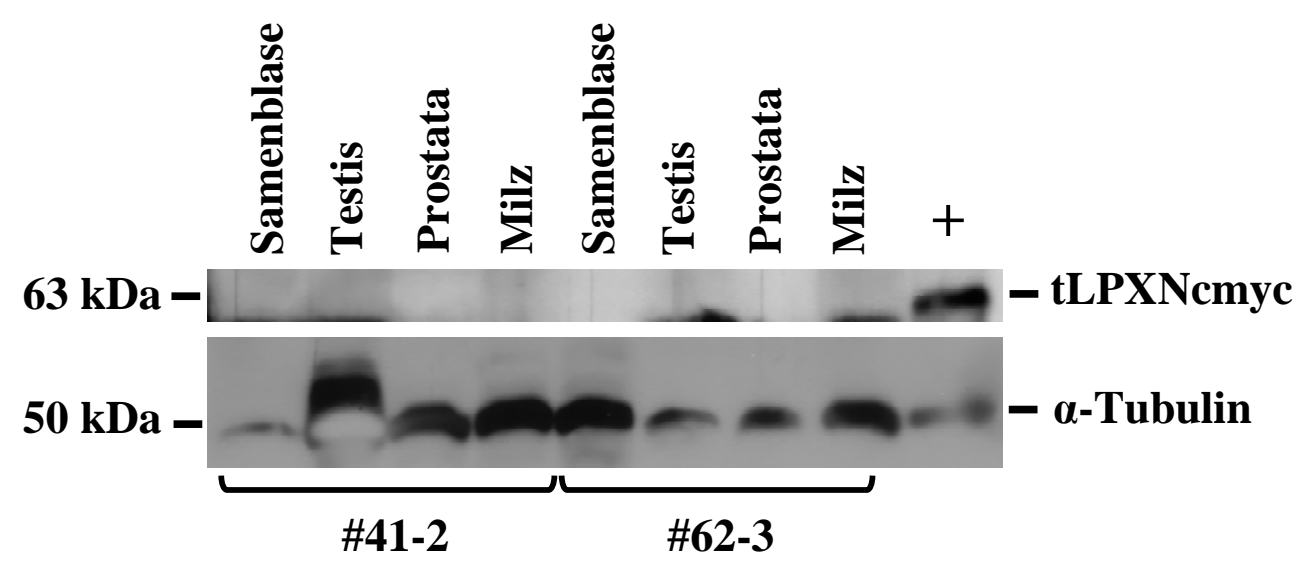

B

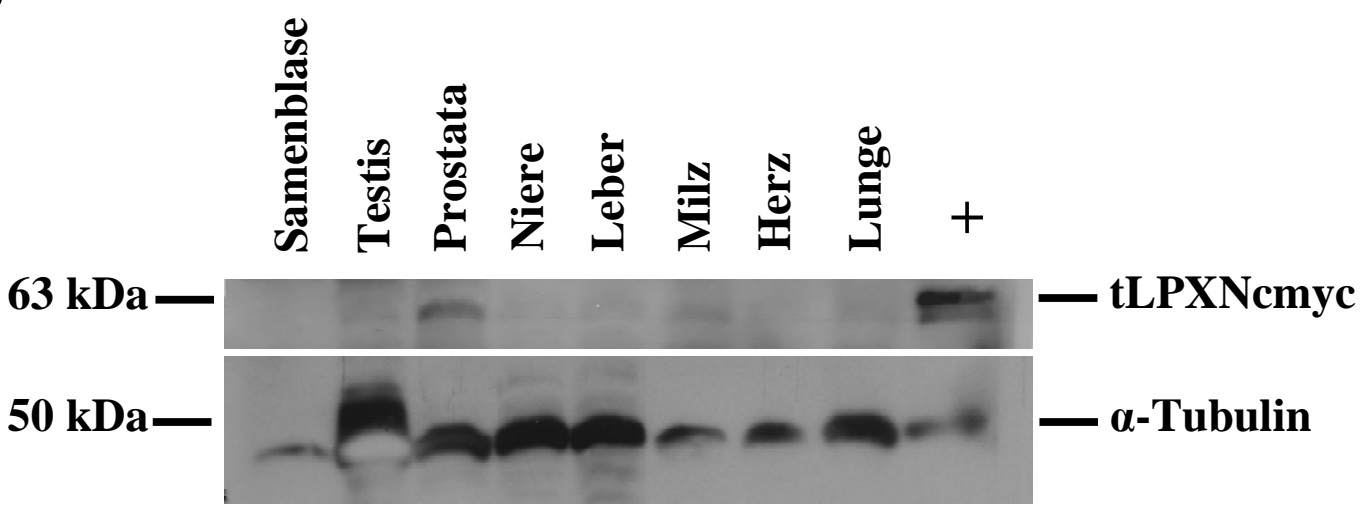

\#19-J 


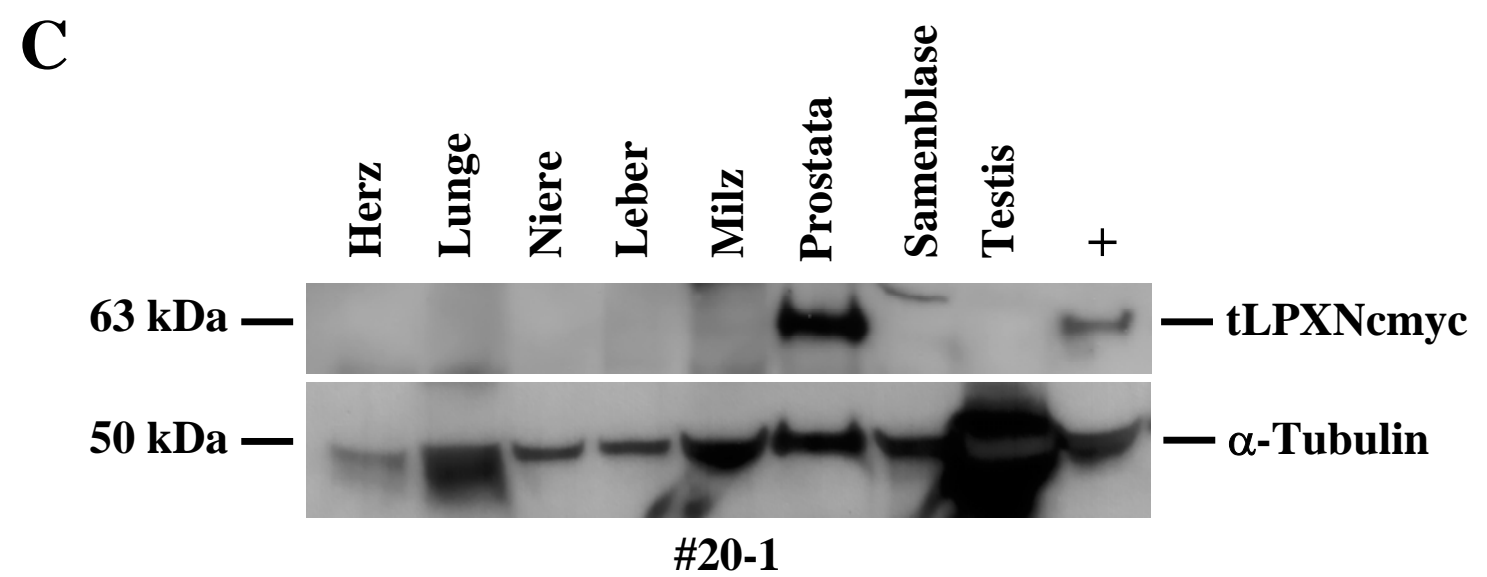

\begin{abstract}
Abb. 3.43: Western Blot-Analysen zur Überprüfung der Prostata-spezifischen Expression des transgenen Leupaxin-cmyc-Fusionsproteins. Je ein männliches transgenes Tier jeder Mauslinie wurde getötet und die Organe herauspräpariert. Nach der Isolierung der Gesamt-Proteine aus den Geweben wurden diese über SDSPAGE aufgetrennt und einer Western Blot-Analyse mit einem cmyc-spezifischen Antikörper unterzogen. Als Positivkontrolle diente Gesamt-Protein von LNCaP-Zellen, die mit dem transgenen Konstrukt transfiziert und anschließend mit DHT stimuliert worden waren. Als Kontrolle der aufgetragenen Proteinmengen wurde ein Antikörper gegen $\alpha$-Tubulin verwendet. A. Die Mauslinien \#41 (Tier \#41-2, T/-) und \#62 (Tier \#62-3, T/-) zeigen keine Expression des Transgens tLPXNcmyc. Sie wurden daher nicht weiter analysiert. B. Die Mauslinie \#19 (Tier \#19-J, T/T) zeigt eine schwache Expression des Transgens tLPXNcmyc in der Prostata. C. Bei der Mauslinie \#20 (Tier \#20-1, T/-) ist die stärkste Prostata-spezifische Expression des transgenen Leupaxins zu beobachten.
\end{abstract}

\title{
3.7.6 Immunhistochemische Analyse der transgenen Leupaxin-Mäuse
}

Die nachfolgenden Analysen wurden in Zusammenarbeit mit PD Dr. Stefan Schweyer, (Abteilung Pathologie, Universitätsklinikum Göttingen) durchgeführt.

Um die Expression des transgenen Leupaxins auf zellulärer Ebene zu untersuchen, wurde der gesamte Urogenitaltrakt von transgenen Mäusen präpariert und in Formalin fixiert. Nach der Einbettung in Paraffin wurden Gewebeschnitte angefertigt und diese zur Dektektion des transgenen Leupaxins mit einem Leupaxin-spezifischen Antikörper behandelt (siehe 2.27). Sowohl in der Mauslinie \#19 (Abb. 3.44) als auch in der Mauslinie \#20 (Abb. 3.45) ist eine Prostata-spezifische Expression des transgenen Leupaxins zu beobachten. Die Expression beschränkt sich auf den dorsalen und ventralen Lappen der Prostatae (Abb. 3.44A), wie dies bereits für den Probasin-Promotor beschrieben worden ist [Greenberg et al., 1995]. Weiterhin 
ist keine Expression im Stroma der Prostatae noch in anderen Organen des Urogenitaltraktes festzustellen (z.B. Testis, Abb. 3.44D und 3.45D). Das transgene Leupaxin lokalisiert im Zytoplasma von luminalen Epithelzellen der Prostata, die als sekretorische Zellschicht an das Lumen grenzen (Abb. 3.44C und 3.45C). Zur Kontrolle wurden auch Gewebeschnitte einer FVB-Wildtyp-Maus mit dem Leupaxin-spezifischen Antikörper behandelt (Abb. 3.46A und B). Weiterhin wurde ein Prostata-Gewebeschnitt einer transgenen Leupaxin-Maus (19-72) nur mit dem Sekundärantikörper behandelt (Abb. 3.46C). In beiden Überprüfungen sind kaum Hintergrund-Signale zu verzeichnen.
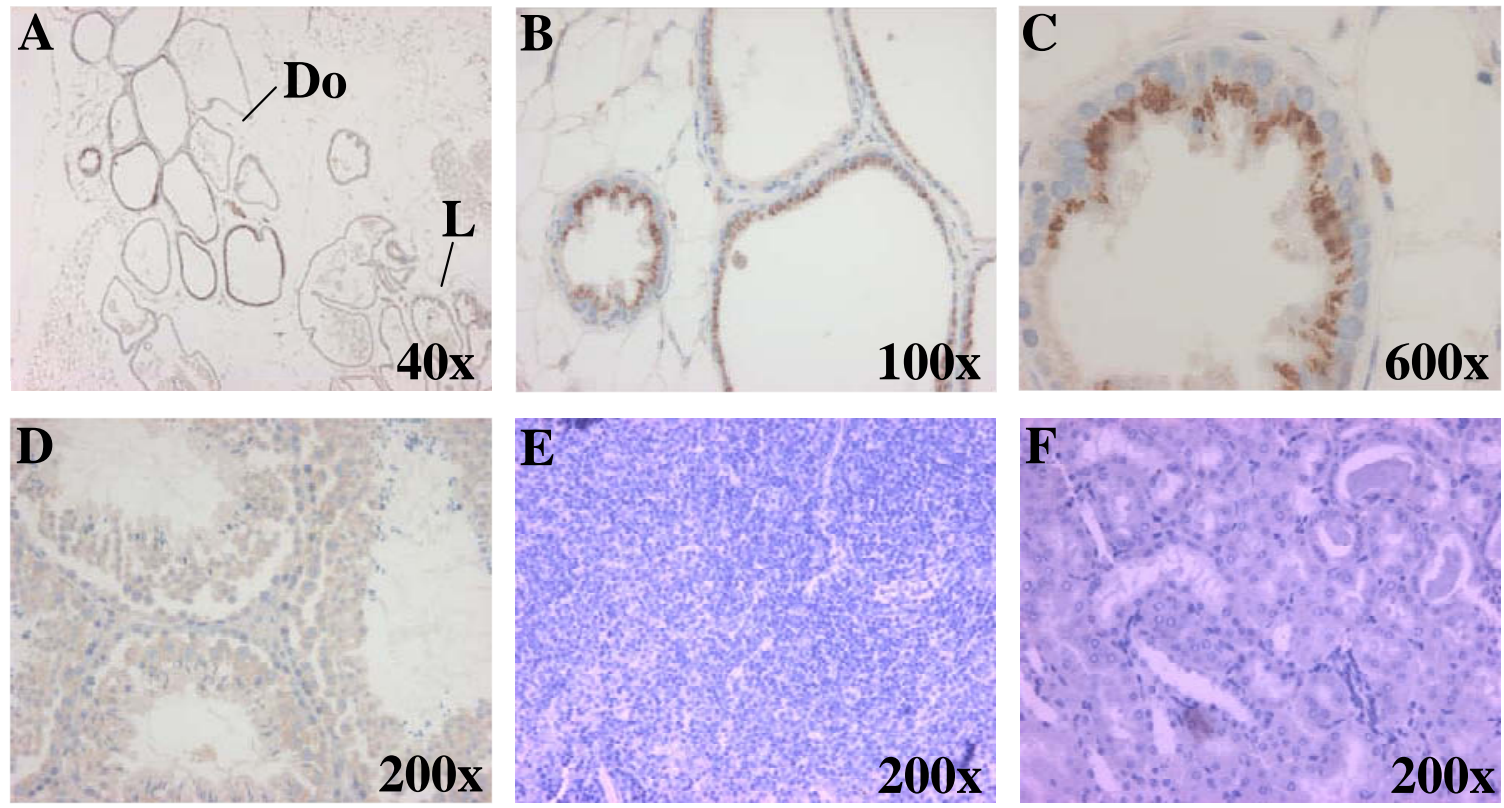

Abb. 3.44: Immunhistochemische Analysen zur Expression des transgenen Leupaxin-cmycFusionsproteins in verschiedenen Geweben/Organen der Maus K der Linie \#19 (T/T). Der gesamte Urogenitaltrakt sowie die Organe Milz, Niere, Leber und Lunge der Maus \#19-K wurden präpariert, in Formalin fixiert und in Paraffin eingebettet. Die Gewebeschnitte wurden zur Detektion des transgenen LeupaxinFusionsproteins mit einem Leupaxin-spezifischen Antikörper, wie unter 2.30.4 beschrieben, behandelt. Die Gegenfärbung erfolgte mit Hämalaun. A. Bild der Prostata in 40facher Vergrößerung. Es ist deutlich zu erkennen, dass die Expression des Leupaxin-Transgens sich auf den dorsalen Lappen (Do) der Prostata beschränkt, wohingegen der laterale Lappen (L) keine Färbung zeigt. B. Bild der Prostata in 100facher Vergrößerung. Ausschnitt aus A. C. Bild der Prostata in 600facher Vergrößerung. In dem Ausschnitt aus B. ist deutlich zu erkennen, dass das Leupaxin-Transgen in den luminalen Epithelzellen exprimiert ist. D - F. Im Testis (D.), in der Milz (E.) und in der Niere (F) sind lediglich Hintergrund-Signale zu erkennen (Aufnahmen in 200facher Vergrößerung). 

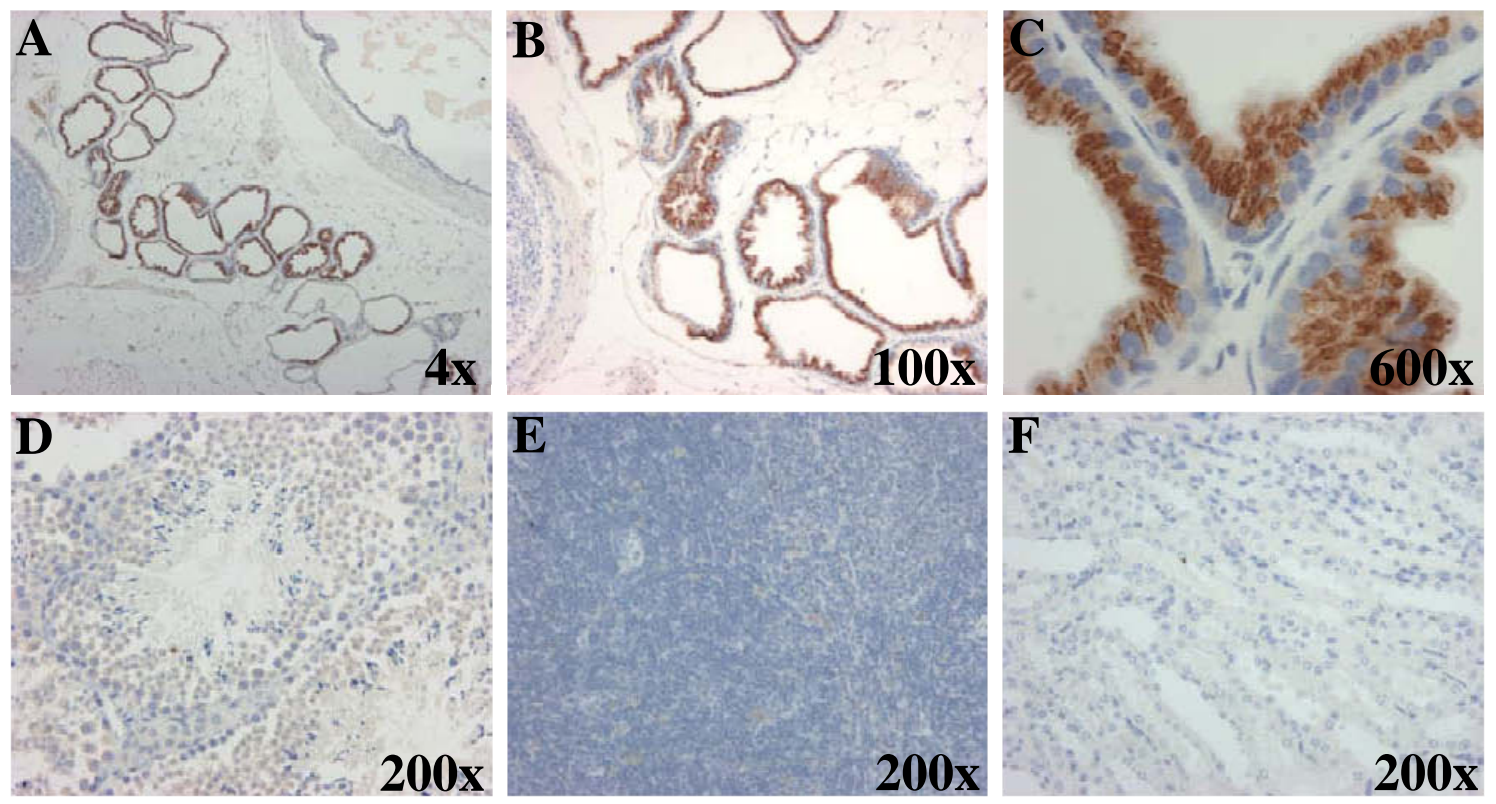

Abb. 3.45: Immunhistochemische Analysen zur Expression des transgenen Leupaxin-cmycFusionsproteins in der Maus 12 der Linie \#20 (T/-). Der gesamte Urogenitaltrakt sowie die Organe Milz, Niere, Leber und Lunge der Maus \#20-12 wurden präpariert, in Formalin fixiert und in Paraffin eingebettet. Die Gewebeschnitte wurden zur Detektion des transgenen Leupaxin-Fusionsproteins mit einem Leupaxinspezifischen Antikörper, wie unter 2.30 .4 beschrieben, behandelt. Die Gegenfärbung erfolgte mit Hämalaun. A. Bild der Prostata in 40facher Vergrößerung. Es sind starke Signale für Leupaxin in den dorsalen Bereichen der Prostata zu erkennen B. Bild der Prostata in 100facher Vergrößerung. Ausschnitt aus A. C. Bild der Prostata in 600facher Vergrößerung. In dem Ausschnitt aus B. ist deutlich zu erkennen, dass die Expression des Leupaxin-Transgens in den luminalen Epithelzellen stattfindet, die direkt an das Lumen angrenzen. D - F. Im Testis (D.), in der Milz (E.) und in der Niere (F) sind lediglich Hintergrund-Signale zu erkennen (Aufnahmen in 200facher Vergrößerung).
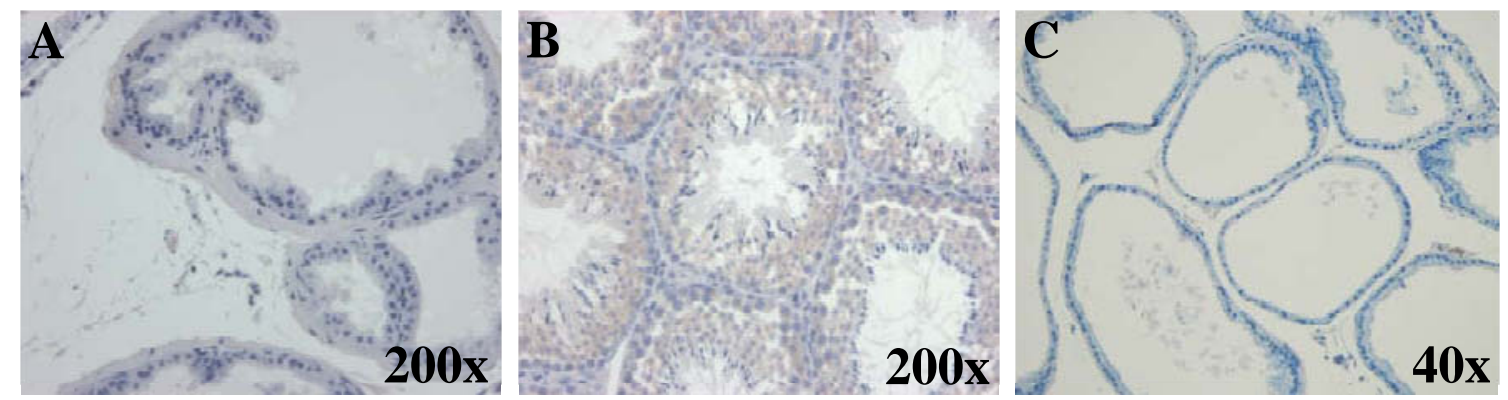

Abb. 3.46: Analysen zur Kontrolle der Spezifität der angewendeten immunhistochemischen Methode. A. und B. Zur Kontrolle der Spezifität des Leupaxin-Antikörpers wurden der gesamte Urogenitaltrakt sowie die Organe Milz, Niere, Leber und Lunge der Wildtyp-Maus 19-E präpariert, in Formalin fixiert und in Paraffin 
eingebettet. Die Gewebeschnitte wurden zur Färbung mit einem Leupaxin-spezifischen Antikörper, wie unter 2.30.4 beschrieben, behandelt. Die Gegenfärbung erfolgte mit Hämalaun. Es wurden keine spezifischen Signale, weder in der Prostata (A.), noch in anderen Organen wie z.B. Testis (B.) erhalten. C. Zur Überprüfung des verwendeteten Sekundärantikörpers wurde ein Prostata-Gewebeschnitt der transgenen Leupaxin-Maus 19-72 (T/-) nur mit dem Sekundärantikörper gefärbt und mit Hämalaun gegengefärbt. Es sind kaum HintergrundSignale in der Abbildung zu beobachten.

\subsubsection{Histologische Analysen der Prostatae in verschiedenen Altersstadien der transgenen Leupaxin-Mäuse der Linien \#19 und \#20}

Um zu untersuchen, ob durch die Überexpression von Leupaxin Veränderungen in der Prostata entstehen, wurden $\mathrm{zu}$ verschiedenen Zeitpunkten von transgenen Tieren der Urogenitaltrakt sowie Milz, Leber und Lunge präpariert, diese in Formalin fixiert und in Paraffin eingebettet. Anschließend wurden die Gewebeschnitte mit HE gefärbt (siehe 2.30). Die histologischen Analysen wurden in Zusammenarbeit mit PD Dr. Stefan Schweyer durchgeführt. Dabei konnten bisher keine auffälligen morphologischen Veränderungen der Prostatae in den verschiedenen Altersstadien der transgenen Leupaxin-Mäuse beobachtet werden (Tab. IX). Zur Kontrolle der Expression wurden bei transgenen Mäusen aus verschiedenen Altersstadien Immunfärbungen mit einem Leupaxin-spezifischen Antikörper durchgeführt. In der Tabelle 3.VIII sind die bisherigen Ergebnisse der histologischen Analysen zusammengefaßt. Die älteste Maus der Linie \#19 war 1 Jahr alt, für die Mauslinie \#20 konnten im Rahmen dieser Doktorarbeit bisher lediglich 9 Monate alte Mäuse generiert werden. Bisher konnten keine histologischen Veränderungen in den Prostatae der transgenen Leupaxin-Mäuse beider Mauslinien (\#19 und \#20) festgestellt werden. 
Tab. 3.IX: Übersicht über die bisher durchgeführten histologischen Analysen in den transgenen Mauslinien \#19 und \#20. Die angegebenen Nummern bzw. Buchstaben stellen die jeweiligen verwendeten Mäuse dar.

\begin{tabular}{|c|c|c|c|c|c|}
\hline \multirow{2}{*}{$\begin{array}{l}\text { Alter in } \\
\text { Wochen }\end{array}$} & \multicolumn{2}{|c|}{ Mauslinie 19} & \multicolumn{2}{|c|}{ Mauslinie 20} & \multirow{2}{*}{ Kontrolle } \\
\hline & $\mathbf{T} /-$ & $\mathbf{T} / \mathbf{T}$ & $\mathbf{T} /-$ & $\mathbf{T} / \mathbf{T}$ & \\
\hline $8 \mathrm{~W}$ & & $\begin{array}{l}\mathrm{B} \\
\mathrm{D} \\
\mathrm{O} \\
\mathrm{P}\end{array}$ & $\begin{array}{c}75 \mathrm{~A} \\
10\end{array}$ & $\begin{array}{c}92 \\
30 \mathrm{~A} \\
37 \mathrm{~B} \\
34 \mathrm{~B}\end{array}$ & wt \\
\hline Summe $8 \mathrm{~W}$ & $\overline{0}$ & 4 & 2 & 4 & \\
\hline $16 \mathrm{~W}$ & 72 & $\begin{array}{l}\mathrm{G} \\
\mathrm{Q} \\
\mathrm{R} \\
\mathrm{S}\end{array}$ & $\begin{array}{c}36 \\
53 \\
21 \mathrm{~A} \\
31 \mathrm{~A} \\
52 \mathrm{~A}\end{array}$ & $\begin{array}{l}32 \mathrm{~A} \\
98 \mathrm{~A}\end{array}$ & $\overline{w t}$ \\
\hline Summe $16 \mathrm{~W}$ & 1 & 4 & 5 & 2 & \\
\hline $24 \mathrm{~W}$ & 71 & $\begin{array}{c}\mathrm{I} \\
\mathrm{K} \\
97 \\
98 \\
\mathrm{~T}\end{array}$ & $\begin{array}{l}12 \\
35 \\
38 \\
70\end{array}$ & $\begin{array}{c}69 \mathrm{~A} \\
68 \mathrm{~A} \\
1 \mathrm{~A}\end{array}$ & $20-39$ \\
\hline Summe 24 W & 1 & 5 & 4 & 3 & \\
\hline $36 \mathrm{~W}$ & 39 & $\begin{array}{l}\mathrm{L} \\
\mathrm{M} \\
\mathrm{N}\end{array}$ & $\begin{array}{c}3 \\
11 \\
14\end{array}$ & & $20-54$ \\
\hline Summe $36 \mathrm{~W}$ & $\overline{1}$ & 3 & 3 & $\overline{0}$ & \\
\hline $48 \mathrm{~W}$ & $\begin{array}{l}31 \\
33 \\
41\end{array}$ & & & & $\overline{19-45}$ \\
\hline Summe $48 \mathrm{~W}$ & $\overline{3}$ & $\overline{0}$ & $\overline{0}$ & $\overline{0}$ & \\
\hline
\end{tabular}




\section{Diskussion}

\subsection{Zusammenfassung der Ergebnisse}

Leupaxin wurde bereits in vorhergehenden Untersuchungen mit Hilfe der Mikrodissektion und anschließender Atlas ${ }^{\mathrm{TM}}$-Array-Hybridisierung als differentiell exprimiertes Gen im humanen kapselinvasiven Prostatakarzinom identifiziert [Voigt, 2003]. In der vorliegenden Arbeit konnten immunhistochemische Analysen an humanen Prostatakarzinomen mit einem Leupaxin-spezifischen Antikörper dieses Ergebnis bestätigen. Bei 22\% der untersuchten radikalen Prostatektomie-Präparate (13 aus 59) zeigte sich eine Leupaxin-Expression ausschließlich in den Epithelzellen des Prostatakarzinoms. Die Expression von Leupaxin korrelierte dabei direkt mit dem Gleason-Muster der Leupaxin-positiven Tumorbereiche sowie mit dem Gleason Score des gesamten Prostatakarzinoms. Diese eindeutige Korrelation weist darauf hin, dass Leupaxin möglicherweise in die Progression des Prostatakarzinoms involviert ist. Einen weiteren Hinweis darauf ergab die Expressionsanalyse von Leupaxin in den etablierten Prostatakarzinom (PCa)-Zelllinien LNCaP, PC-3 und DU 145. Mittels Western Blot-Analyse konnte gezeigt werden, dass Leupaxin in den androgen-unabhängigen, invasiven PC-3- und DU 145-Zellen sechs- bzw. zweifach stärker exprimiert wird als in den androgen-abhängigen, nicht invasiven LNCaP-Zellen. Subzellulär ist Leupaxin in diesen PCaZellen hauptsächlich in den sog. focal adhesion sites lokalisiert, wobei in 1-3\% der Zellen eine zusätzliche Kernlokalisation beobachtet werden konnte. Bei Inhibierung des normalen zellulären Exportin 1-vermittelten Kernexports akkumulierte das GFP-LeupaxinFusionsprotein im Kern, was auf ein Kernexportsignal (nuclear export signal $=$ NES) in der Leupaxin-Aminosäuresequenz hinweist. In der nachfolgenden Mutationsanalyse mit GFPLeupaxin-Fusionsproteinen konnte ein NES im Bereich der LD-Motive von Leupaxin bestätigt werden, wobei hauptsächlich das LD4-Motiv mit Unterstützung des LD-3-Motivs für den Kernexport von Leupaxin verantwortlich ist. Weiterhin konnte gezeigt werden, dass Leupaxin über die LIM-Domänen mit der Ligandenbindungsdomäne des Androgenrezeptors (AR) in liganden-abhängiger Weise interagiert und die transkriptionelle Aktivität des AR erhöht. Mit dem Glukokortikoid- und dem Progesteronrezeptor interagiert Leupaxin ebenfalls über die LIM-Domänen, jedoch ist diese Interaktion unabhängig von den Rezeptorliganden. Für diese Rezeptoren stellt Leupaxin einen Koaktivator in An- und Abwesenheit der Rezeptorliganden dar. 
Um den Einfluss von Leupaxin auf Proliferation, Invasion und Migration in den PCa-Zellen näher zu analysieren, wurde die Leupaxin-Expression in den PCa-Zelllinien mit Hilfe der RNAi-Technik herunterreguliert. Dabei konnte gezeigt werden, dass die androgen-abhängigen LNCaP-Zellen sich vom Boden der Kulturschale ablösen und apoptotisch werden (50\% Apoptose 120 h nach Transfektion). Die androgen-unabhängigen und invasiven PC-3- und DU 145-Zellen zeigten diesen Effekt nicht, jedoch konnte bei ihnen nach Herunterregulierung der Leupaxin-Expression eine um bis zu 78\% verminderte Invasivität und eine stark beeinträchtigte Migrationsfähigkeit festgestellt werden. Die Proliferation wird durch Leupaxin weder in LNCaP- noch in PC-3- und DU 145-Zellen beeinflusst. Mit Hilfe eines Zelladhäsions-Arrays wurde die differentielle Expression von Zelladhäsions-relevanten Genen nach Herunterregulierung der Leupaxin-Expression untersucht. Dabei konnte für Catenin delta 1 (CTNND1) demonstriert werden, dass es sowohl in LNCaP- als auch in PC-3und DU 145-Zellen mit verminderter Leupaxin-Expression stärker exprimiert wird als in den entsprechenden Kontroll-Zellen. Die Untersuchung des MAPK-Signalweges mittels PhosphoMAPK-Array zeigte, dass die Herunterregulierung der Leupaxin-Expression in LNCaPZellen zu einer Verringerung der Phosphorylierung und damit der Aktivität der Proteinkinase ERK2, nicht aber von ERK1 führt. Auch die Proteinkinase MEK1/2, die in der Signalkaskade upstream von ERK2 liegt, ist geringer phosphoryliert als in den entsprechenden KontrollZellen. In PC-3- und DU 145-Zellen mit herunterregulierter Leupaxin-Expression konnte keine Veränderung im Phosphorylierungsstatus von ERK1/2 beobachtet werden.

Zur Verifizierung der in vitro-Daten wurde ein transgenes Mausmodell mit Prostataspezifischer Überexpression von Leupaxin etabliert. Das Konstrukt wurde im Rahmen der Diplomarbeit von Frau Herr [2005] generiert. Insgesamt wurden zwei transgene LeupaxinMauslinien etabliert. Bei beiden Mauslinien konnte eine Prostata-spezifische Expression des transgenen Leupaxins mittels Western Blot und Immunhistochemie nachgewiesen werden. Dabei zeigte die Mauslinie \#19 eine schwache Expression und die Mauslinie \#20 eine starke Expression des transgenen Leupaxins in der Prostata. In einer histologischen Analyse der Prostatae aus verschiedenen Altersstadien der transgenen Leupaxin-Mäuse konnte keine Veränderung im Prostataepithel beobachtet werden. Diese Analysen bestätigen daher die Hypothese, dass Leupaxin kein Initiator der Tumorbildung ist. Es ist vielmehr anzunehmen, dass Leupaxin ein in die Progression des Prostatakarzinoms involviertes Protein darstellt. 


\subsection{Zur Initiation und Progression von malignen Läsionen}

Die zur Entwicklung von Tumoren notwendigen Eigenschaften der Zelle sind in folgendem Satz zusammengefaßt: Tumorzellen besitzen Defekte in den regulatorischen Kreisläufen, die die normale Proliferation und Homöostase kontrollieren. Hanahan und Weinberg [2000] postulierten, dass sechs essentielle Veränderungen in der Physiologie der Zellen notwendig sind, die gemeinsam das maligne Wachstum verursachen: (1) die Autonomie der Wachstumssignale, (2) die Unempfindlichkeit gegenüber wachstumsinhibierenden Signalen (Anti-Wachstum), (3) die Umgehung des programmierten Zelltods (Apoptose), (4) ein endloses Replikationspotential, (5) die fortwährende Angiogenese sowie (6) die Gewebeinvasion und Metastasenbildung (Abb. 4.1).

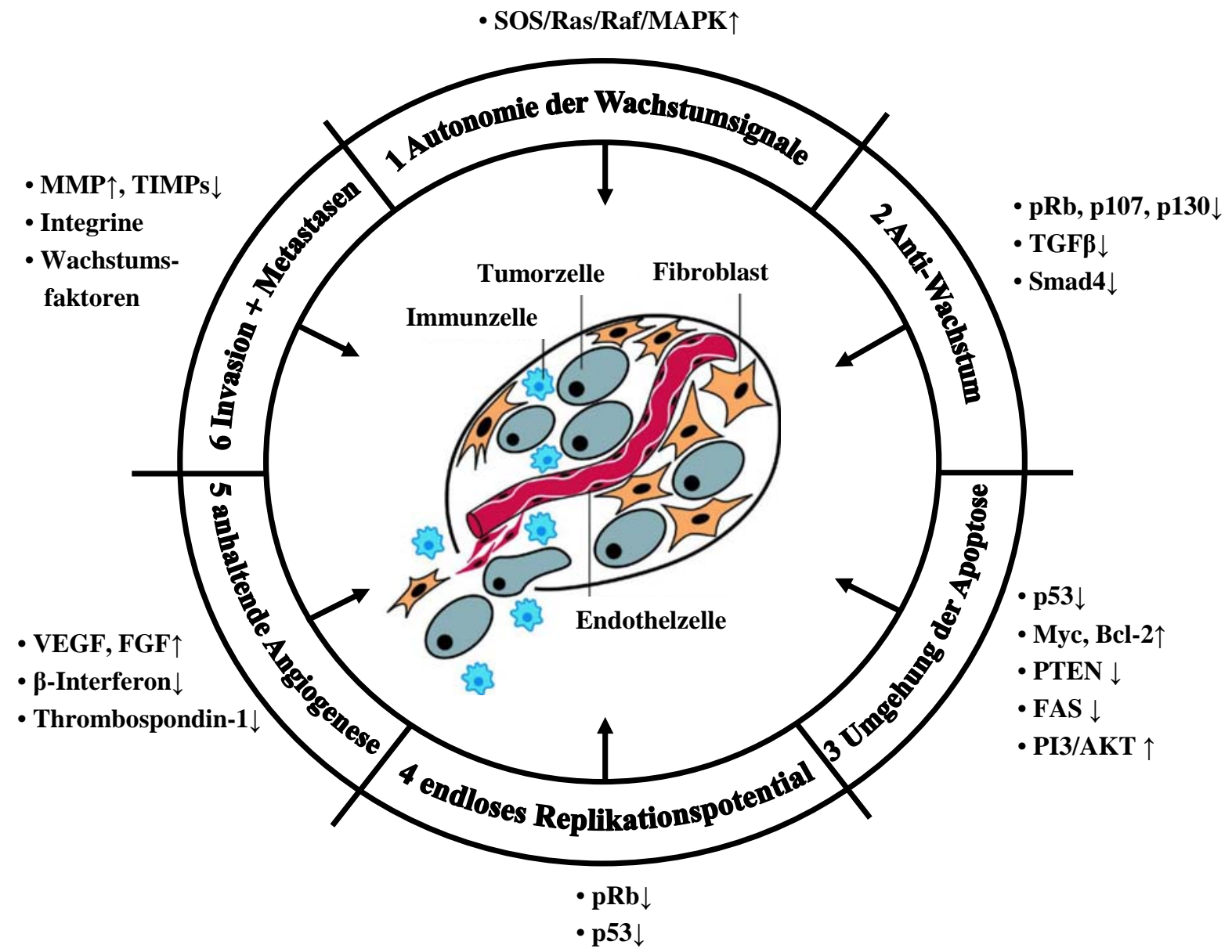

Abb. 4.1: Erworbene Eigenschaften von Tumorzellen, modifiziert nach Hanahan und Weinberg [2000]. Tumorzellen müssen sechs essentielle Veränderungen in ihrer Physiologie erwerben, die gemeinsam das maligne Wachstum verursachen. Es werden jeweils Beispiele für involvierte Proteine angegeben. $\downarrow=$ gestörte oder Verlust der Funktion; $\uparrow=$ Amplifikation oder Überexpression. Abkürzungen: pRb (Retinoblastomprotein), TGF $\beta$ 
(transforming growth factor $\beta$ ), PTEN (phosphatase and tensin homolog), VEGF (vascular endothelial growth factor), FGF (fibroblast growth factor), MMP (Matrixmetalloproteinase), TIMP (tissue inhibitor of metalloproteinase).

(1) Der komplexe Mechanismus der erworbenen Autonomie der Wachstumssignale entsteht durch Veränderungen in den Komponenten der downstream zytoplasmatischen Zellkreisläufe, welche die Signale von liganden-aktivierten Wachstumsfaktor-Rezeptoren und Integrinen erhalten und weiter prozessieren. Der SOS-Ras-Raf-MAPK-Signalweg spielt hierbei eine herausragende Rolle. In ca. 25\% der humanen Tumore liegt das Ras-Protein strukturell verändert vor, so dass mitogene Signale in die Zelle ohne Stimulation der normalen upstream -Regulatoren geleitet werden [Bianco et al., 2006]. Etwa die Hälfte aller humanen Darmkarzinome enthalten z.B. ein verändertes ras Onkogen [Kinzler et al., 1996]. Jedoch sind auch die heterotypen Signale zwischen verschiedenen Zelltypen innerhalb eines Tumors wichtig für die Erklärung der Tumorzellproliferation. Es wird vermutet, dass viele Wachstumssignale für die Proliferation der Tumorzellen aus den Stromazellkomponenten der Tumormasse stammen [Hanahan et al., 2000].

(2) Die Unempfindlichkeit gegenüber wachstumsinhibierenden Signalen ist mit dem Zellzyklus assoziiert, speziell mit den Komponenten, die den Übergang der Zelle von der G1Phase in den Wachstumszyklus kontrollieren. Die Mehrzahl der antiproliferativen Signale laufen über das Retinoblastomprotein (pRb) oder dessen Verwandte p107 und p130. Die Störung des pRb-Signalweges setzt E2F-Transkriptionsfaktoren frei, wodurch die Zellproliferation ermöglicht wird. Ein wichtiges Signalmolekül, das den pRb-Signalweg abhängig vom Zelltyp über verschiedene Mechanismen aktiviert, ist der AntiWachstumsfaktor TGF $\beta$ (transforming growth factor $\beta$ ). In verschiedenen Tumortypen ist dieser Signalweg verändert. So wurden sowohl eine Herunterregulierung des TGF $\beta$-Rezeptors als auch veränderte, nicht-funktionelle TGF $\beta$-Rezeptoren in verschiedenen Tumoren beschrieben [Bachman et al., 2005]. Weiterhin wurden Mutationen in downstream-Signalmolekülen des TGF $\beta$-Rezeptors nachgewiesen, z.B. in Smad 4, CDK4 (cyclin-dependent kinase 4) oder pRb selbst. Ein weiterer Mechanismus der Tumorzellen, den wachstumsinhibierenden Signalen zu entgehen, ist die Umgehung der vorherbestimmten terminalen Differenzierung.

(3) Resistenz gegenüber Apoptose können Tumorzellen über verschiedene Strategien erwerben, wobei sowohl die Sensoren als auch die Effektoren der Apoptose in den Signalwegen betroffen sind. In mehr als 50\% der humanen Karzinome ist z.B. das 
proapoptotische Protein p53 durch Mutationen in dessen Gen funktionell inaktiviert [Sun, 2006].

(4) Die deregulierte Proliferation allein reicht nicht aus für die Bildung einer großen Tumormasse, denn jede Zelle besitzt ein zellautonomes Programm, das die Multiplikation limitiert. Zum einen wird dies durch die Telomer-Verkürzungen nach jeder Teilung erreicht, zum anderen durch ein sog. Alterungsprogramm, deren beider Veränderungen zu nicht begrenzten Teilungen der Zellen führt [Bailey et al., 2006; Shin et al., 2006].

(5) Für die normalen Zellfunktionen sind Sauerstoff und Nährstoffe wichtig, die über das Blutsystem zugeführt werden. Unkontrolliertes Wachstum kann dazu führen, dass Zellen innerhalb eines Tumors aufgrund von Mangel an Sauerstoff und Nährstoffen absterben. Nur wenn Tumorzellen Fähigkeiten erwerben, die Angiogenese zu fördern, können sie überleben. So sind z.B. VEGF ( $\underline{\text { vascular }}$ endothelial growth factor) und/oder FGF (fibroblast growth factor) in vielen Tumoren im Vergleich zum Normalgewebe hochreguliert [Roy et al., 2006]. Bei anderen Tumoren sind die endogenen Angiogenese-Inhibitoren Thrombospondin-1 und/oder $\beta$-Interferon herunterreguliert [Rege et al., 2005; Ren et al., 2006; Roy et al., 2006]. (6) Die Tumorinvasion und Metastasenbildung sind wichtige Aspekte der Tumorprogression, und die Bildung von Metastasen ist in 90\% die Ursache von Krebstod [Sporn, 1996]. Untersuchungen haben jedoch gezeigt, dass die Tumorinvasivität einen eigenständigen Prozess in der Tumorprogression darstellt. So konnte gezeigt werden, dass die Invasion inhibiert werden kann, aber das Tumorwachstum dabei nicht beeinflusst wird [Takaoka et al., 1998]. Die Tumorzellen müssen verschiedene Fähigkeiten erwerben, um invasiv in das umgebende Gewebe eindringen zu können, d.h. die Zellen müssen die extrazelluläre Matrix (ECM) erkennen und diese unter anderem durch proteolytische Degradierung modifizieren. Danach kann die aktive Migration durch den Matrixraum mit anschließender Proliferation dieser Tumorzellen an der ektopischen, aber nächstliegenden Stelle erfolgen [Wells, 2000]. Während der Invasion verändern die Tumorzellen die Affinität für die ECM. Dabei setzen die Tumorzellen Proteasen frei, durch die die ECM degradiert und die Zellpassage durch das Stroma und der Eintritt in das umliegende Gewebe gefördert werden. Insbesondere drei Gruppen von Proteinen und ihre anschließenden Signalkaskaden sind für den Erwerb der invasiven Eigenschaft einer Tumorzelle verantwortlich. Dazu gehören die Integrine, die Matrix-Metalloproteinasen (MMP) und ihre Inhibitoren (TIMPS), sowie die Gruppe der Wachstumsfaktor-Rezeptoren.

Die Integrine gehören zur Familie der Zelloberflächen-Glykoproteine, die mit spezifischen Komponenten der ECM interagieren. Nach der Ligandenbindung bilden Integrine cluster, 
wobei an ihrem zytoplasmatischen Teil Aktin-assoziierte Protein wie $\alpha$-Aktinin, Vinkulin und Paxillin binden, so dass eine Verbindung zwischen den Integrinen und dem Zytoskelett entsteht [Sastry et al., 2000]. Diese Multiproteinkomplexe werden als focal adhesion sites bezeichnet. Die Integrine übertragen molekulare Informationen der zellulären Umgebung, die die Zellform, das Überleben, die Proliferation, die Migration und die Gentranskription beeinflussen [Aplin et al., 1999]. Die Integrine selbst besitzen keine Kinase-Domäne und keine enzymatische Aktivität. Daher binden Adapter- oder Signalmoleküle, um die Informationen weiterzuleiten. Paxillin scheint dabei als eine Art Gerüst-Protein für weitere Elemente, wie FAK und SRC, die in die Integrin-vermittelten Signalwege involviert sind, zu wirken. Die Aktivierung der FAK induziert eine Umformung der focal adhesion sites [Schlaepfer et al., 1999], die als erster Schritt in Richtung verstärkter Zellmotilität und Gewebeinfiltration durch transformierte Zellen angesehen wird. Veränderungen in der Integrin-Expression sind in invasiven und metastasierenden Zellen vorhanden [Varner et al., 1996; Lukashev et al., 1998].

Die zweite Gruppe umfasst MMPs und ihre Inhibitoren (TIMPs), die eine Rolle beim pathologischen Matrixabbau im Rahmen der Tumorinvasion und -metastasierung spielen. Die MMPs sind in der Lage, verschiedene Komponenten der Matrix wie Elastin, Gelatin und vor allem das ubiquitäre Kollagen zu degradieren [Lemaitre et al., 2006; VanSaun et al., 2006]. Weitere Studien haben gezeigt, dass die Anzahl der produzierten MMPs mit der Malignität der Tumorzellen korreliert [Giambernardi et al., 1998]. Die MMP-Gentranskription wird durch diverse extrazelluläre Stimuli, wie Zytokine (Interleukin-4 und -10) und Wachstumsfaktoren (EGF, TGF- $\alpha$ ) induziert [Hidalgo et al., 2001].

Die Wachstumsfaktoren (wie z.B. der EGF, IGF-I und IGF-II) gehören zu der dritten Gruppe von Proteinen, deren Signalkaskaden in den Erwerb invasiver Eigenschaften von Tumorzellen involviert sind. Es konnte gezeigt werden, dass der EGF-Rezeptor in einer großen Zahl von menschlichen Tumoren überexprimiert wird [Richter et al., 2005]. Dabei wurde festgestellt, dass nur invasive Tumore eine Überexpression dieses Wachstumsfaktor-Rezeptors aufweisen, während in nicht invasiven Tumoren keine Hochregulierung der EGFR-Expression gezeigt werden konnte. Sowohl die Integrine als auch die Wachstumsfaktoren beeinflussen die Zellmotilität. Die Zellmotilität stellt einen zentralen Punkt in der Tumorinvasion dar, da die Zellen physikalische Barrieren überwinden müssen, um an ektopischen Stellen wachsen zu können. Allerdings gibt es Unterschiede in der Beeinflussung der Zellmotilität durch die Integrine und durch die Wachstumsfaktoren: während die Integrin-induzierte Zellmotilität die Tumorinvasion ermöglicht, fördert die Wachstumsfaktor-induzierte Zellmotilität diese. Die 
Wachstumsfaktoren-induzierte Zellmotilität wirkt daher über andere Signalwege [Bornfeldt et al., 1994; Chen et al., 1994; Kundra et al., 1994; Carloni et al., 1997].

\subsubsection{Zur Initiation und Progression des Prostatakarzinoms}

Das Prostatakarzinom resultiert wie andere Tumorarten aus der Akkumulation von sowohl genetischen als auch epigenetischen Veränderungen, die das normale Drüsenepithel zu präneoplastischen und weiter zu invasiven Karzinomen transformieren. Die charakteristischen genetischen Veränderungen und die Abfolgen dieser Veränderungen wurden bis jetzt in der Entwicklung und Progression des Prostatakarzinoms nicht identifiziert. Dies wird zum Teil der merklichen Heterogenität und multifokalen Natur des Prostatakarzinoms zugeschrieben. Bisher ist es schwer festzustellen, ob Prostatakrebs durch Vererbung einer oder mehrerer spezifischer genetischer Veränderungen verursacht werden kann. Weniger als 10\% der Prostatakarzinome sind erblich bedingt; die meisten sind von sporadischer Natur [Gronberg et al., 1997]. Daher wird vorgeschlagen, dass verschiedene genetische Mechanismen und multiple genetisch kontrollierte Faktoren in die Bildung von sporadischen Tumoren involviert sind [Brothman et al., 1999].

Die normale Prostatadrüse besteht aus drei distinkten Zelltypen: die sekretorische Zelle, die Basalzelle und die neuroendokrine Zelle. Neuere Studien zeigen, dass es sog. ProstataStammzellen gibt. Nach heutiger Erkenntnis wird postuliert, dass die pluripotenten Stammzellen zunächst in Basalzellen differenzieren und anschließend in sekretorische und/oder neuroendokrine Zellen [Uzgare et al., 2004]. Welcher Zelltyp genau für die Initiation des Prostatakarzinoms verantwortlich ist, ist noch unbekannt. Neuere Studien demonstrieren, dass der Krebs auch als abnormales Organ mit Tumorwachstum ausgehend von einer Population von Stammzellen betrachtet werden kann [Al-Hajj et al., 2004; Beachy et al., 2004] (Abb. 4.2). 


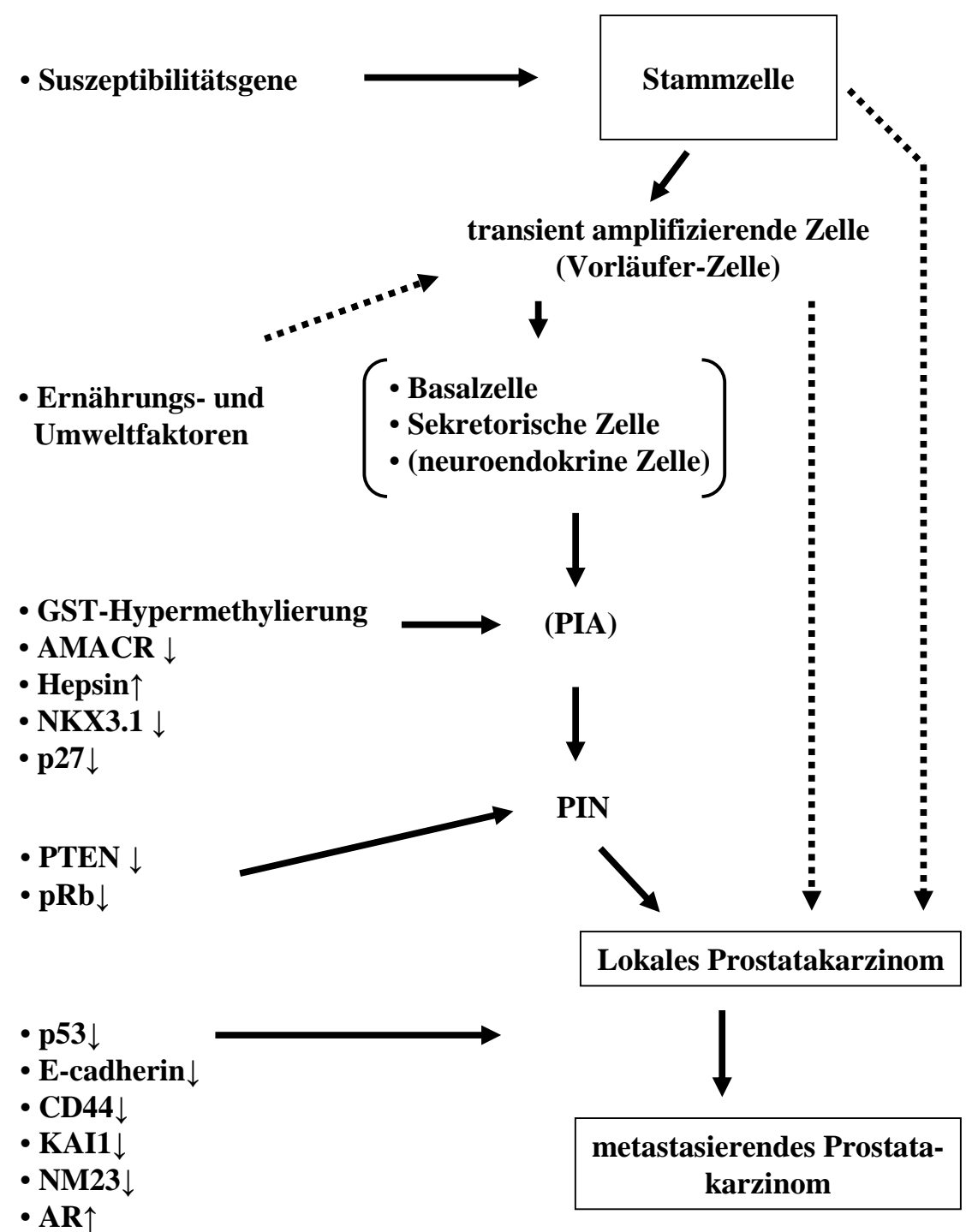

Abb. 4.2: Mögliche molekulare Pathogenese des Prostatakarzinoms [Konishi et al., 2005]. Nicht dargestellt sind chromosomale Verluste und Telomerlängen-Verkürzung, die ebenfalls zur Prostata-Tumorigenese beitragen. PIA: Proliferierende inflammatorische Atrophie, die möglicherweise zur Entstehung von Prostatakarzinomen führt. PIN: Prostata Intraepitheliale Neoplasie. $\uparrow=$ Überexpression oder Amplifikation; $\downarrow=$ gestörte oder Verlust der Funktion. Abkürzungen: GST (Glutathion-S-Transferase), AMACR ( $\alpha$-MethylacylCoA racemase), NM23 (nonmetastatic protein 23), AR (Androgenrezeptor).

Der Androgenrezeptor (AR) spielt eine wichtige Rolle bei Wachstum und Überleben von sowohl normalem Prostataepithel als auch von Prostatakarzinomzellen. Sowohl normales als auch malignes Prostatagewebe entwickelt sich unter Androgen-Entzug zurück, obwohl dieser Effekt beim Karzinom nur temporär ist (siehe Einleitung 1.1). Die Funktion des AR ist 
zwischen normalem Prostata- und malignem Prostatagewebe unterschiedlich. Während der AR ein Schlüsselregulator für die Funktion der Prostata und das Überleben der normalen Prostataepithelzellen darstellt, ist er zu einem Auslöser von unkontrolliertem Zellwachstum im Prostatakarzinom geworden [Heinlein et al., 2004]. Eine AR-Expression wird in primären Prostatatumoren und während der Progression in hormon-sensitiven als auch in hormonunabhängigen Karzinomen beobachtet [Sadi et al., 1991; Chodak et al., 1992; Ruizeveld de Winter et al., 1994]. Die Frage, ob eine erhöhte Expression des AR die Entstehung von Prostatakarzinomen auslösen kann, wurde in verschiedenen Mausmodellen getestet. Stanbrough et al. [2001] konnten zeigen, dass die Prostata-spezifische Expression des murinen AR in einem transgenen Mausmodell in 45\% der älteren Mäusen (>12 Monate) Prostata Intraepitheliale Neoplasien (PIN) auslöst. Die beobachteten PINs, die zumeist als Vorgänger des Prostatakarzinoms gelten, traten fokal auf und waren eher das Ergebnis eines sporadischen, sekundär genetischen oder epigenetischen Effekts als das primäre Resultat des AR-Transgens. In einer weiteren Studie wurde der humane Wildtyp-AR, die LNCaP-ARVariante AR(T877A) und eine weitere Variante AR(E231G) jeweils Prostata-spezifisch in transgenen Mäusen überexprimiert [Han et al., 2005]. Sowohl bei der Überexpression des Wildtyp-AR als auch bei der Variante AR(T877A), die zur Aktivierung des AR durch Antagonisten wie Progesteron, Östrogen, adrenale Androgene und Hydroxyflutamid führt, konnten keine abnormalen histologischen Veränderungen der Prostatae in Mäusen bis 12 Monate beobachtet werden. Nur die Variante AR(E231G) konnte eine schnelle Entstehung von PINs auslösen (Dysplasie in 100\% der Mäuse im Alter von 12 Wochen), die sich zu $100 \%$ in invasive und metastasierende Prostatakarzinome innerhalb von 12 Monaten weiterentwickelten. Die Mutation E231G liegt in einem hochkonservierten Motiv in der Nterminalen Domäne des AR und ist sowohl für die Struktur der N-terminalen Domäne als auch für die Rekrutierung von AR-Kofaktoren (z.B. CHIP) verantwortlich. Eine Überexpression des AR selbst kann demnach kein Prostatakarzinom auslösen, jedoch kann diese sekundäre genetische und epigenetische Ereignisse so unterstützen, dass die Entstehung und vor allem die Progression des Prostatakarzinoms gefördert wird. Der Androgenrezeptor wird vor allem im Zusammenhang mit der Progression vom androgen-abhängigen zum androgen-unabhängigen Prostatakarzinom beschrieben. Dabei wird postuliert, dass eine erhöhte AR-Aktivität für das androgen-unabhängige Prostatakarzinom veranwortlich ist [Chen et al., 2004; Edwards et al., 2005a] (siehe Abschnitt 4.5.1). 


\subsection{Zur Expression der Paxillin-Proteinfamilie und deren potentielle Rolle in der Entwicklung und bei verschiedenen Erkrankungen}

Für Paxillin konnte gezeigt werden, dass es sowohl in die Integrin-vermittelten Signalwege als auch in den durch Wachstumsfaktoren-induzierten Signalkaskaden involviert ist. Beide Signalwege sind sowohl bei der Initiation als auch bei der Progression von humanen Karzinomen verändert. Aufgrund der hohen Homologien der Paxillin-Familienmitglieder (Paxillin, ARA55 und Leupaxin) ist eine Rolle dieser Proteine bei der Entwicklung und Tumorigenese wahrscheinlich.

Paxillin stellt ein evolutionär hoch konserviertes Protein dar. Paxillin kodierende cDNAs konnten bisher bei Mensch [Salgia et al., 1995b], Maus [Mazaki et al., 1998; Hagel et al., 2002], Frosch [Ogawa et al., 2001], Zebrafisch [Crawford et al., 2003], Fliege [Wheeler et al., 2001; Yagi et al., 2001], in Dictyostelium discoideum [Glockner et al., 2002] und in Hefe (Saccharomyces cerevisiae) [Mackin et al., 2004] nachgewiesen werden. Die Paxillin mRNA wird in allen adulten Geweben des Menschen, außer im Gehirn exprimiert [Salgia et al., 1995a; Mazaki et al., 1997; Yuminamochi et al., 2003].

ARA55 wurde nur in Mensch und Maus identifiziert, in niederen eukaryontischen Lebewesen konnte das Protein bisher nicht nachgewiesen werden. Im Gegensatz zu Paxillin zeigt ARA55 ein limitiertes Expressionsmuster [Shibanuma et al., 1994]. ARA55 wird speziell in glatter Muskulatur, in myoepithelialen Zellen und in Blutplättchen exprimiert [Yuminamochi et al., 2003]. Auch in den epithelialen Zellen von untersuchten Geweben wie z.B. Magen, Darm, Leber, Haut, Brustdrüse und Prostata wurde ARA55 nicht detektiert [Li et al., 2002; Yuminamochi et al., 2003].

Die Expression des Leupaxin-Gens konnte bisher nur bei Mensch und Maus experimentell nachgewiesen werden. Weiterhin finden sich in der Datenbank von NCBI Hinweise, dass Leupaxin-ähnliche Proteine im Hund (XP_540583), im Rind (AAX46523), in der Ratte (AAH88217) und im Huhn (XP_508444) exprimiert werden. Aus der Literatur ist bekannt, dass Leupaxin hauptsächlich in Zellen hämatopoetischen Ursprungs und in lymphoiden Geweben wie Milz, Lymphknoten, Thymus und Appendix exprimiert wird [Lipsky et al., 1998]. Außerdem wurde eine sehr geringe Expression von Leupaxin in Knochenmark und Gehirn beschrieben. Die Promotorelemente von Paxillin, ARA55 und Leupaxin wurden bisher noch nicht charakterisiert, jedoch wird die Expression der Paxillin mRNA ähnlich wie bei ARA55 durch TGF $\beta$ induziert [Akiyama et al., 2000]. Retinsäure induziert die Expression 
der ARA55 mRNA, sodass ARA55 Retinsäure-abhängige Differenzierungsprozesse fördern kann [Shibanuma et al., 1998].

Während der Entwicklung zeichnet sich die Expression von Paxillin durch eine komplexe Regulation aus. In der frühen Gastrula der Maus wird die Paxillin mRNA nur im extraembryonalen Gewebe exprimiert, wohingegen ARA55 und Leupaxin im embryonalen Gewebe exprimiert werden [Hagel et al., 2002]. Später in der Gastrulation wird Paxillin im mesodermalen und endodermalen Gewebe exprimiert. Paxillin-positive Strukturen sind dabei z.B. das Endokardium, die dorsale Aorta und die Chorda dorsalis [Hagel et al., 2002]. Obwohl stark motile Zellen der Neuralleiste Paxillin exprimieren [Hagel et al., 2002], ist nur eine geringe neurale Expression zu beobachten. Ähnliche Expressionsmuster für Paxillin wurden auch in Zebrafisch [Crawford et al., 2003] und Drosophila [Wheeler et al., 2001; Yagi et al., 2001] beschrieben. Die $\alpha$-Paxillin-Isoform wird zuerst exprimiert, gefolgt von der Hochregulation der $\beta$-Isoform während der mittleren Phase der Gastrulation [Mazaki et al., 1998]. Während der Nierenentwicklung der Maus wird Paxillin sehr stark exprimiert, wohingegen postnatal Paxillin herunterreguliert und eine 43- bis $47 \mathrm{kDa}$ immunreaktive Bande, wahrscheinlich ARA55 oder die Isoform Paxillin $\delta$, hochreguliert wird [Sorenson et al., 1999]. Die Expression und Tyrosin-Phosphorylierung von Paxillin ändert sich während der Embryogenese, was auch das Expressions- und Phosphorylierungsprofil von FAK wiederspiegelt [Turner, 1991; Turner et al., 1993].

Die Bedeutung von Paxillin für die Embryonalentwicklung wurde durch die Generierung eines knock out-Mausmodells für das Paxillin-Gen bestätigt [Hagel et al., 2002]. Der embryonal lethale Phänotyp der knock out-Mäuse, trotz Expression der Familienmitglieder ARA55 und Leupaxin, zeigte die Unfähigkeit der einzelnen Mitglieder der PaxillinProteinfamilie sich gegenseitig zu kompensieren.

Obwohl bisher keine humane Krankheit eindeutig mit der Expression eines mutierten Paxillin-Proteins in Zusammenhang gebracht wurde, ist eine Duplikation der chromosomalen Region des humanen Paxillin-Gens (12q24) in schweren muskuloskelettalen, kardiovaskulären und Zentralnervensystem-Fehlbildungssyndromen beobachtet worden [Melnyk et al., 1981; Roberts et al., 1981; MacDonald et al., 1985]. Weiterhin wurde die Region q24 auf Chromosom 12 in einem Mikrozell-vermitteltem Chromosomentransferscreening in Prostatakarzinomzellen als Region identifiziert, die einen Tumorsuppressor enthält [Ichikawa et al., 2000]. Paxillin bindet zudem an das anti-apoptotische Protein Bcl-2 [Sorenson et al., 1999; Sorenson, 2004]. Bei Induktion von Apoptose wird Paxillin an den Aminosäurepositionen D102 und D301 durch Caspasen gespalten. Wird jedoch ein Paxillin- 
Protein exprimiert, das diese Caspase-Schnittstellen nicht enthält, werden die Zellen vor Apoptose geschützt. Die Fakten unterstützen die wichtige Rolle von Paxillin im Überleben der Zelle. Der Einfluss von Paxillin bei der Tumorentwicklung wurde mit dem Befund deutlich, dass die Bindung von Paxillin an den NF2-Tumorsuppressor (Merlin/Schwannomin) die Pathogenese der Neurofibromatose Typ2 in Menschen mit Exon 2-Mutationen vermittelt [Fernandez-Valle et al., 2002]. Eine Rolle von Paxillin in der Papillomavirus-vermittelten Zelltransformation, die mit Gebärmutterhalskrebs assoziiert ist, wird postuliert, wobei diese durch die Bindung von Paxillin an das E6-Protein vermittelt wird [Das et al., 2000].

Zusätzliche Rollen bei der Entwicklung von Tumoren wurden Paxillin zugedacht, da es die Eigenschaft besitzt, durch Integrin- und Wachstumsfaktor-Rezeptor-Ligation phosphoryliert zu werden. Von diesen transmembranen Rezeptoren ist bekannt, dass sie in Tumorigenese und Invasion involviert sind (siehe 4.2). Studien, in denen die Funktion von Paxillin in normalen und Krebszellen direkt manipuliert wurde, gefolgt von der Untersuchung der Konsequenzen auf die Zellfunktion haben klare Rollen für Paxillin identifiziert. Die Analyse der Expression und Aktivitäten der Mitglieder der Paxillin-Proteinfamilie in verschiedenen Krebsarten wird die potentielle Rolle dieser Proteine bei Krebs und anderen Krankheiten erhellen.

Paxillin wird in Brustkrebszellen transkriptionell durch Behandlung mit dem Wachstumsfaktor Heregulin hochreguliert, und die erhöhte Expression von Paxillin korreliert dabei direkt mit der Expression des onkogenen HER2/3-Rezeptors, sowohl in aggressiven Brustkrebs-Zelllinien als auch in humanen Grad III-Mammakarzinomen [Vadlamudi et al., 1999]. Im Gegensatz dazu wurde im Hunde- und Katzenmodell eine Assoziation zwischen einer reduzierten Expression von Paxillin und einer erhöhten Expression von p130CAS mit metastasierenden Mammakarzinomen festgestellt [Scibelli et al., 2003]. Dies stimmt mit dem Befund überein, dass es einen funktionellen Antagonismus zwischen Paxillin und p130CAS im Zusammenhang mit der epithelialen-mesenchymalen Transition und Motilität in einem Maus-Brustzell-Modell gibt [Yano et al., 2000]. Beim Lungenkrebs wurde ebenfalls eine reduzierte Expression und Tyrosin-Phosphorylierung von Paxillin bei der Bildung des metastasierenden Karzinoms postuliert [Salgia et al., 1999; Jackson et al., 2003]. Geringe Expressionslevel von Paxillin wurden auch im kleinzelligen Bronchialkarzinom beobachtet. Weiterhin konnte eine kürzlich erschienene Studie demonstrieren, dass eine geringe PaxillinExpression im Mammakarzinom mit einem aggressiven Tumorverhalten assoziiert ist [Madan et al., 2006]. Zusätzlich korreliert eine hohe Paxillin-Expression in den invasiven Mammakarzinomen mit einem negativen Lymphknoten-Status, und eine Aktivierung von 
Paxillin korreliert invers mit der Lympho-vaskulären Invasion [Madan et al., 2006]. Im Gegensatz dazu wurde eine Hochregulierung von Paxillin im proliferierenden Prostataepithel beobachtet, die mit einem erhöhten Metastasen-Potential korreliert [Tremblay et al., 1996; Aprikian et al., 1997], wobei eine erhöhte Tyrosin-Phosphorylierung von Paxillin eine wichtige Rolle spielt [Aprikian et al., 1997]. Eine erhöhte Paxillin-Expression wurde ebenfalls beim experimentellen Akuten Nephritischen Syndrom [Koukouritaki et al., 1998], im metastasierenden Nierenzellkarzinom [Jenq et al., 1996] und in hochmetastasierenden Subzelllinien des Osteosarkoms [Azuma et al., 2005] festgestellt. Die offensichtlichen Widersprüche inbezug auf die direkte Korrelation zwischen Paxillin-Expression bzw. -Phosphorylierung und der Aggressivität des Krebses zeigen die gewebespezifische und kontextspezifische Rolle von Paxillin bei der zellulären Funktion auf.

ARA55 wird während der zellulären Seneszenz hochreguliert und während der RasTransformation oder spontanen Immortalisierung herunterreguliert [Shibanuma et al., 1994]. Eine induzierte Expression von ARA55 in immortalisierten humanen Fibroblasten induziert Seneszenz und blockiert die Koloniebildung in einem FAK-abhängigen Mechanismus [Shibanuma et al., 1997; Ishino et al., 2000]. Diese Daten unterstützen die Möglichkeit, dass ARA55 Tumorsuppressor-Funktionen besitzt. Obwohl ARA55 nicht in immortalisierten und/oder transformierten Zelllinien exprimiert wird, konnte ARA55 jedoch in Prostatakarzinom-Zelllinien und klinischen -Proben sowie in epithelialen Karzinomen und in vielen Brustkrebs-Zelllinien nachgewiesen werden. Die bekannten Rollen für ARA55 als Adaptorprotein und Steroidhormonrezeptor-Koaktivator positionieren ARA55 als einen potentiellen Hauptvermittler in der Karzinogenese in diesen Geweben. Als Androgenrezeptor (AR)-Koaktivator wurde ARA55 auch im Zusammenhang mit Prostatakarzinomen untersucht. So zeigte eine Studie von Fujimoto et al. [2001], dass ARA55 in hochgradigen Prostatakarzinomen (Gleason Score 8-10) stärker exprimiert wird als in mittelgradigen Karzinomen (Gleason Score 5-7). Nach Behandlung der Patienten mit einer androgenunterdrückenden Therapie wurde eine höhere Expression von ARA55 in den Prostatakarzinomen der Patienten mit einer schlechten Reaktion auf die Therapie (gemessen am sinkenden PSA (prostate specific antigen)-Wert festgestellt. Patienten mit einer guten Reaktion auf die Therapie zeigten eine geringere ARA55-Expression im Prostatakarzinom. Eine weitere Studie kam zu dem Schluss, dass ARA55 in hormon-unabhängigen Prostatakarzinomen geringer exprimiert wird als in den zuvor unbehandelten Prostatakarzinomen. Jedoch wurde in dieser Studie eine negative Korrelation zwischen der ARA55-Expression und des rezidiv-freien Überlebens oder der gesamten Überlebensdauer 
bei Patienten mit hormon-unabhängigem Prostatakarzinom festgestellt [Miyoshi et al., 2003]. Mestayer et al. [2003] beobachteten, dass die ARA55-Expression in Prostatatumoren im Vergleich zu Normalgewebe reduziert ist.

Diese oben genannten, sich widersprechenden Ergebnisse bezüglich der ARA55-Expression sind zu erklären, wenn die Resultate neuerer Studien betrachtet werden. Es wurde gezeigt, dass das ARA55-Gen nicht in den LNCaP- und DU 145-Zellen, aber in PC-3- und in Stromazellen der Prostata exprimiert wird [Nessler-Menardi et al., 2000; Fujimoto et al., 2001; Wang et al., 2002]. Die hauptsächliche Expression von ARA55 in Stromazellen der Prostata wurde mittels mRNA-in situ-Hybridisierung [Li et al., 2002] und Immunhistochemie [Heitzer et al., 2006] bestätigt. In den zuvor erwähnten Studien wurden RT-PCR-Analysen an Gesamt-Tumorgewebe durchgeführt, wodurch keine Unterscheidung zwischen Stroma- und Epithelzellen vorgenommen werden konnte. Daher ist es schwer zu beurteilen, ob die beobachteten Veränderungen in der Expression von ARA55 in individuellen Zellen oder eine Veränderung der Balance zwischen Stroma- und Epithelzellgehalt in den Tumoren darstellt. Im Gegensatz dazu wurde eine Überexpression von Paxillin in invasiven PC-3 und DU 145Zellen im Vergleich zu den nicht-invasiven LNCaP-Zellen beobachtet. Weiterhin wurde gezeigt, dass Paxillin zusammen mit FAK einen Einfluss auf die Progression und Invasion von Prostatakarzinomen besitzt [Tremblay et al., 1996]. Detaillierte Studien zur Expression von Paxillin im humanen Prostatakarzinom stehen jedoch noch aus.

\subsection{Ist Leupaxin in die Initiation oder Progression von humanen Prostatatumoren involviert?}

Die Literaturdaten zur Expression und zum Einfluss auf Initiation und/oder Progression von Paxillin und ARA55 in Prostata- und anderen Karzinomen sind sehr gegensätzlich und variieren zwischen den verschiedenen Gewebetypen und zwischen verschiedenen Arbeitsgruppen. Sie konnten daher nicht als Anhaltspunkte bei der Untersuchung von Leupaxin im humanen Prostatakarzinom zu Rate gezogen werden.

In vorangegangenen Untersuchungen wurde Leupaxin als differentiell exprimiertes Gen im humanen Prostatakarzinom identifiziert [Voigt, 2003]. Dabei wurde die Methode der Mikrodissektion angewendet, so dass Probenmaterial nur einer Zellpopulation verwendet werden konnte. Damit konnte in einem einzigen Prostatakarzinom zwischen normalem, 
zentralem Tumor- und kapselinvasivem Tumor-Prostatagewebe unterschieden werden. Auch die anschließenden RT-PCR-Analysen an weiteren acht Prostatakarzinomen wurden an RNA aus mikrodissezierten Zellen durchgeführt. Da diese Methode jedoch sehr aufwendig und für eine größere Anzahl von Tumoren zeit- und kostspielig ist, wurde im Rahmen dieser Arbeit eine immunhistochemische Analyse an 59 radikalen Prostatektomie-Präparaten mit einem Leupaxin-spezifischen Antikörper durchgeführt. Bei 22\% der untersuchten Prostatakarzinome konnte eine Expression von Leupaxin in den Epithelzellen des Prostatakarzinoms nachgewiesen werden, nicht aber in normalen Drüsen, hyperplastischen Drüsen oder in Stromazellen der Prostata. Dabei wurde ein fokales Expressionsmuster von Leupaxin in den meisten Prostatakarzinomen festgestellt, d.h. nur bestimmte Tumorbereiche zeigten eine Expression von Leupaxin, wohingegen auch benachbarte Tumorareale Leupaxin-negativ waren. Zudem wurde eine direkte Korrelation zwischen der Leupaxin-Expression und dem Gleason-Muster des Leupaxin-positiven Tumorbereiches sowie dem Gleason Score des gesamten Prostatakarzinoms festgestellt.

Die Analyse der Expression von Leupaxin in den etablierten Prostatakarzinom-Zelllinien konnte dies bestätigen, denn in den invasiven, androgen-unabhängigen PC-3- und DU 145Zellen wird Leupaxin 6- bzw. 2-fach stärker exprimiert als in den nicht invasiven, androgenabhängigen LNCaP-Zellen. Für Paxillin wurde ein ähnliches Expressionsmuster in den PCaZelllinien festgestellt [Tremblay et al., 1996]. Weitere Hinweise, welche Rolle Leupaxin in den Prostatakarzinomzellen spielt, konnten aus den in vitro-Studien erhalten werden. Bei Herunterregulierung der Leupaxin-Expression in den PCa-Zelllinien mit Hilfe der RNAInterferenz-Technik wurde festgestellt, dass die PC-3- und DU 145-Zellen eine um bis zu 78\% verminderte Invasivität zeigten. Weiterhin wurde durch den knock down der LeupaxinExpression die Migrationsfähigkeit dieser Zellen stark beeinträchtigt. Auch in der Studie zur Funktion von Leupaxin in Osteoklasten konnte gezeigt werden, dass bei einer Verminderung der Leupaxin-Expression in diesen Zellen eine Reduktion der Migrationsfähigkeit und damit auch der Fähigkeit zur Matrix-Resorption der Osteoklasten auftritt [Gupta et al., 2003]. Weiterhin konnte im Rahmen der Diplomarbeit von Frau Herr [2005] gezeigt werden, dass auch die hoch-invasive und Östrogenrezeptor-negative Mammakarzinomzelllinie MDA-MB231 bei verminderter Leupaxin-Expression eine reduzierte Invasivität besitzt. Die Herunteregulierung der Leupaxin-Expression dagegen hatte keinen Einfluss auf die Proliferationsfähigkeit der PCa-Zelllinien. Für Paxillin und ARA55 konnte dagegen in PCaZellen gezeigt werden, dass beide Proteine in die Proliferation der Zellen involviert sind. Dabei besitzen sie unterschiedliche Funktionen: während die Expression von Paxillin die 
Proliferation in einem positiven Sinne beeinflusst, vermindert eine verstärkte Expression von ARA55 die Proliferation der Zellen [Thomas et al., 1999a].

Ein komplett anderer Effekt nach der Leupaxin-Herunterregulierung konnte in den androgenabhängigen LNCaP-Zellen beobachtet werden. Diese Zellen exprimieren im Gegensatz zu den PC-3- und DU 145-Zellen einen funktionellen Androgenrezeptor. Beim knock down der Leupaxin-Expression veränderten die LNCaP-Zellen zunächst ihre Morphologie. Sie rundeten sich ab und lösten sich anschließend vom Boden der Zellkulturflasche [Voigt, 2003]. Fünf Tage nach der Transfektion waren bereits 50\% der Zellen apoptotisch. Es konnte weiterhin gezeigt werden, dass Leupaxin mit dem Androgenrezeptor in liganden-abhängiger Weise interagiert. Diese Interaktion führte in einem Transaktivierungsassay auch zu einer Erhöhung der transkriptionellen Aktivität des AR. Die Messung der Konzentration eines stark ARresponsiven Genprodukts, PSA, im Kulturmedium von LNCaP-Zellen mit herunterregulierter Leupaxin-Expression zeigte, dass der AR eine verringerte Aktivität aufweist. Ob dies nun direkt durch den Verlust der Interaktion von AR und Leupaxin oder über bisher unbekannte Signalwege geschieht, konnte bisher noch nicht bewiesen werden. Zudem ist nicht auszuschließen, dass nicht die Anwesenheit des AR, sondern möglicherweise die unterschiedliche Expression von Leupaxin-Interaktionspartnern bzw. up- und downstream Signalwegspartnern die verschiedenen Effekte beim knock down von Leupaxin in den PCaZelllinien auslösen. Jedoch repräsentieren LNCaP-Zellen am ehesten das frühe, nicht-invasive und androgen-abhängige Prostatakarzinom. Eine androgen-unterdrückende Therapie, die zum Funktionsverlust des AR führt, kann in diesen Tumoren Apoptose auslösen. Eine Herunterregulierung der AR-Expression in LNCaP-Zellen führt ebenfalls zu Inhibition des Zellwachstums und Apoptose in diesen Zellen [Haag et al., 2005; Liao et al., 2005; Yang et al., 2005]. Wie bereits in Abschnitt 4.2 beschrieben, ist der AR selbst nicht in die Entstehung von Prostatakarzinomen involviert. Sollten die in den LNCaP-Zellen beobachteten Effekte aus der Interaktion von AR und Leupaxin resultieren, ist auch dies ein weiterer Hinweis, dass Leupaxin keine Rolle bei der Initiation von Prostatakarzinomen spielt.

Sowohl die Daten aus der immunhistochemischen Analyse zur Leupaxin-Expression in den humanen Prostatektomie-Präparaten als auch die in vitro-Daten zur Herunterregulierung der Leupaxin-Expression sprechen für einen Einfluss von Leupaxin auf die Progression und Invasion des Prostatakarzinoms. Mit Hilfe eines transgenen Mausmodells sollte jedoch endgültig geklärt werden, welche Auswirkungen die Überexpression von Leupaxin auf Prostataepithelzellen hat. Daher wurden transgene Leupaxin-Mäuse generiert, die eine Prostata-spezifische Überexpression von Leupaxin aufweisen. Verwendet wurde dazu der 
etablierte Prostata-spezifische Minimalpromotor des Ratten-Probasin-Gens (rPb). Greenberg et al. [1994] konnten zeigen, dass dieser Minimalpromotor ausreicht, um das CAT (Chloramphenicol Acetyltransferase)-Gen spezifisch in der Prostata der transgenen Mäuse zu exprimieren. Die Expression des rPb-CAT-Konstruktes ist dabei hauptsächlich auf die lateralen, dorsalen und ventralen Lappen der Prostata beschränkt. Es konnte gezeigt werden, dass die Expression des CAT-Gens unter der Kontrolle des rPb-Promotors vom Entwicklungsstand und der hormonellen Regulation durch Androgene der transgenen Mäuse abhängig ist. So konnte ein 70facher Anstieg der CAT-Aktivität in der Prostata der transgenen Mäuse zwischen der zweiten und siebten Woche beobachtet werden [Greenberg et al., 1994]. Die Expression des transgenen Leupaxins beschränkt sich wie erwartet auf die dorsalen und ventralen Lappen der Maus-Prostatae. Insgesamt wurden zwei verschiedene transgene Leupaxin-Mauslinien untersucht. Während die Mauslinie \#20 eine starke Expression des Transgens zeigt, kann in der Mauslinie \#19 nur eine schwache Expression beobachtet werden. Sollte Leupaxin die Initiation von Prostatakarzinomen auslösen, wurde eine Bildung von Primärtumoren vor allem in den dorsalen und ventralen Lappen der Prostatae erwartet. Jedoch konnte eine histologische Untersuchung der Prostatae von verschiedenen Altersstadien der beiden transgenen Leupaxin-Mauslinien keine malignen Veränderungen aufzeigen. Die ältesten untersuchten Mäuse waren ca. 1 Jahr alt. Somit hat eine Überexpression von Leupaxin keinen direkten Einfluss auf die Entstehung des Prostatakarzinoms.

Auch die Prostata-spezifische Überexpression des AR in einem transgenen Mausmodell resultiert nicht direkt in der Entstehung von PINs oder Prostatakarzinomen innerhalb von 12 Monaten [Stanbrough et al., 2001; Han et al., 2005]. Sekundäre genetische und epigenetische Ereignisse waren notwendig, PINs in Mäusen (älter als 12 Monate) auszulösen. Daher ist es sinnvoll die transgenen Leupaxin-Mäuse zusätzlich mit TRAMP (transgenic adenocarcinoma in mouse prostate)-Mäusen $\mathrm{zu}$ verpaaren. Die TRAMP-Mäuse sind ein etabliertes Mausmodell für Prostatakarzinome. Bei der Herstellung der TRAMP-Mäuse wurde der Minimalpromotor des Ratten-Probasingens verwendet, unter dessen Kontrolle das SV40-LTA (Simian Virus 40-Tumor-Antigen) steht [Greenberg et al., 1995]. Das SV40-LTA wirkt durch Interaktionen mit den Retinoblastom- und p53-Tumorsuppressorgen-Produkten als Onkoprotein [Linzer et al., 1979; DeCaprio et al., 1988]. Die TRAMP-Mäuse entwickeln schon nach 12 Wochen milde bis schwere Hyperplasien, nach 18 Wochen schwere Hyperplasien und Adenokarzinome, die dem humanen Prostatakarzinom ähneln. Im Alter von 24-30 Wochen zeigen alle TRAMP-Mäuse Primärtumoren in der Prostata, und Metastasen in Lymphknoten und Lungen sind üblich [Greenberg et al., 1995]. Bei einer Verpaarung dieser 
TRAMP-Mäuse mit den transgenen Leupaxin-Mäusen kann z.B. untersucht werden, ob Leupaxin wirklich in vivo einen Einfluss auf die Invasivität von Tumorzellen besitzt.

Es wurden bereits verschiedene transgene und knock out-Mausmodelle mit der TRAMP-Maus verpaart, um die tumorigenen Eigenschaften unterschiedlicher Genprodukte in vivo zu analysieren. Der Proliferations-spezifische Transkriptionsfaktor forkhead box M1 (FoxM1) wird in einer Reihe von aggressiven humanen Karzinomen überexprimiert [Lee et al., 2004; Pilarsky et al., 2004; Obama et al., 2005; Wonsey et al., 2005]. Erhöhte Proteinlevel von FoxM1 korrelieren mit einer hohen Proliferationsrate in humanen Prostatakarzinomen. Wird FoxM1 in PCa-Zelllinien herunterreguliert, wird die Zellproliferation und das Verankerungsunabhängige Wachstum dieser Zellen beeinträchtigt. Die Verpaarung transgener FoxM1Mäuse, die FoxM1 unter der Kontrolle des ubiquitären Promotors ROSA26 exprimieren, mit den TRAMP-Mäusen zeigte eine verstärkte Entwicklung, Proliferation und Wachstum der Prostatatumoren [Kalin et al., 2006]. Weiterhin konnte für Caveolin-1, welches in humanen Prostatakarzinomen überexprimiert wird, demonstriert werden, dass es eine tumorunterstützende Funktion besitzt. Dazu wurden Caveolin-1 knock out-Mäuse mit den TRAMP-Mäusen verpaart, wodurch die Progression zu hoch invasiven und metastasierenden Tumoren in den TRAMP-Mäusen verhindert wurde [Williams et al., 2005]. Die TRAMPMäuse wurden ebenfalls mit einem transgenen Mausmodell verpaart, das eine Variante des Tumorsuppressor-Gens p53, p53 ${ }^{\mathrm{R} 172 \mathrm{~L}}$, Prostata-spezifisch unter der Kontrolle des rPbPromotors exprimiert. Die Variante p53 ${ }^{\mathrm{R} 172 \mathrm{~L}}$ kommt natürlicherweise vor und besitzt einen Arginin-zu-Leucin-Aminosäureaustausch an Position 172 der Aminosäuresequenz. Die transgenen $\mathrm{rPb}-\mathrm{p} 53^{\mathrm{R} 172 \mathrm{~L}}$-Mäuse zeigten keinen veränderten Prostata-Phänotyp. Nach Verpaarung mit den TRAMP- Mäusen zeigte sich jedoch, dass die Expression von $\mathrm{p} 53^{\mathrm{R} 172 \mathrm{~L}} \mathrm{zu}$ deutlich reduzierter Tumorhäufigkeit und zu vermindertem Tumorwachstum führt [Hernandez et al., 2003]. Die Prostata-spezifische Überexpression des antiapoptotischen Proteins Bcl-2 bewirkt bei einer Verpaarung der TRAMP-Maus mit dem Mausmodell rPb-Bcl-2 dagegen eine verstärkte Tumorproliferation im Vergleich zu den Tumoren der homozygoten TRAMPMäuse [Bruckheimer et al., 2000]. Mit Hilfe dieser Verpaarungen lassen sich folglich die Auswirkungen bestimmter Genprodukte in vivo auf die Tumorprogression untersuchen. Daher ist es auch sinnvoll, die transgenen Leupaxin-Mäuse mit den TRAMP-Mäusen zu verpaaren, um so den putativen Einfluss von Leupaxin auf die Invasivität der Prostatatumorzellen in vivo zu überprüfen. 


\subsection{Wie kann Leupaxin die Progression von Prostatakarzinomen beeinflussen?}

Im vorangegangenen Abschnitt wurde gezeigt, dass Leupaxin nicht in die Initiation, jedoch in die Progression von Prostatakarzinomen involviert ist. Aber wie erfüllt es diese Funktion? Bei der Beantwortung dieser Frage muss in Betracht gezogen werden, dass Leupaxin einerseits in den focal adhesion sites lokalisiert ist und damit direkt oder indirekt mit Integrinen und Signalmolekülen interagiert, die die Zelladhäsion und -migration und damit auch die Invasion beeinflussen. Andererseits interagiert Leupaxin mit und transaktiviert die Steroidhormonrezeptoren, speziell den Androgenrezeptor, und ist ebenfalls im Kern lokalisiert. Daher besteht die Möglichkeit, dass Leupaxin die Invasion der Prostatakarzinomzellen über genregulierende Funktionen verändert.

\subsubsection{Hypothese 1: Einfluss von Leupaxin auf die Androgenrezeptor-regulierte Genexpression}

Das fortgeschrittene hormon-unabhängige Prostatakarzinom (PCa) ist mit den heutigen Therapieverfahren nicht heilbar. Es ist stark invasiv und metastasiert in die anliegenden Gewebe wie Samenblasen, Lymphknoten, aber auch Knochenmark und Lunge, was letztendlich zum Tod des Patienten führt. Das Fehlschlagen der androgen-unterdrückenden Therapien wird mit Modifikationen der AR-Aktivität in Verbindung gebracht, die möglicherweise zum hormon-unabhängigen Prostatakarzinom führt. Die Suche nach genetischen Veränderungen in einer Reihe von PCa-Xenografts zeigte, dass das einzige gemeinsame Merkmal bei der Transition zu hormon-unabhängigen Stadien die Hochregulation des AR, zusammen mit dem Agonismus von AR-Blockern und Veränderungen in der relativen Anwesenheit von AR-Koaktivatoren und -Repressoren an den Promotoren von AR-Zielgenen sind [Chen et al., 2004; Hendriksen et al., 2006]. Die vorgeschlagenen Mechanismen zur Erklärung der Entwicklung des androgen-unabhängigen Prostatakarzinoms können in drei generelle Kategorien eingeteilt werden [Chen et al., 2004]. Die erste Kategorie beinhaltet das Demaskieren von Signalwegen in der Tumorzelle, die die Proliferation fördern und die Apoptose inhibieren, so dass der AR nicht mehr relevant für die Progression der Krankheit ist. Ein Beispiel ist die hochregulierte Expression des antiapoptotischen Bcl-2-Gens in späten PCa-Entwicklungsstadien [Catz et al., 2003]. Diese 
Hypothese der AR-Umgehung wird unterstützt durch Studien, die zeigen, dass eine Methylierung des AR-Gens zu einer verringerten oder zu einem kompletten Verlust der ARExpression in einigen hormon-unabhängigen PCa-Fällen führen kann [Kinoshita et al., 2000; Sasaki et al., 2002].

Die zweite Kategorie involviert das AR-Gen selbst, z.B. wurden Amplifikationen des ARGens oder Punktmutationen in bis zu 5\% bzw. 10-20\% der PCa-Fälle beschrieben, wobei diese häufiger in hormon-unabhängigen als in hormon-sensitiven Tumoren auftreten [Edwards et al., 2005a]. Diese AR-Modifikationen sollen die Resistenz durch Veränderung der AR-Funktion hervorrufen, so dass auch andere Liganden außer DHT, z.B. Östrogen oder Hydrocortison, oder sogar AR-Antagonisten wie Hydroxyflutamid als Agonisten des AR fungieren [Veldscholte et al., 1992; Matias et al., 2002].

Die dritte Kategorie der androgen-umgehenden Mechanismen umfasst die Kontrolle der ARFunktion durch posttranslationale Modifikationen, häufig via Phosphorylierung durch verschiedene Kinase-Kaskaden. Eine konstitutiv aktivierte MAPK (mitogen-activated protein kinase)- oder PI3K/AKT-Signalkaskade, die durch Onkogene wie z.B. HER2, HRas oder den Verlust der PTEN-Funktion hervorgerufen werden, verursachen eine liganden-unabhängige Aktivierung des AR, was in einer vermehrten Rekrutierung von AR-Kofaktoren und damit in einer erhöhten Transkriptionsaktivität des AR resultiert [Craft et al., 1999; Gioeli et al., 2002; Uzgare et al., 2003; Edwards et al., 2005b]. Gleichfalls kann eine Veränderung der Balance zwischen Koaktivatoren und Korepressoren die AR-Aktivität beeinflussen [Gregory et al., 2001; Mestayer et al., 2003].

AR-Kofaktoren gehören zu einer Proteinklasse, die direkt oder über Multiproteinkomplexe an den AR binden und damit die transkriptionelle Aktivität des AR erhöhen oder inhibieren. Es kann vermutet werden, dass AR-Koaktivatoren in die Entwicklung von androgenunabhängigen Prostatakarzinomen involviert sind. Diese Koaktivatoren können die ARAktivität unter den Bedingungen einer niedrigen Ligandenkonzentration, z.B. während einer androgen-unterdrückenden Therapie, oder durch die Veränderung der AR-Spezifität gegenüber Antagonisten verändern, so dass Anti-Androgene und Östrogene an den AR binden und diesen aktivieren können. Kürzliche Studien konnten zeigen, dass z.B. die Koaktivatoren SRC-1, SRC-3 (steroid receptor coactivtor), p300, Tip60 und c-Jun den AR u.a. in Abwesenheit des Liganden aktivieren und in hormon-unabhängigen Prostatakarzinomen und PCa-Zelllinien überexprimiert sind [Edwards et al., 2005b].

Die Herunterregulierung der Leupaxin-Expression führte in den AR-positiven LNCaP-Zellen zur Induktion von Apoptose, während die AR-negativen PCa-Zellen PC-3 und DU 145 diesen 
Effekt nicht zeigten. Weiterhin wurde gezeigt, dass Leupaxin mit dem AR interagiert und ihn in Anwesenheit des Liganden DHT auch aktiviert. Bei Herunterregulierung der LeupaxinExpression konnte daher auch eine Reduktion der PSA-Bildung gezeigt werden. Dies deutet darauf hin, dass der Effekt der Leupaxin-Herunterregulierung möglicherweise mit der verringerten Aktivität des AR zusammenhängt (Abb. 4.3), die in LNCaP-Zellen zu Apoptose führt [Haag et al., 2005; Liao et al., 2005; Yang et al., 2005].

Auch für SRC-1, einem Mitglied der Familie der Steroidrezeptor-Koaktivatoren (steroid receptor coactivator), dessen Expression in Prostatakarzinomen signifikant mit dem Gleason Score, der extrakapsulären Ausbreitung und der Metastasenbildung in den Beckenlymphknoten korreliert [Agoulnik et al., 2005], konnte ein ähnlicher Effekt beobachtet werden. Bei Herunterregulierung der SRC-1-Expression mittels RNAi in den androgenabhängigen LNCaP-Zellen und in den androgen-unabhängigen, jedoch AR-abhängigen LNCaP-C4-2-Zellen tritt eine Reduktion des Zellwachstums ein. Dabei wurde auch die Expression von AR-Zielgenen wie PSA und Maspin, eine Serin-Protease und Tumorsuppressorprotein, beeinflusst. AR-negative PC-3- und DU 145-Zellen zeigten diesen Effekt nach dem knock down der SRC-1-Expression nicht [Agoulnik et al., 2005].

Die Hypothese, dass Leupaxin über die Interaktion mit dem AR die Progression des PCa fördert, wird gestützt durch die Tatsache, dass Leupaxin zwischen Zytoplasma und Kern pendelt. Wird der normale zelluläre Exportin-1-vermittelte Export inhibiert (mittels Leptomycin B-Behandlung), akkumuliert Leupaxin im Kern. Weiterhin konnte ein funktionelles Kernexportsignal ( $\underline{\text { nuclear }}$ export signal $=$ NES) im Bereich des LD4-Motivs von Leupaxin identifiziert werden. Wie Leupaxin jedoch in den Kern gelangt, ist noch unbekannt. Kernlokalisationssequenzen wurden in der Leupaxin-Aminosäuresequenz nicht identifiziert. Es könnte zum einen über die Interaktion mit dem AR in den Kern gelangen, denn im BiFC-Assay konnte eine Interaktion zwischen Leupaxin und dem AR im Zytoplasma beobachtet werden. Andererseits könnten auch andere Interaktionspartner beim Transport in den Kern mitwirken, denn das GFP-Fusionsprotein GFP-LPXN-LD, welches nur die vier LDMotive von Leupaxin enthält, akkumuliert bei Leptomycin-B-Behandlung ebenfalls im Kern (Daten nicht gezeigt). 


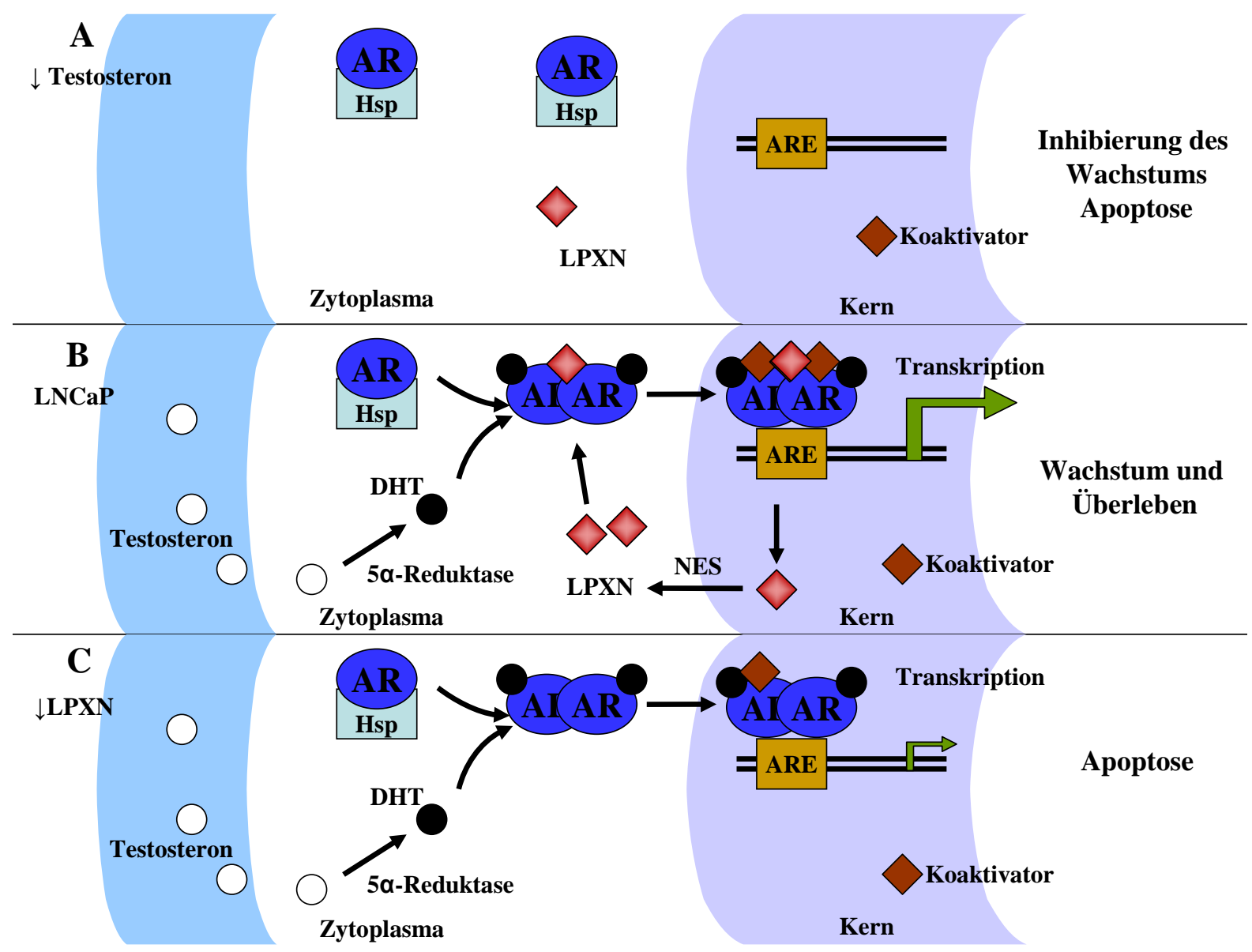

Abb. 4.3: Putativer Einfluss von Leupaxin auf die Wirkungsweise von Androgenen und des Androgenrezeptors in LNCaP-Zellen. A. Wirkungsweise der androgen-unterdrückenden Therapie. B. Wirkungsweise des Androgenrezeptors (AR) und von Leupaxin (LPXN) in den androgen-abhängigen LNCaP-Zellen. C. Hypothese zum Effekt der Herunterregulierung der Leupaxin-Expression in den LNCaPZellen. DHT $=$ Dihydrotestosteron; Hsp $=$ Hitzeschockprotein; NES $=$ Kernexportsignal; ARE $=$ androgen response element. $\downarrow$ Herunterregulierung. 


\subsubsection{Hypothese 2: Direkter Einfluss von Leupaxin auf die Genregulation}

Eine weitere Möglichkeit zur Beeinflussung der Zellmorphologie, Migration und Invasion der Prostatakarzinomzellen durch Leupaxin ist die direkte Interaktion von Leupaxin mit weiteren Transkriptionsfaktoren. Dadurch könnte Leupaxin die Transkription von Zelladhäsionsrelevanten Genen direkt regulieren. Für ARA55 konnte gezeigt werden, dass es den Transkriptionsfaktor c-Fos transaktivieren kann [Shibanuma et al., 2003]. Weiterhin fungiert ARA55 als Koaktivator des Transkriptionsfaktors Sp1, wobei es mit den Transkriptionsregulatoren p300 und Smad3 interagiert [Shibanuma et al., 2004].

Im Rahmen dieser Arbeit wurde daher auch untersucht, ob die Herunterregulierung der Leupaxin-Expression einen Einfluss auf die Expression von Zelladhäsions-relevanten Genen besitzt. Dabei konnte gezeigt werden, dass die Expression von CTNND1 (Genprodukt: p120CTN) hochreguliert wird. p120CTN ist ein Tyrosinkinase-Substrat, das in die ligandeninduzierten Rezeptorsignalkaskaden von EGF (epidermal growth factor), PDGF (platelet derived growth factor) und CSF1 (colony-stimulating factor) als auch in die Zelltransformation durch SRC involviert ist. p120CTN ist eine Hauptkomponente des Multiprotein-Zell-Zelladhäsionskomplexes, welcher auch E-Cadherin, $\alpha$-Catenin, $\beta$-Catenin und $\gamma$-Catenin enthält. p120CTN gehört zur p120-Proteinfamilie, die eine charakteristische Organisation ihrer Armadillo-Repeat-Domäne gemeinsam haben. Zu dieser Proteinfamilie gehören weiterhin die Proteine p0071, $\delta$-Catenin/NPRAP (ㅁeural plakophilin-related armadillo-repeat protein) und ARVCF (armadillo-repeat gene deleted in $\underline{V C S} \underline{F}$ ). Die Interaktion zwischen den Cadherinen und den Mitgliedern der p120-Proteinfamilie wird über deren Armadillo-Repeat-Domäne vermittelt. Wie bei anderen Komponenten des Cadherin/Catenin-Komplexes könnte ein Defekt in p120CTN zur Malignität von Zellen führen. In etwa 10\% der invasiven duktalen Mammakarzinome konnte ein kompletter Verlust der p120CTN-Expression gezeigt werden [Dillon et al., 1998]. Beim Prostatakarzinom konnte in 45\% der untersuchten Fälle ein Expressionsverlust von p120CTN festgestellt werden. Die Herunterregulierung der p120CTN-Expression korreliert dabei signifikant mit dem Gleason Score und dem Tumorstadium [Kallakury et al., 2001]. Auch in anderen Tumoren wie Darm-, Blasen-, Magen-, Lungen- und Pankreastumoren konnte eine veränderte Expression von p120CTN festgestellt werden [Thoreson et al., 2002]. Die Funktion von p120CTN wird in der Literatur kontrovers diskutiert. Einerseits stabilisiert die Interaktion von p120CTN mit Cadherinen die Lebenszeit der Cadherine, wodurch Zell-Zelladhäsionen verstärkt werden. 
Auf der anderen Seite führt eine Überexpression von p120CTN zur Verkleinerung von focal adhesion sites, morphologischen Änderungen der Zellen und reduzierter Zellmotilität [Anastasiadis et al., 2000; Hatzfeld, 2005].

Der Promotor von CTNND1 wurde bisher noch nicht charakterisiert. Eine im Rahmen dieser Arbeit durchgeführte Computer-Analyse der genomischen Sequenz von CTNND1 zeigt, dass im Bereich $1 \mathrm{~kb}$ upstream des Transkriptionsstartpunktes Sp1- und AP1-Bindungsstellen vorhanden sind (Abb. 4.4). Weiterhin wurden mehrere Bindungsstellen für die Steroidhormonrezeptoren AR, GR und PGR gefunden. Leupaxin könnte somit gemeinsam mit Sp1 und AP1 oder mit dem AR, GR und PGR die Transkription von CTNND1 negativ beeinflussen. Im Maspin-Promotor wurde z.B. eine AR-Bindungsstelle (ARE) identifiziert, die auf die Expression von Maspin negativ wirkt [He et al., 2005]. Das heißt, ist der AR aktiv und kann an das ARE binden, wird die Transkription von Maspin vermutlich durch die Rekrutierung von Korepressoren unterdrückt.

\section{Putative Bindungsstellen für Transkriptionsfaktoren in CTNND1}

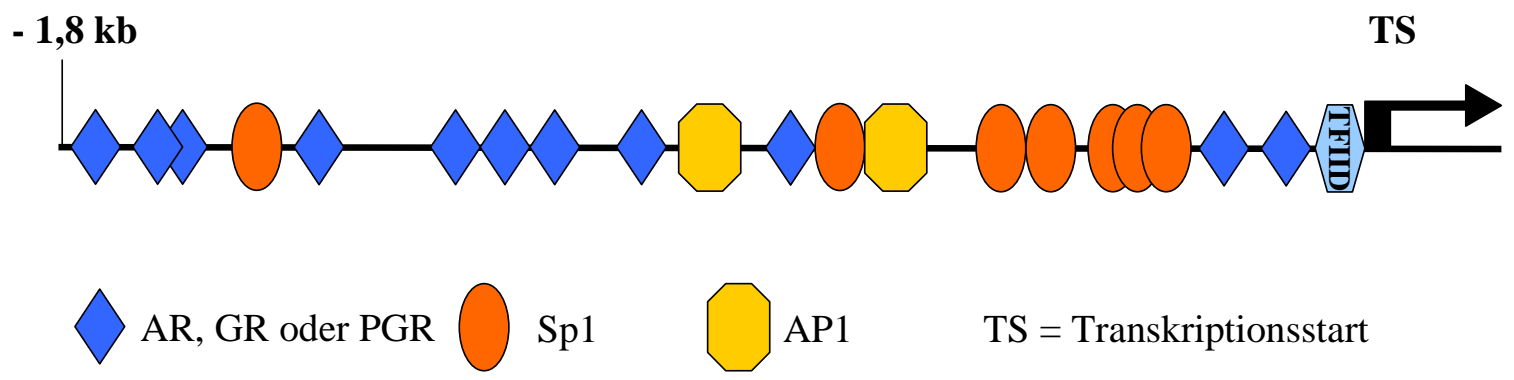

Abb. 4.4: Putative Bindungsstellen für Transkriptionsfaktoren im CTNND1-Gen. Mittels ComputerAnalyse konnte der Bereich bis 1,8 kb upstream des Transkriptionsstartpunktes als evolutionär konservierter Bereich identifiziert werden [www.dcode.org]. Dieser Bereich enthält eine Reihe an putativen Bindungsstellen für die Steroidhormonrezeptoren Androgenrezeptor (AR), Glukokortikoidrezeptor (GR) und Progesteronrezeptor (PGR), sowie auch für Sp1 und AP1[www.cbil.upenn.edu/cgi-bin/tess/tess]. Auf die Darstellung aller anderen Transkriptionsfaktoren wurde verzichtet.

Ob nun Leupaxin die Regulation der CTNND1-Expression indirekt über den AR oder direkt über andere Transkriptionsfaktoren beeinflusst, muss noch geklärt werden. Dass dieser Effekt jedoch Leupaxin-spezifisch ist, zeigt die Tatsache, dass Leupaxin-überexprimierende, androgen-unabhängige LNCaP-Zellen eine geringere CTNND1-Expression besitzen (neue 
Daten). Weiterhin konnte der Effekt der Hochregulierung der p120CTN-Expression nach dem knock down von Leupaxin auch in den AR-negativen DU 145-Zellen und auf mRNA-Ebene auch für die PC-3-Zellen bestätigt werden. Daher ist es wahrscheinlich, dass Leupaxin einen direkten Einfluss auf die Expression von CTNND1 über z.B. Interaktion mit Transkriptionsfaktoren (z.B. Sp1 und AP1) ausübt.

\subsubsection{Hypothese 3: Leupaxin besitzt direkten Einfluss auf die Invasion und Migration über Interaktionen mit Proteinen an den focal adhesion sites}

Da Leupaxin hauptsächlich in den focal adhesion sites lokalisiert ist, kann es auch durch direkte Interaktionen mit Integrinen und Zytoskelett-Proteinen, aber auch mit Proteinkinasen und -phosphatasen die Invasion und Migration von PCa-Zellen beeinflussen. Die Signaltransduktion z.B. über die mitogen-activated protein (MAP)-Kinasen spielt eine Schlüsselrolle in einer Reihe von zellulären Prozessen wie Proliferation, Differenzierung und Zelltod. Es gibt drei Hauptgruppen von MAPK: ERK1/2, JNKs and p38-Kinasen (Abb. 4.5). MAPKs können durch viele verschiedene Stimuli aktiviert werden. Generell werden ERK1/2 in Antwort auf Wachstumsfaktoren und Phorbolester aktiviert, während JNKs und p38Kinasen mehr von Stressstimuli wie osmotischer Schock, UV-Bestrahlung und ZytokinStimulierung aktiviert werden. Obwohl jede MAPK einzigartige Charakteristika besitzt, teilen sich die verschiedenen MAPK-Signalwege einige Eigenschaften. Jede Familie der MAPKs besteht aus einem Set von drei evolutionär konservierten, sequentiell handelnden Kinasen: eine MAPK, eine MAPK-Kinase (MAPKK), und eine MAPKK-Kinase (MAP3K). Die MAP3K stellen Serin/Threonin-Kinasen dar, die durch Phosphorylierung und/oder als Resultat ihrer Interaktion mit einem small GTP-binding protein der Ras/Rho-Familie in Antwort auf extrazelluläre Stimuli aktiviert werden. Die Aktivierung der MAP3K führt zur Phosphorylierung und Aktivierung der MAPKK, welche anschließend die MAPK-Aktivität durch die duale Phosphorylierung von Threonin und Tyrosin-Resten stimulieren. Einmal aktiviert, phosphorylieren die MAPKs ihre Zielsubstrate an Serin- und Threonin-Resten und anschließend an Prolin-Resten. Die Substratselektivität wird oft durch spezifische Interaktionsmotive bei den physiologischen Substraten erreicht. Weiterhin wird die MAPKSpezifität durch Interaktionen mit Adapterproteinen vermittelt, die die Signalwege in spezifischen Modulen durch simultanes Binden von verschiedenen Komponenten 
organisieren. Der breite Umfang von zellulären Funktionen, die durch die MAPK vermittelt werden, ergibt sich aus der Phosphorylierung von verschiedenen Substraten, wie z.B. Phospholipasen, Transkriptionsfaktoren, zytoskelettalen Proteinen und anderen Proteinkinasen [Koul et al., 2004].

Das ERK1/2-Modul (in Abb. 4.5 rot markiert) ist die klassische Mitogen-Kinasekaskade, die aus den MAP3K A-Raf, B-Raf, C-Raf, den MAPKK MEK1 und MEK2, und den MAPK ERK1 und ERK2 besteht. ERK1 und ERK2 sind zu 83\% homolog und in allen Geweben in verschiedenen Stärken exprimiert. Sie werden vor allem durch Wachstumsfaktoren, Serum und Phorbolester, aber auch durch Liganden der Heterotrimeren G-Protein gekoppelten Rezeptoren (GPCR), Zytokine, osmotischen Stress und Mikrotubuli-Disorganisation aktiviert [Lewis et al., 1998]. Typischerweise transmittieren Zelloberflächenrezeptoren wie Tyrosinkinasen und G-Protein gekoppelte Rezeptoren die aktivierenden Signale auf die Raf/MEK/ERK-Kaskade über die verschiedenen Isoformen der small GTP-binding proteins Ras [Campbell et al., 1998]. Die Aktivierung von Ras wird durch die Rekrutierung von SOS (son of sevenless), einem Ras-aktivierenden Guaninnukleotid-Austauschfaktor, vermittelt. SOS stimuliert Ras zum Tausch von GDP zu GTP, wodurch eine Interaktion mit einer Reihe von downstream-Effektoren wie z.B. die Isoformen der Serin/Threonin-Kinase Raf möglich wird. Aktiviertes Raf bindet an und phosphoryliert die dual-spezifische Kinase MEK1/2, welche wiederum ERK1/2 phosphoryliert und aktiviert. Aktiviertes ERK1/2 phosphoryliert zahlreiche Substrate in allen Zellkompartimenten, wie z.B. Membranproteine (CD120a, Syk und Calnexin), Kernsubstrate (SRC-1, Pax6, NF-AT, Elk-1, MEF2, c-Fos, c-Myc und STAT3), zytoskelettale Proteine (Neurofilamente und Paxillin) und verschiedene Kinasen (FAK, RSK1) [Roux et al., 2004]. 


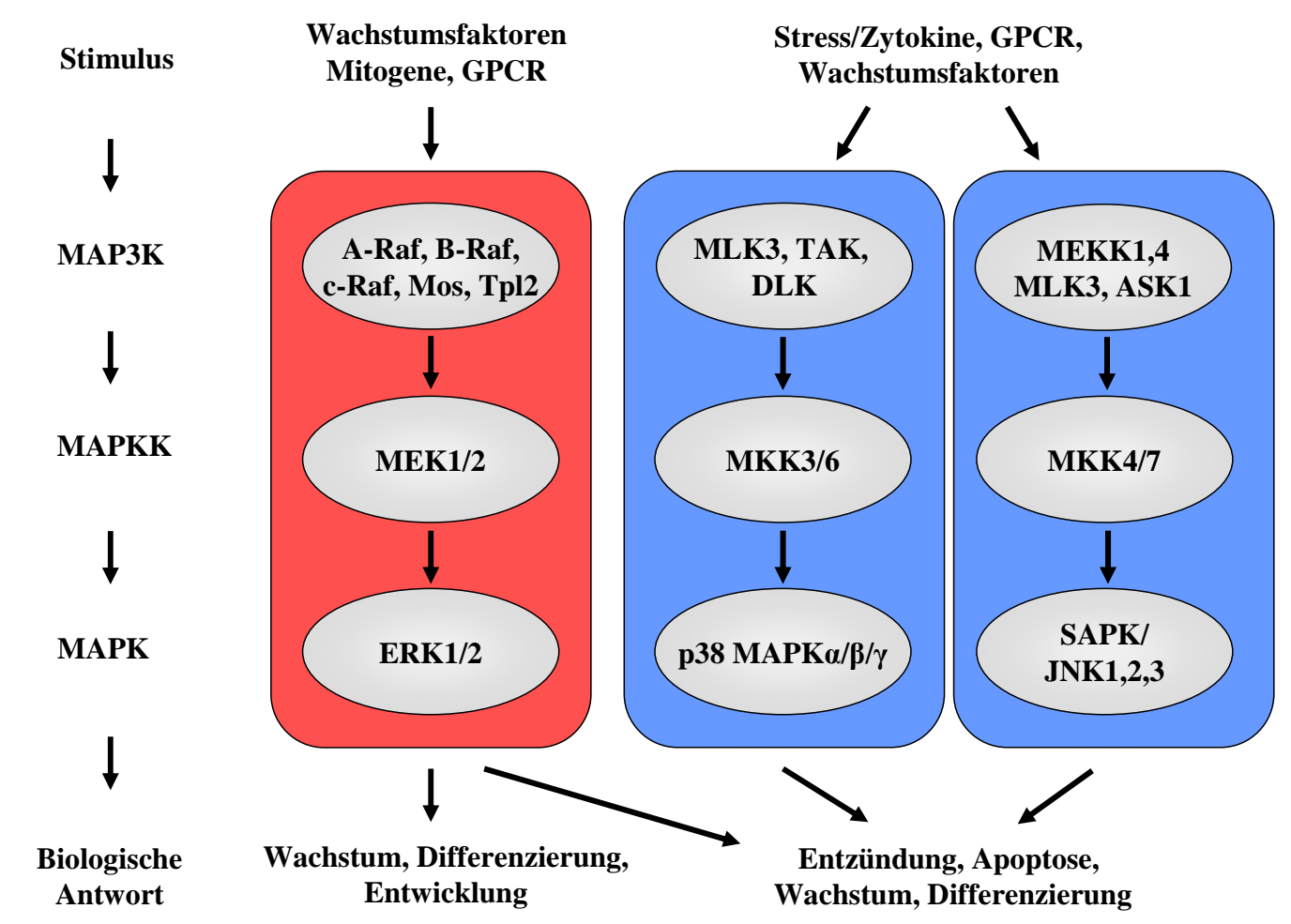

Abb. 4.5: Schematische Darstellung der mitogen-activated kinase (MAPK)-Signalkaskaden. Es gibt drei Hauptgruppen: ERK1/2 (linkes Modul), p38 MAPK (mittleres Modul) und JNK (rechtes Modul). Die Signalwege werden durch eine Reihe von extrazellulären Stimuli aktiviert. Anschließend werden über Bindungsund Phosphorylierungs-abhängige Prozesse die Kaskaden durchlaufen, wodurch es auch zur Potenzierung des Signals kommt. Am Ende der Kaskaden stehen Transkriptionsfaktoren, Membranproteine, zytoskelettale Proteine und andere Kinasen, die die entsprechenden Antworten der Zelle auf den äußeren Stimulus umsetzen. GPCR = G-Protein gekoppelte Rezeptoren .

Es ist bereits bekannt, dass Leupaxin mit einigen Kinasen wie z.B. PYK2 und FAK, aber auch mit Phosphatasen wie PTP-PEST interagiert [Lipsky et al., 1998; Gupta et al., 2003; Watanabe et al., 2005]. Daher wurde im Rahmen dieser Arbeit der Phosphorylierungsstatus und damit die Aktivität von einigen Mitgliedern der MAPK-Signalkaskaden untersucht. Dabei konnte in den LNCaP-Zellen mit herunterregulierter Leupaxin-Expression eine geringere Aktivität von MEK1/2 und ERK2 im Vergleich zu den Kontrollzellen festgestellt werden. Hingegen zeigten AKT an beiden untersuchten Phosphorylierungsstellen (T308 und S473) und c-Raf an der Phosphorylierungsstelle S259 keine Veränderungen (Abb. 4.6). In den androgen-unabhängigen und invasiven PC-3- und DU 145-Zellen konnte nach Leupaxin 
knock down weder für ERK1/2, noch für AKT eine Veränderung im Phosphorylierungsstatus beobachtet werden.

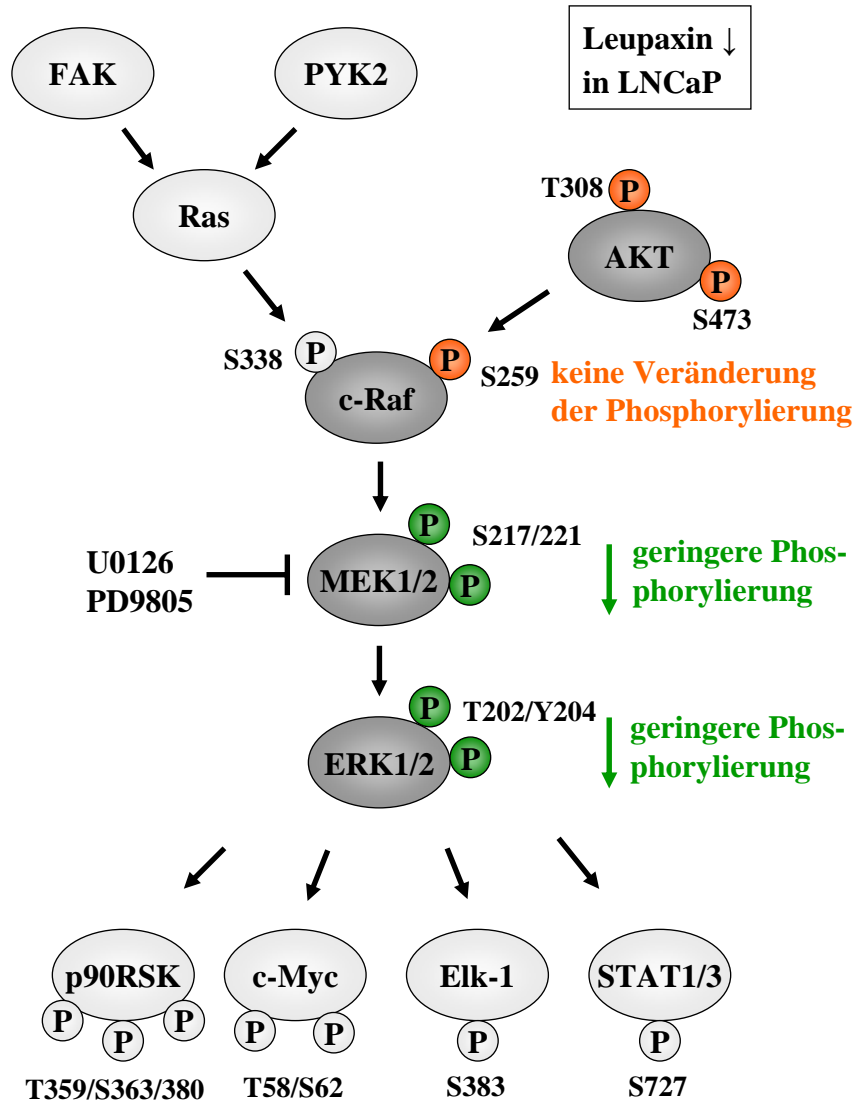

Abb. 4.6: Zusammenfassung der Ergebnisse zur Aktivität von Mitgliedern des ERK1/2-Signalweges nach Herunterregulierung der Leupaxin-Expression in LNCaP-Zellen. Dargestellt sind die untersuchten Proteine (grau) mit den entsprechenden Phosphorylierungsstellen. Grün markiert wurden die Phosphorylierungsstellen mit reduziertem Phosphorylierungsgrad. Rot markiert wurden die Phosphorylierungsstellen ohne Veränderung. Die hellgrau gekennzeichneten Proteine könnten weitere involvierte Proteine upstream- und downstream der bisher identifizierten Kaskadenmitglieder darstellen.

An welcher Stelle Leupaxin in den ERK1/2-Signalweg eingreift, muss noch genau untersucht werden (Abb. 4.7). Für Paxillin konnte gezeigt werden, dass nach Zelladhäsion und hepatocyte growth factor-Behandlung die SRC-Phosphorylierung von Paxillin Y118 zur Bildung einer ERK1/2-Bindungsstelle führt, wodurch ERK1/2 an die focal adhesion sites rekrutiert wird [Ishibe et al., 2003]. Paxillin bindet dann Raf und MEK1/2, um ERK1/2 in den focal adhesions zu aktivieren. Die ERK1/2-Phosphorylierung führt anschließend zur Assoziation von FAK mit Paxillin, um die Zellausbreitung und -motilität zu erhöhen [Liu et 
al., 2002]. Lokal aktiviertes ERK1/2 an der Membranperipherie ist zudem für den Abbau von focal adhesions notwendig, ein essentieller Prozess während der Zellmigration [Webb et al., 2004]. ERK1/2 sind auch in das Überleben einer Zelle involviert. Erste Hinweise auf diese Funktion wurden aus der Beobachtung erhalten, dass in einer großen Anzahl menschlicher Tumore eine Mutation in einem Mitglied der Ras- oder Raf-Gene enthalten ist, die zu einem konstitutiv aktiven ERK1/2-Signalweg führen. Daher stellen Inhibitoren des Raf/MEK/ERKSignalweges mögliche Therapie-Ansätze gegen Krebs dar [Thompson et al., 2005].

MAPK phosphorylieren auch die Mitglieder der SRC-Familie (siehe Abschnitt 4.5.1), wobei die Fähigkeit zur Bildung von Koaktivator-Komplexen mit dem AR gefördert wird [Heinlein et al., 2004]. Auch der AR selbst wird durch MAPK phosphoryliert und kann z.B. den Koregulator ARA70 verstärkt binden, was zu einer erhöhten transkriptionellen Aktivität des AR führt [Yeh et al., 1999]. Demnach könnte ein knock down der Leupaxin-Expression in den LNCaP-Zellen zu einer unterbrochenen Raf/MEK/ERK-Signalkaskade führen, die in einer verminderten Phosphorylierung von ERK1/2 resultiert, wodurch sowohl Zelladhäsions- und Apoptose-relevante Proteine als auch die AR-Aktivität selbst beeinflusst werden.

In den PC-3- und DU 145-Zellen konnte bisher keine Veränderung im ERK-Signalweg beobachtet werden. Jedoch zeigen diese Zellen trotzdem eine verminderte Invasion und Migration nach Herunterregulierung der Leupaxin-Expression. Möglicherweise ist dies die Folge von deregulierten Signalwegen, die im Rahmen dieser Arbeit nicht untersucht worden sind. Andererseits spricht allein die Tatsache, dass Leupaxin in den focal adhesion sites lokalisiert ist und z.B. mit der zytoplasmatischen Domäne von Integrin $\alpha 4$ und mit $\alpha$-Tubulin interagiert, für eine direkte Rolle von Leupaxin in Invasion und Migration.

Die genauen Funktionen von Paxillin während der Migration, die einen wichtigen Schritt bei der Invasion darstellt (Abschnitt 4.1), wurden bereits intensiv analysiert. Die Migration kann in verschiedene diskrete Schritte unterteilt werden: die Protrusion/Polarisierung, Anheftung/Adhäsionsaufbau, Traktion/Translokation und Adhäsionsabbau/Retraktion [Webb et al., 2003; Wehrle-Haller et al., 2003]. Paxillin ist in jeden Schritt durch dessen multiple Interaktionen involviert und dient als eine Art Gerüstprotein zwischen verschiedenen Signalwegen [Brown et al., 2004]. Ex vivo kultivierte Paxillin-defiziente Mausfibroblasten zeigen abnormale focal adhesions, reduzierte Zellmigration sowie eine ineffiziente Lokalisierung von FAK. Weiterhin besitzen diese Paxillin $^{-/}$-Fibroblasten Defekte im kortikalen Zytoskelett und in der Zellausbreitung auf Fibronektin [Hagel et al., 2002]. Auch hoch invasive Melanomzellen, die das Gangliosid GD3 überexprimieren, sind weniger invasiv nach Herunterregulierung der Paxillin-Expression mittels siRNA [Hamamura et al., 2005]. 
Die Tatsache, dass AR-negative PC-3- und DU 145-Zellen eine verminderte Invasivität und Migration nach Herunterregulierung der Leupaxin-Expression zeigen, deutet darauf hin, dass Leupaxin ähnliche Funktionen wie Paxillin bei beiden Prozessen übernimmt (Abb. 4.8). Diese Vermutung wird durch die Daten einer eben veröffentlichten Studie gestützt. Die Autoren konnten zeigen, dass Leupaxin in Osteoklasten mit SRC interagiert und eine Überexpression von Leupaxin zu verstärkter Zelladhäsion und damit auch Matrixresorption in diesen Zellen führt [Sahu et al., 2006].

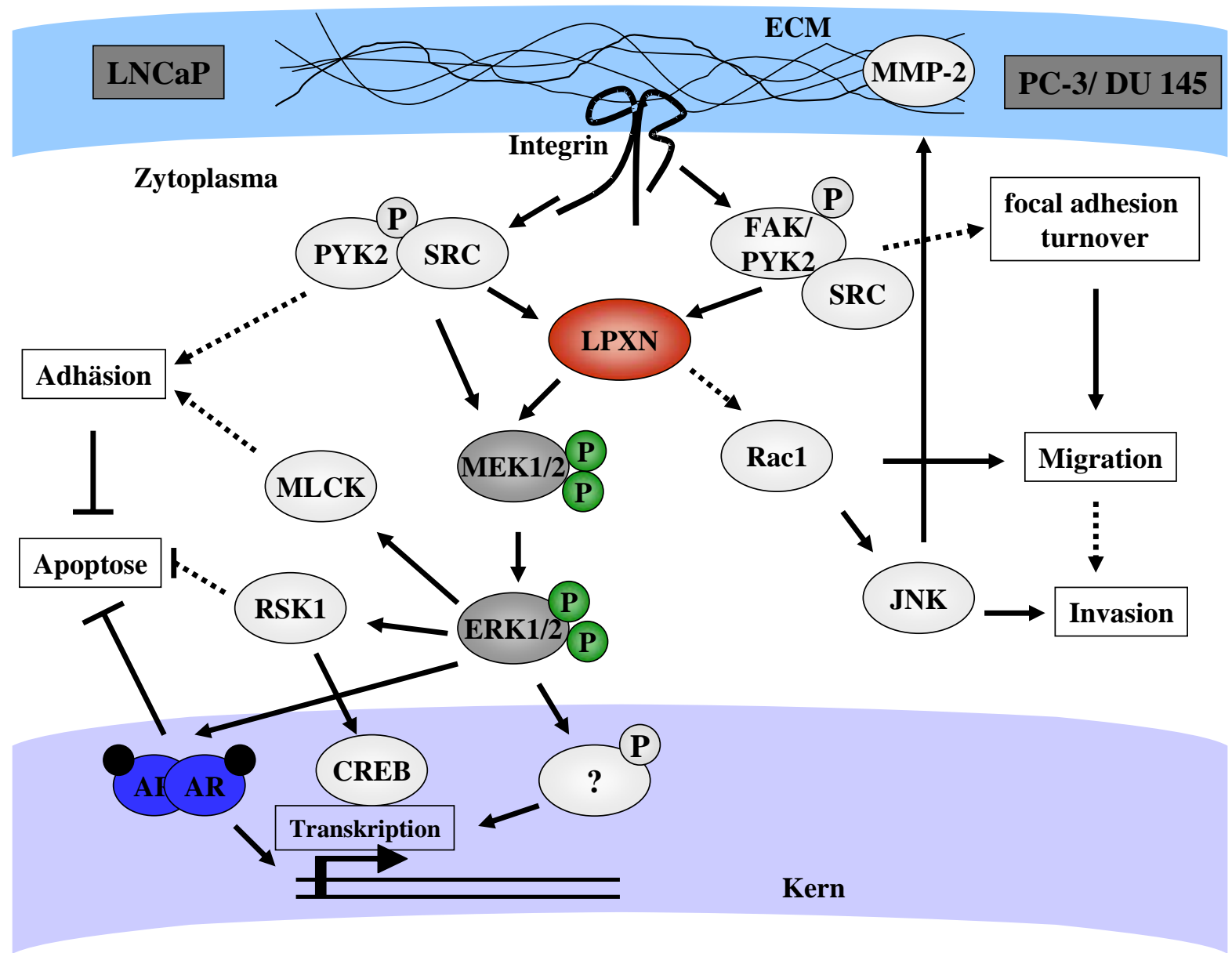

Abb. 4.7: Putativer Einfluss von Leupaxin auf die Adhäsion, Apoptose, Migration und Invasion in PCaZellen. Auf der linken Seite ist der mögliche Wirkungsmechanismus von Leupaxin in den LNCaP-Zellen dargestellt. LNCaP-Zellen exprimierten kein FAK, sondern nur PYK2. Nach Adhäsion wird PYK2 autophosphoryliert, und es entsteht eine Bindungsstelle für SRC. SRC und PYK2 interagieren beide mit Leupaxin (LPXN) [Gupta et al., 2003; Sahu et al., 2006], wodurch Leupaxin phosphoryliert werden könnte. Anschließend könnte dieser Komplex MEK1/2 und ERK1/2 zu den focal adhesion sites rekrutieren, wodurch MEK1/2 phosphoryliert und ERK1/2 durch MEK1/2 aktiviert wird. Dann könnte ERK1/2 z.B. den AR und andere Transkriptionsfaktoren aktivieren, wodurch Gene für Adhäsion und Überleben der Zelle transkribiert werden. ERK1/2 kann aber auch RSK1 phosphorylieren, die wiederum den Transkriptionsfaktor CREB aktiviert. 
Dadurch wird die Transkription von anti-apoptotischen Proteinen wie Bcl-2 erhöht. RSK1 phosphoryliert aber ebenfalls direkt bisher unbekannte Kinasen, die z.B. das pro-apoptotische Protein BAD phosphorylieren und in einen inaktiven Zustand versetzen. Auf der rechten Seite ist der mögliche Wirkungsmechanismus von Leupaxin in den AR-negativen PC-3- und DU 145-Zellen dargestellt. Nach Adhäsion werden FAK/PYK2 autophosphoryliert, und es entsteht wieder eine Bindungsstelle für SRC (siehe oben). Das an den Komplex rekrutierte Leupaxin und evtl. auch CAS interagieren mit dem Guanin-Austauschfaktor DOCK180/ELMO, der wiederum die p21-GTPase Rac1 aktiviert. Rac1 ist notwendig für die Aktin-Polymerisierung und damit für die Plasmamembran-Protrusion und die Extension der Lamellipodien während der Migration. Rac1 kann aber auch den JNK-Signalweg anschalten, der in der Aktivierung von z.B. MMP-2 resultiert. Durch den Abbau der extrazellulären Matrix (ECM) kann die Invasion gefördert werden.

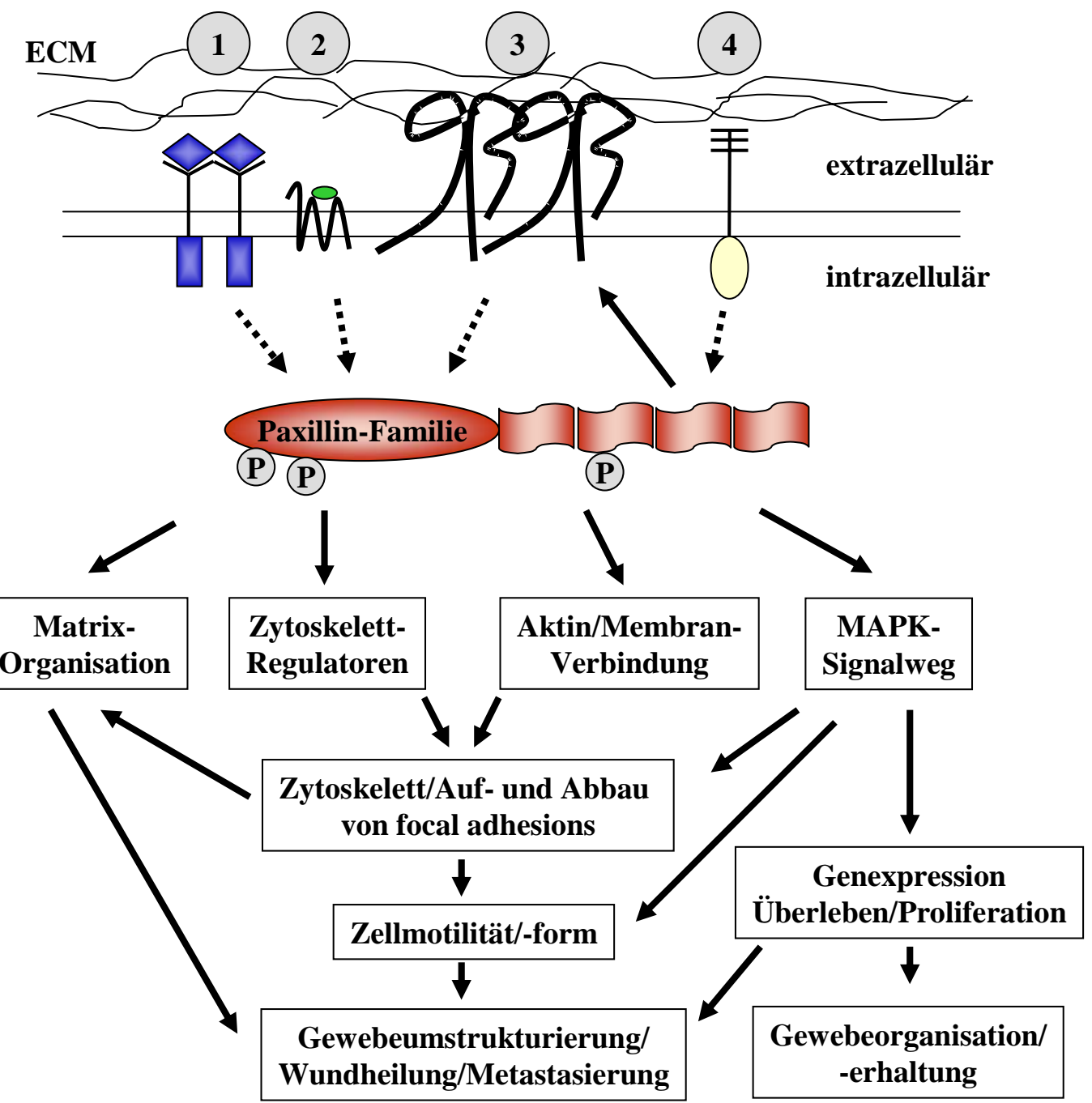

Abb. 4.8: Übersicht über den Einfluss der Paxillin-Proteinfamilie (modifiziert nach Brown et al. [2004]). Transmembrane Rezeptoren teilen sich Adaptorproteine wie Paxillin, um die Signalintegration und transduktion zu erhöhen. Molekulare Adapterproteine wie Paxillin fördern ihrerseits die optimale Signaltransduktion durch ihre Eigenschaft, verschiedene Vermittler der spezifischen Signalwege an die 
entsprechenden Regionen in der Zelle (z.B. focal adhesion sites) zu rekrutieren, an denen die RezeptorAktivierung stattfindet. Sie stellen ebenfalls eine Plattform dar, über die verschiedene Signalwege miteinander in Beziehung treten können. Dadurch können Zellen auf ihre Umgebung schnell reagieren, wie z.B. schnelle Veränderung des Zytoskeletts, die die Zellform, Adhäsion und Motilität beeinflussen, aber auch langanhaltende Veränderungen der Genexpression.

\subsection{Perspektiven}

Die vielfältigen Interaktionen von Paxillin und dessen Involvierung in verschiedenste Signalwege sind bereits seit über einem Jahrzehnt bekannt. Aufgrund der hohen Homologie zwischen Paxillin und Leupaxin und der Tatsache, dass sie gemeinsame Interaktionspartner besitzen, ist anzunehmen, dass auch Leupaxin in einer Zelle nicht nur eine der im Abschnitt 4.5 diskutierten, hypothetischen Funktionen wie die AR-Koaktivierung, die direkte Genregulation oder die Beteiligung an der Adhäsion/Invasion übernimmt. Vielmehr wird es ein Zusammenspiel aller Funktionen von Leupaxin geben, das durch die Verknüpfung der verschiedenen Signalwege zu der entsprechenden Zelltyp-abhängigen Reaktion führt. Die Aufklärung der Leupaxin-involvierenden Signalwege könnte so das Verständnis über die beobachteten Reaktionen von Zellen fördern und Leupaxin als Marker für die Progression des Prostatakarzinom einsetzbar machen. Weiterhin könnte dann eine entsprechende Reduktion der Leupaxin-Expression als Therapiemöglichkeit in Betracht gezogen werden.

Leupaxin wird in 22\% der Prostatakarzinome überexprimiert und die Expression korreliert dabei mit der Progression des Karzinoms. Dieses Wissen reicht nicht aus, Aussagen über die weitere Behandlung dieser Patienten und damit über deren Überlebenschance treffen zu können. Dazu sind umfangreichere Daten inbezug auf die Expression von Leupaxin in humanen Prostatakarzinomen notwendig, wobei vor allem die Follow-Up-Daten der Patienten mit Prostatakarzinom hilfreich sind. So stellt sich die Frage, ob Leupaxin in Folge von z.B. androgen-unterdrückenden und AR-blockierenden Therapien hochreguliert wird, oder ob es sich um ein spontanes Ereignis während der Tumorigenese handelt, das in einem vorteilhaften Wachstum dieser Tumorzellen und anschließend in Invasion resultiert. Die Korrelation der Leupaxin-Expression mit den Patienten-Daten wie Erfolg der androgen-unterdrückenden Therapie, PSA-Werte und auch Überlebensrate der Patienten könnte aussagen, ob Leupaxin als putativer Marker für die Diagnose von fortgeschrittenen und evtl. androgen-unabhängigen Prostatakarzinomen eingesetzt werden kann. 
Mit diesem Wissen könnten individuell auf den Patienten abgestimmte Therapien entwickelt werden, bei denen z.B. die Expression von Leupaxin Prostata-spezifisch inhibiert wird, und dadurch die Invasion und Metastasenbildung verringert oder sogar verhindert werden kann. Erste Hinweise dazu können auch aus der Verpaarung der transgenen Leupaxin-Mäuse mit den TRAMP-Mäusen erhalten werden. Kann allein die Überexpression von Leupaxin in der Prostata das Wachstum und die Metastasierung der Prostatakarzinome verstärken? Oder wird dieser Effekt nur unter androgen-reduzierten Bedingungen erzielt? Zelllinien, die aus den TRAMP-Tumoren stammen, können hierbei das ideale in vitro-Modell darstellen. Dabei kann auch untersucht werden, ob Leupaxin die transkriptionelle Aktivität des AR bei Anwesenheit von AR-Antagonisten fördert.

Bevor jedoch erste Schritte in Richtung Therapie unternommen werden können, muss die Funktion von Leupaxin detaillierter untersucht werden. Auch in bezug auf die anderen Mitglieder der Paxillin-Proteinfamilie muss geklärt werden, in welche spezifischen Signalwege Leupaxin eingebunden ist und wo vor allem die Unterschiede zu Paxillin und ARA55 liegen. Dazu ist die Kenntnis von weiteren Interaktionspartnern von Leupaxin notwendig. Daher wird zur Zeit in unserer Arbeitsgruppe ein yeast-two-hybrid-screening einer Prostata-cDNA-Bibliothek durchgeführt. Die so identifizierten Proteine sollen anschließend über weitere unabhängige Methoden auf die Interaktion mit Leupaxin hin überprüft werden. Möglicherweise können so weitere Signalwege identifiziert werden, in die Leupaxin involviert ist.

Die Herunterregulierung der Leupaxin-Expression führte in den androgen-abhängigen, ARpositiven LNCaP-Zellen zu morphologischen Veränderungen, Verlust der Zelladhäsion und Apoptose. Androgen-unabhängige und AR-negative PC-3- und DU 145-Zellen zeigten diesen Effekt nicht. Ob diese Verschiedenheit in der Reaktion auf den knock down der LeupaxinExpression wirklich nur auf die Anwesenheit des AR zurückzuführen ist, könnte die Untersuchung in weiteren Zelllinien zeigen. LNCaP-C4-2 stellt eine Subzelllinie von LNCaP dar, die durch Implantation in kastrierte Nacktmäuse in eine androgen-unabhängige Zelllinie umgewandelt wurde. Diese Subzelllinie exprimiert jedoch den AR, und eine Reduktion der AR-Expression resultiert in vermindertem Zellwachstum und Apoptose [Agoulnik et al., 2005]. Auch die Re-Expression des AR in PC-3- und DU 145-Zellen und die anschließende Herunterregulierung der Leupaxin-Expression könnten Auskunft über die AR-Abhängigkeit im LNCaP-Zellmodell geben. Stabil transfizierte PC-3- und DU 145-Zellklone wurden während dieser Arbeit bereits etabliert. 
Im Rahmen dieser Arbeit konnte ebenfalls gezeigt werden, dass Leupaxin in den ERK1/2Signalweg integriert ist und eine verminderte Leupaxin-Expression auch zu einer reduzierten Aktivität von ERK2 und deren upstream-MAPKK MEK1/2 führt. Welche weiteren Signalkaskaden-Mitglieder in diesen Prozess involviert sind, kann durch die Untersuchung der Phosphorylierung und damit der Aktivität der in Abbildung 4.6 hellgrau dargestellten Proteine geklärt werden. Wichtig vor allem sind hier PYK2 und FAK, für die ein Einfluss auf die Invasion von Prostatakarzinomzellen bereits bekannt ist [Schlaepfer et al., 2004; Lipinski et al., 2005]. Möglicherweise wird die ERK2-Aktivität auch ausschließlich über die Interaktion von Leupaxin mit ERK2 und MEK1/2 gefördert. Über ein direktes yeast-twohybrid-Experiment und Koimmunopräzipitation kann die Interaktion zwischen Leupaxin und ERK1/2 und/oder MEK1/2 und auch die dafür wichtigen Bindungsstellen identifiziert werden. Da nun auch bekannt ist, dass Leupaxin mit SRC interagiert [Sahu et al., 2006], sollten die Phosphorylierungsstadien von FAK und PYK2 in den PC-3- und DU 145-Zellen mit herunterregulierter Leupaxin-Expression überprüft werden. Eine Veränderung der Phosphorylierung würde erste Hinweise über den Mechanismus der beobachteten reduzierten Invasion in diesen Zellen liefern.

Leupaxin wurde im Rahmen der Diplomarbeit von Frau Herr [2005] funktionell auch in Mammakarzinomzellen untersucht. Die Herunterregulierung der Leupaxin-Expression in den invasiven und ER $\alpha$-negativen Mammakarzinomzellen MDA-MB-231 zeigte ebenfalls eine Reduktion der Invasion, aber keine Veränderung der Proliferation. Weiterhin konnte eine Interaktion von Leupaxin mit ER $\alpha$ und $\operatorname{ER} \beta$ nachgewiesen werden. Daher ist es sinnvoll eine größere Anzahl von humanen Mammakarzinomen auf die Expression von Leupaxin hin zu analysieren und die Ergebnisse mit dem Tumorstadium, ER/PGR-und HER2-Expression zu korrelieren. Möglicherweise finden sich hier Hinweise für eine Rolle von Leupaxin in der Progression von Mammakarzinomen. 


\section{Zusammenfassung}

Leupaxin stellt ein zytoskelettales Adapterprotein dar und wird aufgrund seiner Domänenstruktur der Paxillin-Protein-Familie zugeordnet, der auch Paxillin und ARA55 angehören. Bisherige Literaturdatenzeigen, dass die Expression von Leupaxin hauptsächlich auf Zellen hämatopoetischen Ursprungs beschränkt ist. In vorangegangenen Untersuchungen mittels Mikrodissektion und anschließender Atlas ${ }^{\mathrm{TM}}$-Array-Hybridisierung wurde Leupaxin jedoch als differentiell exprimiertes Gen im humanen Prostatakarzinom im Vergleich zu Normalgewebe identifiziert [Voigt, 2003].

In der vorliegenden Arbeit konnten immunhistochemische Analysen mit einem Leupaxinspezifischen Antikörper an 59 humanen Prostatektomie-Präparaten dieses Ergebnis bestätigen. Bei 22\% der untersuchten Prostatakarzinome wurde eine zumeist fokale Expression von Leupaxin ausschließlich im Epithel des Karzinoms detektiert. Die Expression von Leupaxin korrelierte dabei direkt mit dem Gleason-Muster der Leupaxin-positiven Tumorbereiche sowie mit dem Gleason Score des gesamten Prostatakarzinoms. Diese direkte Korrelation weißt darauf hin, dass Leupaxin in die Progression von Prostatakarzinomen involviert ist. Weiterhin ergab die Western Blot-Analyse zur Expression von Leupaxin in etablierten Prostatakarzinom (PCa)-Zelllinien, dass Leupaxin in den invasiven, androgenunabhängigen PC-3- und DU 145-Zellen sechs- bzw. zweimal stärker exprimiert wird als in den nicht-invasiven, androgen-abhängigen LNCaP-Zellen. Subzellulär ist Leupaxin in diesen PCa-Zellen primär in den Kontaktstellen der Zellen mit der extrazellulären Matrix (sog. focal adhesion sites) lokalisiert. Eine zusätzliche geringe Kernlokalisation von Leupaxin konnte in 1-3\% der Zellen beobachtet werden. Wurde der normale zelluläre Exportin 1-vermittelte Kernexport durch die Zugabe von Leptomycin B inhibiert, konnte eine Akkumulation eines GFP-Leupaxin-Fusionsproteins im Kern festgestellt werden. Dies weist auf ein Kernexportsignal (nuclear export signal = NES) innerhalb der Leupaxin-Aminosäuresequenz hin. Die anschließende Mutationsanalyse mit Hilfe von GFP-Leupaxin-Fusionsproteinen zeigte, dass Leupaxin ein NES hauptsächlich im LD4-Motiv besitzt, wobei jedoch das LD3Motiv am Export von Leupaxin mit beteiligt ist.

Die Frage nach der Funktion von Leupaxin im Kern führte zur Identifizierung von Leupaxin als Interaktionspartner des Androgenrezeptors (AR). Dabei bindet Leupaxin mit seinen LIMDomänen liganden-abhängig an die Ligandenbindungsdomäne des AR. Zusätzlich resultiert diese Interaktion in einer erhöhten transkriptionellen Aktivität des AR in einem 
Transaktivierungsassay. Leupaxin interagiert über die LIM-Domänen weiterhin mit dem Glukokortikoidrezeptor und dem Progesteronrezeptor, jedoch in liganden-unabhängiger Weise. Dabei fördert Leupaxin die transkriptionelle Aktivität der beiden Steroidhormonrezeptoren in An- und Abwesenheit der Rezeptorliganden.

Um die Funktion von Leupaxin näher zu charakterisieren, wurden die Leupaxin-Expression in den PCa-Zelllinien mit Hilfe der RNA-Interferenz-Methode herunterreguliert. Dabei zeigten die androgen-abhängigen LNCaP-Zellen zunächst eine Veränderung der Morphologie [Voigt, 2003]. Nach 48 h begannen sie sich vom Boden der Kulturschale zu lösen, und 50\% der Zellen waren nach 5 Tagen apoptotisch. Bei den androgen-unabhängigen PC-3- und DU 145Zellen konnten die o.g. Effekte nach der Herunterregulierung der Leupaxin-Expression nicht beobachtet werden. Jedoch wurde bei diesen Zellen durch die Inhibierung der LeupaxinExpression eine um bis zu 78\% reduzierte Invasivität in einem in vitro-Matrigel-Assay nachgewiesen. Weiterhin war die Migrationsfähigkeit dieser Zellen stark beeinträchtigt. Die Proliferation von LNCaP-, PC-3- und DU 145-Zellen wird durch den knock down der Leupaxin-Expression nicht beeinflusst.

Aufgrund der beobachteten Effekte wurde mit Hilfe eines Zelladhäsions-Arrays die Expression von zelladhäsions-relevanten Genen nach Herunterregulierung der LeupaxinExpression untersucht. Dabei wurde das zur Familie der p120-Catenine gehörende CTNND1 (Genprodukt:p120CTN) identifiziert. Die nachfolgende Überprüfung der Ergebnisse mittels quantitativer real time PCR und Western Blot bestätigte, das CTNND1/p120CTN sowohl in LNCaP- als auch in PC-3- und DU 145-Zellen mit verminderter Leupaxin-Expression stärker exprimiert wird als in den entsprechenden Kontrollzellen.

Leupaxin interagiert mit den Kinasen FAK und PYK2, sowie mit der Phosphatase PTP-PEST [Lipsky et al., 1998; Gupta et al., 2003]. Daher wurde im Rahmen dieser Arbeit der Phosphorylierungsstatus von Mitgliedern der MAPK-Signalkaskade nach Herunterregulierung der Leupaxin-Expression untersucht. Dabei konnte gezeigt werden, dass der knock down von Leupaxin in LNCaP-Zellen zu einer reduzierten Phosphorylierung und damit zu einer geringeren Aktivität der Proteinkinase ERK2, nicht aber von ERK1 führt. Die MAPK-Kinase MEK1/2, die in der Signalkaskade upstream von ERK2 liegt, ist ebenfalls geringer phosphoryliert als in den entsprechenden Kontroll-LNCaP-Zellen. Weiterhin konnte eine Beteiligung von AKT über die c-Raf-Phosphorylierungsstelle S259 in den LNCaP-Zellen ausgeschlossen werden. In PC-3- und DU 145-Zellen mit herunterregulierter LeupaxinExpression konnte keine Veränderung im Phosphorylierungsstatus von ERK1/2 und AKT beobachtet werden. 
Weiterhin wurde im Rahmen dieser Arbeit ein transgenes Mausmodell mit Prostataspezifischer Überexpression von Leupaxin in den Epithelzellen etabliert. Das LeupaxinKonstrukt wurde im Rahmen der Diplomarbeit von Frau Herr [Herr, 2005] generiert. Es wurden insgesamt zwei unabhängige transgene Mauslinien etabliert (\#19 und \#20). Mittels Western Blot- und immunhistochemischer Analyse konnte eine Prostata-spezifische Expression des transgenen Leupaxins bei beiden Mauslinien im dorsalen und ventralen Lappen der Prostata nachgewiesen werden. Die Mauslinie \#19 zeigte dabei eine schwache Expression, während die Mauslinie \#20 eine starke Expression des Transgens zeigte. Die nachfolgende histologische Analyse von Prostatae aus verschiedenen Altersstadien (2 bis 12 Monate) der Leupaxin-Mäuse beider Mauslinien zeigte keine Veränderungen im Prostataepithel. Dieses Ergebnis bestätigt, dass Leupaxin nicht in die Initiation von Prostatakarzinomen involviert ist. Zusammengefaßt weisen die in der vorliegenden Arbeit erhobenen in vitro- und in vivo-Daten darauf hin, dass Leupaxin eher eine Rolle bei der Progression von Prostatakarzinomen spielt. 


\section{Literaturverzeichnis}

Agoulnik, IU, A Vaid, WE Bingman, 3rd, H Erdeme, A Frolov, CL Smith, G Ayala, MM Ittmann and NL Weigel (2005). "Role of SRC-1 in the promotion of prostate cancer cell growth and tumor progression." Cancer Res 65(17): 7959-67.

Akiyama, N, Y Matsuo, H Sai, M Noda and S Kizaka-Kondoh (2000). "Identification of a series of transforming growth factor beta-responsive genes by retrovirus-mediated gene trap screening." Mol Cell Biol 20(9): 3266-73.

Al-Hajj, M and MF Clarke (2004). "Self-renewal and solid tumor stem cells." Oncogene 23(43): 7274-82.

Altschul, SF, W Gish, W Miller, EW Myers and DJ Lipman (1990). "Basic local alignment search tool." J Mol Biol 215(3): 403-10.

Anastasiadis, PZ and AB Reynolds (2000). "The p120 catenin family: complex roles in adhesion, signaling and cancer." J Cell Sci 113 (Pt 8): 1319-34.

Aoto, H, H Sasaki, M Ishino and T Sasaki (2002). "Nuclear translocation of cell adhesion kinase beta/proline-rich tyrosine kinase 2." Cell Struct Funct 27(1): 47-61.

Aplin, AE, AK Howe and RL Juliano (1999). "Cell adhesion molecules, signal transduction and cell growth." Curr Opin Cell Biol 11(6): 737-44.

Aprikian, AG, L Tremblay, K Han and S Chevalier (1997). "Bombesin stimulates the motility of human prostate-carcinoma cells through tyrosine phosphorylation of focal adhesion kinase and of integrin-associated proteins." Int J Cancer 72(3): 498-504.

Azuma, K, M Tanaka, T Uekita, S Inoue, J Yokota, Y Ouchi and R Sakai (2005). "Tyrosine phosphorylation of paxillin affects the metastatic potential of human osteosarcoma." Oncogene 24(30): 4754-64.

Bachman, KE and BH Park (2005). "Duel nature of TGF-beta signaling: tumor suppressor vs. tumor promoter." Curr Opin Oncol 17(1): 49-54. 
Bailey, SM and JP Murnane (2006). "Telomeres, chromosome instability and cancer." Nucleic Acids Res 34(8): 2408-17.

Beachy, PA, SS Karhadkar and DM Berman (2004). "Tissue repair and stem cell renewal in carcinogenesis." Nature 432(7015): 324-31.

Bellis, SL, JT Miller and CE Turner (1995). "Characterization of tyrosine phosphorylation of paxillin in vitro by focal adhesion kinase." J Biol Chem 270(29): 17437-41.

Bianco, R, D Melisi, F Ciardiello and G Tortora (2006). "Key cancer cell signal transduction pathways as therapeutic targets." Eur J Cancer 42(3): 290-4.

Böcking, A and U Riede (1993). Allgemeine und spezielle Pathologie. Stuttgart, Georg Thieme Verlag.

Bornfeldt, KE, EW Raines, T Nakano, LM Graves, EG Krebs and R Ross (1994). "Insulin-like growth factor-I and platelet-derived growth factor-BB induce directed migration of human arterial smooth muscle cells via signaling pathways that are distinct from those of proliferation." J Clin Invest 93(3): 1266-74.

Bradford, MM (1976). "A rapid and sensitive method for the quantitation of microgram quantities of protein utilizing the principle of protein-dye binding." Anal Biochem 72: 248-54.

Brothman, AR, TM Maxwell, J Cui, DA Deubler and XL Zhu (1999). "Chromosomal clues to the development of prostate tumors." Prostate 38(4): 303-12.

Brown, MC, JA Perrotta and CE Turner (1996). "Identification of LIM3 as the principal determinant of paxillin focal adhesion localization and characterization of a novel motif on paxillin directing vinculin and focal adhesion kinase binding." J Cell Biol 135(4): 1109-23.

Brown, MC, JA Perrotta and CE Turner (1998). "Serine and threonine phosphorylation of the paxillin LIM domains regulates paxillin focal adhesion localization and cell adhesion to fibronectin." Mol Biol Cell 9(7): 1803-16.

Brown, MC and CE Turner (2004). "Paxillin: adapting to change." Physiol Rev 84(4): 1315-39. 
Bruckheimer, EM, S Brisbay, DJ Johnson, JR Gingrich, N Greenberg and TJ McDonnell (2000). "Bcl-2 accelerates multistep prostate carcinogenesis in vivo." Oncogene 19(46): 5251-8.

Burnstein, KL (2005). "Regulation of androgen receptor levels: implications for prostate cancer progression and therapy." J Cell Biochem 95(4): 657-69.

Campbell, SL, R Khosravi-Far, KL Rossman, GJ Clark and CJ Der (1998). "Increasing complexity of Ras signaling." Oncogene 17(11 Reviews): 1395-413.

Carloni, V, RG Romanelli, M Pinzani, G Laffi and P Gentilini (1997). "Focal adhesion kinase and phospholipase $\mathrm{C}$ gamma involvement in adhesion and migration of human hepatic stellate cells." Gastroenterology 112(2): 522-31.

Catz, SD and JL Johnson (2003). "BCL-2 in prostate cancer: a minireview." Apoptosis 8(1): 29-37.

Chen, CD, DS Welsbie, C Tran, SH Baek, R Chen, R Vessella, MG Rosenfeld and CL Sawyers (2004). "Molecular determinants of resistance to antiandrogen therapy." Nat Med 10(1): 33-9.

Chen, P, H Xie, MC Sekar, K Gupta and A Wells (1994). "Epidermal growth factor receptor-mediated cell motility: phospholipase $\mathrm{C}$ activity is required, but mitogen-activated protein kinase activity is not sufficient for induced cell movement." J Cell Biol 127(3): 84757.

Chodak, GW, DM Kranc, LA Puy, H Takeda, K Johnson and C Chang (1992). "Nuclear localization of androgen receptor in heterogeneous samples of normal, hyperplastic and neoplastic human prostate." J Urol 147(3 Pt 2): 798-803.

Cogoni, C and G Macino (2000). "Post-transcriptional gene silencing across kingdoms." Curr Opin Genet Dev 10(6): 638-43.

Craft, N, Y Shostak, M Carey and CL Sawyers (1999). "A mechanism for hormoneindependent prostate cancer through modulation of androgen receptor signaling by the HER2/neu tyrosine kinase." Nat Med 5(3): 280-5. 
Crawford, BD, CA Henry, TA Clason, AL Becker and MB Hille (2003). "Activity and distribution of paxillin, focal adhesion kinase, and cadherin indicate cooperative roles during zebrafish morphogenesis." Mol Biol Cell 14(8): 3065-81.

Das, K, J Bohl and SB Vande Pol (2000). "Identification of a second transforming function in bovine papillomavirus type 1 E6 and the role of E6 interactions with paxillin, E6BP, and E6AP." J Virol 74(2): 812-6.

DeCaprio, JA, JW Ludlow, J Figge, JY Shew, CM Huang, WH Lee, E Marsilio, E Paucha and DM Livingston (1988). "SV40 large tumor antigen forms a specific complex with the product of the retinoblastoma susceptibility gene." Cell 54(2): 275-83.

de Wet, JR, KV Wood, M DeLuca, DR Helinski and S Subramani (1987). "Firefly luciferase gene: structure and expression in mammalian cells." Mol Cell Biol 7(2): 725-37.

Dillon, DA, T D'Aquila, AB Reynolds, ER Fearon and DL Rimm (1998). "The expression of p120ctn protein in breast cancer is independent of alpha- and beta-catenin and E-cadherin." Am J Pathol 152(1): 75-82.

Edwards, J and JM Bartlett (2005a). "The androgen receptor and signal-transduction pathways in hormone-refractory prostate cancer. Part 1: Modifications to the androgen receptor." BJU Int 95(9): 1320-6.

Edwards, J and JM Bartlett (2005b). "The androgen receptor and signal-transduction pathways in hormone-refractory prostate cancer. Part 2: Androgen-receptor cofactors and bypass pathways." BJU Int 95(9): 1327-35.

Elbashir, SM, J Harborth, W Lendeckel, A Yalcin, K Weber and T Tuschl (2001a). "Duplexes of 21-nucleotide RNAs mediate RNA interference in cultured mammalian cells." Nature 411(6836): 494-8.

Elbashir, SM, W Lendeckel and T Tuschl (2001b). "RNA interference is mediated by 21and 22-nucleotide RNAs." Genes Dev 15(2): 188-200.

Elbashir, SM, J Harborth, K Weber and T Tuschl (2002). "Analysis of gene function in somatic mammalian cells using small interfering RNAs." Methods 26(2): 199-213. 
Feinberg, AP and B Vogelstein (1983). "A technique for radiolabeling DNA restriction endonuclease fragments to high specific activity." Anal Biochem 132(1): 6-13.

Fernandez-Valle, C, Y Tang, J Ricard, A Rodenas-Ruano, A Taylor, E Hackler, J Biggerstaff and $\mathbf{J}$ Iacovelli (2002). "Paxillin binds schwannomin and regulates its densitydependent localization and effect on cell morphology." Nat Genet 31(4): 354-62.

Fields, S and O Song (1989). "A novel genetic system to detect protein-protein interactions." Nature 340(6230): 245-6.

Fujimoto, N, S Yeh, HY Kang, S Inui, HC Chang, A Mizokami and C Chang (1999). "Cloning and characterization of androgen receptor coactivator, ARA55, in human prostate. " J Biol Chem274(12): 8316-21.

Fujimoto, N, A Mizokami, S Harada and T Matsumoto (2001). "Different expression of androgen receptor coactivators in human prostate." Urology 58(2): 289-94.

Fujita, H, K Kamiguchi, D Cho, M Shibanuma, C Morimoto and K Tachibana (1998). "Interaction of Hic-5, A senescence-related protein, with focal adhesion kinase." J Biol Chem 273(41): 26516-21.

Gershoni, JM and GE Palade (1982). "Electrophoretic transfer of proteins from sodium dodecyl sulfate-polyacrylamide gels to a positively charged membrane filter." Anal Biochem 124(2): 396-405.

Gershoni, JM and GE Palade (1983). "Protein blotting: principles and applications." Anal Biochem 131(1): 1-15.

Giambernardi, TA, GM Grant, GP Taylor, RJ Hay, VM Maher, JJ McCormick and RJ Klebe (1998). "Overview of matrix metalloproteinase expression in cultured human cells." Matrix Biol 16(8): 483-96.

Gioeli, D, SB Ficarro, JJ Kwiek, D Aaronson, M Hancock, AD Catling, FM White, RE Christian, RE Settlage, J Shabanowitz, DF Hunt and MJ Weber (2002). "Androgen receptor phosphorylation. Regulation and identification of the phosphorylation sites." $J$ Biol Chem 277(32): 29304-14. 
Gleason, DF (1992). "Histologic grading of prostate cancer: a perspective." Hum Pathol 23(3): 273-9.

Glockner, G, L Eichinger, K Szafranski, JA Pachebat, AT Bankier, PH Dear, R Lehmann, C Baumgart, G Parra, JF Abril, R Guigo, K Kumpf, B Tunggal, E Cox, MA Quail, M Platzer, A Rosenthal and AA Noegel (2002). "Sequence and analysis of chromosome 2 of Dictyostelium discoideum." Nature 418(6893): 79-85.

Greenberg, NM, FJ DeMayo, PC Sheppard, R Barrios, R Lebovitz, M Finegold, R Angelopoulou, JG Dodd, ML Duckworth, JM Rosen and et al. (1994). "The rat probasin gene promoter directs hormonally and developmentally regulated expression of a heterologous gene specifically to the prostate in transgenic mice." Mol Endocrinol 8(2):230-9.

Greenberg, NM, F DeMayo, MJ Finegold, D Medina, WD Tilley, JO Aspinall, GR Cunha, AA Donjacour, RJ Matusik and JM Rosen (1995). "Prostate cancer in a transgenic mouse." Proc Natl Acad Sci U S A 92(8): 3439-43.

Greenlee, RT, T Murray, S Bolden and PA Wingo (2000). "Cancer statistics, 2000." CA Cancer J Clin 50(1): 7-33.

Gregory, CW, B He, RT Johnson, OH Ford, JL Mohler, FS French and EM Wilson (2001). "A mechanism for androgen receptor-mediated prostate cancer recurrence after androgen deprivation therapy." Cancer Res 61(11): 4315-9.

Gronberg, H, SD Isaacs, JR Smith, JD Carpten, GS Bova, D Freije, J Xu, DA Meyers, FS Collins, JM Trent, PC Walsh and WB Isaacs (1997). "Characteristics of prostate cancer in families potentially linked to the hereditary prostate cancer 1 (HPC1) locus." Jama 278(15): 1251-5.

Gupta, A, BS Lee, MA Khadeer, Z Tang, M Chellaiah, Y Abu-Amer, J Goldknopf and KA Hruska (2003). "Leupaxin is a critical adaptor protein in the adhesion zone of the osteoclast." J Bone Miner Res 18(4): 669-85.

Haag, P, J Bektic, G Bartsch, H Klocker and IE Eder (2005). "Androgen receptor down regulation by small interference RNA induces cell growth inhibition in androgen sensitive as well as in androgen independent prostate cancer cells." J Steroid Biochem Mol Biol 96(3-4): 251-8. 
Hagel, M, EL George, A Kim, R Tamimi, SL Opitz, CE Turner, A Imamoto and SM Thomas (2002). "The adaptor protein paxillin is essential for normal development in the mouse and is a critical transducer of fibronectin signaling." Mol Cell Biol 22(3): 901-15.

Hamamura, K, K Furukawa, T Hayashi, T Hattori, J Nakano, H Nakashima, T Okuda, H Mizutani, H Hattori, M Ueda, T Urano, KO Lloyd and K Furukawa (2005). "Ganglioside GD3 promotes cell growth and invasion through p130Cas and paxillin in malignant melanoma cells." Proc Natl Acad Sci U S A 102(31): 11041-6.

Hammond, SM, AA Caudy and GJ Hannon (2001). "Post-transcriptional gene silencing by double-stranded RNA." Nat Rev Genet 2(2): 110-9.

Han, G, G Buchanan, M Ittmann, JM Harris, X Yu, FJ Demayo, W Tilley and NM Greenberg (2005). "Mutation of the androgen receptor causes oncogenic transformation of the prostate." Proc Natl Acad Sci U S A 102(4): 1151-6.

Hanahan, D (1983). "Studies on transformation of Escherichia coli with plasmids." $J$ Mol Biol 166(4): 557-80.

Hanahan, D and RA Weinberg (2000). "The hallmarks of cancer." Cell 100(1): 57-70.

Hatzfeld, M (2005). "The p120 family of cell adhesion molecules." Eur J Cell Biol 84(2-3): 205-14.

Hayward, SW, MA Rosen and GR Cunha (1997). "Stromal-epithelial interactions in the normal and neoplastic prostate." Br J Urol 79 Suppl 2: 18-26.

He, B, JT Minges, LW Lee and EM Wilson (2002). "The FXXLF motif mediates androgen receptor-specific interactions with coregulators." J Biol Chem 277(12): 10226-35.

He, ML, AL Jiang, PJ Zhang, XY Hu, ZF Liu, HQ Yuan and JY Zhang (2005). "Identification of androgen-responsive element ARE and Sp1 element in the maspin promoter." Chin J Physiol 48(3): 160-6.

Heinlein, CA and C Chang (2004). "Androgen receptor in prostate cancer." Endocr Rev 25(2): 276-308.

Heitzer, MD and DB DeFranco (2006). "Hic-5/ARA55, a LIM domain-containing nuclear receptor coactivator expressed in prostate stromal cells." Cancer Res 66(14): 7326-33. 
Hendriksen, PJ, NF Dits, K Kokame, A Veldhoven, WM van Weerden, CH Bangma, J Trapman and G Jenster (2006). "Evolution of the androgen receptor pathway during progression of prostate cancer." Cancer Res 66(10): 5012-20.

Hernandez, I, LA Maddison, Y Wei, F DeMayo, T Petras, B Li, JR Gingrich, JM Rosen and NM Greenberg (2003). "Prostate-specific expression of p53(R172L) differentially regulates p21, Bax, and mdm2 to inhibit prostate cancer progression and prolong survival." Mol Cancer Res 1(14): 1036-47.

Herr, A-M (2005). "Analysen zur Expression und Funktion des Leupaxin Gens in humanen Karzinomen." Institut für Humangenetik,Georg-August-Universität, Göttingen.

Hidalgo, M and SG Eckhardt (2001). "Matrix metalloproteinase inhibitors: how can we optimize their development?" Ann Oncol 12(3): 285-7.

Horoszewicz, JS, SS Leong, E Kawinski, JP Karr, H Rosenthal, TM Chu, EA Mirand and GP Murphy (1983). "LNCaP model of human prostatic carcinoma." Cancer Res 43(4): 1809-18.

Hutvagner, G and PD Zamore (2002). "RNAi: nature abhors a double-strand." Curr Opin Genet Dev 12(2): 225-32.

Ichikawa, T, S Hosoki, H Suzuki, K Akakura, T Igarashi, Y Furuya, M Oshimura, CW Rinker-Schaeffer, N Nihei, JC Barrett, JT Isaacs and H Ito (2000). "Mapping of metastasis suppressor genes for prostate cancer by microcell-mediated chromosome transfer." Asian J Androl 2(3): 167-71.

Ishibe, S, D Joly, X Zhu and LG Cantley (2003). "Phosphorylation-dependent paxillin-ERK association mediates hepatocyte growth factor-stimulated epithelial morphogenesis." Mol Cell 12(5): 1275-85.

Ishino, K, Kaneyama, M Shibanuma and K Nose (2000). "Specific decrease in the level of Hic-5, a focal adhesion protein, during immortalization of mouse embryonic fibroblasts, and its association with focal adhesion kinase." J Cell Biochem 76(3): 411-9.

Jackson, JL and MR Young (2003). "Protein phosphatase-2A regulates protein tyrosine phosphatase activity in Lewis lung carcinoma tumor variants." Clin Exp Metastasis 20(4): 357-64. 
Jain, VK and IT Magrath (1991). "A chemiluminescent assay for quantitation of betagalactosidase in the femtogram range: application to quantitation of beta-galactosidase in lacZ-transfected cells." Anal Biochem 199(1): 119-24.

Jainchill, JL, SA Aaronson and GJ Todaro (1969). "Murine sarcoma and leukemia viruses: assay using clonal lines of contact-inhibited mouse cells." J Virol 4(5): 549-53.

Jemal, A, T Murray, E Ward, A Samuels, RC Tiwari, A Ghafoor, EJ Feuer and MJ Thun (2005). "Cancer statistics, 2005." CA Cancer J Clin 55(1): 10-30.

Jenq, W, DR Cooper and G Ramirez (1996). "Integrin expression on cell adhesion function and up-regulation of P125FAK and paxillin in metastatic renal carcinoma cells." Connect Tissue Res 34(3): 161-74.

Kaighn, ME, KS Narayan, Y Ohnuki, JF Lechner and LW Jones (1979). "Establishment and characterization of a human prostatic carcinoma cell line (PC-3)." Invest Urol 17(1): 1623.

Kalin, TV, IC Wang, TJ Ackerson, ML Major, CJ Detrisac, VV Kalinichenko, A Lyubimov and RH Costa (2006). "Increased levels of the FoxM1 transcription factor accelerate development and progression of prostate carcinomas in both TRAMP and LADY transgenic mice." Cancer Res 66(3): 1712-20.

Kallakury, BV, CE Sheehan, E Winn-Deen, J Oliver, HA Fisher, RP Kaufman, Jr. and JS Ross (2001). "Decreased expression of catenins (alpha and beta), p120 CTN, and Ecadherin cell adhesion proteins and E-cadherin gene promoter methylation in prostatic adenocarcinomas." Cancer 92(11): 2786-95.

Karan, D, MF Lin, SL Johansson and SK Batra (2003). "Current status of the molecular genetics of human prostatic adenocarcinomas." Int J Cancer 103(3): 285-93.

Kasai, M, J Guerrero-Santoro, R Friedman, ES Leman, RH Getzenberg and DB DeFranco (2003). "The Group 3 LIM domain protein paxillin potentiates androgen receptor transactivation in prostate cancer cell lines." Cancer Res 63(16): 4927-35.

Kinoshita, H, Y Shi, C Sandefur, LF Meisner, C Chang, A Choon, CR Reznikoff, GS Bova, A Friedl and DF Jarrard (2000). "Methylation of the androgen receptor minimal promoter silences transcription in human prostate cancer." Cancer Res 60(13): 3623-30. 
Kinzler, KW and B Vogelstein (1996). "Lessons from hereditary colorectal cancer." Cell 87(2): 159-70.

Klein, E, G Klein, JS Nadkarni, JJ Nadkarni, H Wigzell and P Clifford (1968). "Surface IgM-kappa specificity on a Burkitt lymphoma cell in vivo and in derived culture lines." Cancer Res 28(7): 1300-10.

Konishi, N, K Shimada, E Ishida and M Nakamura (2005). "Molecular pathology of prostate cancer." Pathol Int 55(9): 531-9.

Kothakota, S, T Azuma, C Reinhard, A Klippel, J Tang, K Chu, TJ McGarry, MW Kirschner, K Koths, DJ Kwiatkowski and LT Williams (1997). "Caspase-3-generated fragment of gelsolin: effector of morphological change in apoptosis." Science 278(5336): 2948.

Koukouritaki, SB, A Tamizuddin and EA Lianos (1998). "Enhanced expression of the cytoskeletal-associated protein, paxillin, in experimental nephrotic syndrome." J Investig Med 46(6): 284-9.

Koul, HK, PD Maroni, RB Meacham, D Crawford and S Koul (2004). "p42/p44 Mitogenactivated protein kinase signal transduction pathway: a novel target for the treatment of hormone-resistant prostate cancer?" Ann N Y Acad Sci 1030: 243-52.

Krebs in Deutschland. 5. überarbeitete, aktualisierte Ausgabe. Gesellschaft der epidemiologischen Krebsregister in Deutschland e.V. und das RKI. Saarbrücken, 2006.

Kundra, V, JA Escobedo, A Kazlauskas, HK Kim, SG Rhee, LT Williams and BR Zetter (1994). "Regulation of chemotaxis by the platelet-derived growth factor receptor-beta." Nature 367(6462): 474-6.

Laemmli, UK (1970). "Cleavage of structural proteins during the assembly of the head of bacteriophage T4." Nature 227(5259): 680-5.

Lee, JS, IS Chu, J Heo, DF Calvisi, Z Sun, T Roskams, A Durnez, AJ Demetris and SS Thorgeirsson (2004). "Classification and prediction of survival in hepatocellular carcinoma by gene expression profiling." Hepatology 40(3): 667-76. 
Lemaitre, V and J D'Armiento (2006). "Matrix metalloproteinases in development and disease." Birth Defects Res C Embryo Today 78(1): 1-10.

Lewis, TS, PS Shapiro and NG Ahn (1998). "Signal transduction through MAP kinase cascades." Adv Cancer Res 74: 49-139.

Li, P, X Yu, K Ge, J Melamed, RG Roeder and Z Wang (2002). "Heterogeneous expression and functions of androgen receptor co-factors in primary prostate cancer." Am $J$ Pathol 161(4): 1467-74.

Liao, X, S Tang, JB Thrasher, TL Griebling and B Li (2005). "Small-interfering RNAinduced androgen receptor silencing leads to apoptotic cell death in prostate cancer." Mol Cancer Ther 4(4): 505-15.

Linzer, DI and AJ Levine (1979). "Characterization of a 54K dalton cellular SV40 tumor antigen present in SV40-transformed cells and uninfected embryonal carcinoma cells." Cell 17(1): 43-52.

Lipinski, CA, NL Tran, E Menashi, C Rohl, J Kloss, RC Bay, ME Berens and JC Loftus (2005). "The tyrosine kinase pyk2 promotes migration and invasion of glioma cells." Neoplasia 7(5): 435-45.

Lipsky, BP, CR Beals and DE Staunton (1998). "Leupaxin is a novel LIM domain protein that forms a complex with PYK2." J Biol Chem 273(19): 11709-13.

Liu, ZX, CF Yu, C Nickel, S Thomas and LG Cantley (2002). "Hepatocyte growth factor induces ERK-dependent paxillin phosphorylation and regulates paxillin-focal adhesion kinase association." J Biol Chem 277(12): 10452-8.

Kent, WJ (2002). "BLAT—the BLAST-like alignment tool." Genome Res12(4):656-64.

Lukashev, ME and Z Werb (1998). "ECM signalling: orchestrating cell behaviour and misbehaviour." Trends Cell Biol 8(11): 437-41.

MacDonald, EA and JJ Holden (1985). "Duplication 12q24----qter in an infant with DandyWalker syndrome." J Neurogenet 2(2): 123-9. 
Mackin, NA, TJ Sousou and SE Erdman (2004). "The PXL1 gene of Saccharomyces cerevisiae encodes a paxillin-like protein functioning in polarized cell growth." Mol Biol Cell 15(4): 1904-17.

Madan, R, MB Smolkin, R Cocker, R Fayyad and MH Oktay (2006). "Focal adhesion proteins as markers of malignant transformation and prognostic indicators in breast carcinoma." Hum Pathol 37(1): 9-15.

Maniatis, T and A Efstratiadis (1980). "Fractionation of low molecular weight DNA or RNA in polyacrylamide gels containing $98 \%$ formamide or $7 \mathrm{M}$ urea." Methods Enzymol 65(1): 299-305.

Matias, PM, MA Carrondo, R Coelho, M Thomaz, XY Zhao, A Wegg, K Crusius, U Egner and P Donner (2002). "Structural basis for the glucocorticoid response in a mutant human androgen receptor (AR(ccr)) derived from an androgen-independent prostate cancer." J Med Chem 45(7): 1439-46.

Matsuya, M, H Sasaki, H Aoto, T Mitaka, K Nagura, T Ohba, M Ishino, S Takahashi, R Suzuki and T Sasaki (1998). "Cell adhesion kinase beta forms a complex with a new member, Hic-5, of proteins localized at focal adhesions." J Biol Chem 273(2): 1003-14.

Mazaki, Y, S Hashimoto and H Sabe (1997). "Monocyte cells and cancer cells express novel paxillin isoforms with different binding properties to focal adhesion proteins." $J$ Biol Chem 272(11): 7437-44.

Mazaki, Y, H Uchida, O Hino, S Hashimoto and H Sabe (1998). "Paxillin isoforms in mouse. Lack of the gamma isoform and developmentally specific beta isoform expression." $J$ Biol Chem 273(35): 22435-41.

Melnyk, AR, L Weiss, DL Van Dyke and P Jarvi (1981). "Malformation syndrome of duplication 12q24.1 leads to qter." Am J Med Genet 10(4): 357-65.

Mestayer, C, M Blanchere, F Jaubert, B Dufour and I Mowszowicz (2003). "Expression of androgen receptor coactivators in normal and cancer prostate tissues and cultured cell lines." Prostate 56(3): 192-200. 
Mickey, DD, KR Stone, H Wunderli, GH Mickey, RT Vollmer and DF Paulson (1977). "Heterotransplantation of a human prostatic adenocarcinoma cell line in nude mice." Cancer Res 37(11): 4049-58.

Miyoshi, Y, H Ishiguro, H Uemura, K Fujinami, H Miyamoto, Y Miyoshi, H Kitamura and Y Kubota (2003). "Expression of AR associated protein 55 (ARA55) and androgen receptor in prostate cancer." Prostate 56(4): 280-6.

Morrison, TB, JJ Weis and CT Wittwer (1998). "Quantification of low-copy transcripts by continuous SYBR Green I monitoring during amplification." Biotechniques 24(6): 954-8, 60, 62.

Nessler-Menardi, C, I Jotova, Z Culig, IE Eder, T Putz, G Bartsch and H Klocker (2000). "Expression of androgen receptor coregulatory proteins in prostate cancer and stromal-cell culture models." Prostate 45(2): 124-31.

Nishiya, N, H Sabe, K Nose and M Shibanuma (1998). "The LIM domains of hic-5 protein recognize specific DNA fragments in a zinc-dependent manner in vitro." Nucleic Acids Res 26(18): 4267-73.

Nix, DA and MC Beckerle (1997). "Nuclear-cytoplasmic shuttling of the focal contact protein, zyxin: a potential mechanism for communication between sites of cell adhesion and the nucleus." J Cell Biol 138(5): 1139-47.

Obama, K, K Ura, M Li, T Katagiri, T Tsunoda, A Nomura, S Satoh, Y Nakamura and Y Furukawa (2005). "Genome-wide analysis of gene expression in human intrahepatic cholangiocarcinoma." Hepatology 41(6): 1339-48.

Ogawa, M, Y Hiraoka, K Taniguchi, Y Sakai and S Aiso (2001). "mRNA sequence of the Xenopus laevis paxillin gene and its expression." Biochim Biophys Acta 1519(3): 235-40.

Ohnuki, Y, MM Marnell, MS Babcock, JF Lechner and ME Kaighn (1980). "Chromosomal analysis of human prostatic adenocarcinoma cell lines." Cancer Res 40(3): 524-34. 
Ohsugi, Y, ME Gershwin, RB Owens and WA Nelson-Rees (1980). "Tumorigenicity of human malignant lymphoblasts: comparative study with unmanipulated nude mice, antilymphocyte serum-treated nude mice, and X-irradiated nude mice." J Natl Cancer Inst 65(4): 715-8.

Ormo, M, AB Cubitt, K Kallio, LA Gross, RY Tsien and SJ Remington (1996). "Crystal structure of the Aequorea victoria green fluorescent protein." Science 273(5280): 1392-5.

Petit, V, B Boyer, D Lentz, CE Turner, JP Thiery and AM Valles (2000). "Phosphorylation of tyrosine residues 31 and 118 on paxillin regulates cell migration through an association with CRK in NBT-II cells." J Cell Biol 148(5): 957-70.

Pilarsky, C, M Wenzig, T Specht, HD Saeger and R Grutzmann (2004). "Identification and validation of commonly overexpressed genes in solid tumors by comparison of microarray data." Neoplasia 6(6): 744-50.

Prehn, RT (1999). "On the prevention and therapy of prostate cancer by androgen administration." Cancer Res 59(17): 4161-4.

Rege, TA, CY Fears and CL Gladson (2005). "Endogenous inhibitors of angiogenesis in malignant gliomas: nature's antiangiogenic therapy." Neuro-oncol 7(2): 106-21.

Ren, B, KO Yee, J Lawler and R Khosravi-Far (2006). "Regulation of tumor angiogenesis by thrombospondin-1." Biochim Biophys Acta 1765(2): 178-88.

Richter, M and H Zhang (2005). "Receptor-targeted cancer therapy." DNA Cell Biol 24(5): 271-82.

Roberts, SH, T Mattina, KM Laurence, G Sorge and L Pavone (1981). "Partial trisomy 12q: report of a case and review." J Med Genet 18(6): 470-3.

Roux, PP and J Blenis (2004). "ERK and p38 MAPK-activated protein kinases: a family of protein kinases with diverse biological functions." Microbiol Mol Biol Rev 68(2): 320-44.

Roy, H, S Bhardwaj and S Yla-Herttuala (2006). "Biology of vascular endothelial growth factors." FEBS Lett 580(12): 2879-87. 
Ruizeveld de Winter, JA, PJ Janssen, HM Sleddens, MC Verleun-Mooijman, J Trapman, AO Brinkmann, AB Santerse, FH Schroder and TH van der Kwast (1994). "Androgen receptor status in localized and locally progressive hormone refractory human prostate cancer." Am J Pathol 144(4): 735-46.

Sadi, MV, PC Walsh and ER Barrack (1991). "Immunohistochemical study of androgen receptors in metastatic prostate cancer. Comparison of receptor content and response to hormonal therapy." Cancer 67(12): 3057-64.

Sahu, SN, MA Khadeer, BW Robertson, S Nunez, G Bai and A Gupta (2006). "Association Of Leupaxin With Src In Osteoclasts." Am J Physiol Cell Physiol.

Saiki, RK, S Scharf, F Faloona, KB Mullis, GT Horn, HA Erlich and N Arnheim (1985). "Enzymatic amplification of beta-globin genomic sequences and restriction site analysis for diagnosis of sickle cell anemia." Science 230(4732): 1350-4.

Salgia, R, B Brunkhorst, E Pisick, JL Li, SH Lo, LB Chen and JD Griffin (1995a). "Increased tyrosine phosphorylation of focal adhesion proteins in myeloid cell lines expressing p210BCR/ABL." Oncogene 11(6): 1149-55.

Salgia, R, JL Li, DS Ewaniuk, YB Wang, M Sattler, WC Chen, W Richards, E Pisick, GI Shapiro, BJ Rollins, LB Chen, JD Griffin and DJ Sugarbaker (1999). "Expression of the focal adhesion protein paxillin in lung cancer and its relation to cell motility." Oncogene 18(1): 67-77.

Salgia, R, JL Li, SH Lo, B Brunkhorst, GS Kansas, ES Sobhany, Y Sun, E Pisick, M Hallek, T Ernst and et al. (1995b). "Molecular cloning of human paxillin, a focal adhesion protein phosphorylated by P210BCR/ABL." J Biol Chem 270(10): 5039-47.

Sambrook, J, EF Fritsch and T Maniatis (1989). Molecular cloning: a laboratory manual. New York, USA, Cold Spring Habour.

Sasaki, M, Y Tanaka, G Perinchery, A Dharia, I Kotcherguina, S Fujimoto and R Dahiya (2002). "Methylation and inactivation of estrogen, progesterone, and androgen receptors in prostate cancer." J Natl Cancer Inst 94(5): 384-90.

Sastry, SK and K Burridge (2000). "Focal adhesions: a nexus for intracellular signaling and cytoskeletal dynamics." Exp Cell Res 261(1): 25-36. 
Schaller, MD and JT Parsons (1995). "pp125FAK-dependent tyrosine phosphorylation of paxillin creates a high-affinity binding site for Crk." Mol Cell Biol 15(5): 2635-45.

Schlaepfer, DD, CR Hauck and DJ Sieg (1999). "Signaling through focal adhesion kinase." Prog Biophys Mol Biol 71(3-4): 435-78.

Schlaepfer, DD and SK Mitra (2004). "Multiple connections link FAK to cell motility and invasion." Curr Opin Genet Dev 14(1): 92-101.

Schweyer, S, B Hemmerlein, HJ Radzun and A Fayyazi (2000). "Continuous recruitment, co-expression of tumour necrosis factor-alpha and matrix metalloproteinases, and apoptosis of macrophages in gout tophi." Virchows Arch 437(5): 534-9.

Scibelli, A, D d'Angelo, A Pelagalli, S Tafuri, L Avallone, R Della Morte and N Staiano (2003). "Expression levels of the focal adhesion-associated proteins paxillin and p130CAS in canine and feline mammary tumors." Vet Res 34(2): 193-202.

Sharp, PA (2001). "RNA interference--2001." Genes Dev 15(5): 485-90.

Shibanuma, M, JR Kim-Kaneyama, K Ishino, N Sakamoto, T Hishiki, K Yamaguchi, K Mori, J Mashimo and K Nose (2003). "Hic-5 communicates between focal adhesions and the nucleus through oxidant-sensitive nuclear export signal." Mol Biol Cell 14(3): 1158-71.

Shibanuma, M, JR Kim-Kaneyama, S Sato and K Nose (2004). "A LIM protein, Hic-5, functions as a potential coactivator for Sp1." J Cell Biochem 91(3): 633-45.

Shibanuma, M, J Mashimo, T Kuroki and K Nose (1994). "Characterization of the TGF beta 1-inducible hic-5 gene that encodes a putative novel zinc finger protein and its possible involvement in cellular senescence." J Biol Chem 269(43): 26767-74.

Shibanuma, M, E Mochizuki, R Maniwa, J Mashimo, N Nishiya, S Imai, T Takano, M Oshimura and K Nose (1997). "Induction of senescence-like phenotypes by forced expression of hic-5, which encodes a novel LIM motif protein, in immortalized human fibroblasts." Mol Cell Biol 17(3): 1224-35.

Shibanuma, $\mathbf{M}$ and $\mathbf{K}$ Nose (2002). "Regulation of cellular phenotypes by Hic-5 that localizes both in the focal adhesion and in the nucleus." Seikagaku 74(5): 408-11. 
Shibanuma, M and K Nose (1998). "Forced expression of hic-5, a senescence-related gene, potentiates a differentiation process of RCT-1 cells induced by retinoic acid." Int $J$ Biochem Cell Biol 30(1): 39-45.

Shin, JS, A Hong, MJ Solomon and CS Lee (2006). "The role of telomeres and telomerase in the pathology of human cancer and aging." Pathology 38(2): 103-13.

Sorenson, CM (2004). "Interaction of bcl-2 with Paxillin through its BH4 domain is important during ureteric bud branching." J Biol Chem 279(12): 11368-74.

Sorenson, CM and N Sheibani (1999). "Focal adhesion kinase, paxillin, and bcl-2: analysis of expression, phosphorylation, and association during morphogenesis." Dev Dyn 215(4): 371-82.

Sporn, MB (1996). "The war on cancer." Lancet 347(9012): 1377-81.

Stanbrough, M, I Leav, PW Kwan, GJ Bubley and SP Balk (2001). "Prostatic intraepithelial neoplasia in mice expressing an androgen receptor transgene in prostate epithelium." Proc Natl Acad Sci U S A 98(19): 10823-8.

Stone, KR, DD Mickey, H Wunderli, GH Mickey and DF Paulson (1978). "Isolation of a human prostate carcinoma cell line (DU 145)." Int J Cancer 21(3): 274-81.

Sun, Y (2006). "p53 and its downstream proteins as molecular targets of cancer." Mol Carcinog 45(6): 409-15.

Takaoka, A, Y Hinoda, S Satoh, Y Adachi, F Itoh, M Adachi and K Imai (1998). "Suppression of invasive properties of colon cancer cells by a metastasis suppressor KAI1 gene." Oncogene 16(11): 1443-53.

Thomas, JW, MA Cooley, JM Broome, R Salgia, JD Griffin, CR Lombardo and MD Schaller (1999a). "The role of focal adhesion kinase binding in the regulation of tyrosine phosphorylation of paxillin." J Biol Chem 274(51): 36684-92.

Thomas, SM, M Hagel and CE Turner (1999b). "Characterization of a focal adhesion protein, Hic-5, that shares extensive homology with paxillin." J Cell Sci 112 (Pt 2): 181-90.

Thompson, $\mathbf{N}$ and $\mathbf{J}$ Lyons (2005). "Recent progress in targeting the Raf/MEK/ERK pathway with inhibitors in cancer drug discovery." Curr Opin Pharmacol 5(4): 350-6. 
Thompson, TA, MN Gould, JK Burkholder and NS Yang (1993). "Transient promotor activity in primary rat mammary epithelial cells evaluated using particle bombardment gene transfer. " In Vitro Cell Dev Biol29A(2):165-70.

Thoreson, MA and AB Reynolds (2002). "Altered expression of the catenin p120 in human cancer: implications for tumor progression." Differentiation 70(9-10): 583-9.

Trachtenberg, J and B G (2002). "Looking to the future: Advances in the management of hormone-refractory prostate cancer." Eur Urol Suppl.1: 44-53.

Tremblay, L, W Hauck, AG Aprikian, LR Begin, A Chapdelaine and S Chevalier (1996). "Focal adhesion kinase (pp125FAK) expression, activation and association with paxillin and p50CSK in human metastatic prostate carcinoma." Int J Cancer 68(2): 164-71.

Turner, CE and MC Brown (1998). "Purification and assays for paxillin." Methods Enzymol 298: 77-89.

Turner, CE, JR Glenney, Jr. and K Burridge (1990). "Paxillin: a new vinculin-binding protein present in focal adhesions." J Cell Biol 111(3): 1059-68.

Turner, CE (1991). "Paxillin is a major phosphotyrosine-containing protein during embryonic development." J Cell Biol 115(1): 201-7.

Turner, CE, MD Schaller and JT Parsons (1993). "Tyrosine phosphorylation of the focal adhesion kinase pp125FAK during development: relation to paxillin." J Cell Sci 105 (Pt 3): $637-45$

Tuschl, T (2001). "RNA interference and small interfering RNAs." Chembiochem 2(4): 23945.

Tuschl, T, PD Zamore, R Lehmann, DP Bartel and PA Sharp (1999). "Targeted mRNA degradation by double-stranded RNA in vitro." Genes Dev 13(24): 3191-7.

Uzgare, AR, PJ Kaplan and NM Greenberg (2003). "Differential expression and/or activation of P38MAPK, erk1/2, and jnk during the initiation and progression of prostate cancer." Prostate 55(2): 128-39. 
Uzgare, AR, Y Xu and JT Isaacs (2004). "In vitro culturing and characteristics of transit amplifying epithelial cells from human prostate tissue." J Cell Biochem 91(1): 196-205.

Vadlamudi, R, L Adam, B Tseng, L Costa and R Kumar (1999). "Transcriptional upregulation of paxillin expression by heregulin in human breast cancer cells." Cancer Res 59(12): 2843-6.

VanSaun, MN and LM Matrisian (2006). "Matrix metalloproteinases and cellular motility in development and disease." Birth Defects Res C Embryo Today 78(1): 69-79.

Varner, JA and DA Cheresh (1996). "Integrins and cancer." Curr Opin Cell Biol 8(5): 72430.

Veldscholte, J, CA Berrevoets, C Ris-Stalpers, GG Kuiper, G Jenster, J Trapman, AO Brinkmann and E Mulder (1992). "The androgen receptor in LNCaP cells contains a mutation in the ligand binding domain which affects steroid binding characteristics and response to antiandrogens." J Steroid Biochem Mol Biol 41(3-8): 665-9.

Voigt, S (2003). "Isolierung und Charakterisierung von differentiell exprimierten Genen im humanen Prostatakarzinom." Institut für Humangenetik,Georg-August-Universität, Göttingen.

Wang, X, Y Yang, X Guo, ER Sampson, CL Hsu, MY Tsai, S Yeh, G Wu, Y Guo and C Chang (2002). "Suppression of androgen receptor transactivation by Pyk2 via interaction and phosphorylation of the ARA55 coregulator." J Biol Chem 277(18): 15426-31.

Wang, Y and TD Gilmore (2003). "Zyxin and paxillin proteins: focal adhesion plaque LIM domain proteins go nuclear." Biochim Biophys Acta 1593(2-3): 115-20.

Watanabe, N, N Amano, H Ishizuka and K Mashima (2005). "Leupaxin binds to PEST domain tyrosine phosphatase PEP." Mol Cell Biochem 269(1-2): 13-7.

Webb, DJ, K Donais, LA Whitmore, SM Thomas, CE Turner, JT Parsons and AF Horwitz (2004). "FAK-Src signalling through paxillin, ERK and MLCK regulates adhesion disassembly." Nat Cell Biol 6(2): 154-61.

Webb, DJ and AF Horwitz (2003). "New dimensions in cell migration." Nat Cell Biol 5(8): 690-2. 
Wehrle-Haller, B and BA Imhof (2003). "Actin, microtubules and focal adhesion dynamics during cell migration." Int J Biochem Cell Biol 35(1): 39-50.

Wells, A (2000). "Tumor invasion: role of growth factor-induced cell motility." Adv Cancer Res 78: 31-101.

Wheeler, GN and RO Hynes (2001). "The cloning, genomic organization and expression of the focal contact protein paxillin in Drosophila." Gene 262(1-2): 291-9.

\section{Williams, TM, GS Hassan, J Li, AW Cohen, F Medina, PG Frank, RG Pestell, D Di} Vizio, M Loda and MP Lisanti (2005). "Caveolin-1 promotes tumor progression in an autochthonous mouse model of prostate cancer: genetic ablation of Cav-1 delays advanced prostate tumor development in tramp mice." J Biol Chem 280(26): 25134-45.

Wonsey, DR and MT Follettie (2005). "Loss of the forkhead transcription factor FoxM1 causes centrosome amplification and mitotic catastrophe." Cancer Res 65(12): 5181-9.

Woods, AJ, MS Roberts, J Choudhary, ST Barry, Y Mazaki, H Sabe, SJ Morley, DR Critchley and JC Norman (2002). "Paxillin associates with poly(A)-binding protein 1 at the dense endoplasmic reticulum and the leading edge of migrating cells." J Biol Chem 277(8): 6428-37.

Yagi, R, S Ishimaru, H Yano, U Gaul, H Hanafusa and H Sabe (2001). "A novel muscle LIM-only protein is generated from the paxillin gene locus in Drosophila." EMBO Rep 2(9): 814-20.

Yang, L, J Guerrero, H Hong, DB DeFranco and MR Stallcup (2000). "Interaction of the tau2 transcriptional activation domain of glucocorticoid receptor with a novel steroid receptor coactivator, Hic-5, which localizes to both focal adhesions and the nuclear matrix." Mol Biol Cell 11(6): 2007-18.

Yang, Q, KM Fung, WV Day, BP Kropp and HK Lin (2005). "Androgen receptor signaling is required for androgen-sensitive human prostate cancer cell proliferation and survival." Cancer Cell Int 5(1): 8. 
Yano, H, H Uchida, T Iwasaki, M Mukai, H Akedo, K Nakamura, S Hashimoto and H Sabe (2000). "Paxillin alpha and Crk-associated substrate exert opposing effects on cell migration and contact inhibition of growth through tyrosine phosphorylation." Proc Natl Acad Sci U S A 97(16): 9076-81.

Yeh, S, HK Lin, HY Kang, TH Thin, MF Lin and C Chang (1999). "From HER2/Neu signal cascade to androgen receptor and its coactivators: a novel pathway by induction of androgen target genes through MAP kinase in prostate cancer cells." Proc Natl Acad Sci U S A 96(10): 5458-63.

Yuminamochi, T, Y Yatomi, M Osada, T Ohmori, Y Ishii, K Nakazawa, S Hosogaya and Y Ozaki (2003). "Expression of the LIM proteins paxillin and Hic-5 in human tissues." $J$ Histochem Cytochem 51(4): 513-21.

Zetter, BR (1990). "The cellular basis of site-specific tumor metastasis." $N$ Engl $J$ Med 322(9): 605-12.

Zhang, J, LX Zhang, PS Meltzer, JC Barrett and JM Trent (2000). "Molecular cloning of human Hic-5, a potential regulator involved in signal transduction and cellular senescence." Mol Carcinog 27(3): 177-83.

Zhou, ZX, B He, SH Hall, EM Wilson and FS French (2002). "Domain interactions between coregulator ARA(70) and the androgen receptor (AR)." Mol Endocrinol 16(2): 287300. 


\section{Lebenslauf}

\section{Persönliche Daten:}

Name

Geburtsdatum

Geburtsort

Staatsangehörigkeit

\section{Bildungsweg:}

1986-1987

1987-1988

1988-1992

1992-1998

1998-2002

2002-2003

2003
Silke Kaulfuß, geb. Voigt

06.06.1979

Löbau/Sachs.

deutsch
Besuch der Polytechnischen Oberschule „Maxim Gorki“ in Freiberg/Sachs.

Besuch der Polytechnischen Oberschule „Carl Böhme“ in Freiberg/Sachs.

Besuch einer Klasse mit erweitertem Russisch-Unterricht an der Polytechnischen Oberschule „Clara Zetkin“ in Freiberg/Sachs. Besuch des Gymnasiums „Geschwister Scholl“ in Freiberg/Sachs.

Biologiestudium an der Georg-August-Universität in Göttingen Diplomarbeit am Institut für Humangenetik der Georg-AugustUniversität in Göttingen

Experimentelle Arbeiten zur Dissertation am Institut für Humangenetik der Georg-August-Universität in Göttingen 


\section{Danksagung}

Ich möchte mich an dieser Stelle bei Herrn Prof. Dr. W. Engel für die Bereitschaft, diese Arbeit zu betreuen, seine konstruktive Kritik und sein Interesse am Fortgang der Arbeit bedanken. Darüber hinaus danke ich ihm für die schnelle und gründliche Durchsicht der Manuskripte.

Bei Herrn Prof. Dr. R. Hardeland bedanke ich mich für die Übernahme des Korreferats.

Meinem Betreuer PD Dr. Peter Burfeind danke ich für die Überlassung des Themas, sowie die Möglichkeit, selbständig und weitgehend unabhängig arbeiten zu können. Ich danke ihm für die vielen Anregungen und Ideen, für das Vertrauen und die freundschaftliche Unterstützung, die zu meiner Motivation und zum Gelingen dieser Arbeit entscheidend beigetragen haben.

Dann möchte ich mich bei meinen Kollegen aus den Laboren 311/312 für die gute Zusammenarbeit und die freundschaftliche Atmosphäre im Laboralltag bedanken. Ganz besonders bedanke ich mich bei Michael Kickstein und Antje Schneeberg für ihre Unterstützung und Hilfsbereitschaft.

Bei PD Dr. Bernhard Hemmerlein und Dr. Paul Thelen bedanke ich mich für die gute und erfolgreiche Zusammenarbeit bei den immunhistochemischen und real time RT-PCRAnalysen. Herrn PD Dr. Stefan Schweyer danke ich sehr für die Unterstützung bei den Apoptose-Studien und den histologischen Analysen der transgenen Mäuse.

Stefan Wolf möchte ich für seine Hilfsbereitschaft bei allen Fragen und Problemen der Tierhaltung und seine tatkräftige Unterstützung beim Präparieren der Mäuschen ganz herzlich danken.

Auch bedanke ich mich bei allen anderen Mitarbeitern des Instituts für Humangenetik.

Ein lieber Dank geht vor allem an die Labormädels: Anna, Conny, Maren, Sandra, Anja, Antje und natürlich Roser. Und an meine Freunde Ari und Lars!

Meinem Mann danke ich für seine unendliche Geduld...

Mein herzlichster Dank gilt natürlich meiner Familie, besonders meinen Eltern für ihre uneingeschränkte Unterstützung bei allen Fragen des Lebens. Danke! 